\author{
UNIVERSIDADE DE SÃO PAULO \\ ESCOLA DE ENGENHARIA DE SÃO CARLOS \\ PROGRAMA DE POS-GRADUAÇÃO EM GEOTECNIA
}

LOANA HENRIQUEZ SANCHEZ

\title{
AVALIAÇÃO DE SOLUÇÕES ALTERNATIVAS PARA O AUMENTO DE CAPACIDADE DE CARGA DE FUNDAÇÕES POR ESTACAS HELICOIDAIS
}

São Carlos-SP

2014 


\title{
AVALIAÇÃO DE SOLUÇÕES ALTERNATIVAS PARA O AUMENTO DE CAPACIDADE DE CARGA DE FUNDAÇÕES POR ESTACAS HELICOIDAIS
}

\author{
Dissertação apresentada à Escola de Engenharia \\ de São Carlos, da Universidade de São Paulo, \\ como parte dos requisitos para obtenção do \\ título de Mestre em Ciências, Programa de Pós \\ Graduação em Geotecnia.
}

ORIENTADORA: PROF ${ }^{\text {a }}$ DRA. CRISTINA DE HOLLANDA CALVANTI TSUHA

\section{VERSÃO CORRIGIDA}

Original se encontra disponível na Unidade que aloja o Programa

São Carlos-SP

2014 
AUTORIZO A REPRODUCÃO TOTAL OU PARCIAL RESTE TRABALHO, POR QUALQUER MEIO COONVENCIONAL OU ELETROONICO, PARA FINS DE ESTUDO E PESQUISA, DESDE QUE CITADA A FONTE.

SAMCHEZ, LOANA HENRIQUEZ

Avaliaçå de Soluçbes Alternativas para o Aumento

$3211=$

de Capacidade de Carga de Fundacbes por Estacas

Helicoidais / LOANA HENRIQUEZ SAMCHEZ; orientadora

Cristina de Hollanda Calvanti Tsuha. SAo Carlos, 2014.

Dissertaça (Mestrado) - Programa de Pos-Graduaçto e Área de Concentraçấo em Geotecnia -- Escola de Engenharia de SAo Carlos da Universidade de SAo Paulo, 2014.

1. FundaçBes. 2. Estaca Helicoida1. 3. Capacidade de Carga. 4. Prova de Carga. 5. Injeçoes com Calda de Cimento. I. Titulo. 


\section{FOLHA DE JULGAMENTO}

Candidata: Engenheira LOANA HENRIQUEZ SANCHEZ.

Título da dissertação: "Avaliação de soluções alternativas para o aumento de capacidade de carga de fundaçōes por estacas helicoidais".

Data da defesa: 27/06/2014

\section{Comissão Julgadora:}

Profa. Dra. Cristina de Hollanda Cavalcanti $T_{\text {su ha }}$ (Orientadora)

(Escola de Engenharia de São Carlos/EESC)

Prof. Titular José Carlos Angelo Cintra

(Escola de Engenharia de Sāo Carlos/EESC)

Prof. Dr. David de Carvalho

(Universidade Estadual de Campinas/UNICAMP)
Resultado:
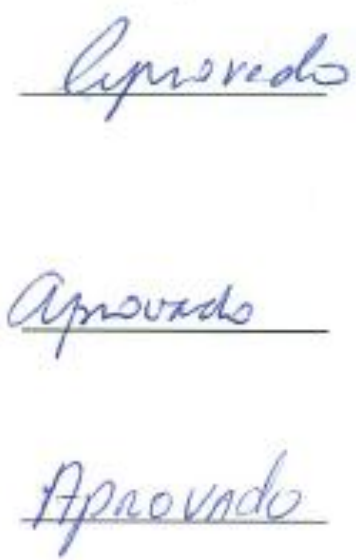

Coordenador do Programa de Pós-Graduaçāo em Geotecnia:

Prof. Titular Osni José Pejon

Presidente da Comissão de Pós-Graduação:

Prof. Titular Denis Vinicius Coury 
À minha amada filha Andiara Isabella, grande presente que Deus me concedeu, maior incentivo para que eu continuasse na minha jornada. 


\section{AGRADECIMENTOS}

A realização desta dissertação foi um culminar de um percurso acadêmico de vários anos, demandando horas de estudo, esforço e dedicação, que não teria sido possível sem o apoio e colaboração de diversas pessoas, a quem gostaria de expressar os meus agradecimentos.

Em primeiro lugar a Deus, por me mostrar que tudo na vida tem um porquê. Sem a ajuda Dele, nada seria possível.

A meus pais, Victor e Maria Elena, pelo amor, constante estímulo, apoio incondicional e dedicação persistente ao longo da minha vida.

A meus irmãos Cinthia, Luis e Mariusa, pela amizade, carinho, apoio incondicional e auxílio nas horas mais difíceis.

A meus sobrinhos Mateo e Valeria, pelo amor, carinho e momentos de risos compartilhados.

À minha pequena Andiara Isabella, pelo amor, força e compressão nas minhas ausências durante esta fase.

À minha orientadora, Prof ${ }^{a}$. Dra. Cristina de Hollanda Cavalcanti Tsuha, pelo grande apoio e confiança depositada em mim para a realização desta pesquisa.

A todos os professores do Departamento de Geotecnia, que contribuíram para o meu crescimento profissional.

Aos funcionários do Departamento de Geotecnia, pela amizade e auxílio que me brindaram sempre.

A meus colegas de turma de mestrado, Vanessa, Liz, Breno, Felipe, Bianca, Bruno e Gustavo, pela convivência e amizade durante esse período.

A meus amigos incondicionais durante as provas de carga, João e Thaise, pela delicada colaboração nos ensaios experimentais.

A meus amigos Juan, Andrea, Damalis, Anabel, Patricia, Zorany, Ana Elisa, Chris, Mariana, Philipe, Tania, Karen, Maria Jose, Lucy, Jorge por todas as palavras de incentivo durante todo esse tempo. 
Ao CNPq, Conselho Nacional de Desenvolvimento Cientifico e Tecnológico, e à CAPES, Coordenação de Aperfeiçoamento de Pessoal de Nível Superior, pelo auxílio financeiro que possibilitou o desenvolvimento deste trabalho.

À Vercon, pelo apoio financeiro para a realização das provas de carga realizadas nesta pesquisa.

A todos aqueles que direta ou indiretamente contribuíram para a realização deste trabalho, meu mais profundo e sincero muito obrigada! 
"Nunca consideres o estudo como uma obrigação, mas como uma oportunidade de entrar no maravilhoso mundo do conhecimento". Albert Einstein. 


\section{RESUMO}

\section{SANCHEZ, L.H., Avaliação de Soluções Alternativas para o Aumento de Capacidade} de Carga de Fundações por Estacas Helicoidais. 154 p. Dissertação de Mestrado - Escola de Engenharia de São Carlos, Universidade de São Paulo, 2014.

A utilização de estacas helicoidais como fundação de linhas de transmissão de energia elétrica tem aumentando significativamente no Brasil. No entanto, em alguns casos de obra, a camada de solo adequada para se instalarem as hélices da estaca encontra-se em profundidade economicamente inviável para o uso deste tipo de fundação. Esta foi a razão que motivou a presente pesquisa, que tem como objetivo avaliar soluções para a instalação de estacas helicoidais mais curtas, ancoradas em solo de capacidade inferior à necessária para atender às cargas de projeto.

Nesta dissertação, foram avaliadas duas soluções alternativas para o aumento de capacidade de carga de fundações por estacas helicoidais, para os casos de carregamento de tração e compressão. A primeira alternativa verificada foi a injeção de calda de cimento em torno das hélices da ponta da estaca. A segunda solução testada foi o preenchimento com argamassa em torno da haste da estaca acima das hélices.

Foram realizadas na presente pesquisa nove provas de carga (cinco de tração e quatro de compressão): três em estacas helicoidais convencionais, quatro em estacas helicoidais com injeção de calda de cimento e duas em estacas helicoidais com fuste de argamassa. Após a realização de provas de carga nas estacas, estas foram exumadas para se verificar a forma da coluna de argamassa e as formas de bulbos resultantes das injeções realizadas com calda de cimento.

A partir dos resultados dos ensaios, foi verificado que a capacidade de carga da estaca á tração pode ser aumentada usando-se as alternativas testadas. Porém, são necessários mais ensaios para avaliar a eficiência destes procedimentos em diferentes condições de solo e configuração de estacas.

Palavras-chave: fundações, estaca helicoidal, capacidade de carga, prova de carga, injeções com calda de cimento. 


\begin{abstract}
SANCHEZ, L.H., Evaluation of Alternative Solutions to Increase Helical Pile Capacity. 154 p. Master Dissertation. School of Engineering at São Carlos, University of São Paulo, São Carlos, 2014.

The use of helical piles as foundation for transmission lines has increased significantly in Brazil. However, in some sites, the soil layer suitable for installing the pile helices are considerably deep and it is economically unviable to use this type of foundation. This reason motivated the current study, which aims to evaluate solutions for the installation of helical piles anchored in soil with low capacity.

In this research, it was evaluated two alternative solutions to improve the helical pile capacity. The first alternative is injecting a water/ cement mixture which is delivered to the ground throught holes, placed between the upper and bottom helices. The second alternative solution is helical piles with a mortar shaft.

Nine pile load tests were performed for the present investigation (five in tension and four in compression): three on conventional helical piles, four on helical piles with injection, and two on helical piles with mortar shaft. After that, the helical piles were exhumed for the verification of the shaft shape and the forms of the bulbs resulting from injections performed with cement mixture.

The results of these tests indicated that the uplift capacity of helical piles can be increased by using the alternatives tested. However, more tests are needed to evaluate the effectiveness of these procedures, in different soil conditions and pile configurations.
\end{abstract}

Keywords: foundation, helical pile, pile capacity, pile load test, water-cement injection 


\section{LISTA DE FIGURAS}

Figura 1 - Instalação de estaca helicoidal em mar aberto (LUTENEGGER, 2011)........6

Figura 2 - Farol de Maplin Sands no Rio Thames na Inglaterra (PERKO, 2009).......... 7

Figura 3 - Emenda de tubos de uma estaca (A.B. CHANCE Co., 2004)....................... 8

Figura 4 - Hélices e seção típica de uma estaca helicoidal com duas extensões (CARVALHO, 2007).....

Figura 5 - Instalação de estacas helicoidais (A.B. CHANCE Co., 1994)...................... 11

Figura 6 - Estaca helicoidal com graute ao redor do fuste (VICKARS \& CLEMENCE 2000).

Figura 7 - Processo de instalação de estaca helicoidal com graute (A.B. CHANCE, 2004).

Figura 8 - Diferenças entre uma estaca helicoidal e uma estaca helicoidal com fuste de graute (adaptada de LUTENEGGER, 2014).....

Figura 9 - Estacas helicoidais com graute profundas e curtas em diferentes perfis de solo (LUTENEGGER, 2014).

Figura 10 - Processo de instalação da estacaTurbo Pier com graute (MANKE, 2004). 21

Figura 11- Mecanismo de transferência de carga em uma estaca helicoidal com graute na ponta (BIAN, 2006)

Figura 12 - Densificação do solo ao redor da argamassa injetada na compactação por injeção (WARNER, 2004).

Figura 13 - a) permeação, b) jet grouting, c) faturamento, d) compactação (MOSELEY, 2004).

Figura 14 - Representação gráfica: 1) regra européia e 2) regra americana, adaptado de Warner (2004). 26

Figura 15 - a) Método cilindro de cisalhamento, b) Método capacidade individuais (HOYT \& CLEMENCE, 1989).

Figura 16 - Superfície de ruptura adotada em areias (DAS, 1990).

Figura 17 - Superfície de ruptura idealizada (MITSCH \& CLEMENCE, 1985). 31

Figura 18 - Esquema de transferência de carga em estacas helicoidais submetidas a esforços de compressão: a) método das capacidades individuais; b) método do cilindro de cisalhamento (PERKO, 2009).

Figura 19 - Estaca helicoidal submetida a um esforço compressivo pelo método do 
cilindro de cisalhamento (PERKO, 2009). 42

Figura 20 - Esquema do cálculo da capacidade de carga de estacas com graute, segundo Vickars \& Clemence (2000).

Figura 21 - Capacidade de carga total da estaca helicoidal com graute (LI, 2006). 48

Figura 22 - Parcelas de capacidade de carga de uma estaca helicoidal com bulbo (BIAN, 2006). 51

Figura 23 - Ruptura por cisalhamento na superfície da estaca: à esquerda estaca escavada e à direita, estaca helicoidal comfuste grauteado (LI 2006). 54

Figura 24 - a) Localização da Vercon Ind.; b) Fotografia da área do lugar onde foram realizadas as sondagens e da área onde foram instaladas as estacas; c) Vista frontal da Vercon Industrial

Figura 25 - Planta das estacas instaladas e a localização das sondagens SP-01, SP-02.58

Figura 26 - Perfil de solo da sondagem SP-01.

Figura 27- Seção guiatípica das estacas E1, E2 e A1. 62

Figura 28 - Modelo de estaca utilizada nos ensaios das estacas com injeção C1 e C2.. 63

Figura 29 - Identificação das estacas Ensaiadas.

Figura 30 - Procedimento de instalação das estacas helicoidais.

Figura 31- Chapas de aço soldadas na haste da estaca (a primeira contém as aletas e a segunda contém o furo.

Figura 32 - Processo de instalação e preenchimento da argamassa no fuste da estaca helicoidal (A-1).

Figura 33 - Instalação da estaca com emenda tipo rosca e com furos na seção guia para aplicação de injeção no final da instalação.

Figura 34 - (a) acoplamento com rosca para realização da injeção; (b) processo de injeção da estaca. 68

Figura 35 - Foto da cabeça da estaca C1 após término do processo de injeção. 68

Figura 36 - a) ensaio de compressão em andamento; b) corpos-de-prova cilíndricos de $5 \times 10 \mathrm{~cm}$ cilíndricos ensaiados.

Figura 37 - Esquema típico das montagens das provas de carga à tração.

Figura 38 - Esquema típico das montagens das provas de carga à compressão. 71

Figura 39 - Durante o processo de escavação (em vermelho estão indicadas as estacas a 
serem extraídas). 73

Figura 40 - Escavação mecânica e manual prévio para extração da estaca A1 e estaca C1

Figura 41 - Fuste de argamassa observado na estaca helicoidal A1, após a escavação. 74

Figura 42- Preenchimento da injeção observado ao longo da estaca C1 89

Figura 43- Preenchimento da injeção observado ao longo da estaca C2 89

Figura 44- Exumação da estaca helicoidal A1 .96

Figura 45- Coluna de argamassa da estaca A1. 97

Figura 46- Forma da estaca A1 verificada após a escavação. 97

Figura 47- Exumação da estaca helicoidal C1. 98

Figura 48- Vazio acima e abaixo das hélices, após os ensaios realizados de tração e de compressão na estaca $\mathrm{C} 1$ 99

Figura 49- Estaca $\mathrm{C} 1$ após injeção calda de cimento. .99

Figura 50- Exumação da estaca $\mathrm{C} 2$ - primeira parte 100

Figura 51- Exumação da estaca C2 - segunda parte (calda de cimento marcado com vermelho). 101

Figura 52- a) exumação da estaca C2; b) modelo do resultado da injeção na estaca. . 102 


\section{LISTA DE GRÁFICOS}

Gráfico 1 - Fator de capacidade de carga à tração $\mathrm{N}_{\mathrm{q}}$ versus profundidade relativa da hélice H/D, (MITSCH \& CLEMENCE, 1985).

Gráfico 2 - Fatores de capacidade de carga combinados com a forma, profundidade e capacidade de carga das estacas (PERKO, 2009).

Gráfico 3 - Torques registrados em todas as estacas instaladas ao longo da profundidade de instalação. 76

Gráfico 4 - Relação Torque/ $\mathrm{N}_{S P T}(\mathrm{SP}-01)$ e profundidade de instalação para as cinco estacas instaladas 78

Gráfico 5 - Carga x deslocamento da prova de carga na estaca E1. 80

Gráfico 6 - Curva carga x deslocamento da prova de carga na estaca E2. 80

Gráfico 7 - Curva carga x deslocamento da prova de carga na estaca $\mathrm{C} 1$. 81

Gráfico 8 - Curva carga x deslocamento da prova de carga na estaca C2. 81

Gráfico 9 - Curva carga x deslocamento da prova de carga na estaca A1.... 82

Gráfico 10 - Curva carga x deslocamento de todas as estacas ensaiadas à tração. .82

Gráfico 11 - Curva carga x deslocamento dos ensaios na estaca E1 (convencional).....92

Gráfico 12 - Curva carga x deslocamento dos ensaios na estaca A1 (fuste de argamassa). 93

Gráfico 13 - Curva carga x deslocamento dos ensaios na estaca C1 (injeção sem rotação)...... . .94

Gráfico 14 - Curva carga x deslocamento dos ensaios na estaca C2 (injeção com rotação). . .94

Gráfico 15 - Curva carga x deslocamento da prova de carga na estaca convencional E1.

Gráfico 16 - Curva carga x deslocamento da prova de carga na estaca com argamassa A1.

Gráfico 17 - Curva carga x deslocamento da prova de carga na estaca injetada C1....118

Gráfico 18 - Curva carga x deslocamento da prova de carga na estaca injetada C2....118

Gráfico 19 - Curva carga x deslocamento de todas as estacas ensaiadas à compressão. 


\section{LISTA DE TABELAS}

Tabela 1 - Geometrias típicas de estacas metálicas helicoidais 10

Tabela 2 - Classificação de solos para estacas helicoidais (CLAYTON, 2013). 14

Tabela 3 - Valores de $K u$ para ângulos de atrito de solo $\varnothing$ (MITSCH \& CLEMENCE, 1985) 30

Tabela 4 - coeficientes de capacidade de carga para solos coesivos (STEPHENSON, 1997).

Tabela 5 - Valores recomendados de $K_{t}$ em função do diâmetro da haste da estaca, segundo Hoyt \& Clemence (1989).

Tabela 6-Valores de $\alpha s(\mathrm{kN} / \mathrm{m} 2)$ para Qu equivalente à critério $\mathrm{D} / 10$ 37

Tabela 7 - Valores de NSPT dos ensaios SPT realizados na área experimental da Vercon Industrial... 58

Tabela 8 - Parâmetros de solo adotados para o solo da SP-01.

Tabela 9 - Configuração das Estacas Helicoidais Instaladas e Ensaiadas 62

Tabela 10 - Sequência de provas de carga realizadas 72

Tabela 11 - Comprimentos da haste da estaca helicoidal acima do nível do terreno..... 75

Tabela 12 - Medidas de torque de instalação das estacas helicoidais registradas ao longo da profundidade. .76

Tabela 13 - Resultados da razão entre torque de instalação e o $\mathrm{N}_{S P T}$ (SP-01) 77

Tabela 14 - Ensaios realizados à Tração 79

Tabela 15 - Cargas e deslocamentos máximos das provas de carga à tração. 79

Tabela 16 - Resultados das provas de carga à tração realizados .83

Tabela 17 - Ganho em capacidade de carga a tração $\left(Q_{u}\right)$ 84

Tabela 18 - Características das estacas ensaiadas

Tabela 19 - Valores estimados e medidos da capacidade de carga à tração das estacas E1 e E2. 86

Tabela 20 - Valores estimados e medidos da capacidade de carga à tração da estaca A1......

Tabela 21 - Valores de Kt das estacas helicoidais ensaiadas à tração no presente projeto. 
Tabela 22 - Resultados das provas de carga à tração e à compressão ( $2^{\circ}$ ciclo), segundo

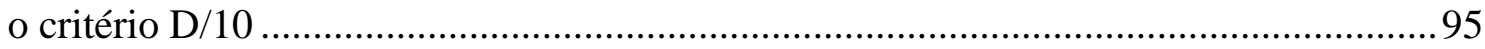

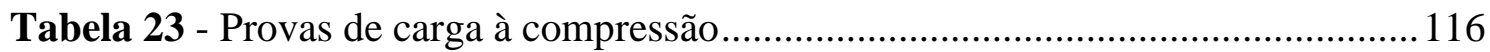




\section{SUMÁRIO}

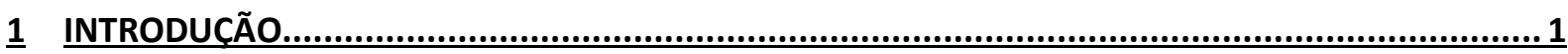

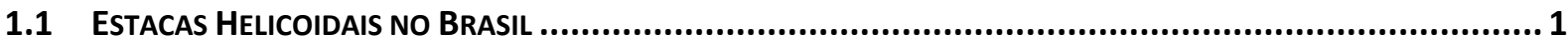

1.2 Estacas Helicoidais com Fuste de ARgamassa e InJetadas com Calda de Cimento.......................... 2

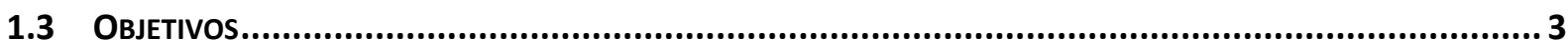

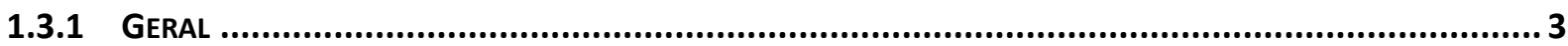

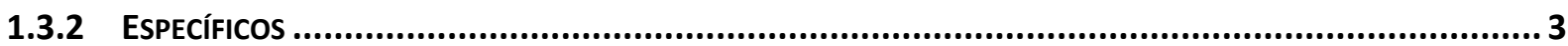

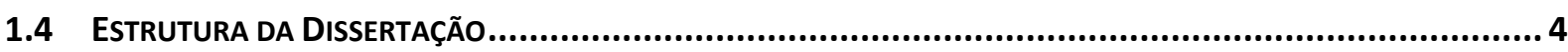

$\underline{2}$ REVISÃO BIBLIOGRÁFICA

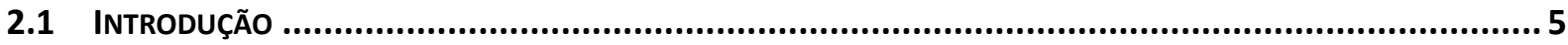

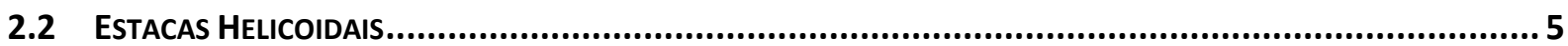

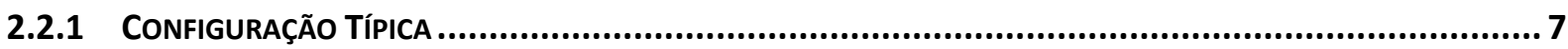

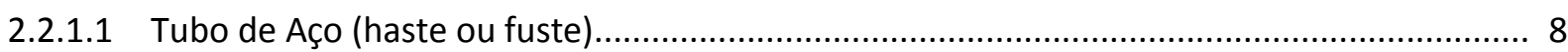

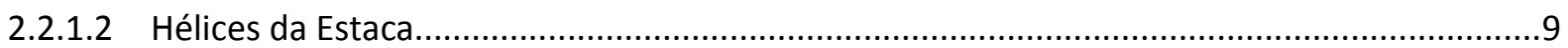

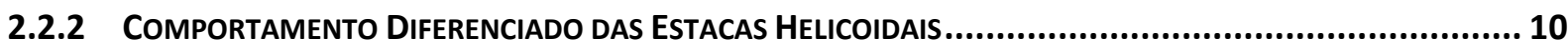

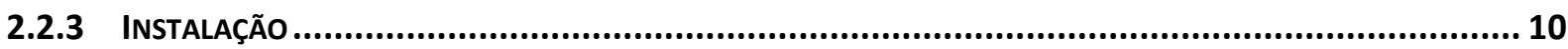

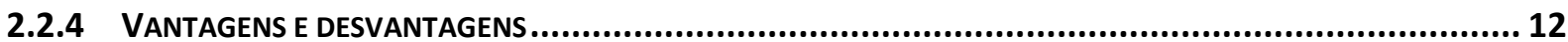

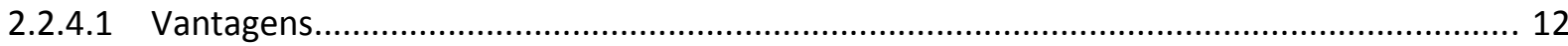

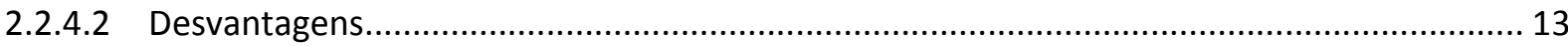

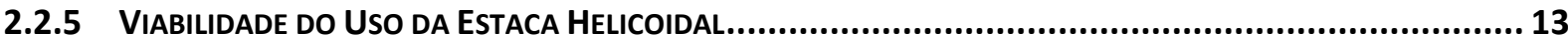

2.3 ESTACAs HeLICoIdAis com Fuste Preenchido com Graute ...................................................... 15

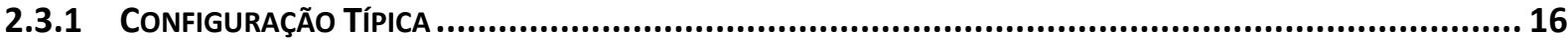

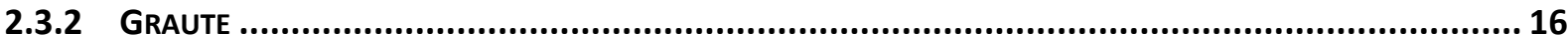

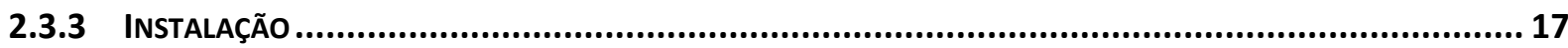

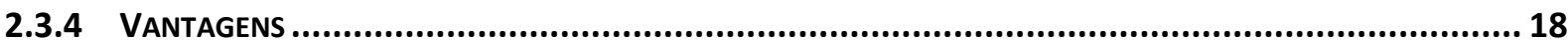

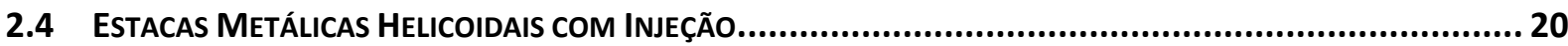

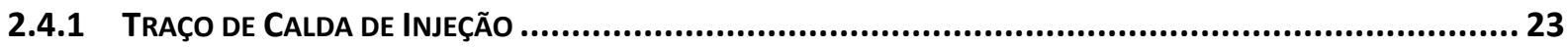

2.4.2 INJEÇÃO

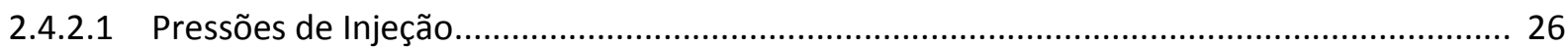

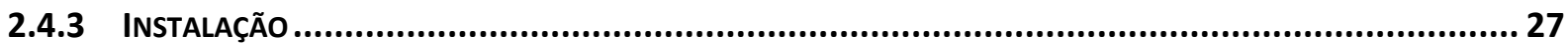

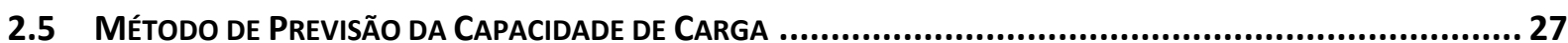




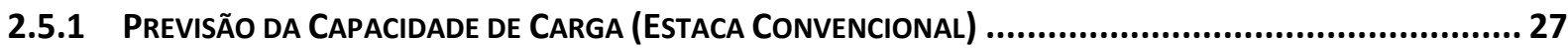

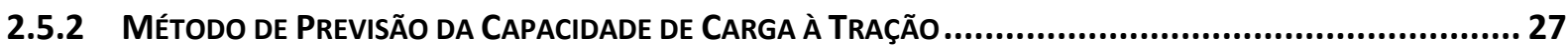

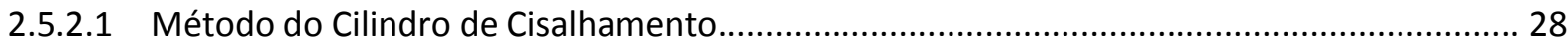

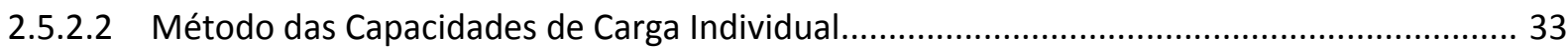

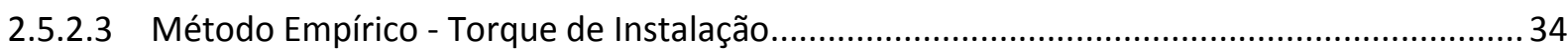

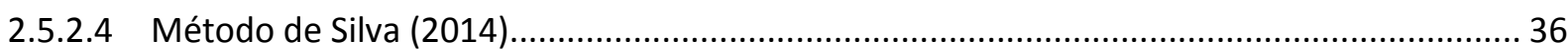

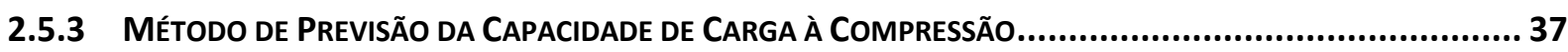

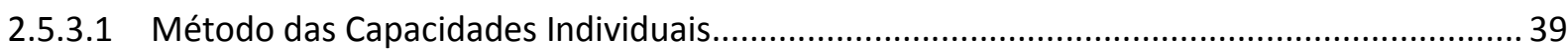

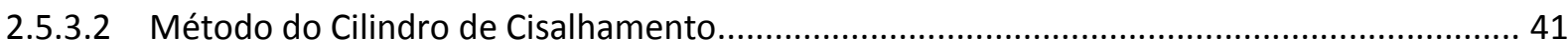

2.5.4 Capacidade de Carga À Compressão x Capacidade de Carga À Tração ....................................43

2.5.5 Capacidade de Carga à Compressão de Estaca Helicoidal com Fuste Preenchido com Graute . 43

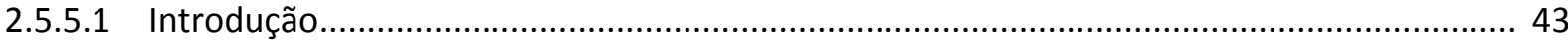

2.5.5.2 Parcela de Resistência por Atrito Lateral................................................................................. 44

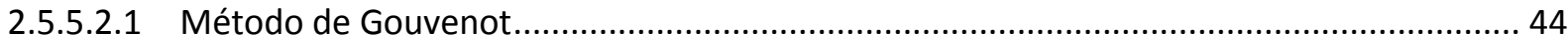

2.5.5.3 Parcela de Capacidade de Carga das Hélices....................................................................... 45

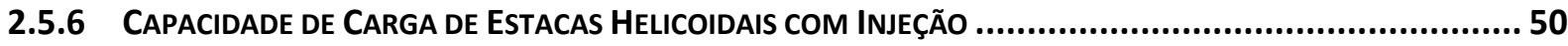

2.5.7 Capacidade de Carga À Tração de Estaca Helicoidal com Fuste Preenchido com Graute......... 53

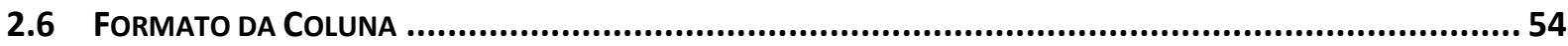

$\underline{3}$ MATERIAIS E MÉTODOS $\quad 56$

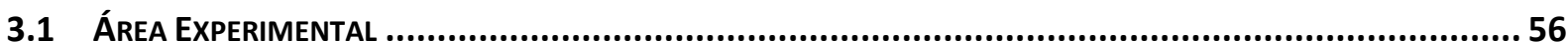

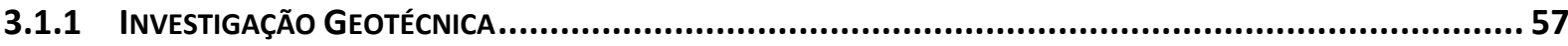

3.1.1.1 Ensaios de Sondagem de Simples Reconhecimento (SPT) .................................................. 57

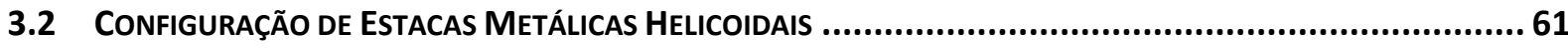

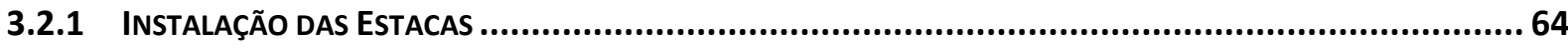

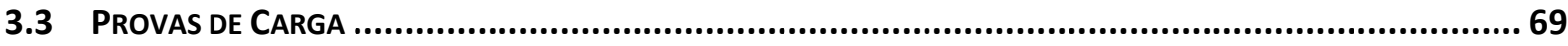

3.4 Escavações e Extrações das Estacas Metálicas Helicoidais ...................................................... 72

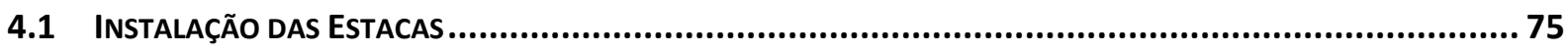

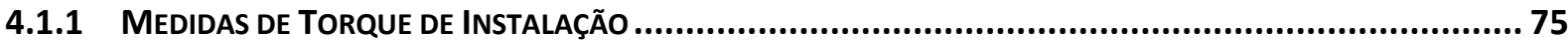

4.1.2 RELAÇÕES ENTRE TORQUE DE INSTALAÇÃO E O N

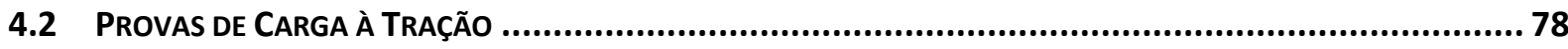




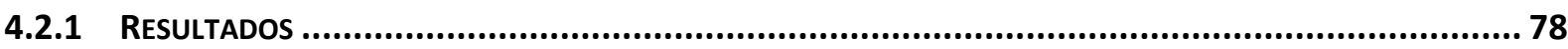

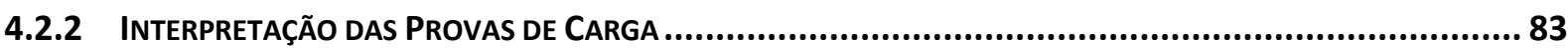

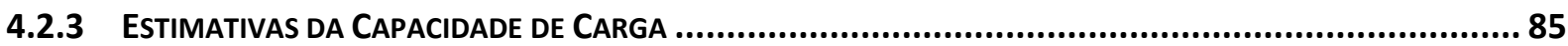

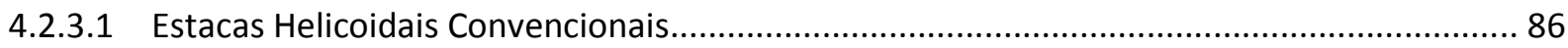

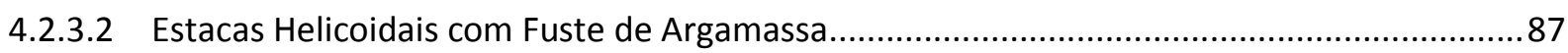

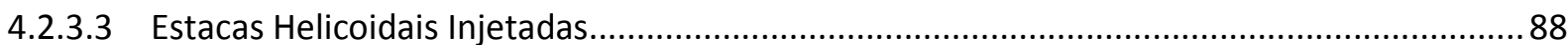

4.2.3.4 Método do Torque de Instalação Para as Estacas Helicoidais Convencionais........................ 90

4.3 Comparações entre Capacidade de Carga À Tração e À Compressão....................................... 91

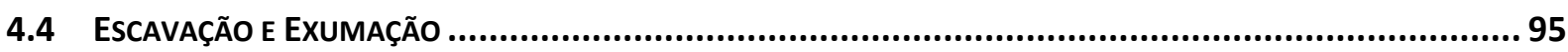

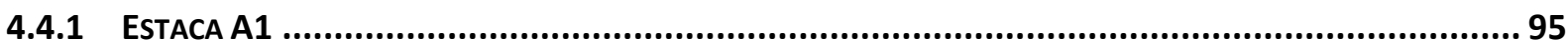

4.4.2 ESTACA C1

4.4.3 ESTACA C2

$\underline{5}$ CONCLUSÕES 103

$6 \underline{6}$ SUGESTÕES PARA FUTURAS PESQUISAS 106

\begin{tabular}{lr} 
REFERÊNCIAS BIBLIOGRÁFICAS & 107 \\
\hline
\end{tabular}

$\begin{array}{ll}\text { APÊNDICE A } & 116\end{array}$

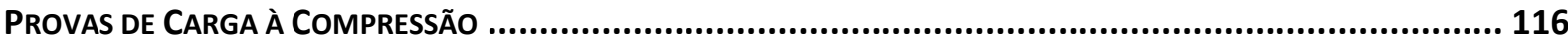

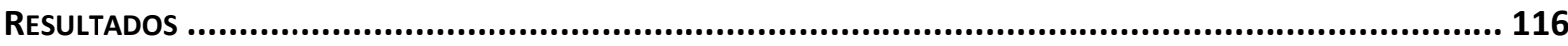

APÊNDICE B $\quad 120$

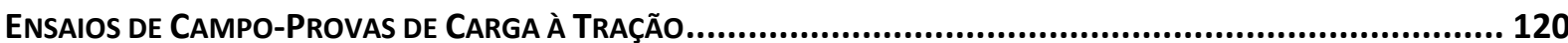

APÊNDICE C 


\section{INTRODUÇÃO}

\subsection{Estacas Helicoidais no Brasil}

As estacas helicoidais são utilizadas como fundações profundas para resistir a esforços axiais de compressão e de tração e, em alguns casos, para suportar carregamentos laterais.

Este tipo de fundação tem sido muito utilizado no Brasil, em obras de torres de linhas de transmissão de energia. No exterior, principalmente nos Estados Unidos e Canadá, usam-se estacas helicoidais para suportar diversos tipos de estruturas: linhas de transmissão de energia, torres de telecomunicações, construções residenciais e comerciais, obras temporárias, reforços de fundações, ancoragem de dutos e muros de contenção, etc.

O uso de estacas helicoidais em linhas de transmissão, quando são necessárias fundações profundas, é extremamente vantajoso comparando-se às outras estacas tradicionais (instalação rápida e fácil, execução em locais de difícil acesso, possibilidade de instalar abaixo do nível da água e de aferir a capacidade de carga usando-se o valor de torque final para sua instalação).

No entanto, ao se utilizar este tipo de estaca no Brasil, têm ocorrido casos em que é necessário ancorar as hélices da estaca em grande profundidade (mais de 20 metros) para atender as cargas de projeto. Nestes casos, são encontradas camadas extensas de solo de baixa capacidade, sendo insuficientes para ancorar as hélices das estacas, impossibilitando-se a instalação de estacas mais curtas.

Portanto, em alguns destes terrenos com extensa camada de solo de baixa capacidade (geralmente solo com valores de $N_{S P T}$ inferiores a 8 golpes $/ 30 \mathrm{~cm}$, aproximadamente) tem sido economicamente inviável o uso deste tipo de fundação.

Deste modo, observando-se este problema, que tem ocorrido em algumas obras de estacas helicoidais, esta pesquisa foi desenvolvida com o intuito de avaliar soluções alternativas para estes casos de estacas helicoidais ancoradas em solos de baixa capacidade.

Estas soluções seriam também indicadas para casos em que logo abaixo da camada de solo de baixa capacidade encontram-se camadas impenetráveis pela estaca (matacão ou rocha), e a estaca fica com suas hélices obrigatoriamente ancoradas em solo de capacidade 
insuficiente para atender ao desempenho esperado da estaca.

\subsection{Estacas Helicoidais com Fuste de Argamassa e Injetadas com Calda de Cimento}

A configuração típica de uma estaca helicoidal consiste em uma série de hélices de forma circular, feitas em chapas de aço soldadas a um tubo central circular ou quadrado, com determinado espaçamento entre elas. Estas estacas são instaladas no solo por aplicação de torque no tubo central. As chapas helicoidais são penetradas por rotação no solo, com o auxílio de um motor hidráulico. A taxa de avanço no solo é igual a um passo de hélice por revolução.

Como citado anteriormente, nesta pesquisa foram testadas duas alternativas para solucionar o problema de estacas helicoidais que devem ser ancoradas em solos de baixa capacidade.

A primeira alternativa, já verificada anteriormente na literatura, é a execução de uma coluna (fuste) de argamassa em torno da haste da estaca acima das hélices. Esta solução foi introduzida por Vickars \& Clemence (2000), que demostraram que a adição de argamassa resulta no aumento da área de atrito em contato com o solo ao longo do fuste da estaca, de modo a contribuir com aumento da capacidade de carga da estaca submetida a esforços axiais, além de evitar problemas de flambagem da haste em estacas instaladas em solos muito moles submetidas a esforços de compressão.

Este tipo de estaca tem sido utilizado com muito sucesso em outros países, em diferentes tipos de solo. Segundo pesquisas feitas por Vickars \& Clemence (2000), Abdelghany \& El Naggar (2010), Lutenegger (2010), e El Sharnourby \& El Naggar (2012), este tipo de estaca com coluna de argamassa (com diâmetros inferiores a $300 \mathrm{~mm}$ ) tem proporcionado aumento considerável da capacidade de carga da estaca.

A segunda alternativa estudada nesta dissertação para se aumentar a capacidade de carga de estacas helicoidais é a injeção de calda de cimento em torno das hélices da ponta da estaca. O principal objetivo da injeção é criar um bulbo (mistura de calda de cimento e solo) entre a primeira hélice e a ponta da estaca, para o aumento da capacidade de carga. 
Em Bian et al. (2008), comentam-se que uma maneira econômica e eficiente para melhorar a capacidade de carga e rigidez de uma fundação existente seria combinar uma estaca metálica helicoidal com argamassa injetada.

Bian (2006) realizou injeções com argamassa em estacas modelos com diferentes configurações de hélice em centrífuga. Neste trabalho, foi verificado o aumento da capacidade de carga das estacas com injeção, que foi quase o dobro dos valores proporcionados pelos modelos de estacas helicoidais convencionais (sem injeção). Este aumento pode ser atribuído às parcelas de resistência por atrito lateral e de ponta proporcionadas pelo bulbo de calda cimento-solo.

\subsection{Objetivos}

\subsubsection{Geral}

Esta dissertação tem como objetivo principal avaliar o desempenho à tração e à compressão de duas soluções alternativas para aumentar a capacidade de carga de estacas helicoidais instaladas em solo de baixa capacidade (solo silte arenoso da região de Betim, Minas Gerais).

\subsubsection{Especificos}

Para alcançar o objetivo geral desta dissertação, delinearam-se outros objetivos de caráter específico, que são os seguintes:

1. Desenvolvimento de procedimentos executivos para a instalação de estacas helicoidais com fuste de argamassa e injetadas com calda de cimento. 
2. Análise da capacidade de carga em estacas helicoidais com fuste de argamassa e injetadas e verificação dos métodos de previsão, por meio de comparações feitas entre os valores de capacidade de carga estimados e medidos durante as provas de carga.

3. Comparação entre capacidade de carga à tração e à compressão das estacas ensaiadas.

\subsection{Estrutura da Dissertação}

Esta dissertação é formada por seis capítulos. No primeiro capítulo, é feita uma introdução que aborda a importância da pesquisa e os objetivos gerais e específicos.

No segundo capítulo, é apresentada uma revisão bibliográfica, baseada nos trabalhos utilizados e consultados. O terceiro capítulo descreve os materiais e métodos utilizados na pesquisa. Nesta parte do texto, são apresentadas as características da área experimental, os equipamentos e os procedimentos utilizados para a execução dos ensaios.

No quarto capítulo, são mostrados os resultados e análises da dissertação. No quinto capítulo, são apresentadas as conclusões do trabalho. Por fim, no sexto capítulo, são indicadas algumas sugestões para continuidade e melhoria neste trabalho. 


\section{REVISÃO BIBLIOGRAFICA}

\subsection{Introdução}

Neste capítulo, são apresentados os conceitos e relatos da literatura necessários para o desenvolvimento e entendimento desta pesquisa. Os tópicos deste item são: estacas helicoidais convencionais, estacas helicoidais com fuste de graute e com injeção de calda de cimento, métodos de capacidade de carga desenvolvidos para estacas tradicionais e com argamassa.

\subsection{Estacas Helicoidais}

Segundo Clemence (1985), as estacas helicoidais consistem basicamente em uma série de hélices de forma circular, feitas em chapa de aço soldadas a um tubo central, com um determinado espaçamento entre elas. De acordo com Hoyt \& Clemence (1989), a estaca helicoidal consiste em uma ou mais hélices de forma circular fixadas a um tubo de aço circular ou quadrado. Ghaly \& Hanna (1991) comentam que a estaca helicoidal pode ser feita com diferentes configurações.

Se for necessário que as estacas avancem em maior profundidade dentro do solo, serão usadas extensões (tubos com ou sem hélices emendados à seção da ponta, conhecidas como seção guia para alcançar a camada de solo com resistência apropriada).

De acordo com Lutenegger (2011), estas estacas foram originalmente inventadas e patenteadas pelo inglês Alexander Mitchell, em 1833. A primeira criação deste engenheiro foram estacas de 6 metros de comprimento, as quais foram utilizadas pela primeira vez em 1838, para compor a fundação de um farol, às margens do Rio Tamisa, na Inglaterra (Figura 2). Esta fundação consistiu de nove estacas helicoidais as quais tinham uma hélice de diâmetro de 1,2 metros e foram instaladas até uma profundidade de 6,7 metros.

Nesta época, a instalação da estaca era realizada por força humana e animal (Figura 1). Esta tecnologia foi adquirida pelos americanos em 1850, para a construção de 100 faróis ao longo da costa leste e do Golfo do México, alguns dos quais podem ser visitados atualmente. 
Segundo Clemence (1985), por volta de 1950, houve um desenvolvimento significativo das estacas helicoidais. Conforme Lutenegger (2011), as primeiras estacas foram instaladas manualmente, porém, mais tarde, com a criação do caminhão com dispositivos hidráulicos de aplicação de torque, a indústria das estacas helicoidais teve um grande desenvolvimento.

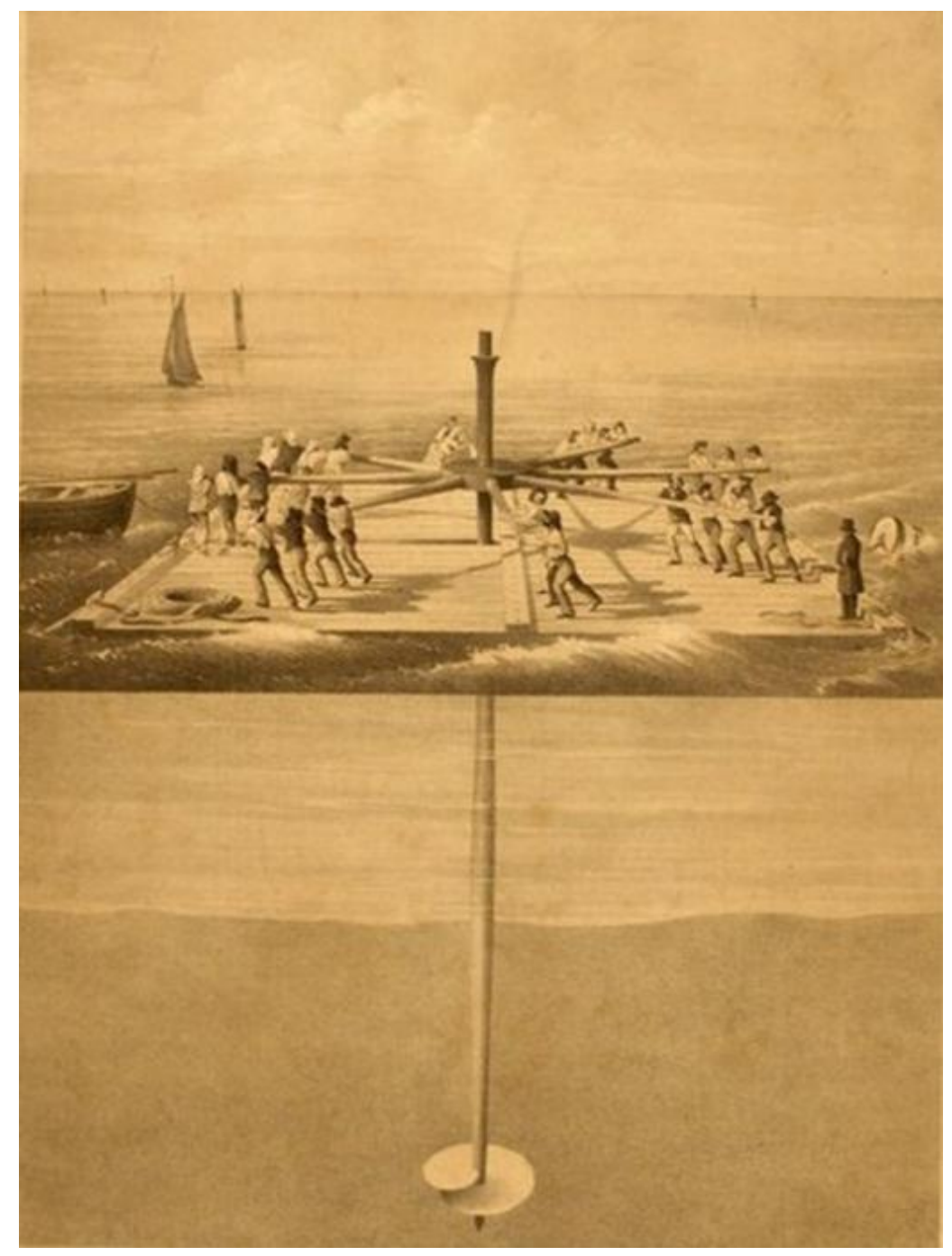

Figura 1 - Instalação de estaca helicoidal em mar aberto (LUTENEGGER, 2011).

Segundo Clemence et al. (1994), numerosas torres de linhas de transmissão de energia foram instaladas nos Estados Unidos utilizando-se este tipo de fundação (executadas em grande quantidade a partir de 1940). 


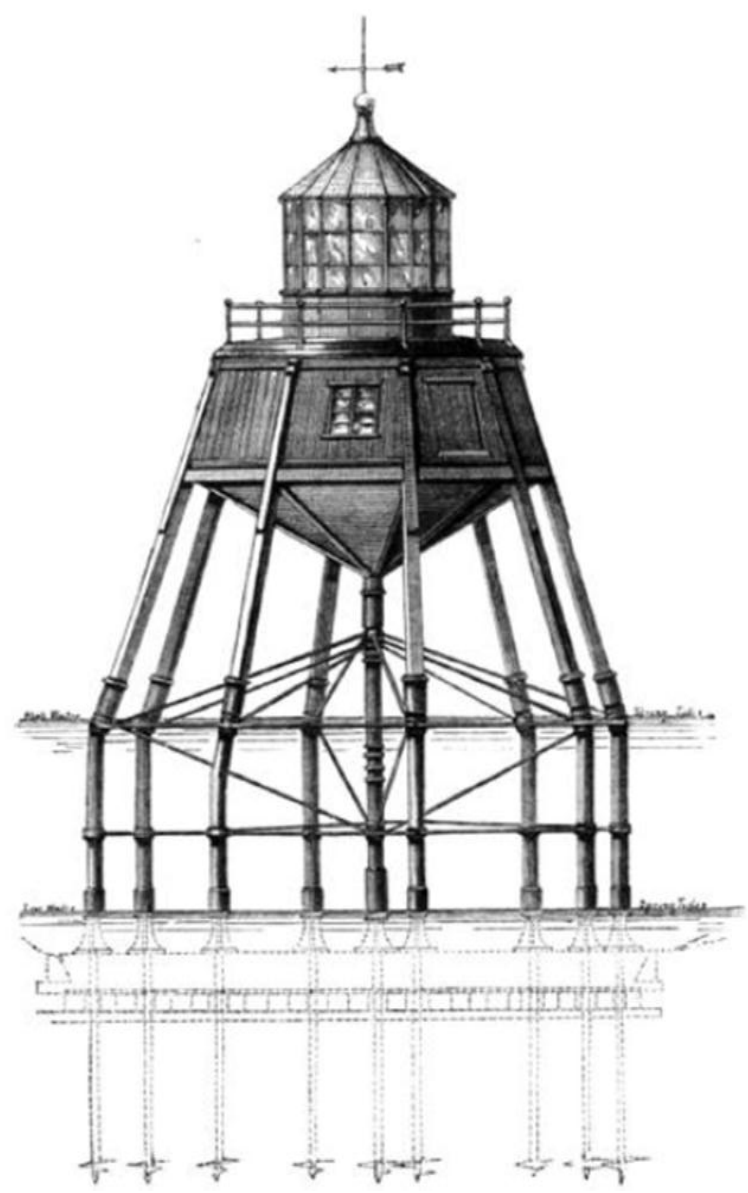

Figura 2 - Farol de Maplin Sands no Rio Thames na Inglaterra (PERKO, 2009).

Conforme Stephenson (2003), este tipo de fundação tem crescido rapidamente no mercado geotécnico. Existem grandes fabricantes de estacas helicoidais em vários países do mundo, entre eles estão Estados Unidos, Japão, Inglaterra, Canadá e Austrália (PERKO, 2000).

\subsubsection{Configuração Típica}

Segundo Mitsch \& Clemence (1985), a configuração típica de uma estaca helicoidal consiste em uma série de hélices de forma circular, feitas em chapas de aço soldadas a um tubo central com um determinado espaçamento entre elas. 


\subsubsection{Tubo de Aço (haste ou fuste)}

Stephenson (2003) cita que a haste central da estaca helicoidal é usada para transmitir o torque durante a instalação e transferir cargas axiais nas hélices. Uma vez instalada, a estaca ou carregamento axial do eixo é transferido para as hélices e por sua vez aos estratos de solo que envolve a estaca. A haste central deve ter área de seção transversal suficiente para suportar a tensão aplicada na estaca de modo que esta não exceda a tensão admissível do material da estaca. Além disso, esta seção deve ser suficiente para suportar o torque necessário para instalação da estaca no terreno.

Segundo Flores et al. (2001), a estaca helicoidal consiste de várias seções. A primeira seção contém as hélices e é chamada de "secção guia", as seções subsequentes são chamadas de "extensões", as quais são lisas e geralmente não têm hélices (variam de 1 a $3 \mathrm{~m}$ de comprimento). Os tubos que compõem a haste são emendados conforme a necessidade de se avançar dentro do solo, a conexão entre a seção guia e as extensões são feitas por meio de parafusos (Figura 3).
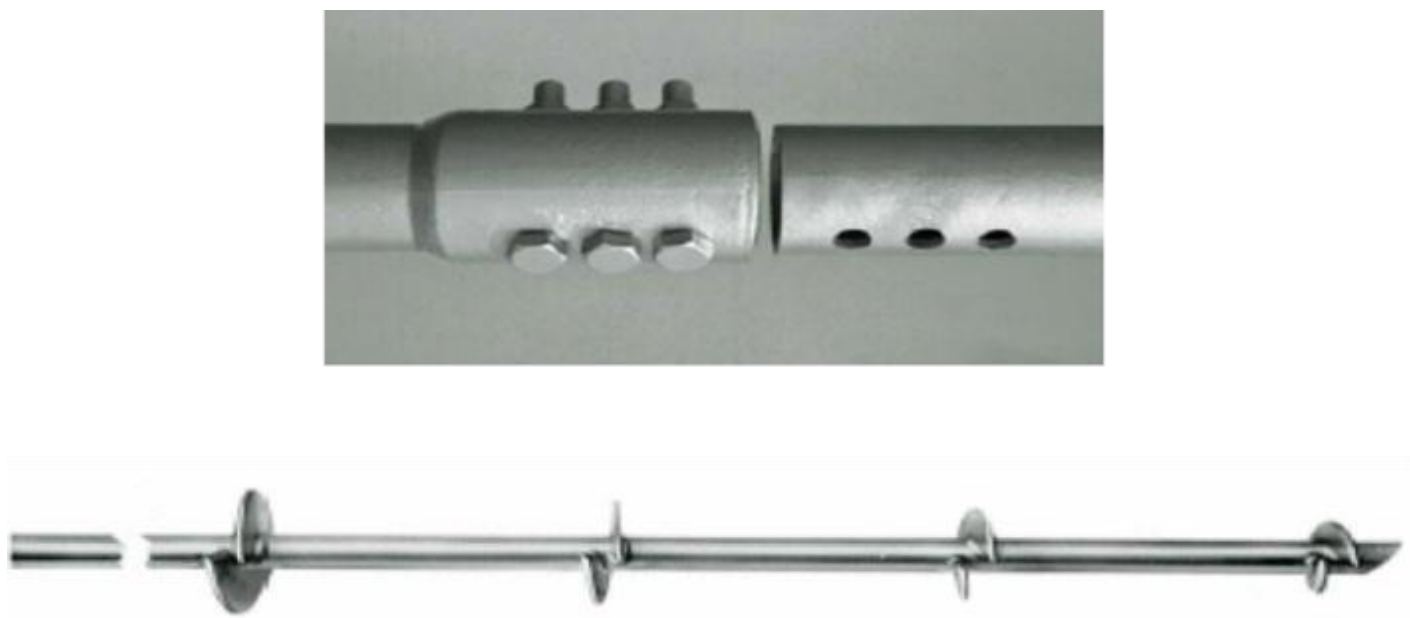

Figura 3 - Emenda de tubos de uma estaca (A.B. CHANCE Co., 2004). 


\subsubsection{Hélices da Estaca}

As hélices das estacas helicoidais usadas no Brasil são fabricadas de aço, com diâmetros que usualmente variam entre 20 e $45 \mathrm{~cm}$. Estas estacas têm suas hélices normalmente espaçadas a uma distância igual a três diâmetros da hélice inferior (3 x Dh), com um passo típico em torno de $8 \mathrm{~cm}$ (ver detalhe na Figura 4).
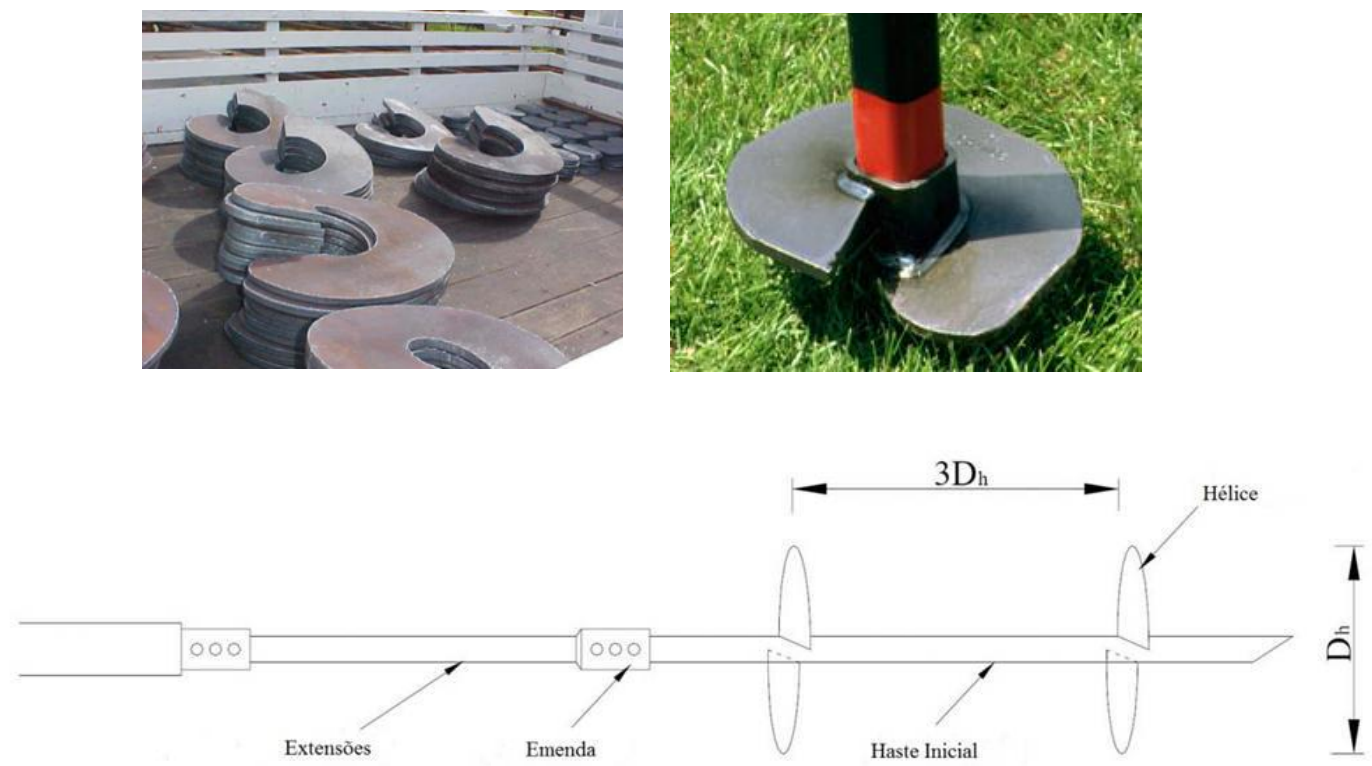

Figura 4 - Hélices e seção típica de uma estaca helicoidal com duas extensões (CARVALHO, 2007).

No Brasil, não existe uma norma sobre a fabricação de estacas helicoidais, nem um padrão estabelecido sobre o número de hélices, espessura e diâmetros, estando a critério do fabricante e do projetista determinarem as especificações a serem adotadas.

Na Tabela 1, é apresentado um resumo de geometrias típicas de estacas metálicas helicoidais, apresentada por vários autores na literatura. 
Tabela 1 - Geometrias típicas de estacas metálicas helicoidais

\begin{tabular}{|c|c|c|}
\hline Referência & $\begin{array}{c}\text { Diâmetro (ou lado) da haste } \\
\text { e geometria }\end{array}$ & Diâmetro de hélice \\
\hline Hoyt et. al. (1995) & $\begin{array}{c}38-44 \mathrm{~mm} \text { haste circular e } \\
\text { quadrada }\end{array}$ & -- \\
\hline $\begin{array}{l}\text { Perko \& Rupiper } \\
(2000)\end{array}$ & $\begin{array}{l}\text { 40-50mm haste quadrada e 50- } \\
\text { 130mm de haste circular, } \\
\text { max.diâm.300mm }\end{array}$ & $\begin{array}{l}\text { 150-360mm, } \\
\text { máximo } 1100 \mathrm{~mm}\end{array}$ \\
\hline $\begin{array}{l}\text { Vickars \& } \\
\text { Clemence (2000) }\end{array}$ & $\begin{array}{c}38-51 \mathrm{~mm} \text { haste quadrada e } \\
89 \mathrm{~mm} \text { haste circular }\end{array}$ & $100-250 \mathrm{~mm}$ \\
\hline $\begin{array}{l}\text { A.B. Chance } \\
\text { Company (1994) }\end{array}$ & $\begin{array}{l}\text { 38-44 mm haste quadrada e } \\
89 \mathrm{~mm} \text { ou haste circular }\end{array}$ & $150,200,250,300$ e $350 \mathrm{~mm}$ \\
\hline
\end{tabular}

\subsubsection{Comportamento Diferenciado das Estacas Helicoidais}

De acordo com Sanhueza (2012), na análise de estacas helicoidais ocorrem muitas semelhanças com as considerações feitas para outros tipos de fundação, porém não devem ser baseadas nas mesmas teorias e métodos de cálculo, devido às diferenças no comportamento por causa da presença de hélices.

\subsubsection{Instalação}

Conforme Clemence et al. (1994), as estacas metálicas helicoidais são instaladas no solo pela aplicação de torque rotacional no sentido horário, aplicada na maioria dos casos por sistema de motor hidráulico de trados mecânicos (Figura 5). As hélices são rotacionadas no solo com ajuda de uma pequena força axial que é empregada inicialmente para auxiliar no processo de instalação. Quando necessário, emenda-se a seção guia com extensões de haste até que a ponta da estaca atinja a profundidade desejada.

De acordo com Stephenson (2003), a instalação pode ser realizada com um caminhão de trado motorizado adaptado, a estaca é instalada até o momento em que se encontra a camada apropriada ou atinge a profundidade desejada.

Conforme Kulhawy (1985), o processo de instalação tem mínimo impacto sobre as 
propriedades do solo penetrado. Quando instalada corretamente (avanço de um passo por volta), supõem-se que todas as hélices sigam o mesmo trajeto que a hélice de ponta enquanto são instaladas no solo. A hélice de ponta corta o solo formando um trajeto espiral, e cada uma das seguintes avança seguindo o mesmo trajeto (estaca com hélices de mesmo passo), deixando o solo praticamente inalterado.

Segundo A.B. Chance (2004), o processo de instalação das estacas é realizado por meio de aplicação de um torque rotacional no sentido horário, que faz com que as hélices girem para dentro do solo com ajuda de uma pequena carga axial, suficiente para manter o avanço da estaca no terreno igual a um passo por volta até a penetração das primeiras hélices.

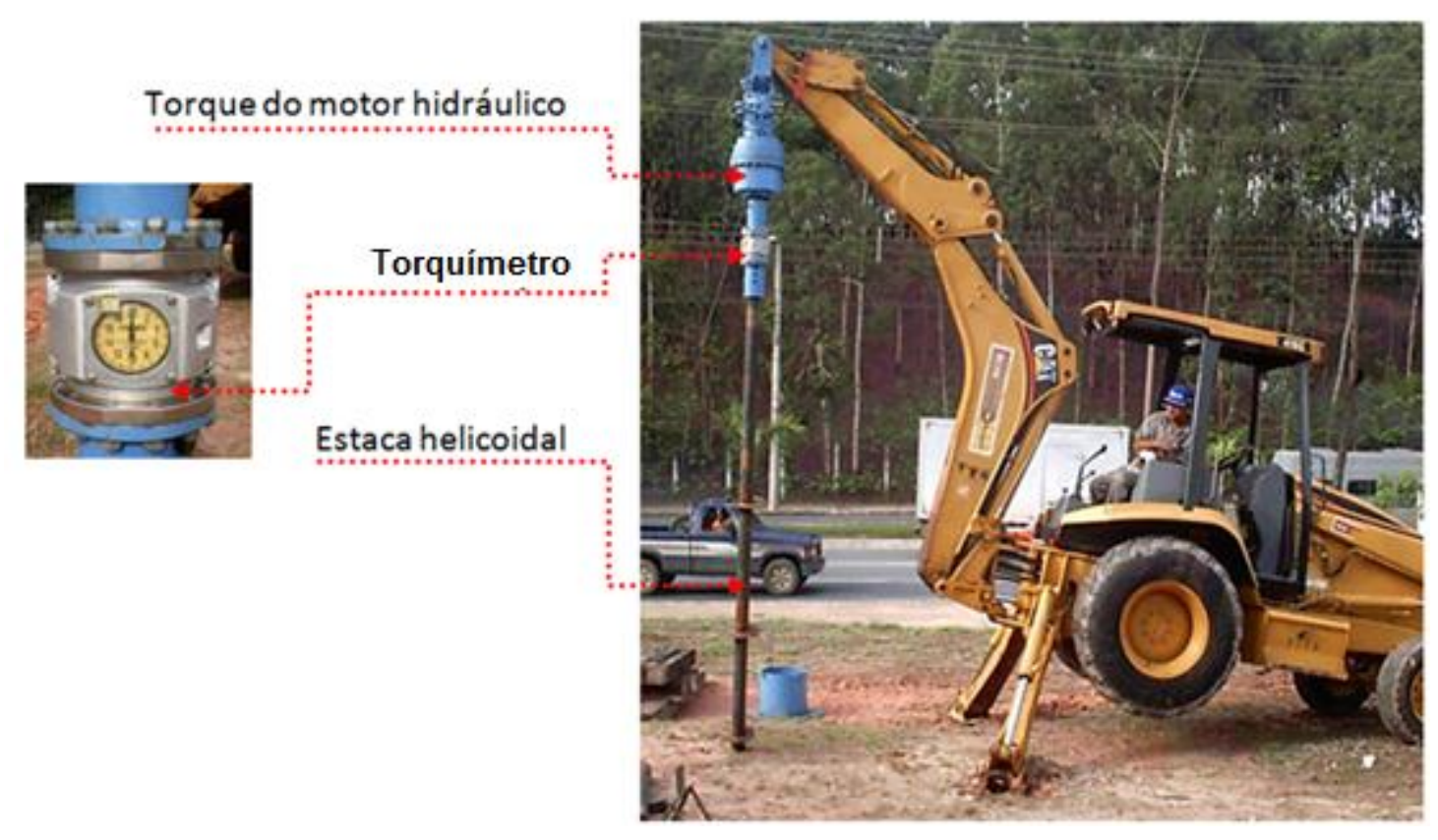

Figura 5 - Instalação de estacas helicoidais (A.B. CHANCE Co., 1994).

A leitura do torque necessário para penetrar a estaca no terreno é feita durante a instalação (geralmente registrada a $100 \mathrm{~cm}$ de penetração), por meio de um torquímetro fixado na cabeça da haste (Figura 5). Por meio de correlações empíricas, a capacidade de carga é diretamente proporcional ao torque medido no final da instalação. Portanto, quando atinge-se o torque requerido em projeto, a instalação é finalizada. 


\subsubsection{Vantagens e desvantagens}

\subsubsection{Vantagens}

Segundo Perko et al. (2000), as principais vantagens das estacas helicoidais em relação aos outros tipos de fundações são os seguintes:

- Resistem ao solapamento em obras de pontes;

- São mais fáceis de serem transportadas aos lugares de difícil acesso;

- Pode ser determinada a capacidade de carga de fundação por meio de correlações com o torque de instalação;

- Podem ser instaladas inclinadas para o aumento de resistência lateral;

- Levam menos tempo para serem instaladas em terrenos de elevado nível de água, sem a necessidade de rebaixamento do lençol freático.

Conforme Ghaly et al. (1991), as principais vantagens das estacas metálicas helicoidais são:

- Este tipo de fundação pode ser carregado imediatamente após a instalação;

- Existem peças que facilitam a montagem de torres de transmissão de energia elétrica sobre este tipo de fundação;

- É uma fundação econômica quando o nível de lençol freático do terreno de instalação é elevado, não sendo necessário o rebaixamento.

Segundo Stephenson (2003), as principais vantagens deste tipo de fundação são:

- Rapidez de instalação;

- Capacidade de serem carregadas imediatamente;

- Resistir aos esforços de tração e de compressão simultaneamente.

Schiavon (2010) comenta sobre outras vantagens, como: adequação à execução em locais de difícil acesso, instalação abaixo do nível do lençol freático, alta capacidade de carga 
tanto à tração como à compressão e possibilidade de adição de novas hélices para quando a capacidade de carga prevista não é atingida.

\subsubsection{Desvantagens}

De acordo com Sanhueza (2012), algumas desvantagens das estacas helicoidais são as seguintes:

a) Muitos métodos de cálculo são empíricos e a capacidade de carga pode ser validada somente com provas de carga;

b) Não podem ser instalados em solos de difícil penetração de modo que estaca seja danificada durante a instalação;

c) Em solos moles ou de baixa capacidade, existe possibilidade de flambagem da estaca quando carregada à compressão.

\subsubsection{Viabilidade do Uso da Estaca Helicoidal}

A empresa A.B. Chance elaborou uma tabela de classificação de solos relacionados à viabilidade deste tipo de fundação (instalação adequada e possível). Nesta tabela (Tabela 2) a classificação é feita com base em resultados de ensaio SPT (deve-se interpretar esta tabela com cautela já que a eficiência no ensaio SPT não está especificada). 
Tabela 2 - Classificação de solos para estacas helicoidais (CLAYTON, 2013).

\begin{tabular}{|c|c|c|c|}
\hline Tipo & Descrição do solo & Classificação geológica & NSPT \\
\hline $\mathbf{0}$ & Rocha Sã & $\begin{array}{l}\text { Granitos: Basaltos, rochas } \\
\text { sedimentares. }\end{array}$ & Impenetrável \\
\hline 1 & $\begin{array}{l}\text { Areia cimentada muito compacta, } \\
\text { cascalho muito grosso. }\end{array}$ & Caliche & 60 a $100+$ \\
\hline 2 & Areia fina compacta; silte e argila dura. & $\begin{array}{l}\text { Caliche, rochas laminada } \\
\text { (alterada) }\end{array}$ & 45 a 60 \\
\hline 3 & $\begin{array}{l}\text { Areia/cascalho compacta; silte e argila } \\
\text { dura/rija }\end{array}$ & $\begin{array}{l}\text { Ardósia, xisto alterado, } \\
\text { gnaisse }\end{array}$ & 35 a 50 \\
\hline 4 & $\begin{array}{l}\text { Areia grossa/cascalho medianamente } \\
\text { compacto; silte e argila rija/muito rija }\end{array}$ & Depósitos glaciais; calcário & 24 a 40 \\
\hline 5 & $\begin{array}{l}\text { Areia grossa/cascalho medianamente } \\
\text { compacto; silte e argila rija/muito rija }\end{array}$ & Saprolitos; solos residuais. & 14 a 25 \\
\hline 6 & Areia fofa a média; silte e argila rija & $\begin{array}{l}\text { Aterros compactados; solos } \\
\text { residuais. }\end{array}$ & $7-15$ \\
\hline 7 & $\begin{array}{l}\text { Areias finas fofas; argila média/rija; } \\
\text { aterros. }\end{array}$ & Argila de lago; aterros & $4-8$ \\
\hline 8 & $\begin{array}{l}\text { Sedimentos orgânicos; cinzas; areia } \\
\text { muito fofa; argila muito mole. }\end{array}$ & $\begin{array}{l}\text { Aterros não consolidados, } \\
\text { depósitos pantanosos }\end{array}$ & $0-5$ \\
\hline
\end{tabular}

Na tabela 2, os solos do tipo 0,1, 2 e parte do solo 3 não são adequados para o uso deste tipo de fundação, já que a ponta e posteriormente as hélices não são capazes de cortar rocha sã e solos muito compactos.

Para a instalação deste tipo de estaca também não é recomendável utilizar solos da classificação 7 e 8. Nestes casos, é recomendável aprofundar a estaca até encontrar camadas da ordem dos solos classificados entre 3 e 5, para evitar possíveis problemas de recalques elevados. 


\subsection{Estacas Helicoidais com Fuste Preenchido com Graute}

Segundo Vickars \& Clemence (2000), durante o início da década de noventa, estacas helicoidais para resistir a esforços de compressão foram instaladas em vários lugares em Vancouver, British Columbia, no Canadá. O perfil de solo típico nesta região é solo aluvial mole, não consolidado, com elevado conteúdo orgânico. A espessura desta camada oscilava entre 3-18m. Em uma tentativa de fazer um fuste de maior diâmetro, em torno da haste da estaca foi adicionado graute por gravidade. $\mathrm{O}$ resultado final foi um sistema de fundação com maior diâmetro de fuste e maior capacidade de carga em comparação a uma estaca helicoidal sem fuste de graute.

A empresa A.B. Chance patenteou este sistema de fundação como Pulldown Micropile, que é referido neste trabalho como estaca helicoidal com fuste de graute.

Estacas helicoidais com graute têm muitas vantagens, segundo a A.B. Chance (2004), sendo:

- Maior capacidade de carga à tração e à compressão, devido ao aumento na área de contato entre fuste e solo, o qual contribui no aumento da resistência por atrito lateral da estaca.

- Maior resistência à flambagem em solos moles em casos de estacas submetidas à compressão, devido ao fuste mais rígido.

O primeiro sistema de estaca com graute e tubo de PVC ao redor do fuste foi investigado por Abdelghany \& El Naggar (2010). Os autores reportaram algumas dificuldades durante a instalação dos tubos de PVC ao redor do furo, como o resultado da resistência do solo, sendo necessário aplicação de torque adicional para se poderem instalar os tubos. As estacas helicoidais com PVC ao redor do fuste com argamassa mostraram uma ligeira melhoria no desempenho comparado com as estacas helicoidais convencionais. Neste trabalho, os autores concluíram que esta é uma opção viável, mas que deveria ser mais pesquisada.

Posteriormente El Sharnouby (2012) instalou estacas helicoidais com argamassa incorporando fibras de aço, as quais foram adicionadas durante o processo de instalação. A principal vantagem da adição das fibras era proporcionar ductilidade e ajudar a resistir cargas 
de terremotos, vento e impacto.

\subsubsection{Configuração Típica}

Segundo Vickars \& Clemence (2000), a estaca helicoidal com graute (Figura 6) consiste em uma haste central de aço, hélices e discos de deslocamento de aço, os quais são colocados acima das hélices, e responsáveis por empurrar o solo deixando um espaço vazio acima deles, onde o graute é colocado por gravidade.

\subsubsection{Graute}

A mistura de graute é depositada no furo aberto (pela passagem dos discos de deslocamento) por gravidade, sem danificar a estrutura do solo. As propriedades do graute são importantes para proporcionar um sistema que seja fácil de instalar e também resultem no desempenho adequado.

Como citado em Vickar \& Clemence (2000), as propriedades ideais do graute são as seguintes:

a) Líquido suficiente para fluir através do furo nas chapas de deslocamentos soldadas ao redor do fuste;

b) Aderência entre haste e graute para poder atingir o aumento da seção do fuste e da parcela de resistência por atrito lateral da fundação;

c) Boa resistência quando está abaixo do nível de água subterrânea;

d) Compatível com a composição química do solo. 


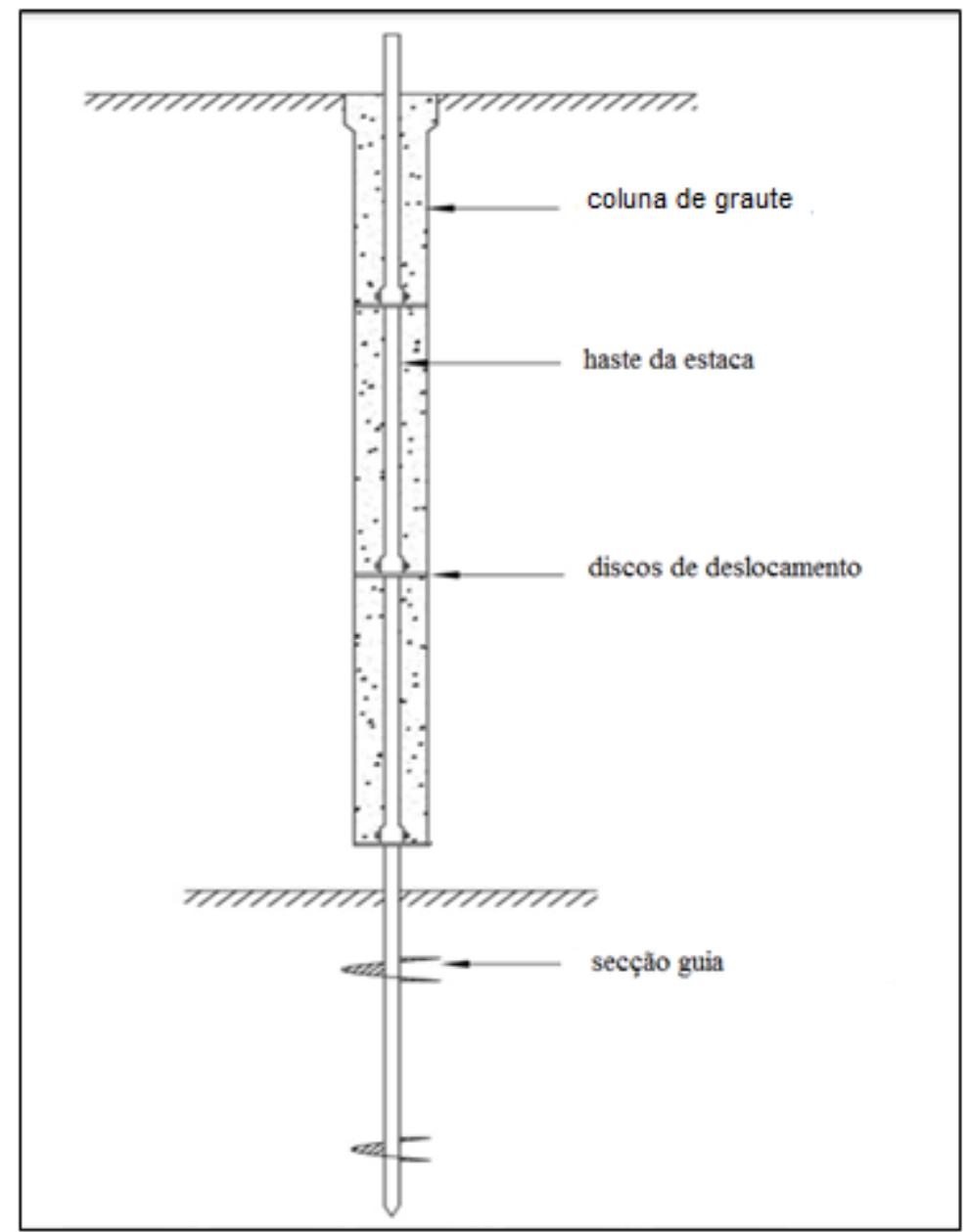

Figura 6 - Estaca helicoidal com graute ao redor do fuste (VICKARS \& CLEMENCE 2000).

Segundo Seider (2002), a seleção da mistura de graute ocorre em função do tipo de solo, da composição química do solo, do lençol freático, da profundidade necessária da coluna e do diâmetro. Por exemplo, se uma estaca com graute está destinada a evitar a flambagem da haste, e o nível do lençol freático está bem abaixo da estaca, o traço normalmente é de cimento Portland tipo I ou II, misturado com uma proporção de água/cimento 0,4 até 0,5 . Já para áreas onde o lençol freático fica próximo à superfície do terreno, o traço geralmente inclui misturas químicas e minerais de cimento e uma proporção de água/cimento de 0,2 a 0,3.

\subsubsection{Instalação}

Os procedimentos típicos de instalação deste tipo de fundação são similares ao da estaca 
helicoidal convencional. O processo (Figura 7) é descrito abaixo, segundo A.B. Chance (2006):

a) A ponta da estaca helicoidal é apoiada no solo e inicia-se o processo de instalação pela aplicação de torque.

b) Depois que a seção guia é instalada e parafusada, a primeira extensão, que possui o primeiro disco de deslocamento (o qual terá a função de empurrar o solo e criar um furo para depois ser preenchido com graute) é emendada à seção guia e o processo de instalação continua com a aplicação do torque.

c) Quando se atinge certa profundidade, o processo de penetração da estaca é finalizado, deposita-se a mistura de graute no furo, e é terminado o processo executivo deste tipo de fundação.

\subsubsection{Vantagens}

De acordo com Vickars \& Clemence (2000), as principais vantagens deste tipo de fundação são:

- A capacidade de carga aumenta devido ao aumento da área de contato do fuste com o solo, aumentando a resistência por atrito lateral da estaca;

- Evitar flambagem no fuste da estaca em terrenos com presença de solo mole;

- Fácil instalação. 


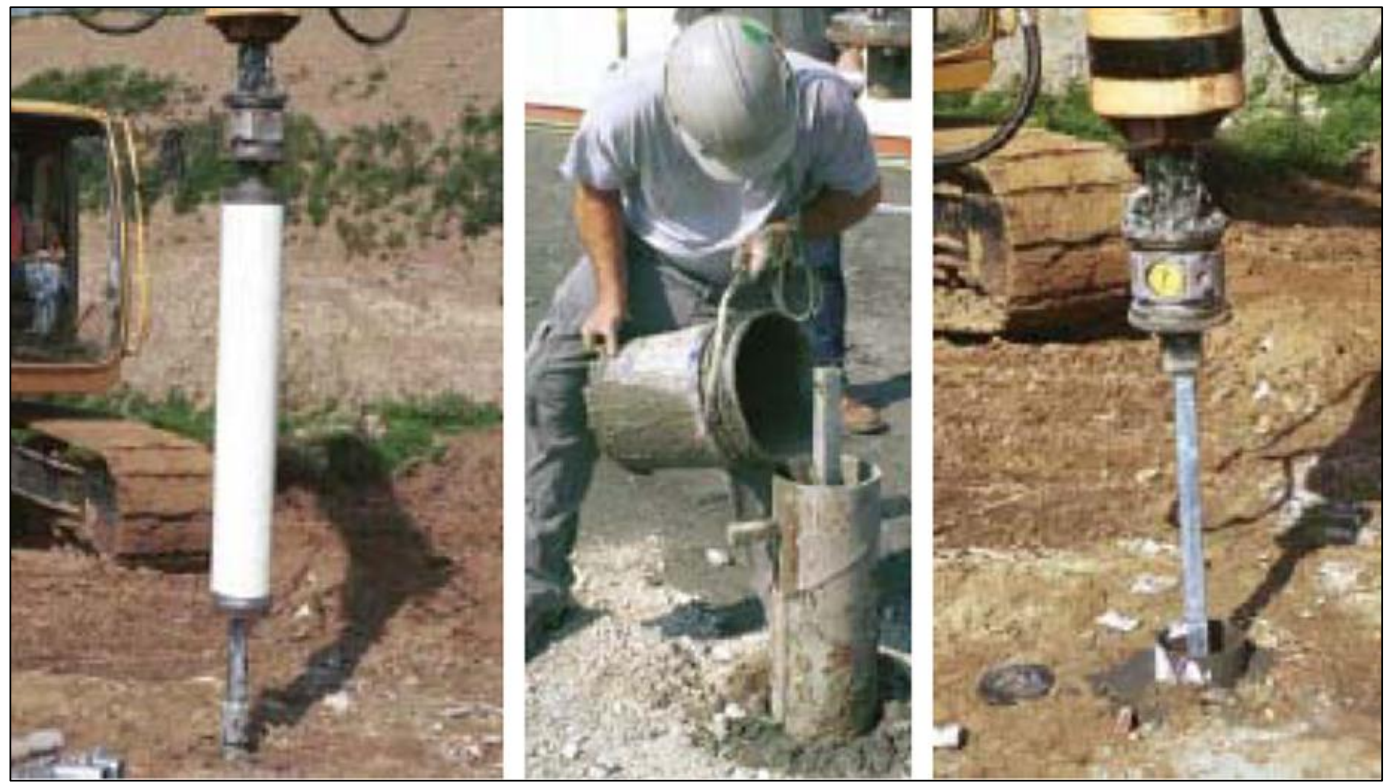

Figura 7 - Processo de instalação de estaca helicoidal com graute (A.B. CHANCE, 2004).

Na Figura 8, compara-se a geometria de uma estaca helicoidal convencional com uma estaca helicoidal com fuste de graute.

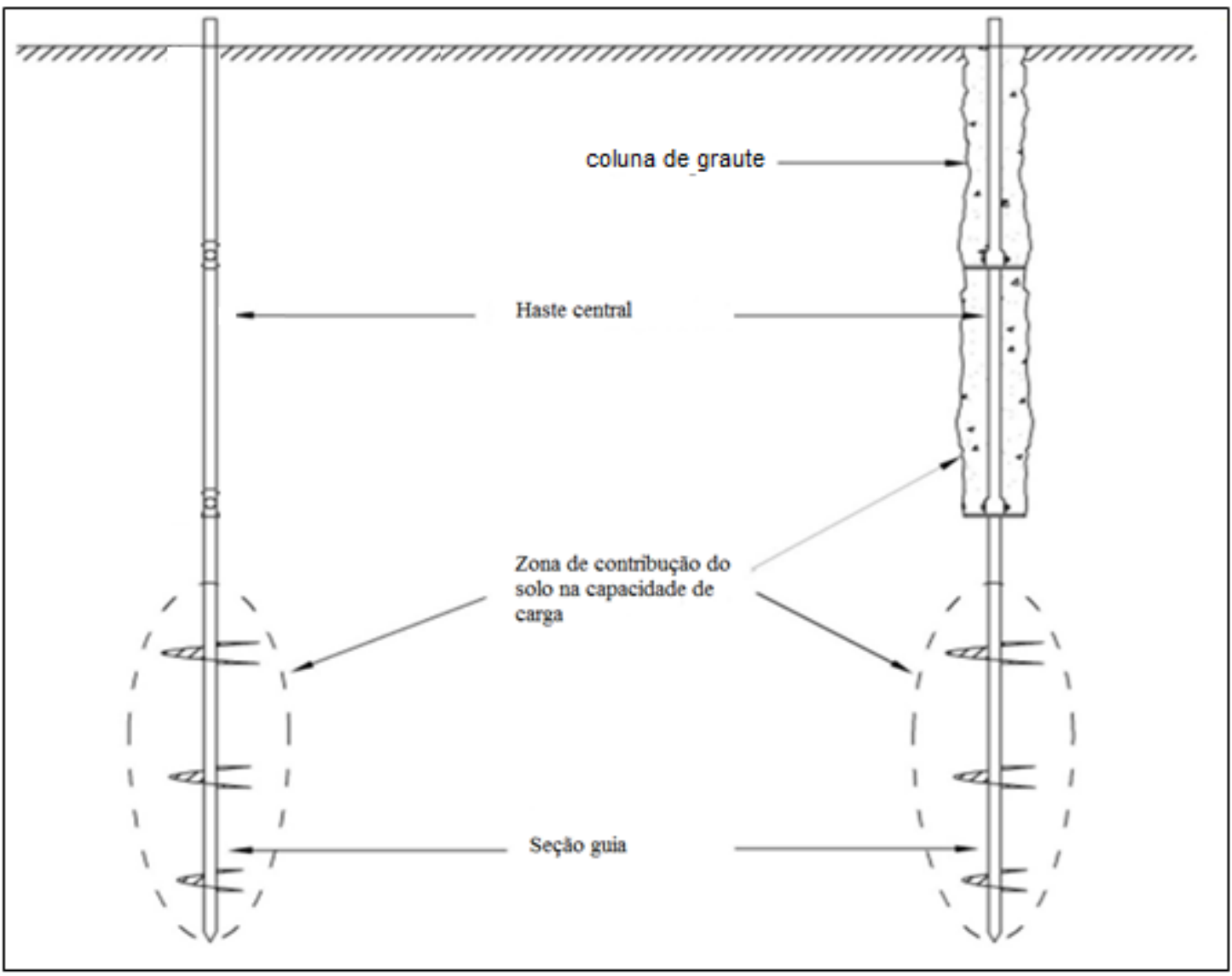

Figura 8 - Diferenças entre uma estaca helicoidal e uma estaca helicoidal com fuste de graute (adaptada de LUTENEGGER, 2014). 
Este tipo de estaca helicoidal melhorada pode ser utilizado em caso de estacas curtas e também em estacas profundas, dependendo do perfil de solo. Como mostrado na Figura 9, as estacas helicoidais com fuste de graute podem ser classificadas quanto à capacidade de carga, como de ponta ou de atrito.

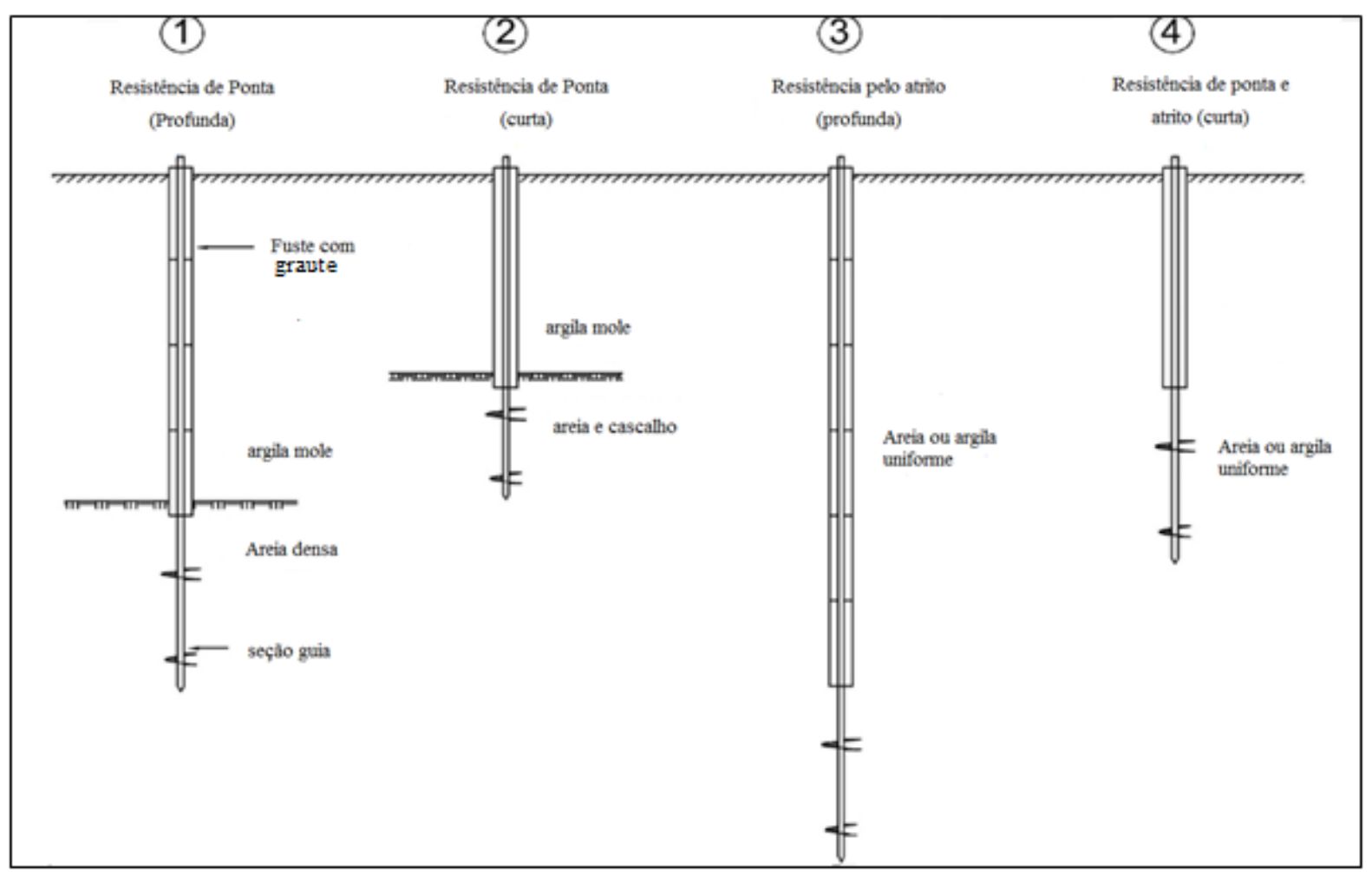

Figura 9 - Estacas helicoidais com graute profundas e curtas em diferentes perfis de solo (LUTENEGGER, 2014).

\subsection{Estacas Metálicas Helicoidais com Injeção}

O Turbo Pier é um modelo de estaca helicoidal com graute. Este tipo de fundação substitui o eixo sólido tradicional do fuste por um orifício na ponta da estaca por onde o graute sairá no momento da instalação. O eixo oco permite a saída do groute ao mesmo tempo em que está sendo instalada a estaca. A Figura 10 mostra o procedimento de instalação, o qual é realizado simultaneamente com a penetração da estaca no solo. Extensões adicionais podem ser utilizadas para o aumento do comprimento da estaca. 


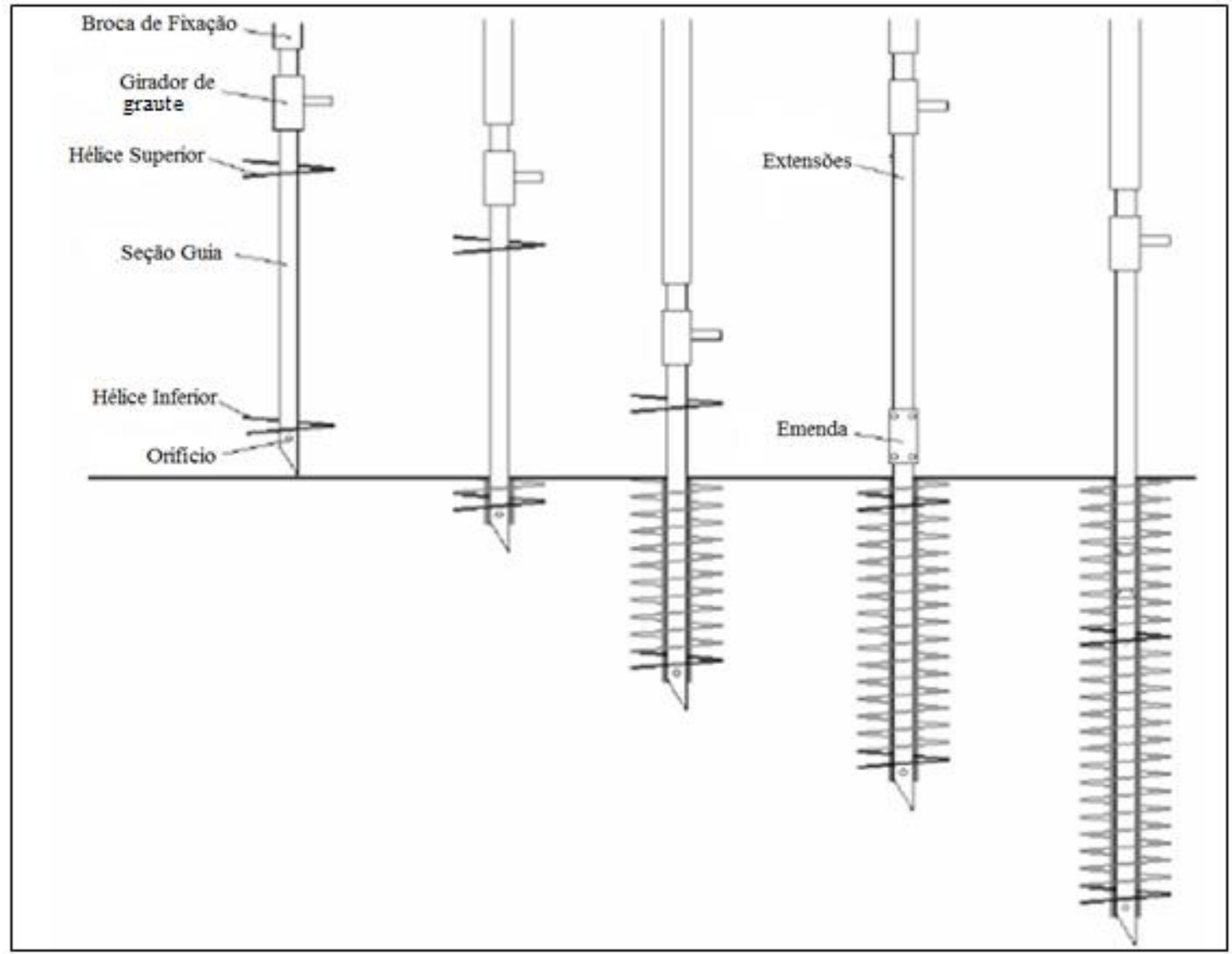

Figura 10 - Processo de instalação da estacaTurbo Pier com graute (MANKE, 2004).

Manke (2004) realizou um programa experimental com 32 estacas helicoidais (modelo reduzido) com graute injetado (Figura 10), em modelos de estaca com escala 1/8 (tubo de aço de $864 \mathrm{~mm}$ de comprimento e diâmetro de $12,7 \mathrm{~mm}$, com duas hélices de $50,8 \mathrm{~mm}$ e passo de 9,5mm; o espaçamento entre as hélices era de 152,4mm de distância), com um par de orifícios localizados a $15,9 \mathrm{~mm}$ da ponta da estaca.

Neste trabalho, as provas de carga foram realizadas para a avaliação do sistema de fundação composta por grupos de estaca de $2 \times 2$ ou $3 \times 3$ construídos com um fuste de aço de $57 \mathrm{~mm}$ e comprimento de $457 \mathrm{~mm}$. As fundações foram instaladas com uma inclinação de 79 graus em relação ao horizontal. Provas de carga de compressão e lateral foram realizadas separadamente. $\mathrm{O}$ uso de graute aumentou a capacidade de carga à compressão da fundação em 74-85\%. Manke (2004) também observou que o diâmetro da coluna de graute resultante foi de aproximadamente 45-60 mm de diâmetro (0,9-1,2 vezes o diâmetro das hélices e 3,54,8 vezes o diâmetro do fuste), com 356-432 mm de comprimento (76-93\% do comprimento do eixo da estaca). 
Bian (2006) realizou injeção de graute em estacas helicoidais em modelos reduzidos e chegou às seguintes conclusões:

- Os bulbos de grautes resultantes variaram de 2,5 a 7,8 vezes em relação ao diâmetro da haste das estacas que ele ensaiou;

- Graute com relação a/c menores proporcionaram maiores bulbos em procedimentos de instalação similares;

- O aumento no peso do bulbo de graute é sensível à profundidade, geralmente é maior para estacas profundas;

- Aplicação de rotação durante a instalação de graute na ponta da estaca ocasionou no aumento do diâmetro do bulbo em aproximadamente 60-100\% e aumento no peso entre 7-12 vezes;

- Para um mesmo tipo de graute, foi observado bulbos de graute maiores quando injetados com pressões maiores.

Embora este tipo de estaca helicoidal seja uma técnica nova e não existam dados de ensaios suficientes e disponíveis para compreender os mecanismos de transferências de carga, o aumento na capacidade de carga tem sido significativo comparando-se às estacas helicoidais convencionais.

Segundo Bian (2006), como mostra a Figura 11, a capacidade de carga total da estaca helicoidal com injeção de graute na ponta está regida por:

- Parcela de atrito ao longo do fuste da estaca;

- Parcela de atrito na interface solo-bulbo;

- Parcela de ponta no final do bulbo, quando a estaca for submetida a esforços de compressão. 


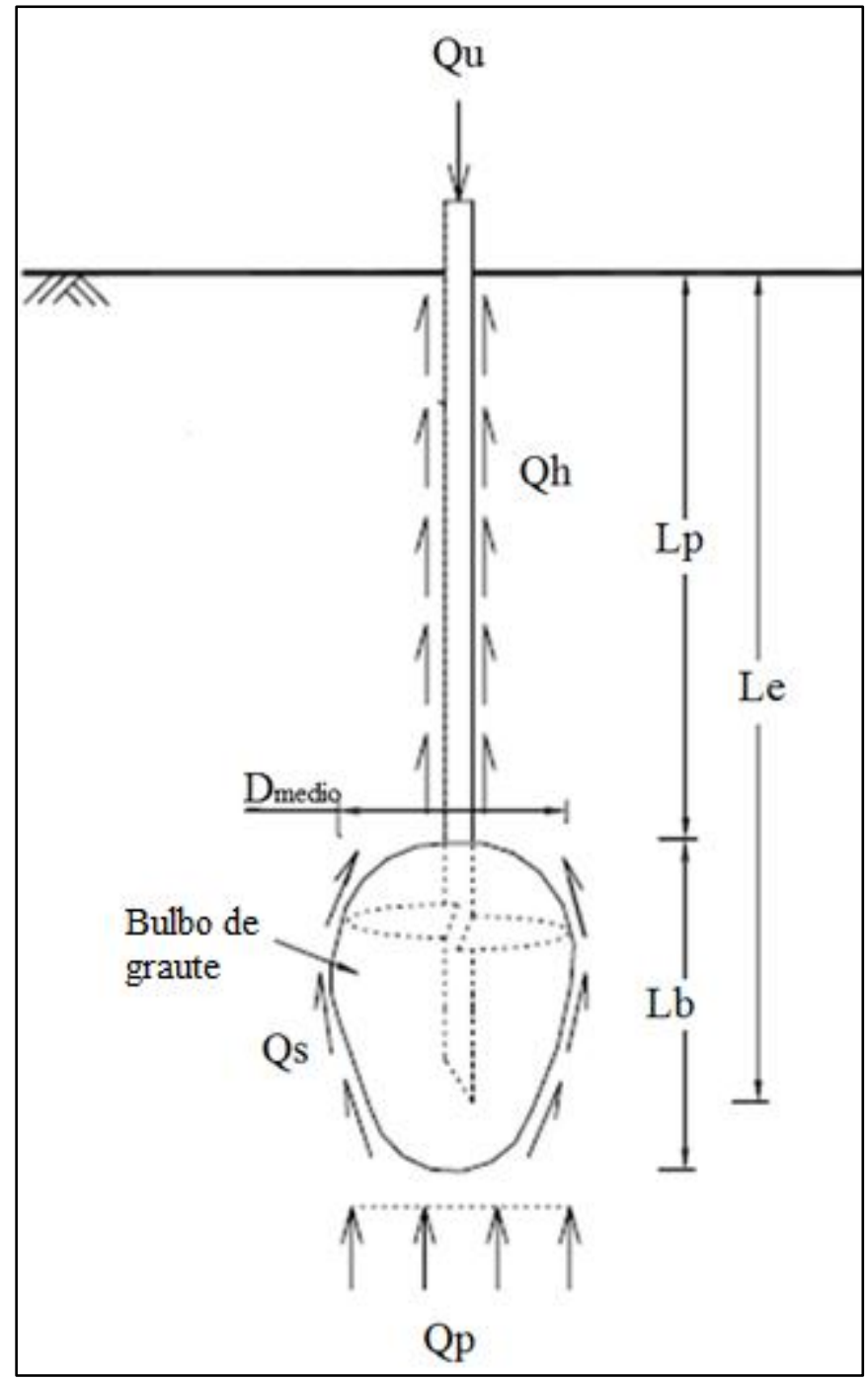

Figura 11- Mecanismo de transferência de carga em uma estaca helicoidal com graute na ponta (BIAN, 2006).

\subsubsection{Traço de Calda de Injeção}

De acordo com Iyomasa (2000), para estabelecer o melhor traço das caldas de injeção, é necessário considerar as seguintes condições:

- Realizar ensaios com a finalidade de se obter a curva tempo de escoamento x fator de sedimentação. A partir dessa curva, pode ser determinada a calda mais injetável;

- É necessário também observar a compatibilidade entre a facilidade de injeção e a resistência mecânica da calda após a cura.

Iyomasa (2000) cita que para maior penetrabilidade das caldas é sugerido iniciar as 
injeções com caldas mais ralas, relação a/c 2:1 e em algumas vezes, até 10:1, aumentando-se progressivamente a quantidade de cimento (menor relação a/c), durante o processo de injeção.

De acordo com Iyomasa (2000), é comum o emprego de produtos químicos, em proporções relativamente baixas, até $5 \%$ em peso do cimento, para melhorar a qualidade das caldas de água/cimento, durante o processo de injeção. Produtos como expansores servem para diminuir a sedimentação. A fluidez da calda pode ser aumentada com emprego de dispersantes ou escorias de alto forno. Esta mistura facilita o bombeamento da calda durante a injeção, além de permitir maior penetração nas fissuras.

\subsubsection{Injeção}

A injeção é um método pelo qual as caldas são inseridas sob pressão para preencher vazios, fissuras, falhas ou cavidades nos maciços de solo ou rochosos, de modo a melhorar as propriedades deste, diminuindo a permeabilidade, aumentando a resistência e reduzindo a deformabilidade.

Ao aplicar injeção da calda nos solos, suas propriedades são modificadas através do preenchimento dos seus vazios ou pela compactação, promovendo o aumento da densidade do solo.

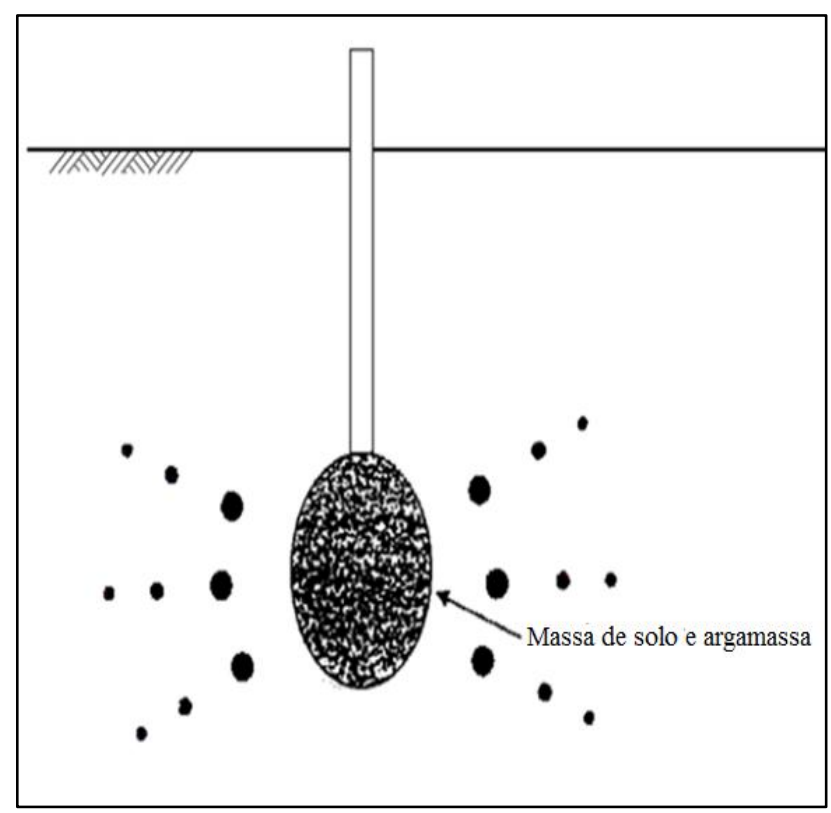

Figura 12 - Densificação do solo ao redor da argamassa injetada na compactação por injeção (WARNER, 2004). 
Segundo Warner (2004) e Nonveiller (1989), a massa injetada se comporta como um sólido, que" cresce" dentro do maciço.

Para aumentar a força e rigidez do solo, as técnicas alternativas com argamassa são:

- Permeação;

- Jet grouting;

- Fraturamento;

- Compactação.

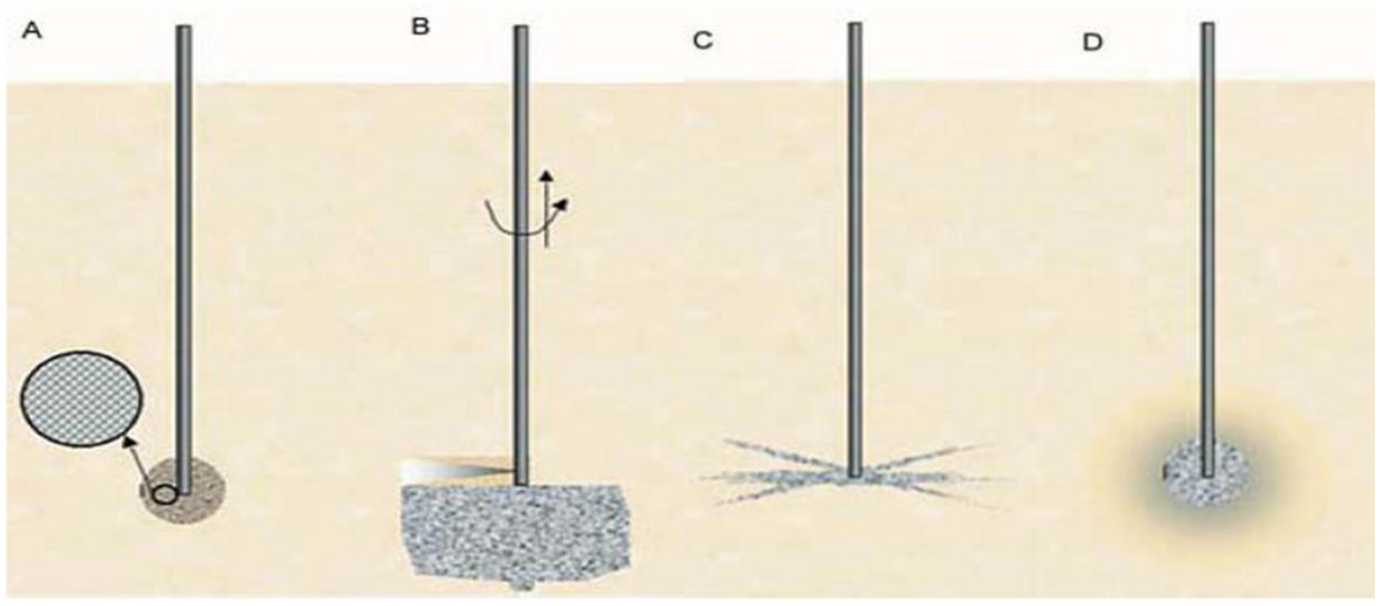

Figura 13 - a) permeação, b) jet grouting, c) faturamento, d) compactação (MOSELEY, 2004).

De acordo com Warner (2004) e Bian (2006), a permeação é a técnica mais comum para permear a argamassa no solo. Jet grouting é a introdução no solo de um material de cimento (geralmente argamassa) através de um ou mais jatos a alta velocidade. A energia deste fluxo faz com que a quebra e reestruturação do solo, misturado com o material de cimento, melhore a resistência do solo. Fraturamento é uma técnica de deslocamento, em que a calda é injetada no interior do solo sob alta pressão através de tubos com válvulas especiais, provocando o processo de fraturamento do solo, sendo as fissuras preenchidas com calda. A compactação envolve a injeção de pressão de uma mistura de cimento de alta densidade, para formar um bulbo de injeção que comprime e compacta o solo, sendo a melhoria produzida pelo aumento da densidade do solo.

Segundo Moraes (2010), apesar de geralmente se utilizarem pressões baixas na técnica de compactação, o método apresenta riscos de vazamento e fraturamento hidráulico, pois a calda injetada se comporta como um fluido. 


\subsubsection{Pressões de Injeção}

Segundo Weaver (2000), as diferentes regras gerais usadas pelos especialistas europeus e americanos de injeções para determinar as pressões a serem utilizadas têm sido alvo de muitas controvérsias ao longo dos anos, entre ambos os grupos.

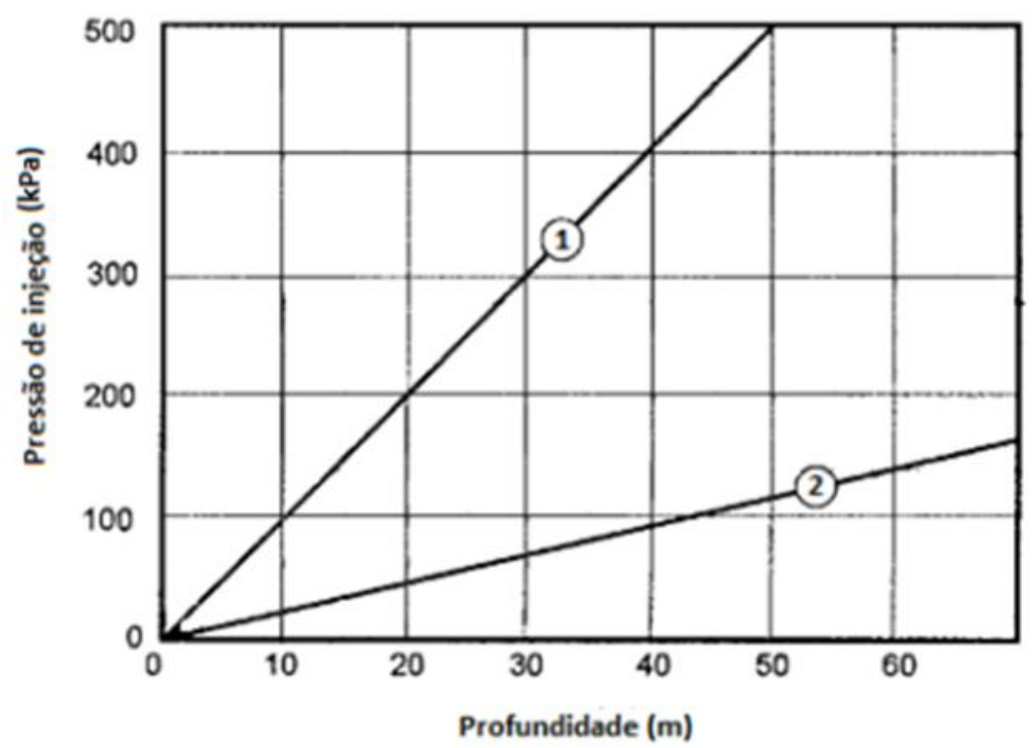

Figura 14 - Representação gráfica: 1) regra européia e 2) regra americana, adaptado de Warner (2004).

Segundo Warner (2004), a regra européia tem sido usada com sucesso em maciços de fundações rochosas de caraterísticas razoáveis. A regra americana se fundamenta geralmente na proteção contra potenciais fenômenos de levantamento hidráulico de estratos horizontais. A aplicação das pressões ditadas por esta regra pode não ser suficiente para garantir a penetração adequada das caldas em fissuras de pequena abertura.

Avaliações dos valores de pressões de ruptura dos solos foram feitas por Santos (1985), a partir dos dados obtidos no tratamento da fundação da barragem de terra de Balbina. Ao se realizar a análise das pressões aplicadas, verificou-se que os valores ficaram entre 0,05 MPa e $0,35 \mathrm{MPa}$ (valores por metro de profundidade), com maior frequência entre 0,05 e 0,2 Mpa.

Bian (2006) observou que quanto maiores os valores de pressão de injeção, maiores eram os bulbos de graute nos modelos de estacas helicoidais. Adicionando-se uma pressão de 0,7 Mpa, proporcionou-se um aumento do diâmetro do bulbo de 20-50\% e um aumento de 10$45 \%$ no peso do bulbo de argamassa. 


\subsubsection{Instalação}

De acordo com Bian (2006), as estacas são instaladas e depois injetadas. Porém, em alguns casos, a instalação e o processo de injeção são feitos ao mesmo tempo.

\subsection{Método de Previsão da Capacidade de Carga}

\subsubsection{Previsão da Capacidade de Carga (Estaca Convencional)}

Segundo Perko et al. (2000), existem três métodos para a previsão da capacidade de carga em estacas helicoidais. Esses métodos são os seguintes:

a) Método cilindro de cisalhamento;

b) Capacidade individual;

c) Torque de instalação.

Perko et al. (2000) sugerem que, quando possível, a decisão do engenheiro deve ser baseada nos resultados dos três métodos, considerando a confiabilidade dos parâmetros e dados fornecidos.

\subsubsection{Método de Previsão da Capacidade de Carga à Tração}

Hoyt \& Clemence (1989) destacam os dois métodos de previsão de capacidade de carga de estacas helicoidais mais utilizados: o método do cilindro de cisalhamento e o método das capacidades de cargas individuais. A Figura 15 ilustra as hipóteses de transferência de carga adotadas nestes dois métodos, para quando a estaca é solicitada à tração. 


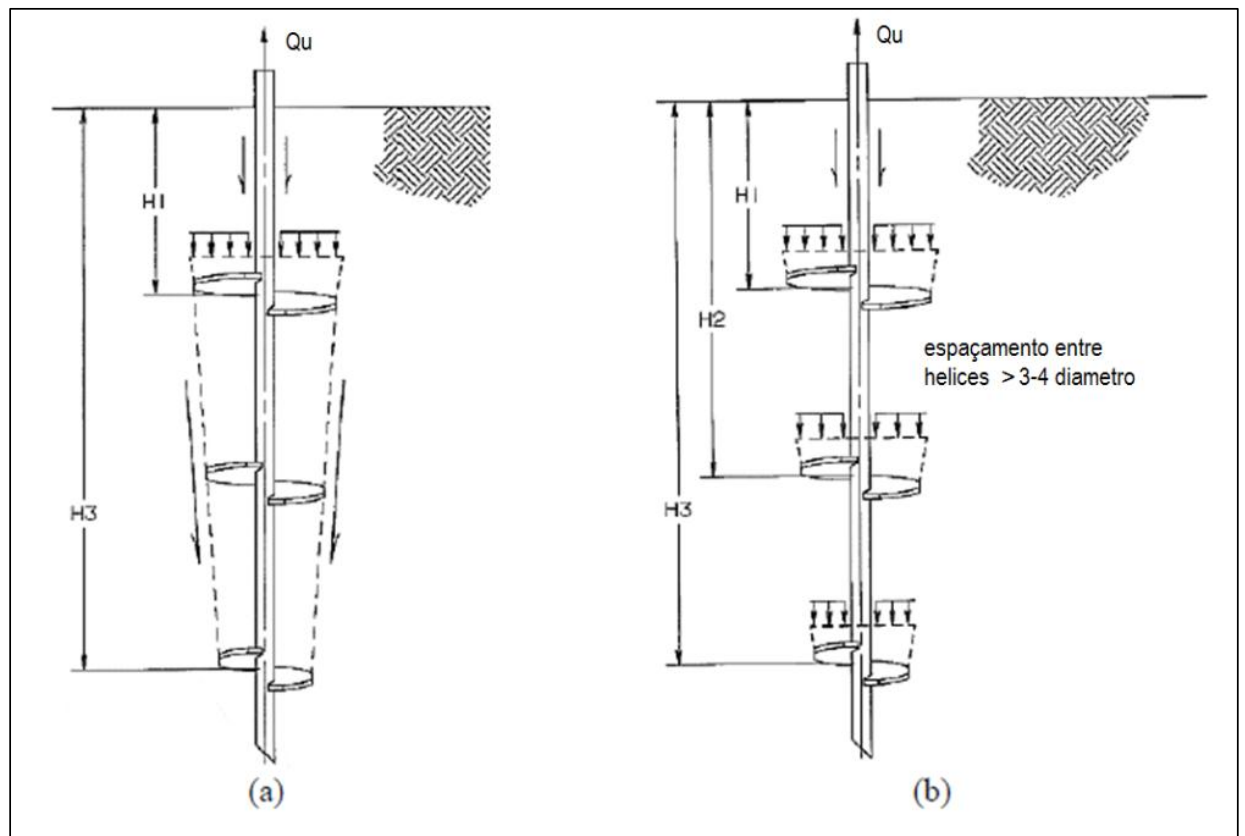

Figura 15 - a) Método cilindro de cisalhamento, b) Método capacidade individuais (HOYT \& CLEMENCE, 1989).

\subsubsection{Método do Cilindro de Cisalhamento}

Este método foi desenvolvido por Mitsch \& Clemence (1985), para estacas helicoidais em areia, e por Mooney et al. (1985), para estacas em argila e silte.

Segundo Hoyt \& Clemence (1989), neste método a capacidade de carga à tração depende das parcelas de: resistência de cisalhamento do cilindro de solo formado entre as hélices de ponta e superior, da capacidade do solo acima da hélice superior e da resistência por atrito lateral na parcela da haste acima da hélice superior. Assume-se que na ruptura o volume de solo contido entre as hélices é inteiramente mobilizado.

De acordo com Das (1990), para a condição de estacas helicoidais rasas em areia temse na Figura 16 a superfície de ruptura adotada neste método. A carga de ruptura da estaca à tração, relativa somente à ruptura do solo $\left(\mathrm{Q}_{\mathrm{u}}\right)$, estimada de acordo com Mitsch \& Clemence (1985) é:

$$
Q_{u}=Q_{p}+Q_{f}
$$

Em que:

$\mathrm{Q}_{\mathrm{p}}=$ capacidade de carga da hélice superior; 
$\mathrm{Q}_{\mathrm{f}}=$ resistência por atrito na superfície cilíndrica formada entre as hélices de ponto e superfície.

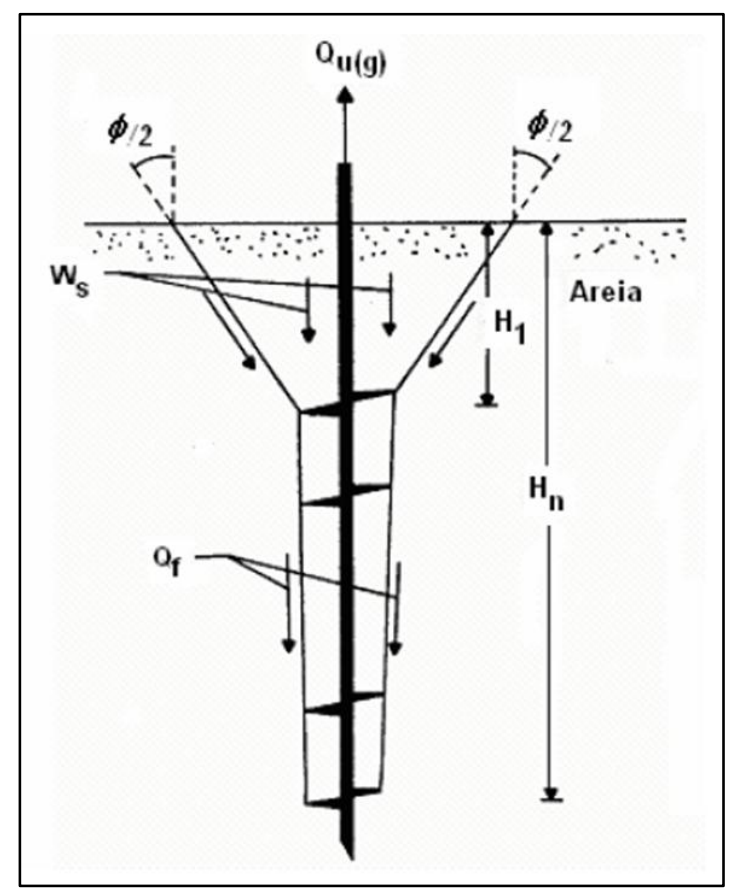

Figura 16 - Superfície de ruptura adotada em areias (DAS, 1990).

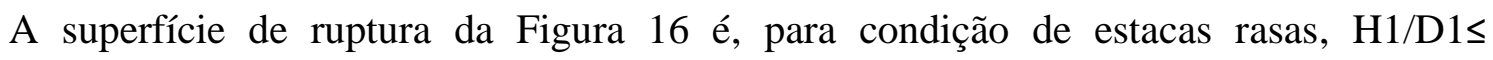
(H1/D1)cr.

$$
Q_{p}=\pi \gamma^{\prime} K_{u}(\tan \emptyset)\left[\cos ^{2}\left(\frac{\emptyset}{2}\right)\right]\left[\frac{D_{1} H_{1}{ }^{2}}{2}+\frac{{H_{1}}^{3} \tan \left(\frac{\emptyset}{2}\right)}{3}\right]+W_{s}
$$

Em que:

$\gamma^{\prime}=$ peso específico efetivo do solo;

$\varnothing=$ ângulo de atrito do solo;

$\mathrm{K}_{\mathrm{u}}=$ coeficiente de empuxo na ruptura à tração;

$\mathrm{W}_{\mathrm{s}}=$ peso do solo dentro da superfície de ruptura.

$\left.W_{s}=\gamma^{\prime}\left\{\frac{\pi}{3} H 1\left[\left(D_{1}\right)^{2}+\left(D_{1}+2 H_{1} \tan \frac{\emptyset}{2}\right)\right)^{2}+(D 1)\left(D 1+2 H_{1} \tan \frac{\emptyset}{2}\right)\right]\right\}$

A resistência por atrito ao longo da superfície cilíndrica formada entre as hélices de topo 
de ponta é dada por:

$$
Q_{f}=\frac{\pi}{2} D_{a} \gamma^{\prime}\left(H_{2}^{2}-H_{1}^{2}\right) K_{u} \tan \emptyset
$$

Em que:

$\mathrm{Da}=$ diâmetro médio das hélices.

Mitsch \& Clemence (1985) recomendam os valores de $K u$ conforme a Tabela 3 para estacas helicoidais submetidas à tração.

Tabela 3 - Valores de $K u$ para ângulos de atrito de solo $\emptyset$ (MITSCH \& CLEMENCE, 1985)

\begin{tabular}{cc}
\hline $\begin{array}{c}\text { Ângulo de atrito do solo } \\
\varnothing \text { (graus) }\end{array}$ & $\begin{array}{c}\text { Valores recomendadas } \\
\mathbf{K}_{\mathbf{u}} \text { estacas helicoidais }\end{array}$ \\
\hline $\mathbf{2 5}$ & 0,70 \\
$\mathbf{3 0}$ & 0,90 \\
$\mathbf{3 5}$ & 1,50 \\
$\mathbf{4 0}$ & 2,35 \\
$\mathbf{4 5}$ & 3,20 \\
\hline
\end{tabular}

Segundo Mitsch \& Clemence (1985), a superfície de ruptura na estaca helicoidal profunda $\left(\mathrm{H} 1 / \mathrm{D} 1>(\mathrm{H} 1 / \mathrm{D} 1)_{\mathrm{CR}}\right)$ instalada em areia é mostrada na Figura 17, em que a capacidade de carga à tração é dada por:

$$
Q_{u=} Q_{s}+Q_{p}+Q_{f}
$$

Em que:

$\mathrm{Q}_{\mathrm{s}=}$ resistência por atrito entre o tubo da estaca e solo acima da hélice do topo;

$\mathrm{Q}_{\mathrm{p}}=$ resistência de carga da hélice superior;

$\mathrm{Q}_{\mathrm{f}=}$ resistência ao cisalhamento na superfície cilíndrica formada entre as hélices de ponta e superior. 


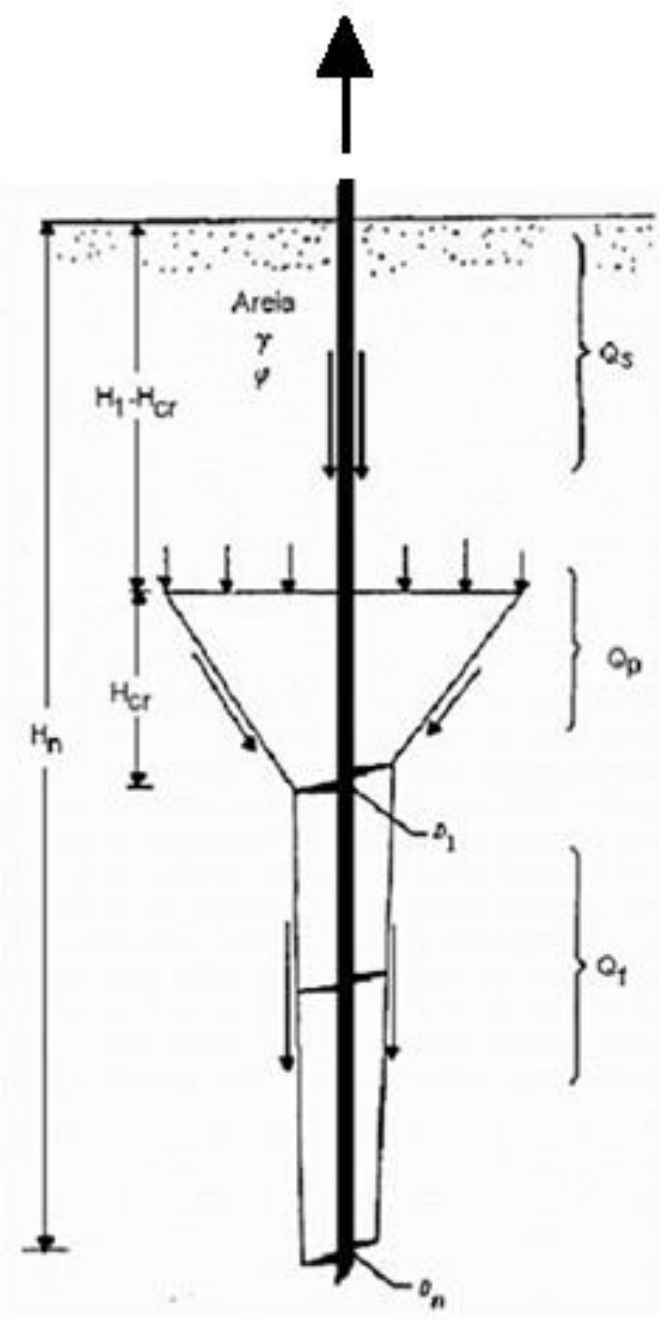

Figura 17 - Superfície de ruptura idealizada (MITSCH \& CLEMENCE, 1985).

A capacidade de carga à tração de estacas helicoidais profundas em areia pode ser calculada, segundo Mitsch \& Clemence (1985), pela equação 6. Mooney et al. (1985) sugerem para estacas em argilas equação 7 e para estacas em silte, a equação 8:

$$
\begin{aligned}
& Q_{u}=\gamma^{\prime} H_{1} A_{1} N_{q}+\frac{\pi}{2} D_{a} \gamma^{\prime}\left({H_{n}}^{2}-{H_{1}}^{2}\right) K_{u} \tan \emptyset+p_{s} H_{1}\left(\frac{\gamma^{\prime} H_{1}}{2}\right) K_{u} \tan \emptyset \\
& Q_{u}=A_{1} c N_{c}+\pi D_{a} c\left(H_{n}-H_{1}\right)+p_{s} H_{1} C_{a} \\
& Q_{u}=\gamma^{\prime} H_{1} A_{1} N_{q}+A_{1} c N_{c}+\frac{\pi}{2} D_{a} \gamma^{\prime}\left({H_{n}}^{2}-{H_{1}}^{2}\right) K_{u} \tan \emptyset+\pi D_{a} c\left(H_{n}-H_{1}\right)+ \\
& p_{s} H_{1} C_{a}+p_{s} H_{1}\left(\frac{\gamma^{\prime} H_{1}}{2}\right) K_{u} \tan \emptyset+p_{s} H_{1} C_{a}
\end{aligned}
$$

Em que:

$\mathrm{K}_{\mathrm{u}}=$ coeficiente de empuxo; 
$\mathrm{A}_{1}=$ área da hélice superior;

$\mathrm{H}_{1}=$ profundidade da hélice superior;

$\mathrm{H}_{\mathrm{n}}=$ profundidade da hélice inferior;

$\mathrm{D}_{\mathrm{n}}=$ diâmetro da hélice inferior;

$\mathrm{D}_{\mathrm{a}}=$ diâmetro médio das hélices;

$\mathrm{N}_{\mathrm{q}}=$ fator da capacidade de carga à tração para areias;

$\mathrm{N}_{\mathrm{c}}=$ fator de capacidade de carga à tração para solo coesivo;

ps = perímetro do tubo da estaca;

c=adesão ao longo do tubo da estaca;

$\varnothing=$ ângulo de atrito do solo.

No Gráfico 1, é apresentado o fator de capacidade de carga à tração $N_{q}$ versus H/D (profundidade relativa da hélice) para estacas helicoidais em areia.

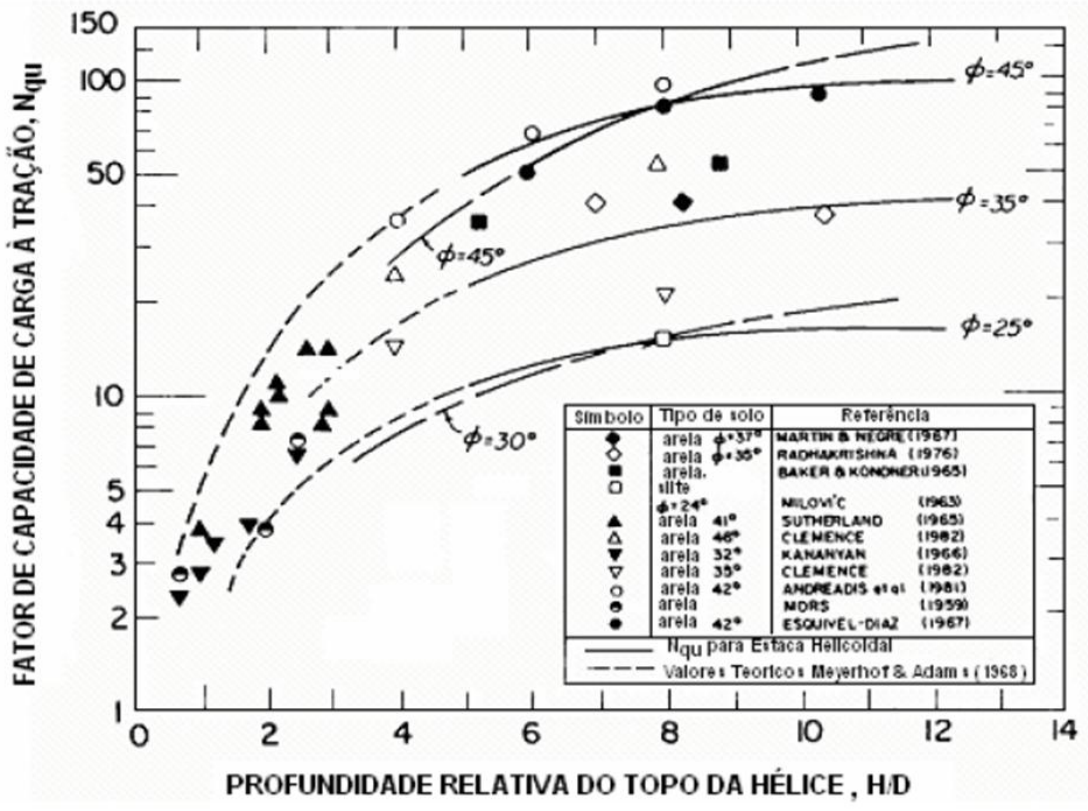

Gráfico 1 - Fator de capacidade de carga à tração $\mathrm{N}_{\mathrm{q}}$ versus profundidade relativa da hélice H/D, (MITSCH \& CLEMENCE, 1985). 
A empresa A.B. Chance (2003) ajustou um fator de capacidade de carga $N_{q}$ para estacas helicoidais à tração. Este fator foi adaptado de Meyerhof (1976), com base na experiência da A.B. Chance Company neste tipo de estacas, segundo a equação 9:

$$
N_{q}=0,5 *(12 * \varphi i)^{\varphi i / 54}
$$

Em que:

pi é o ângulo de atrito interno do solo na profundidade da hélice i.

No caso de solo coesivo, o valor de $\mathrm{N}_{\mathrm{c}}$ varia segundo a forma e a profundidade da fundação e no caso de estacas helicoidais profundas o valor de $\mathrm{N}_{\mathrm{c}}$ é igual a 9 (quando a profundidade da hélice superior for maior ou igual a cinco vezes o seu diâmetro).

\subsubsection{Método das Capacidades de Carga Individual}

De acordo com Clemence et al. (1994), o método das capacidades individuais assume que a ruptura ocorre acima de cada hélice da estaca, e a capacidade de carga total da estaca é dada pela soma dos valores de capacidade de carga relativos a cada hélice.

Perko \& Rupiper (2000) propõem pela equação 10 que o valor da capacidade de carga individual de cada hélice seja o seguinte:

$$
Q_{h i}=A_{i}\left(1,3 c i N_{C}+q_{i} N_{q}\right)
$$

Em que:

Qhi= capacidade de carga da hélice i;

$\mathrm{A}_{\mathrm{i}}=$ área projetada da hélice $\mathrm{i}$;

qi: tensão efetiva na profundidade da hélice i;

ci: coesão na profundidade da hélice i; 
$\mathrm{N}_{\mathrm{c}}$ e $\mathrm{N}_{\mathrm{q}}$ : Fatores de capacidade de carga relativos ao solo acima da hélice i.

Stephenson (1997) propõe que a capacidade de carga de cada hélice seja dada pela equação 11:

$$
Q_{u}=A_{i}\left(c_{i} N_{c}+\frac{1}{2} D_{i} \gamma_{i} N_{\gamma}+q_{i} N_{q}\right)
$$

Em que:

Di=diâmetro da hélice i.

Tabela 4 - coeficientes de capacidade de carga para solos coesivos (STEPHENSON, 1997).

\begin{tabular}{cccc}
\hline & $\mathbf{N}_{\mathbf{c}}$ & $\mathbf{N}_{\gamma}$ & $\mathbf{N q}$ \\
\hline H1/D1 $\leq \mathbf{3}$ & 5,7 & 0 & 1 \\
H1/D1 $>\mathbf{3}$ & 9 & 0 & 1 \\
\hline
\end{tabular}

\subsubsection{Método Empírico - Torque de Instalação}

De acordo com Clemence et al., (1994), um procedimento empírico tem sido desenvolvido pela A.B. Chance Company, no qual a capacidade de carga à tração de estacas helicoidais pode ser estimada com base do torque medido ao final de instalação da estaca (valor medido correspondente à penetração final igual a três vezes o diâmetro da maior hélice da estaca).

Segundo Hoyt \& Clemence (1989), a capacidade de carga $\mathrm{Q}_{\mathrm{u}}$ pode ser calculada empiricamente, pelo torque de instalação de acordo a equação 12:

$$
Q_{u}=K_{t} T
$$

Em que:

$\mathrm{Q}_{\mathrm{u}}$ : capacidade de carga a tração (em lb. $\left.\mathrm{kN}\right)$; 
$\mathrm{K}_{\mathrm{t}}$ : fator empírico do torque $\left(\mathrm{em} \mathrm{ft}^{-1} \cdot \mathrm{m}^{-1}\right)$;

T: torque de médio de instalação (em ft-lb, kN-m).

Na Tabela 5 são apresentados valores de Kt, sugeridos em função do diâmetro da haste da estaca.

Tabela 5 - Valores recomendados de $\mathrm{K}_{\mathrm{t}}$ em função do diâmetro da haste da estaca, segundo Hoyt \& Clemence (1989).

\begin{tabular}{cc}
\hline Diâmetro do fuste & $\mathrm{K}_{\mathrm{t}}$ \\
\hline$<89 \mathrm{~mm}$ & $33 \mathrm{~m}^{-1}$ \\
$89 \mathrm{~mm}$ & $23 \mathrm{~m}^{-1}$ \\
$219 \mathrm{~mm}$ & $9,8 \mathrm{~m}^{-1}$ \\
\hline
\end{tabular}

Perko et al. (2000) citam que pesquisas anteriores indicam que o fator $K_{t}$ varia com a profundidade da estaca. Outros trabalhos mostram que o valor de $K_{t}$ independe das dimensões da hélice e depende significativamente do diâmetro da haste da estaca. Segundo Hargrave \& Thorsten (1992), o fator $K_{\mathrm{t}}$ varia pouco, independentemente do número de hélices da estaca.

Segundo Tsuha (2007), este terceiro método se baseia na correlação entre o torque de instalação da estaca e sua capacidade de carga, ou seja, entre o esforço para que se instale a estaca e a resistência ao arranchamento desta. Este método foi desenvolvido empiricamente, no entanto tem sido utilizado com sucesso na construção de milhares de estacas nos últimos anos.

Tsuha \& Aoki (2010) apresentam uma expressão teórica simplificada para correlacionar a capacidade de carga à tração ao torque de instalação para estacas metálicas helicoidais em areia. Segundo estes autores, a correlação entre a capacidade de carga e o torque depende do ângulo de atrito residual na interface entre a superfície da hélice e o solo. Tsuha \& Aoki (2011) mostram que a magnitude de $K_{t}$ decresce com o aumento nas dimensões da estaca.

As leituras de torque, obtidas durante a instalação deste tipo de estaca no terreno, são 
um indicativo da resistência de cisalhamento do solo na profundidade em que as hélices da estaca atravessam. De acordo com Perko et al. (2000), é difícil relacionar as medidas de torque com o ângulo de atrito e a coesão do solo, devido à complexidade da interação entre as hélices e o solo.

Segundo Radhakrishna (1976) apud Li (2006), a configuração de uma estaca helicoidal pode ser com hélices de mesmo diâmetro (cilíndrica), ou de diâmetros crescentes da ponta para o topo da estaca (cônica). Este autor relatou que para instalar a estaca com hélices crescentes, é necessário $25 \%$ a mais do torque em relação a estacas de configuração cilíndrica (ambas com mesmo diâmetro médio das hélices), quando ambas são instaladas na mesma profundidade. Este fato deve ser considerado na interpretação dos valores de $K_{t}$, visto que este fator representa a razão entre a capacidade de carga e torque final de instalação.

\subsubsection{Método de Silva (2014)}

Silva (2014) desenvolveu um método semi-empírico que assume a hipótese das capacidades individuais de cada hélice. Neste método este autor correlaciona a capacidade de carga individual de cada hélice com o valor de $\mathrm{N}_{\mathrm{SPT}}$ na profundidade da hélice. Este método foi calibrado com provas de cargas em estacas helicoidais realizadas no Brasil, e, portanto já considera o efeito da instalação no solo acima das hélices. Silva (2014) separou estas correlações em dois grupos distintos: situação A, na qual as estacas helicoidais têm as hélices instaladas em solo resistente, e a situação B, que representa estacas helicoidais instaladas em solo com valores de $\mathrm{N}_{\mathrm{SPT}}$ inferiores a 7 golpes $/ 30 \mathrm{~cm}$. A equação proposta pelo autor para a estimativa da capacidade individual de cada hélice é a seguinte:

$$
Q_{u, S P T}=\alpha_{s} A_{e h} \bar{N}_{S P T}
$$

Em que:

$\mathrm{Qu}_{\mathrm{u}, \mathrm{SPT}}$ : capacidade de carga a tração de cada hélice da estaca;

$\mathrm{A}_{\mathrm{eh}}$ : área efetiva da hélice; 
$\alpha_{\mathrm{s}}$ : fator regressor $\left(\mathrm{kN} / \mathrm{m}^{2}\right)$.

Os valores de $\alpha_{\mathrm{s}}$ variam de acordo com o tipo de solo e situação de projeto (A ou B), como mostra a Tabelas 6. Nesta tabela os valores apresentados são relativos a uma capacidade de carga equivalente à carga correspondente a um deslocamento do topo da estaca igual a 10\% do diâmetro médio das hélices.

Silva (2014) também sugere um fator de correção para ajustar o valor de capacidade de carga à tração de estacas helicoidais previsto pela Equação 13. Este fator, que depende da somatória dos valores de $\mathrm{N}_{\mathrm{SPT}}$ ao longo da profundidade de estaca, não foi usado na presente dissertação pelo fato das estacas desta pesquisa serem curtas (4 metros).

Tabela 6-Valores de $\alpha_{\mathrm{s}}(\mathrm{kN} / \mathrm{m} 2)$ para Qu equivalente à critério $\mathrm{D} / 10$.

\begin{tabular}{lcccc} 
& Argila & Silte argiloso & Silte arenoso & Areia \\
\hline Situação A & 34 & - & 58 & 73 \\
Situação B & 58 & 32 & 72 & - \\
\hline
\end{tabular}

\subsubsection{Método de Previsão da Capacidade de Carga à Compressão}

Segundo Stephenson (2003), embora as estacas helicoidais tenham sido utilizadas por muitos anos para fundação de torres, que é um tipo de estrutura em que os esforços críticos atuantes em sua fundação são de tração e não de compressão, recentemente este tipo de estaca tem sido usado em estruturas em que solicitações de compressão são predominantes. Um exemplo de aplicação é o caso de reforços de fundação.

Segundo Stephenson (2003), as vantagens da utilização deste tipo de estaca para reforço de fundação são as seguintes:

a) Relação entre o torque de instalação e a capacidade de carga da estaca. O valor de $K_{t}$ (razão entre capacidade de carga e torque) pode ser obtido 
antecipadamente, por prova de carga na primeira estaca executada, e ser utilizado para controle de qualidade nas instalações das outras estacas.

b) Facilidade para aumentar o comprimento da estaca, por meio da emenda de tubos de extensão.

c) Pode ser instalada abaixo do nível de água.

d) Simplicidade de instalação em locais onde o espaço é limitado, ou não se pode fazer barulho (também em áreas restritas).

Para a previsão da capacidade de carga à compressão de fundações por estacas helicoidais, os métodos mais utilizados são: a) método da capacidade de carga individual; b) método cilindro de cisalhamento. Os esquemas de transferência de carga assumidos para estes dois métodos são ilustrados na Figura 18.

De acordo com Perko (2009) e Tsuha et al. (2012), se o espaçamento entre as hélices for igual a três vezes o diâmetro da hélice ou maior, o método das cargas individuais é mais adequado para a estimativa da capacidade de carga (Figura 18). No caso em que a distância entre as hélices é pequena, a capacidade de carga deve ser estimada pelo método do cilindro de cisalhamento. 


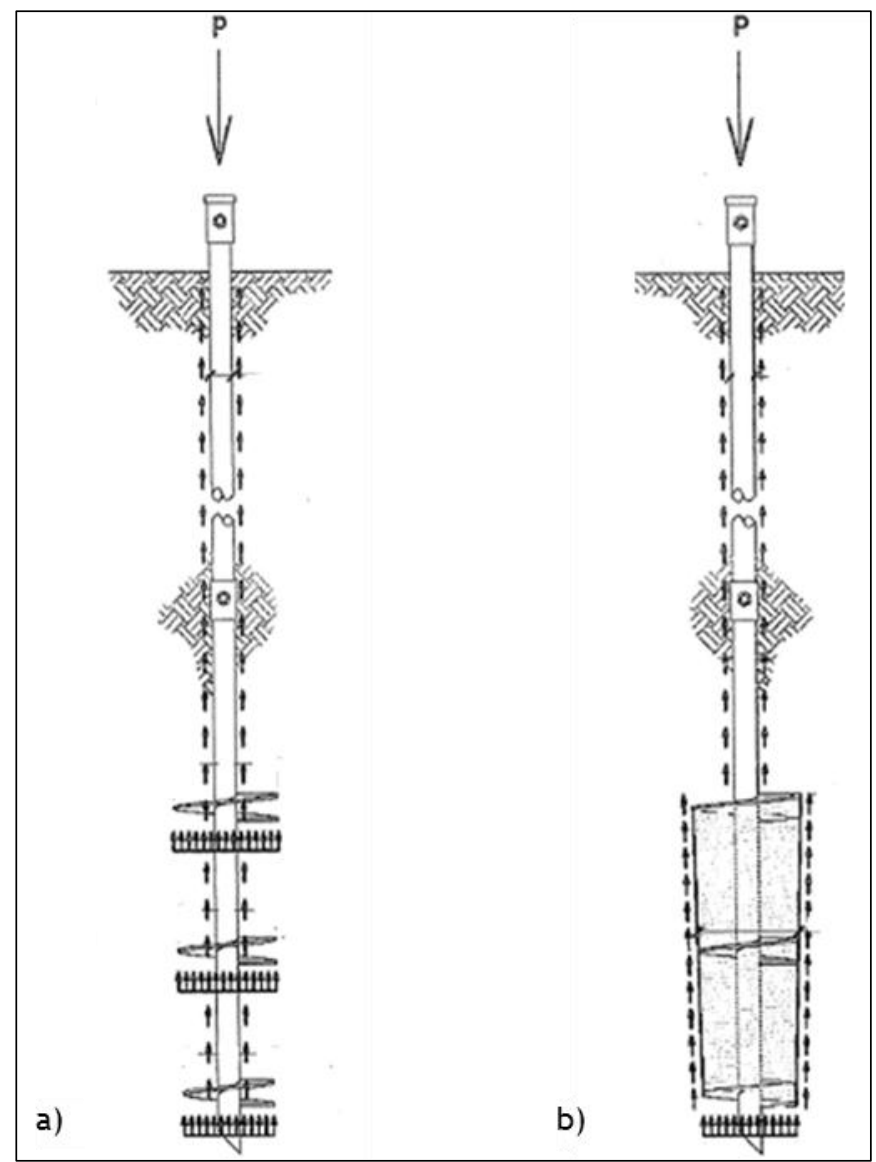

Figura 18 - Esquema de transferência de carga em estacas helicoidais submetidas a esforços de compressão: a) método das capacidades individuais; b) método do cilindro de cisalhamento (PERKO, 2009).

\subsubsection{Método das Capacidades Individuais}

Na previsão da capacidade de carga à compressão, como na de tração, assume-se que rupturas ocorrem em cada hélice individualmente. Uma condição necessária para o uso deste método é que o espaçamento entre as hélices seja igual a três vezes o diâmetro da hélice inferior, para evitar a sobreposição do solo mobilizado entre hélices.

A capacidade de carga da estaca é igual à soma das capacidades individuais de cada hélice, ou seja:

$$
Q_{u l t}=\sum Q_{h}
$$

Em que: 
$\mathrm{Q}_{\mathrm{ult}}=$ Capacidade de carga total da estaca;

$\mathrm{Q}_{\mathrm{h}}=$ Capacidade de carga individual de cada hélice.

Uma distribuição uniforme de tensão é assumida na face de cada hélice (PERKO, 2009). Quando for significantiva, a resistência por atrito ou adesão é considerada ao longo da haste (fuste). A capacidade de carga da estaca à compressão $\left(\mathrm{P}_{\mathrm{u}}\right)$ será então dada pela equação 15:

$$
P_{U}=\sum_{N} Q_{u l t} A_{n}+\alpha H(\pi d)
$$

Em que:

$\mathrm{P}_{\mathrm{u}}=$ Carga de ruptura da fundação em compressão;

$\mathrm{N}=$ número de hélices;

$\mathrm{Qult}_{\text {= }}$ tensão de ruptura do solo abaixo da hélice;

$\mathrm{A}_{\mathrm{n}}=$ área projetada da hélice num plano perpendicular ao eixo do fuste (no caso da hélice inferior, inclui-se a área da ponta da haste);

$\alpha=$ adesão entre o solo e o fuste $\left.\left(\alpha=\frac{2}{3} \times \tau,\right) ; \tau=c+\sigma_{n}^{\prime} \tan \phi\right)$;

H: comprimento do fuste da estaca acima da hélice de superior;

d: diâmetro do fuste.

Considerando-se a tensão de ruptura $q_{u l t}$, segundo Terzaghi (1943), apresentada na equação 16, e a posterior alteração por Meyerhof (1951), a forma e a profundidade deste tipo de estaca, a expressão pode tomar a forma da expressão equação 17 (PERKO, 2009).

$$
\begin{aligned}
& Q_{u l t}=1,3 c N_{c}+q^{\prime} N_{q}+0,3 \gamma B N_{\gamma} \\
& q_{u l t}=c N^{\prime}{ }_{c}+q^{\prime}\left(N^{\prime}{ }_{q}-1\right)+0,5 \gamma D N^{\prime}{ }_{\gamma}
\end{aligned}
$$

Em que:

c: coesão;

q': sobrecarga; 
$\gamma$ : peso específico do solo;

B, D: largura do elemento de fundação ou diâmetro da hélice;

$\mathrm{N}_{\mathrm{c}}, \mathrm{N}_{\mathrm{q}}, \mathrm{N}_{\gamma}$ : fatores de capacidade de carga combinados com a forma, profundidade e capacidade de carga das estacas helicoidais (ver Gráfico 2).

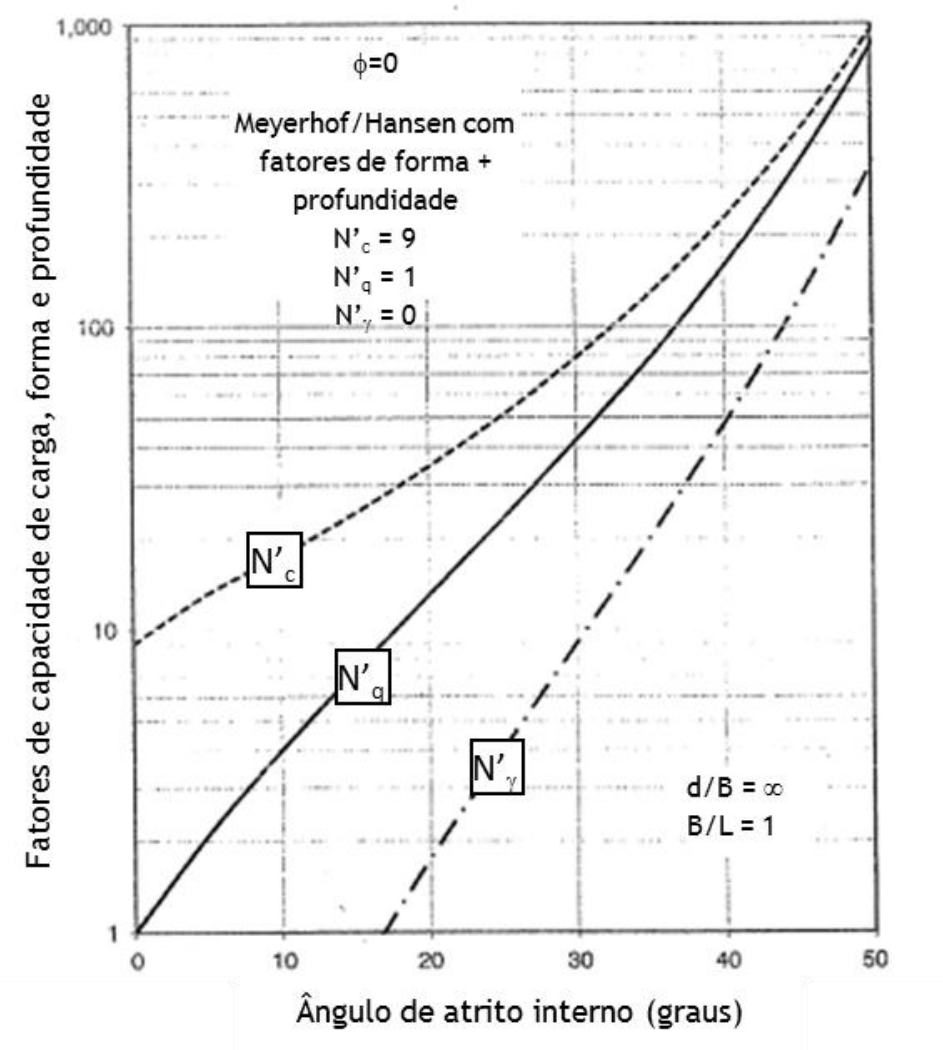

Gráfico 2 - Fatores de capacidade de carga combinados com a forma, profundidade e capacidade de carga das estacas (PERKO, 2009).

\subsubsection{Método do Cilindro de Cisalhamento}

Conforme Perko (2009), no método do cilindro de cisalhamento assume-se que o volume de solo contido entre as hélices é inteiramente mobilizado. A Figura 19 apresenta a distribuição de forças idealizada em uma estaca helicoidal de $n$ hélices pelo método de cilindro de cisalhamento. A capacidade de carga da estaca $\left(\mathrm{P}_{\mathrm{u}}\right)$, pelo método do cilindro de cisalhamento, é calculada pela seguinte equação: 


$$
P_{u}=q_{u l t} A_{1}+T(n-1) s \pi D_{A V G}+\alpha H(\pi d)
$$

Em que:

$\mathrm{P}_{\mathrm{u}}=$ carga de ruptura da fundação submetida à compressão;

$\mathrm{q}_{\mathrm{ult}}$ : tensão de ruptura do solo abaixo da hélice da ponta;

$\mathrm{A}_{1}$ : área da hélice da ponta (incluindo-se a área da ponta da estaca);

T: resistência ao cisalhamento do solo;

s: espaçamento entre as hélices;

$\mathrm{D}_{\mathrm{AVG}}$ : diâmetro médio das hélices;

$\alpha$ : adesão entre o solo e o fuste $(0,67 \mathrm{~T})$;

H: comprimento do fuste acima da hélice de topo;

d: diâmetro de um círculo circunscrito ao contorno do fuste.

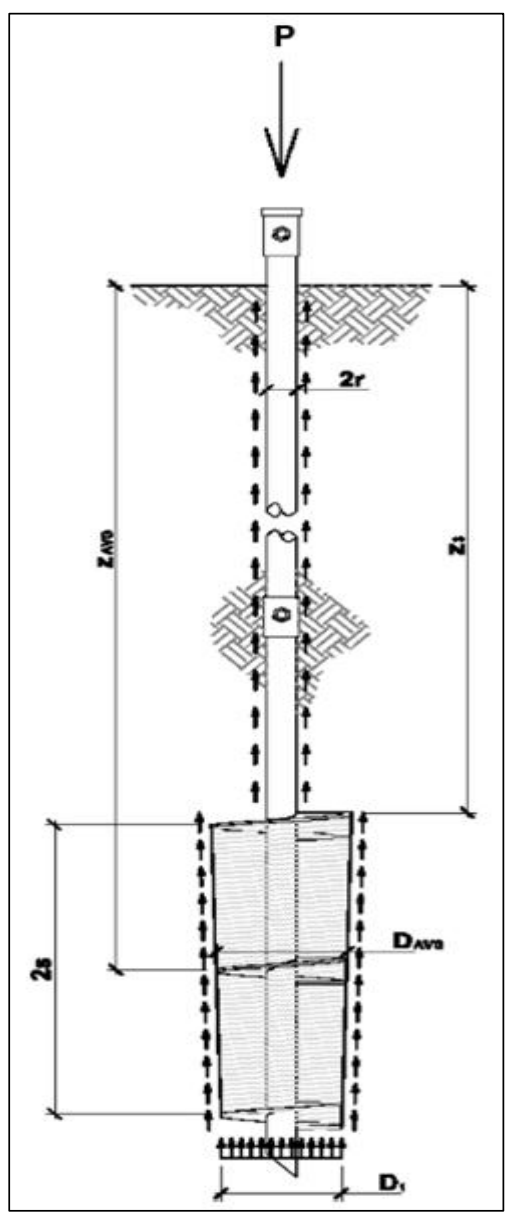

Figura 19 - Estaca helicoidal submetida a um esforço compressivo pelo método do cilindro de cisalhamento (PERKO, 2009). 


\subsubsection{Capacidade de Carga à Compressão x Capacidade de Carga à Tração}

A capacidade de carga de estacas helicoidais à compressão é maior que à tração, devido aos seguintes fatores citados em Trofimendkov \& Mariupolskii (1965):

a) $\mathrm{Na}$ compressão, o solo abaixo da hélice inferior não foi perturbado pela instalação como o solo acima das hélices;

b) A compacidade do solo aumenta com a profundidade;

c) A ponta da haste é mobilizada na compressão.

De acordo com Trofimendkov \& Mariupolshii (1965), para um mesmo tipo de solo a capacidade de carga de estacas metálicas helicoidais à compressão é de 1,4 a 1,5 vezes maior que a capacidade de carga à tração.

Além desses fatores, quando a estaca está em compressão, ainda tem o acréscimo de capacidade de carga devido à resistência da ponta da estaca (ponta da haste), que não ocorre na estaca em tração.

\subsubsection{Capacidade de Carga à Compressão de Estaca Helicoidal com Fuste Preenchido com Graute}

\subsubsection{Introdução}

Em geral, a capacidade de carga à compressão de estacas helicoidais com fuste preenchido por graute é regida pela parcela de ponta devido à resistência gerada pelas hélices e pela parcela de resistência de atrito proporcionada pela coluna de graute (Figura 20).

A capacidade de carga total de uma estaca com fuste de graute submetida a forças axiais de compressão é geralmente estimada utilizando-se os métodos analíticos, originalmente desenvolvidos para prever a capacidade de carga para estacas helicoidais simples.

Neste item, apresenta-se uma descrição breve dos métodos analíticos utilizados para estimar a capacidade de ponta desenvolvida abaixo das hélices e a capacidade de atrito mobilizada ao longo na coluna de graute. 


\subsubsection{Parcela de Resistência por Atrito Lateral}

Segundo Vickars \& Clemence (2000), a coluna de graute aumenta a área de contato da parcela de estaca acima das hélices com o solo, de modo a contribuir com a resistência por atrito lateral no fuste da estaca, além de aumentar a capacidade de resistir carregamentos laterais e resistir à flambagem. Esta pode ser calculada pela seguinte maneira:

$$
Q_{f}=\sum \pi D f_{s} \Delta L_{f}
$$

Em que:

$\mathrm{Q}_{\mathrm{f}}$ : Capacidade total de compressão da resistência pelo atrito, ao longo do eixo;

D: Diâmetro da coluna de graute;

$f_{s}:$ atrito e adesão ao longo da coluna de graute;

$\Delta L_{f}$ : comprimento da coluna de graute.

$\mathrm{O}$ valor do $f_{S}$ (resistência por atrito ao longo da coluna de graute) é em função das tensões horizontais que atuam sobre a coluna de argamassa, a rugosidade da superfície e adesão ou atrito entre a superfície da coluna e o solo envolvente.

Este sistema de fundação é relativamente novo e não foi avaliado o suficiente para fornecer parâmetros para se estimarem os valores do $f_{s}$ de estacas helicoidais com fuste de graute. Para encontrar os valores de $f_{s}$, utilizou-se nesta pesquisa o método de Gouvenot.

\subsection{Método de Gouvenot}

Conforme Gouvenot (1973) apud Li (2006), baseado em resultados de provas de cargas em estacas preenchidas com graute ao redor da haste, foi determinado um método para determinar o atrito. Este método pode ser usado em solos coesivos (c), não coesivos $(\phi)$ e solos mistos $(\mathrm{c}, \phi)$. 
As equações para este método são divididas em três tipos, de acordo com o solo:

- Tipo 1: Areias e cascalhos

$-35^{\circ}<\phi<45^{\circ}$

- Atrito: $f s=\sigma h * \tan \emptyset$

- Tipo 2: Areias, siltes, argila arenosa

$-20^{\circ}<\phi<30^{\circ}, \mathrm{c}=0$

$-0,10<\mathrm{c}<0,5 \mathrm{~kg} / \mathrm{cm}^{2}$

- Atrito: $f s=\sigma_{h} * \sin \phi+c * \cos \phi$

- Tipo 3: Argilas e Xistos

- $f s=c$ para $0,50<\mathrm{c}<1,0 \mathrm{~kg} / \mathrm{cm}^{2}$

- $f s=1 \mathrm{~kg} / \mathrm{cm}^{2}$ para $1,0<\mathrm{c}<2,0 \mathrm{~kg} / \mathrm{cm}^{2}$

Em que:

$\sigma_{H}^{\prime}=k_{o} * \sigma_{v}^{\prime}$

$k_{o}=(1-\operatorname{sen} \phi)$

\subsubsection{Parcela de Capacidade de Carga das Hélices}

Conforme Vickars \& Clemence (2000), a capacidade de carga das hélices de estacas helicoidais com fuste de argamassa pode ser calculada usando-se a seguinte equação:

$$
Q_{h}=\sum A\left(N_{c} c+q N_{q}\right)
$$

Em que: 
$Q_{h}:$ capacidade de carga das hélices;

A: área individual de cada hélice;

c: coesão;

q: tensão lateral;

$\mathrm{N}_{\mathrm{c}}, \mathrm{N}_{\mathrm{q}}$ : fatores de capacidade.

Segundo Vickars \& Clemence (2000), a capacidade de carga à compressão de uma estaca helicoidal com fuste de argamassa, de acordo com a Figura 20, é:

$$
Q_{u}=Q_{f}+Q_{h}
$$

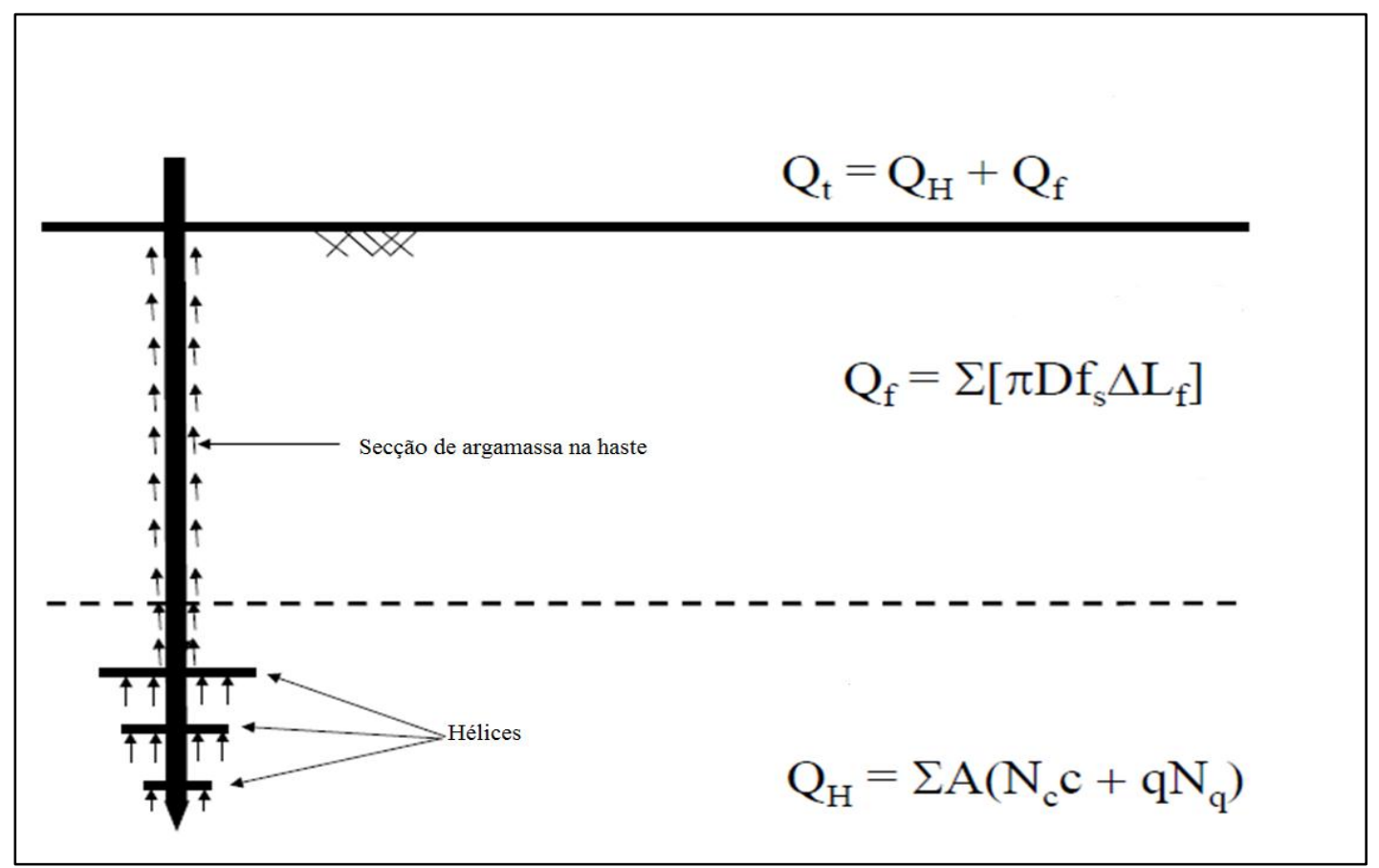

Figura 20 - Esquema do cálculo da capacidade de carga de estacas com graute, segundo Vickars \& Clemence (2000).

Seider et al. (2003) calcularam a capacidade de carga de quatro estacas helicoidais com fuste preenchido, calculando-se a capacidade das hélices e a resistência por atrito lateral separadamente. A parcela das hélices foi estimada utilizando-se o método de torque desenvolvido inicialmente para estacas helicoidais, enquanto para a resistência por atrito na 
coluna de argamassa foi usado o método Gouvenot, o método de Reese e $O^{\prime}$ Neil modificado. Neste trabalho, a capacidade de carga prevista foi em seguida comparada com os resultados de provas de carga e verificou-se que esses métodos analíticos subestimaram a capacidade de carga na maioria dos casos. Eles concluíram que o método originalmente proposto para estacas helicoidais simples pode ser modificado para proporcionar uma melhor previsão.

Wilder (1989) realizou uma série de ensaios de laboratório para investigar a capacidade de carga de estacas helicoidais em areia. Foram ensaiados três tipos de estacas instaladas na mesma profundidade. A comparação entre a estaca helicoidal simples e a estaca helicoidal com fuste preenchido mostrou nesta um aumento de $45 \%$ na capacidade de carga. Este autor recomendou a equação para prever a capacidade de carga de estaca helicoidal com fuste preenchido em areia, conforme mostra a equação abaixo, para uma estaca com três hélices e com fuste grouteado:

$Q_{u}=\gamma\left[\left(N_{q}-1\right)\left(d_{B H}+d_{M H}+d_{T H}+d_{G S}\right)+0.3 N_{\gamma}\left(B_{B H}+B_{M H}+B_{T H}+B_{G S}\right)\right]$

Em que:

$\mathrm{d}_{\mathrm{BH}}$ : Profundidade da hélice localizada na parte inferior;

$\mathrm{d}_{\mathrm{MH}}$ : Profundidade da hélice localizada na parte média;

$\mathrm{d}_{\mathrm{TH}}$ : Profundidade da hélice localizada na parte superior;

$\mathrm{d}_{\mathrm{GS}}$ : Profundidade da coluna de graute;

$\mathrm{B}_{\mathrm{BH}}$ : Diâmetro da hélice inferior;

$\mathrm{B}_{\mathrm{MH}}$ : Diâmetro da hélice média;

$\mathrm{B}_{\mathrm{TH}}$ : Diâmetro da hélice superior;

$\mathrm{B}_{\mathrm{GS}}$ : Diâmetro da coluna de graute;

$\mathrm{N}_{\mathrm{q}}, \mathrm{N}_{\gamma}$ : Fatores de capacidade carga.

De acordo com Li (2006), a estaca helicoidal com fuste preenchido é um sistema de fundação novo, e a capacidade de carga de compressão é geralmente estimada utilizando-se os métodos analíticos para estacas helicoidais convencionais os quais não são apropriados para 
fundações helicoidais com argamassa, já que a capacidade de carga deste sistema de fundação depende do método de instalação e das caraterísticas da estaca.

Li (2006) desenvolveu um método para calcular a capacidade de carga deste tipo de estaca helicoidal, no qual a capacidade de carga da fundação é assumida como sendo a soma entre a resistência do atrito mobilizada ao longo da coluna de graute, a resistência de ponta gerada na base da coluna $\left(\mathrm{Q}_{4}\right.$ na Figura 21) e a capacidade de carga individual das hélices (Figura 21).

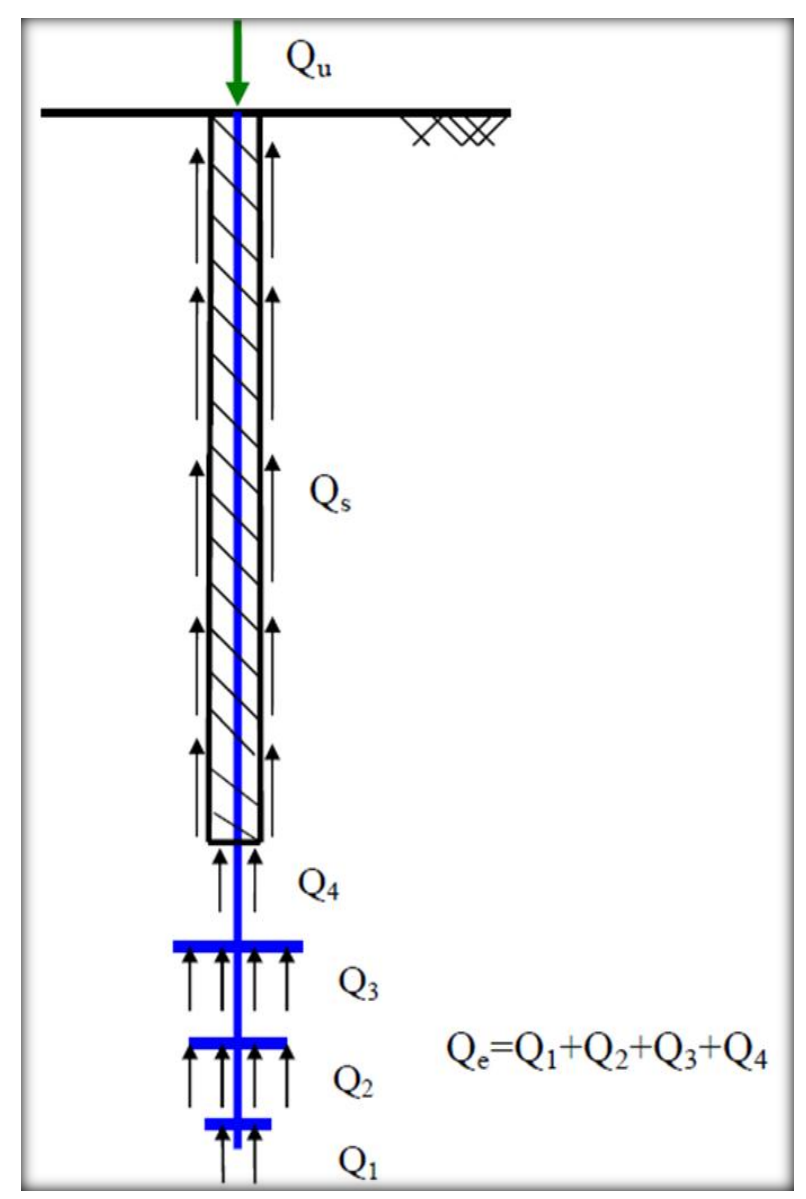

Figura 21 - Capacidade de carga total da estaca helicoidal com graute (LI, 2006).

A equação geral para prever a capacidade de carga total da estaca helicoidal com argamassa, segundo Li (2006), é dada por:

$Q_{u}=Q_{s}+Q_{e}$

Em que: 
$Q_{u}=$ capacidade de carga total da estaca helicoidal com fuste preeenchido;

$Q_{S}=$ resistência por atrito lateral ao longo da coluna de graute;

$Q_{e}=$ resistência de ponta gerada na base da coluna e nas hélices.

Resistência de Atrito Lateral: O atrito mobilizado ao longo do fuste preenchido é calculado utilizando-se a seguinte equação:

$$
\mathrm{Q}_{\mathrm{s}}=\mathrm{f}_{\mathrm{s}} \mathrm{A}_{\mathrm{s}}=\pi(\mathrm{D}+2 \mathrm{~h}) * \mathrm{~L} * \mathrm{f}_{\mathrm{s}}
$$

Em que:

$\mathrm{h}=$ largura dos filetes em forma espiral (Figura 23);

$f_{s}=$ resistência ao atrito lateral;

$D=$ diâmetro nominal da coluna de graute;

$\mathrm{L}=$ comprimento da coluna de graute.

Segundo Li (2006), uma estimativa conservadora do valor de h seria entre 0,5 a 1 polegada.

Nenhum trabalho tem sido desenvolvido para estudar as alterações no estado de tensão no solo, após o processo de instalação de uma estaca helicoidal com argamassa.

Resistência de Ponta: a parcela de resistência de ponta, devido à base da coluna de argamassa e à parcela de capacidade de carga das hélices, é calculada utilizando-se o método das capacidades individuais:

$$
\mathrm{Q}_{\mathrm{e}}=\frac{\pi \mathrm{D}^{2}}{4} f_{\mathrm{g}}+\sum \mathrm{A}_{\mathrm{p}} \mathrm{f}_{\mathrm{e}}
$$

Em que:

D = diâmetro nominal da coluna de argamassa; 
$A_{p}=$ área projetada das hélices;

$f_{g}=$ tensão de ruptura do solo na base da coluna de graute;

$f_{e}=$ tensão de ruptura do solo abaixo hélices.

De acordo com os ensaios de Li (2006), a resistência de ponta na base da coluna de argamassa é desprezível e contribui em uma pequena porcentagem (menos de 5\%) da capacidade.

A capacidade de uma hélice pode ser calculada pela seguinte equação:

$$
f_{e}=c N_{c}+q^{\prime} N_{q}
$$

Em que:

$\mathrm{q}^{\prime}=$ Tensão efetiva vertical;

c= coesão;

$N_{c} N_{q}=$ Fatores de capacidade de carga.

Em pesquisas feitas em estacas helicoidais em solos coesivos, Mitch \& Clemence (1985) observaram que os valores de $N_{c}$ são em função do H/D, em que $\mathrm{H}$ é a profundidade e D o diâmetro da hélice. Quando o valor do raio de H/D é maior que 5, o valor de $N_{c}$ convertese em valor constante de 9,4. Esta observação é similar à recomendada por Skempton (1959). Deste modo, o valor de 9 deve ser utilizado como fator de $N_{c}$ no cálculo do $f_{e}$.

\subsubsection{Capacidade de Carga de Estacas Helicoidais com Injeção}

As estimativas teóricas da capacidade de carga de fundações por estacas helicoidais com injeção são apresentadas por Bian (2006). A capacidade de carga é calculada pela soma da parcela de resistência por atrito lateral entre o solo e a haste da estaca $\left(\mathrm{Q}_{\mathrm{h}}\right)$, a parcela de atrito lateral na interface bulbo-solo $\left(\mathrm{Q}_{\mathrm{s}}\right)$ e a resistência de ponta abaixo no bulbo $\left(\mathrm{Q}_{\mathrm{p}}\right)$, como mostra 
a Figura 22.

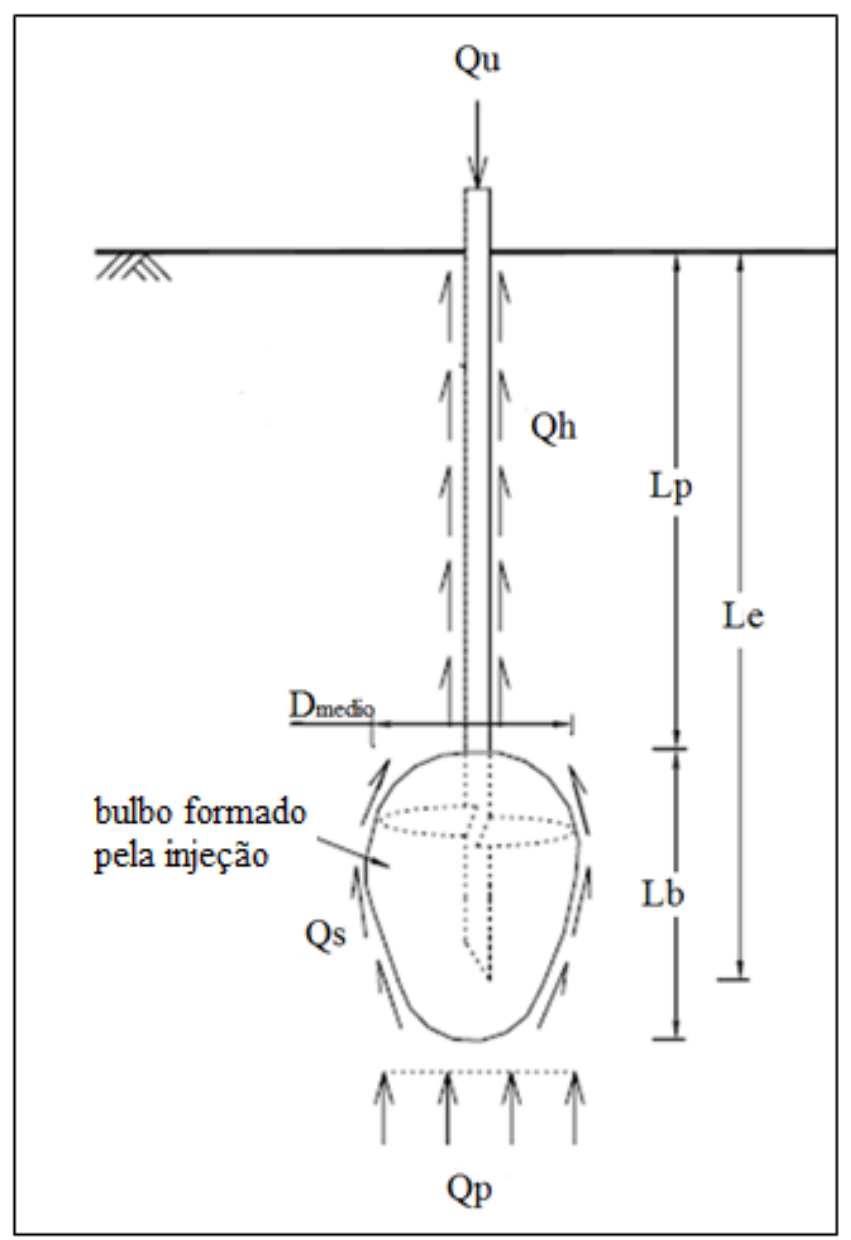

Figura 22 - Parcelas de capacidade de carga de uma estaca helicoidal com bulbo (BIAN, 2006).

\section{- Estimativa do $Q_{s}$}

Para se estimar a resistência por atrito entre a interface bulbo-solo, é utilizada a relação de Coyle e Castello (1981):

$Q_{s}=K \sigma_{o}^{\prime} \tan (\delta) p L_{b}$

Em que:

$\mathrm{K}$ : coeficiente de empuxo lateral do solo;

$\sigma^{\prime} \mathrm{o}=$ tensão efetiva; 
p: perímetro médio do bulbo;

$\mathrm{L}_{\mathrm{b}}$ : comprimento do bulbo;

$\delta$ : ângulo de atrito (solo-bulbo).

Segundo Das (2006), a proporção do bulbo é $\mathrm{L} / \mathrm{D}_{\text {médio }}=15,85, \mathrm{~K}=1,40$, podendo-se considerar a interface de solo-bulbo semelhante ao observado para concreto-solo, portanto $\delta$ pode ser feita como $2 / 3 \emptyset^{\prime}$.

\section{- Estimativa do $Q_{h}$}

Para estimar a resistência por atrito lateral entre a haste e o solo $\mathrm{Q}_{\mathrm{h}}$, é utilizada a equação 31 adotando-se parâmetros diferentes. $\mathrm{O}$ valor de $\delta=0,5 \phi$ (fator estabelecido pela superfície do material).

\section{- Estimativa do $\mathbf{Q}_{\mathbf{p}}$}

Existem vários métodos na literatura para determinar a resistência de ponta $\left(Q_{p}\right)$, de estacas. Para o cálculo do $\mathrm{Q}_{\mathrm{p}}$ da estaca com argamassa, utilizaremos a equação de Meyerhof (1981):

Para areais $Q_{p}=A_{p} * q^{\prime} * N_{q}$

Em que:

$\mathrm{N}_{\mathrm{q}}$ : fator de capacidade de carga;

$\mathrm{A}_{\mathrm{p}}$ : área projetada do bulbo de argamassa, dada por $\left(\pi * D_{\text {médio }}{ }^{2} / 4\right)$;

$q^{\prime}$ : tensão efetiva na base do bulbo de $\operatorname{argamassa}\left(\mathrm{L}_{\mathrm{b}}\right)$.

$\mathrm{Q}_{\mathrm{p}}$ não deve exceder o valor limite de:

$$
Q_{p} \leq A_{p} * q_{l}
$$


Em que a resistência limite é definida como:

$$
q_{l}=0,5 p_{a} N_{q} \tan \phi^{\prime}
$$

Em que:

$\mathrm{p}_{\mathrm{a}}$ : pressão atmosférica $(0,101 \mathrm{Mpa})$;

$\phi^{\prime}$ : ângulo de atrito do solo.

\subsubsection{Capacidade de Carga à Tração de Estaca Helicoidal com Fuste Preenchido com Graute}

Segundo Li (2006), a capacidade de estacas helicoidais com preenchido à tração é composta pelo peso da fundação, pela resistência de atrito lateral ao longo do fuste e pela capacidade de carga à tração das hélices, dada pela equação 35:

$$
Q_{u}=W+Q_{t}+Q_{s}
$$

Em que:

$\mathrm{Q}_{\mathrm{u}}=$ capacidade de carga à tração da estaca helicoidal com fuste preenchido;

$\mathrm{W}$ = peso próprio da estaca e solo atuante como sistema de fundação;

$\mathrm{Q}_{\mathrm{t}}=$ resistência das hélices à tração;

$\mathrm{Q}_{\mathrm{s}}=$ resistência por atrito lateral ao longo da coluna preenchida com graute.

Para a estimativa da parcela de capacidade de carga das hélices à tração (Qt), pode ser utilizado o método das capacidades de carga individuais ou o método do cilindro de cisalhamento. A escolha do método mais adequado dependerá do espaçamento entre as hélices (para hélices suficientemente afastadas entre si, o modelo de ruptura individual é o mais adequado). 


\subsection{Formato da Coluna}

A existência de uma superfície espiralada (devido à trajetória da hélice no solo durante a instalação da estaca), ao longo da coluna de graute, aumenta o diâmetro efetivo da superfície de coluna mobilizada por atrito durante o carregamento da estaca, como pode ser observado na ilustração da Figura 23.

Para fundações por estacas convencionais, a resistência por atrito ocorre na interface entre o elemento estrutural da fundação e o solo. Para as estacas helicoidais com fuste de preenchido, a mobilização ao longo da coluna na ruptura ocorre distante da interface solocoluna, acompanhando a superfície de espiral (Figura 23).
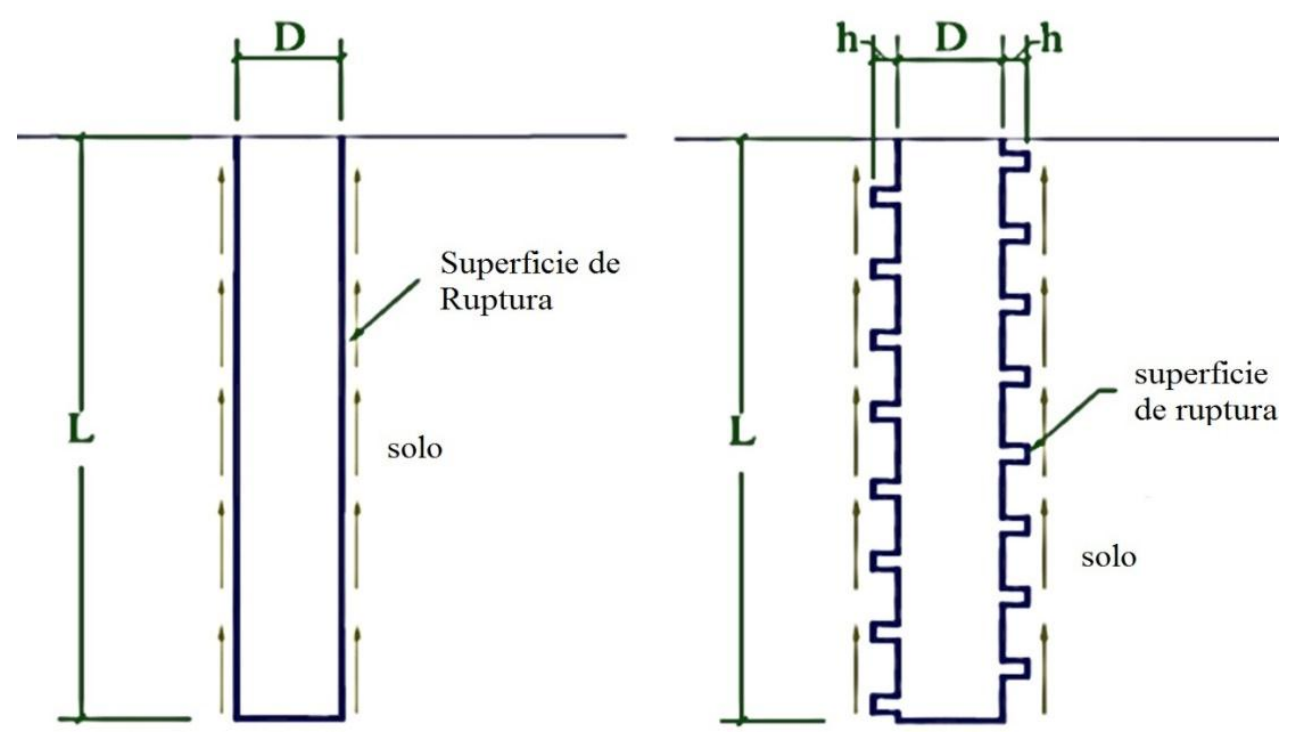

Figura 23 - Ruptura por cisalhamento na superfície da estaca: à esquerda estaca escavada e à direita, estaca helicoidal comfuste grauteado (LI 2006).

A resistência por atrito ao longo da coluna preenchida é proporcional à área da superfície de ruptura, a qual pode ser calculada com a seguinte equação.

$$
A=\pi\left(D_{\text {actual }}\right) L
$$

Em que: 
$\mathrm{A}=$ área da superfície cisalhada na ruptura;

$\mathrm{L}=$ comprimento da coluna de argamassa;

$\mathrm{D}_{\text {actual }}=$ diâmetro efetivo da superfície de ruptura de cisalhamento.

Conforme Li (2006), reconhecendo-se a existência da superfície espiralada (Figura 23), o diâmetro efetivo da superfície de ruptura ao longo da coluna é:

$$
D_{\text {actual }} D_{\text {nominal }}+2 h
$$

Em que:

h= A largura dos filetes em forma espiral devido à instalação das hélices (Figura 23). 


\section{MATERIAIS E MÉTODOS}

O presente capítulo apresenta uma descrição dos materiais, métodos e equipamentos utilizados para a realização desta pesquisa.

\subsection{Area Experimental}

Os ensaios desta pesquisa foram realizados no pátio da empresa Vercon Industrial de Betim, Minas Gerais, que é fabricante de estacas helicoidais no Brasil. A fábrica da Vercon está localizada na Av. Juiz Marco Tulio Isaas, 2777, Riacho das Areias, Betim-MG.

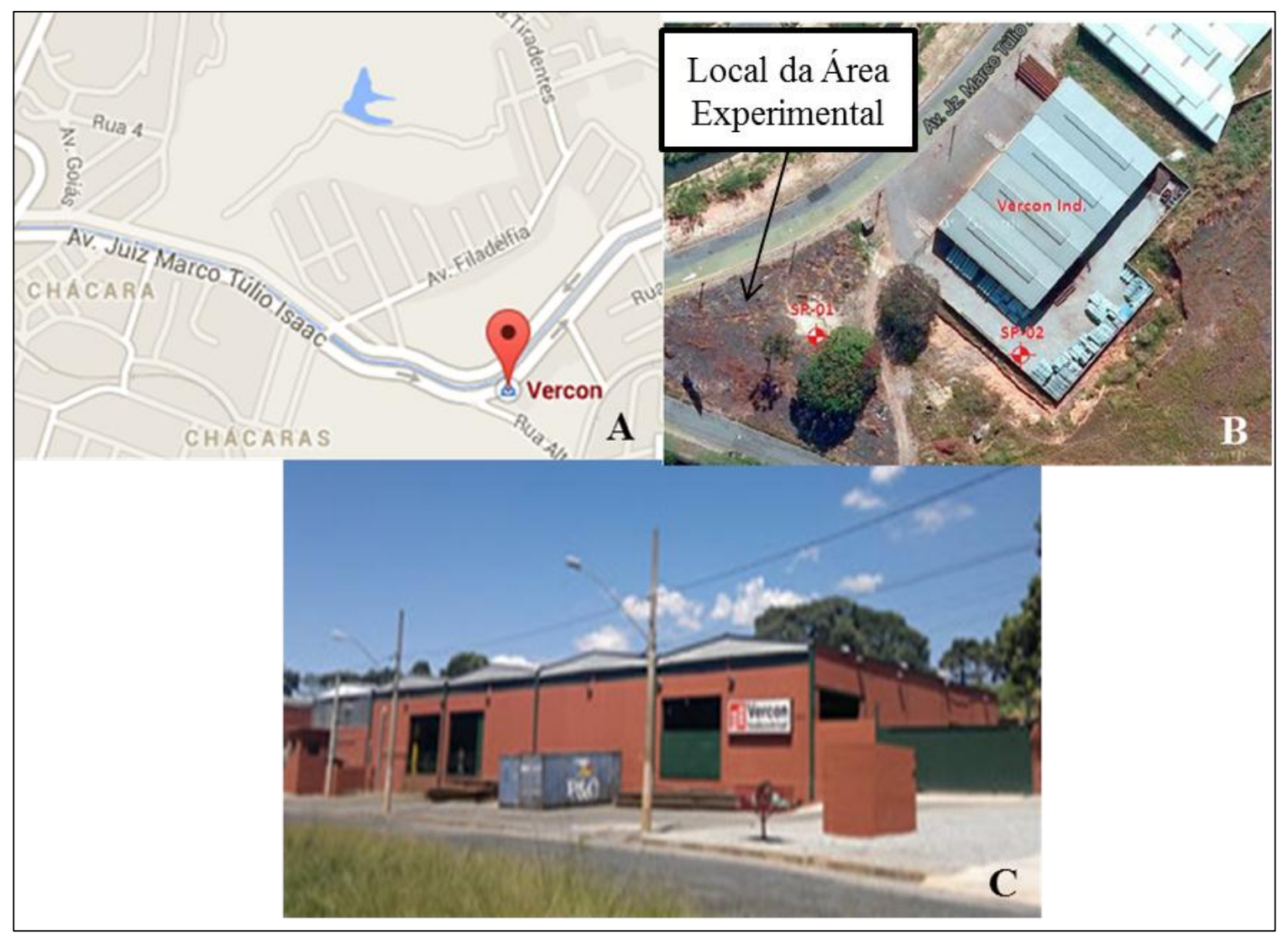

Figura 24 - a) Localização da Vercon Ind.; b) Fotografia da área do lugar onde foram realizadas as sondagens e da área onde foram instaladas as estacas; c) Vista frontal da Vercon Industrial. 
Os ensaios foram realizados em estacas fornecidas e instaladas pela Vercon Industrial. Esta área foi escolhida para o desenvolvimento desta pesquisa pelas seguintes razões:

a. Uma das finalidades desta pesquisa era escavar (exumar) a estaca após as provas de carga, para a verificação das dimensões finais dos bulbos de calda de cimento injetada e do fuste preenchido com argamassa. Pela sondagem deste terreno, as estacas poderiam ser instaladas acima do N.A;

b. O objetivo principal desta dissertação foi verificar o ganho em capacidade de carga de estacas helicoidais melhoradas, quando instaladas em solo de baixa capacidade. Pela sondagem deste terreno, as estacas ficariam instaladas em silte arenoso argiloso com $\mathrm{N}_{\mathrm{SPT}}$ em torno de 6 golpes $/ 30 \mathrm{~cm}$, condição adequada para ser investigada;

c. Disponibilidade de área para realizar os ensaios;

d. As estacas helicoidais utilizadas foram fabricadas pela Vercon Industrial;

e. Equipamento, materiais e ferramentas disponíveis;

f. Mão de obra disponível para ajudar durante a realização dos ensaios;

g. Disponibilidade de poder fazer ajustes nas estacas, já que a área experimental era ao lado da fábrica.

\subsubsection{Investigação Geotécnica}

\subsubsection{Ensaios de Sondagem de Simples Reconhecimento (SPT)}

Para investigar as características do solo de instalação das estacas, foram realizadas duas sondagens de simples reconhecimento SP-01, SP-02.

As sondagens foram executadas de acordo com a NBR-6484/80 da ABNT, realizadas pela empresa SETEF Fundações Ltda. Nesta pesquisa, as estacas estudadas foram instaladas próximas à SP-01. Na Figura 25, é ilustrada a localização das estacas ensaiadas e a sondagem SP-01. Os resultados das sondagens realizadas são apresentados na Tabela 7 e na Figura 26. 


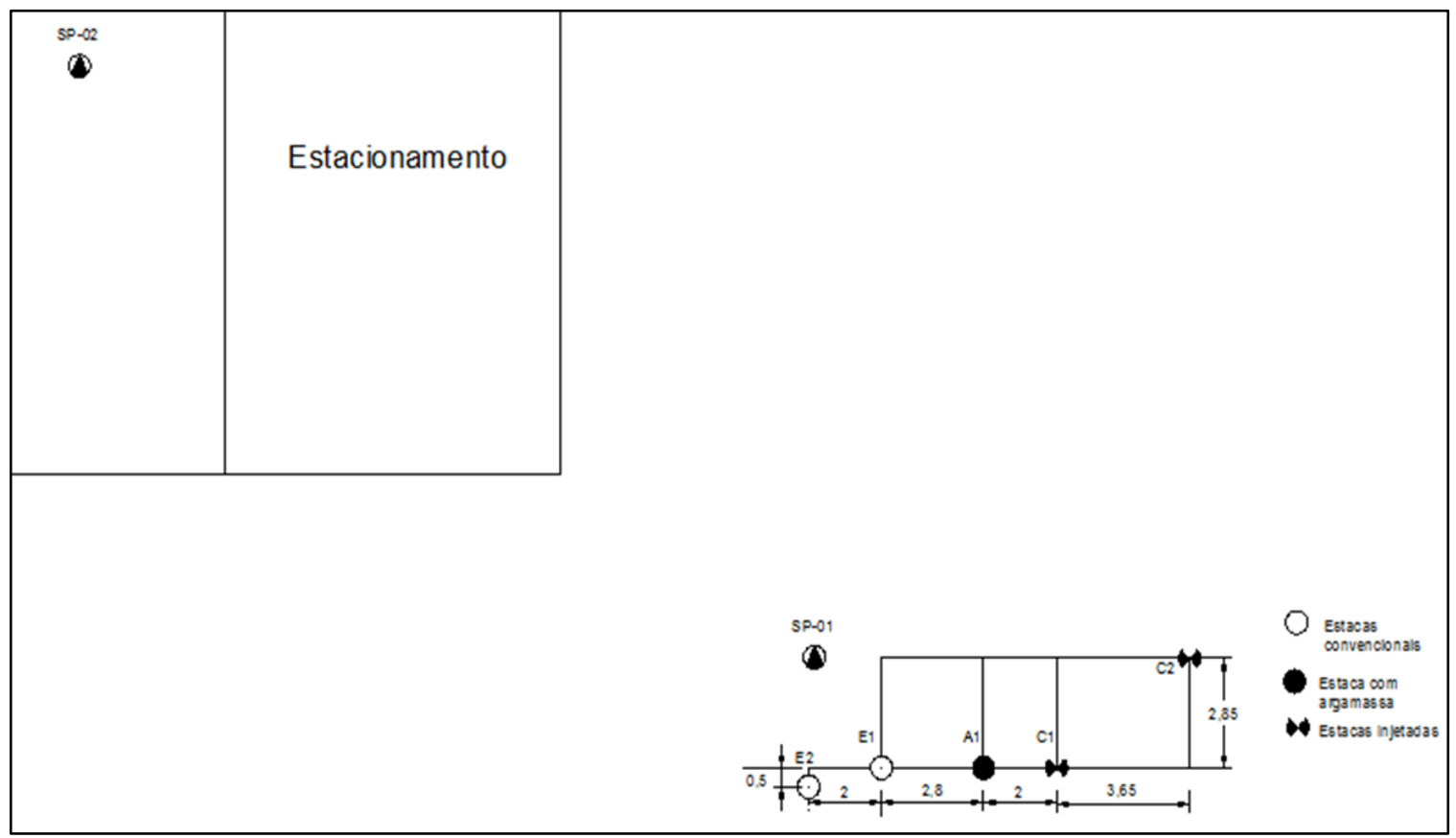

Figura 25 - Planta das estacas instaladas e a localização das sondagens SP-01, SP-02.

Tabela 7 - Valores de NSPT dos ensaios SPT realizados na área experimental da Vercon Industrial.

\begin{tabular}{cccccc}
\hline $\begin{array}{c}\text { Profundidade } \\
{[\mathbf{m}]}\end{array}$ & NSPT01 & NSPT02 & Nmin & Nmax & Nmédio \\
\hline $\mathbf{1}$ & & & & & \\
$\mathbf{2}$ & 7 & 4 & 4 & 4 & 4 \\
$\mathbf{3}$ & 6 & 6 & 6 & 7 & 6,5 \\
$\mathbf{4}$ & 6 & 9 & 6 & 9 & 6 \\
$\mathbf{5}$ & 11 & 11 & 11 & 11 & 11 \\
$\mathbf{6}$ & 7 & 15 & 7 & 15 & 11 \\
$\mathbf{7}$ & 4 & 11 & 4 & 11 & 7,5 \\
$\mathbf{8}$ & 5 & 13 & 5 & 13 & 9 \\
$\mathbf{9}$ & 4 & 16 & 4 & 16 & 10 \\
$\mathbf{1 0}$ & 9 & 19 & 9 & 19 & 14 \\
$\mathbf{1 1}$ & 7 & 17 & 7 & 17 & 12 \\
$\mathbf{1 2}$ & 10 & 19 & 10 & 19 & 14,5 \\
$\mathbf{1 3}$ & 11 & 22 & 11 & 22 & 16,5 \\
$\mathbf{1 4}$ & 15 & 22 & 15 & 22 & 18,5 \\
$\mathbf{1 5}$ & 20 & 21 & 20 & 21 & 20,5 \\
$\mathbf{1 6}$ & 31 & 23 & 23 & 31 & 27 \\
$\mathbf{1 7}$ & 39 & 28 & 28 & 39 & 33,5 \\
$\mathbf{1 8}$ & 63 & 32 & 32 & 63 & 47,5 \\
$\mathbf{1 9}$ & 38 & 39 & 38 & 39 & 38,5 \\
$\mathbf{2 0}$ & 44 & 47 & 44 & 47 & 45,5 \\
$\mathbf{2 1}$ & 44 & 53 & 44 & 53 & 48,5 \\
$\mathbf{2 2}$ & - & 62 & 62 & 62 & 62 \\
\hline & & & & &
\end{tabular}


A Figura 26 mostra o perfil estratigráfico do solo determinado pela sondagem SP-01, a qual foi utilizada como referência para a presente pesquisa, já que era a mais próxima ao lugar onde foram ensaiadas as estacas. Na Figura 26, podem ser observadas as cinco camadas de solo diferentes que foram penetradas no ensaio SPT. O nível do lençol freático foi encontrado na profundidade de $4,56 \mathrm{~m}$.

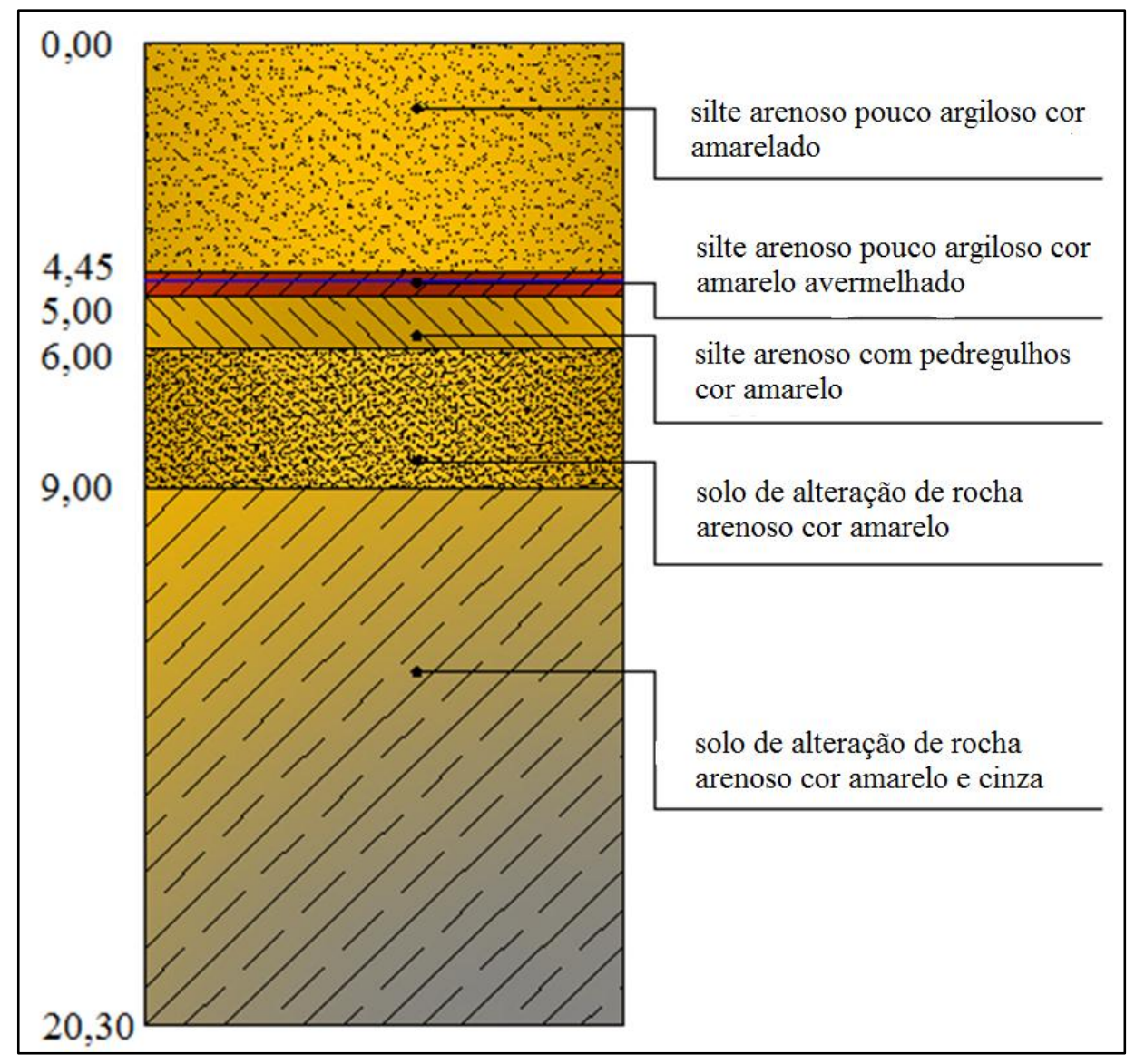

Figura 26 - Perfil de solo da sondagem SP-01.

Como observado na Figura 26, as estacas com profundidade de 4 metros ficaram instaladas em silte arenoso, pouco argiloso, fofo e pouco compacto, cor amarelado, com um SPT variando de 4 a 7 golpes $/ 30 \mathrm{~cm}$.

Como não foram realizados ensaios de laboratório com amostras de solo de instalação das estacas, para os parâmetros de solo com peso específico $(\gamma)$ foram adotados valores sugeridos em Cintra \& Aoki (1999) para areia pouco compacta úmida, segundo o estado de consistência, os quais são em função do índice de resistência à penetração $\left(\mathrm{N}_{S P T}\right)$. Os valores 
mostrados na Tabela 8 mostram o tipo de solo onde as estacas foram instaladas e o índice de $\mathrm{N}_{S P T}$, registrado a cada metro, até atingir os quatro metros.

Para a estimativa do valor de coesão (c), quando não se dispõem de ensaios de laboratório, Teixeria \& Godoy (1996) sugerem a seguinte correlação com o índice de resistência a penetração $\left(\mathrm{N}_{S P T}\right)$ :

$$
C_{u}=10 N(K P a)
$$

No entanto, como a classificação do solo de instalação da estaca era silte arenoso pouco argiloso, considerou-se a hipótese de solo arenoso para os cálculos, com coesão c $=0$.

Tabela 8 - Parâmetros de solo adotados para o solo da SP-01.

\begin{tabular}{|c|c|c|c|c|c|}
\hline SPT & Classificação & $\begin{array}{l}\text { Profundidade } \\
\text { (m) }\end{array}$ & $N_{S P T}$ & $\gamma\left(\mathrm{kN} / \mathrm{m}^{3}\right)$ & $c\left(k N / m^{2}\right)$ \\
\hline & Silte Arenoso & 1 & 4 & 18 & 0 \\
\hline \multirow[t]{3}{*}{ SP-01 } & Pouco & 2 & 7 & 18 & 0 \\
\hline & argiloso, fofo & 3 & 6 & 18 & 0 \\
\hline & $\begin{array}{c}\text { a pouco } \\
\text { compacto }\end{array}$ & 4 & 6 & 18 & 0 \\
\hline
\end{tabular}

Para a estimativa do ângulo de atrito, foi adotada a correlação empírica de Godoy (1983), segundo o índice de resistência a penetração $\left(\mathrm{N}_{\mathrm{SPT}}\right)$ :

$\emptyset=28^{\circ}+0,4 N_{S P T}$

O ângulo de atrito adotado nos cálculos foi de $30^{\circ}$ 


\subsection{Configuração de Estacas Metálicas Helicoidais}

$\mathrm{Na}$ fabricação da estaca, foi utilizado como haste central um tubo circular de $73 \times 8 \mathrm{~mm}$, aço FB70. As estacas continham três hélices de diâmetros crescentes (Figura 29). Após a instalação das estacas, a hélice superior, com diâmetro de $D 1=30 \mathrm{~cm}$, ficou instalada na profundidade de $\mathrm{H} 1=248 \mathrm{~cm}$; a hélice do meio com diâmetro D2 $=25 \mathrm{~cm}$, a uma profundidade de $\mathrm{H} 2=324 \mathrm{~cm}$; a hélice inferior com diâmetro D3 $=20 \mathrm{~cm}$ e uma profundidade de $385 \mathrm{~cm}$.

Todas as medidas de profundidade são relativas ao nível do terreno (NT); a distância entre as hélices era de $762 \mathrm{~mm}, 610 \mathrm{~mm}$ (Figura 32). O passo das hélices era de 7,5 cm. As extensões foram feitas em tubo de aço VMB350COR.

Foram ensaiadas cinco estacas divididas em três grupos distintos, de acordo com o processo de execução:

1. Grupo 1: estacas helicoidais convencionais, E1 e E2;

2. Grupo 2: estacas helicoidais com injeção de nata de cimento, C1 e C2;

3. Grupo 3: estaca helicoidal com fuste de argamassa, A1.

Durante esta pesquisa, foram utilizadas cinco estacas helicoidais, todas com a mesma configuração e modelo, sendo a única variação feita nas estacas $\mathrm{C} 1$ e C2:

a. Emenda rosqueada diferente das outras estacas, devido ao processo de injeção de argamassa.

b. Furos em torno das hélices de 1" para a injeção da calda cimento no solo.

Na Tabela 9 são apresentadas as configurações das estacas instaladas e ensaiadas durante esta pesquisa. Os modelos de estacas helicoidais são mostrados nas Figuras 27, 28 e 29. 
Tabela 9 - Configuração das Estacas Helicoidais Instaladas e Ensaiadas

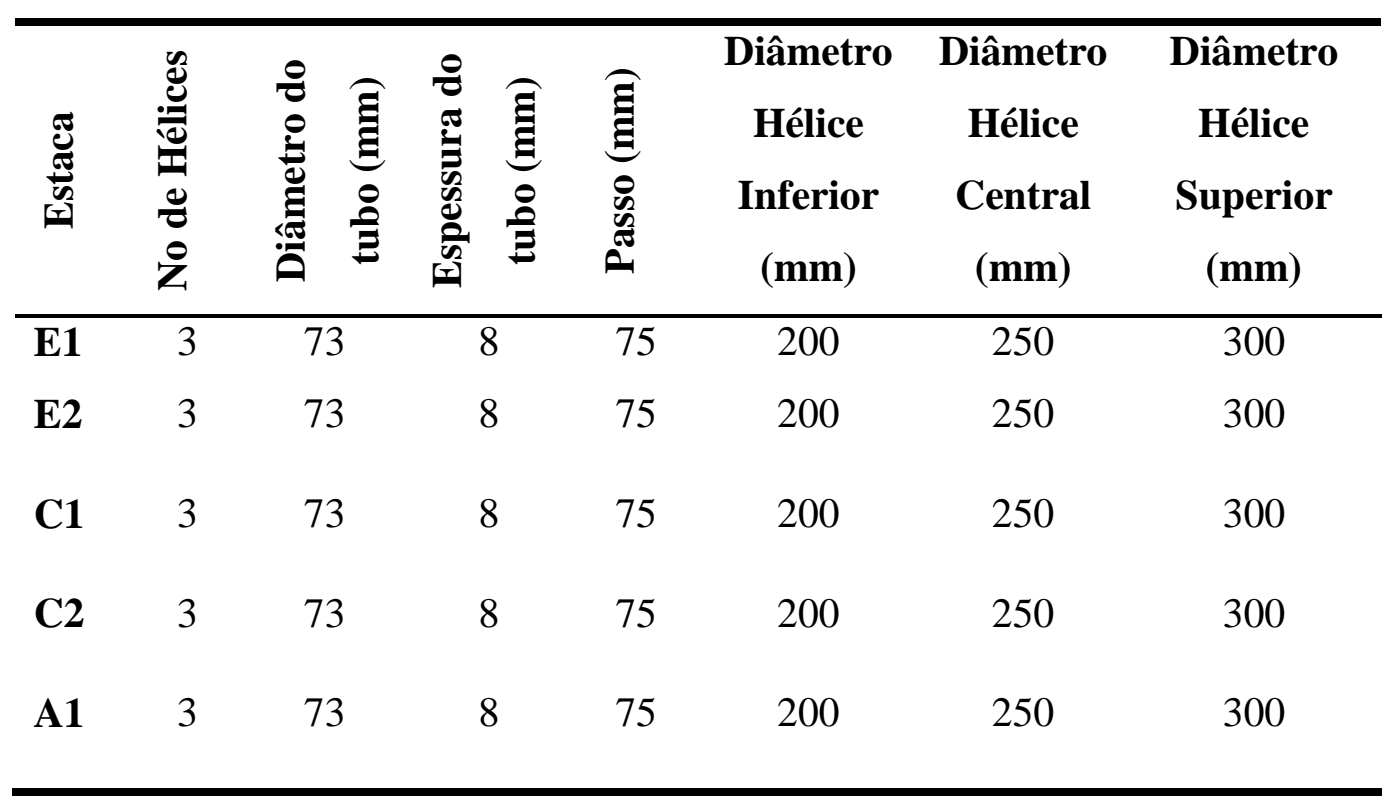

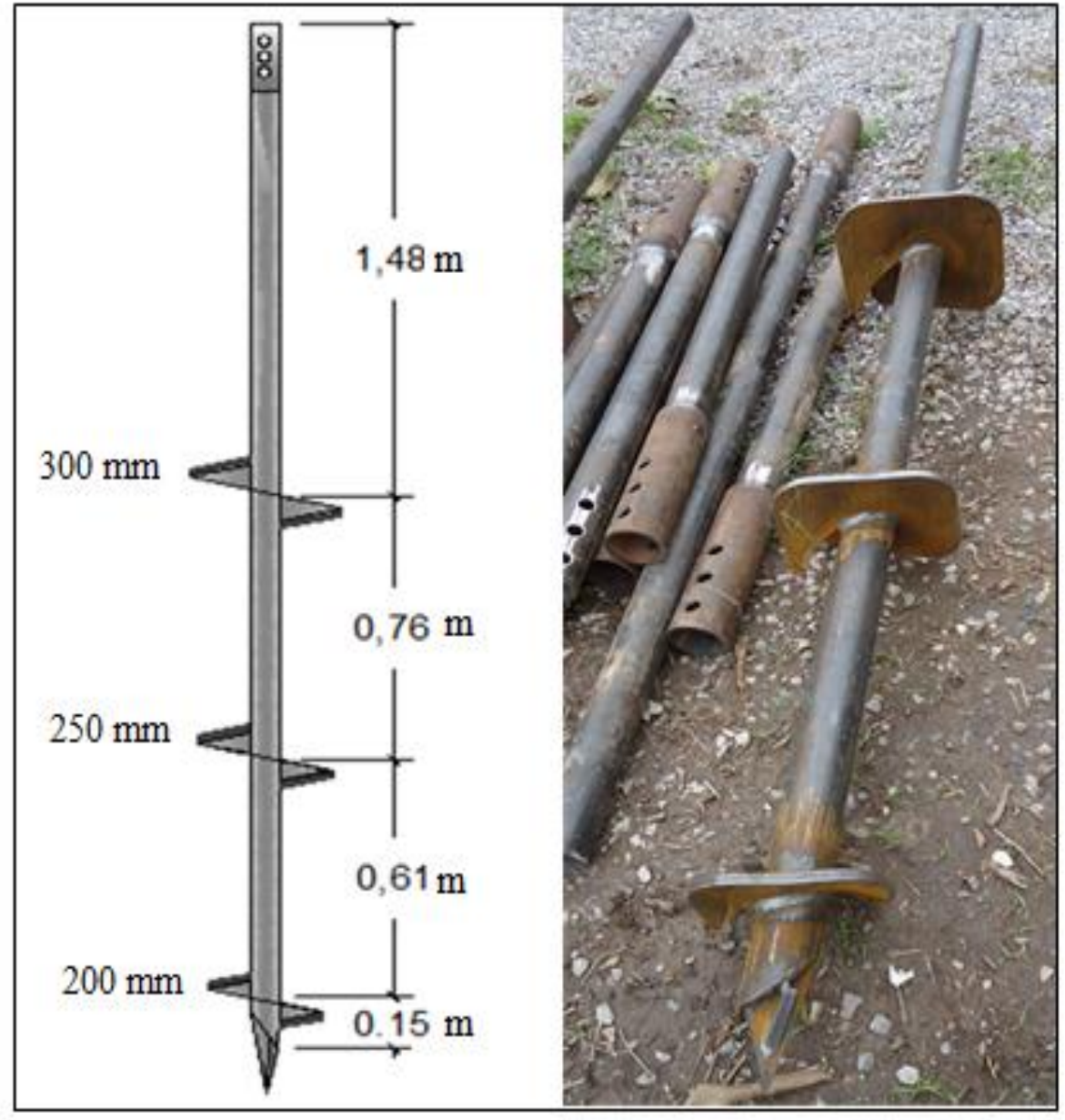

Figura 27- Seção guiatípica das estacas E1, E2 e A1. 


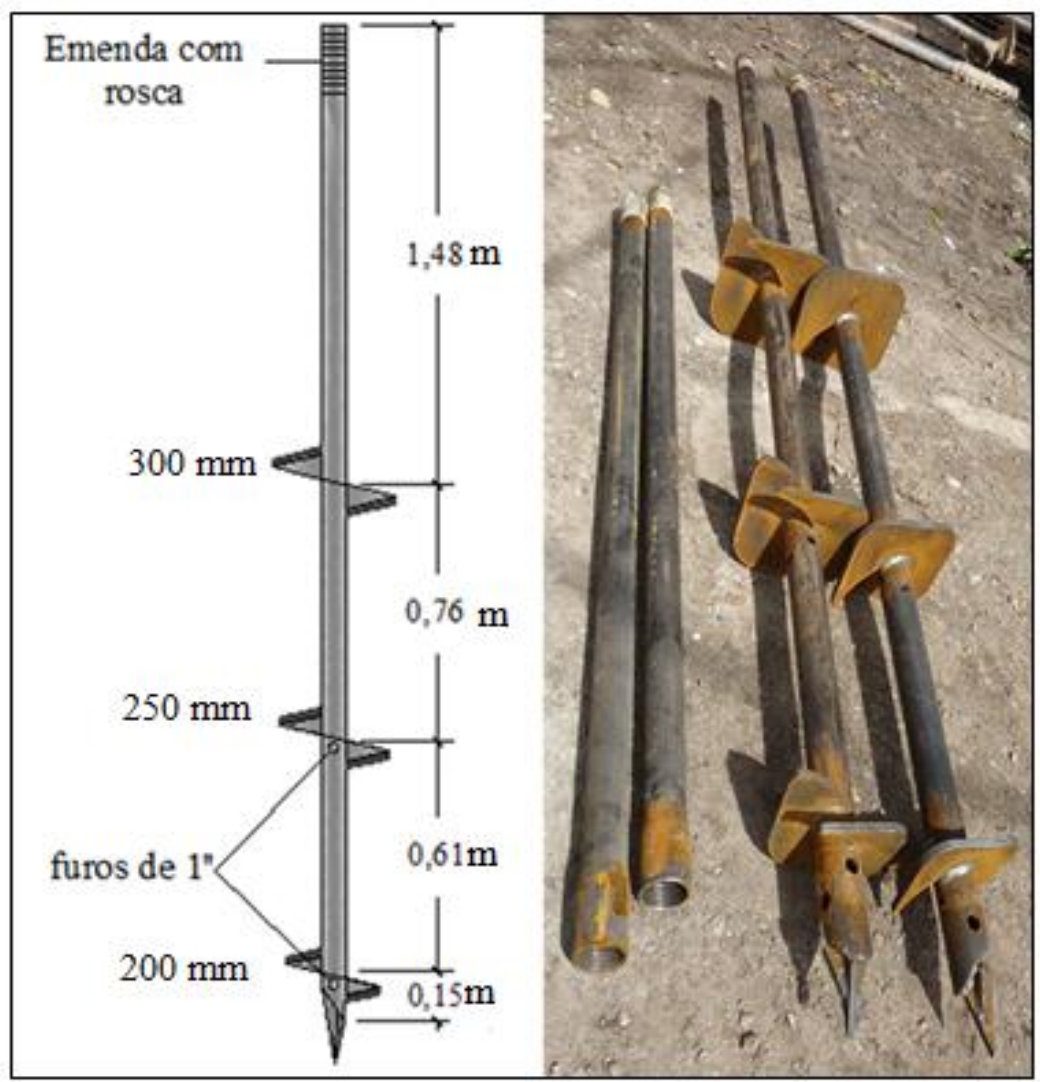

Figura 28 - Modelo de estaca utilizada nos ensaios das estacas com injeção C1 e C2.

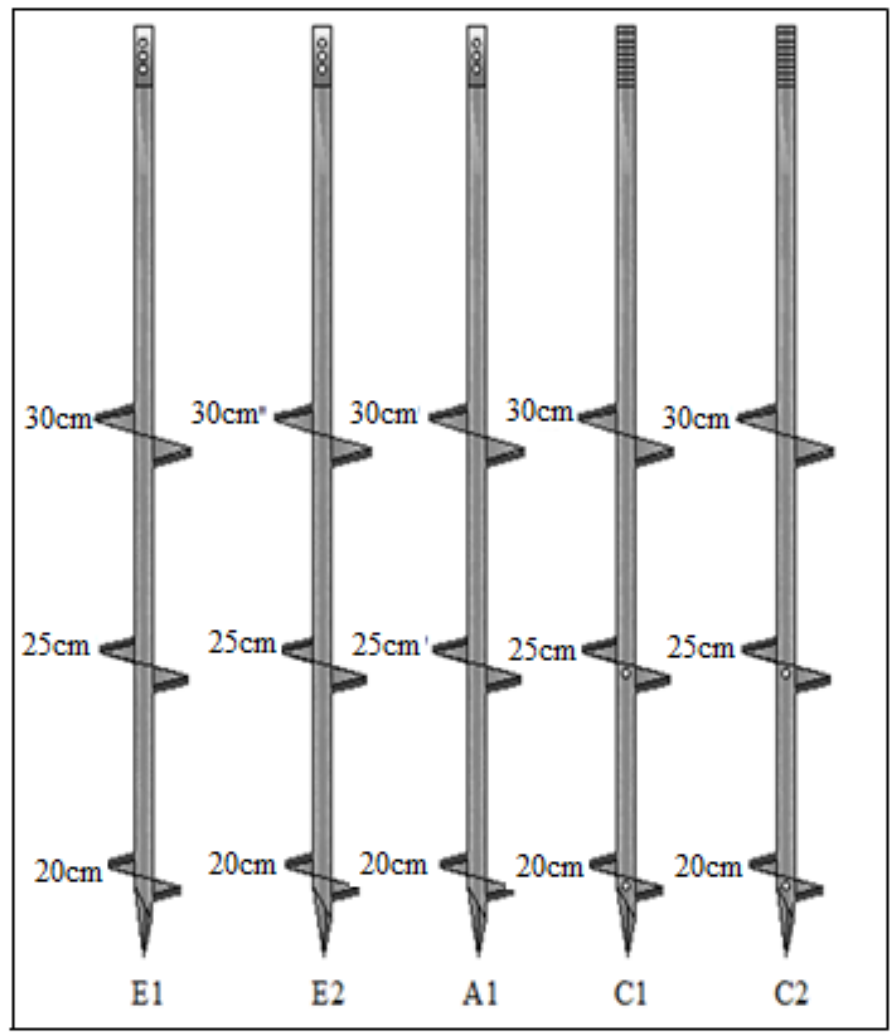

Figura 29 - Identificação das estacas Ensaiadas. 


\subsubsection{Instalação das Estacas}

A instalação das estacas foi realizada com uma retroescavadeira Caterpillar modelo 416 E, na qual foi adaptado um motor hidráulico para a aplicação de torque na estaca (Figura 30). As estacas foram marcadas com giz a cada $0,50 \mathrm{~m}$ para o registro dos valores de torque durante a penetração da estaca neste intervalo.

As estacas convencionais E1 e E2 foram instaladas aplicando-se torque até que a ponta da estaca atingisse a profundidade de $4 \mathrm{~m}$. Foi instalada uma seção guia de $3 \mathrm{~m}$ e uma extensão de $1,4 \mathrm{~m}$ para atingir a profundidade desejada.

Igualmente, a instalação da estaca A1 foi feita até a profundidade de $4 \mathrm{~m}$, deixando-se $40 \mathrm{~cm}$ na superfície para a realização das provas de carga. A execução da estaca A1 (com fuste de argamassa) foi feita em duas etapas. Primeiramente, o processo de instalação foi realizado normalmente, aplicando-se torque até a profundidade de 2,27 m, onde se encontrava a primeira chapa de aço (diâmetro $=20 \mathrm{~cm}$ ), ou o disco de deslocamento.

Como mostra a Figura 31, foram soldadas no disco uma aleta para ajudar a cortar e afastar o solo ao redor do fuste, proporcionando um cilindro vazio acima das hélices, para se realizar a primeira etapa de preenchimento com argamassa.

Posteriormente, foi adicionada uma extensão (emenda parafusada) que incluía o segundo disco de deslocamento soldado na haste tubular. Este disco de deslocamento tinha um furo de uma polegada para permitir a passagem da argamassa (como mostra a Figura 31), e para evitar espaços vazios na concretagem de coluna de argamassa. Finalmente, a estaca foi instalada até a profundidade de $4 \mathrm{~m}$ e depois foi concretada. 


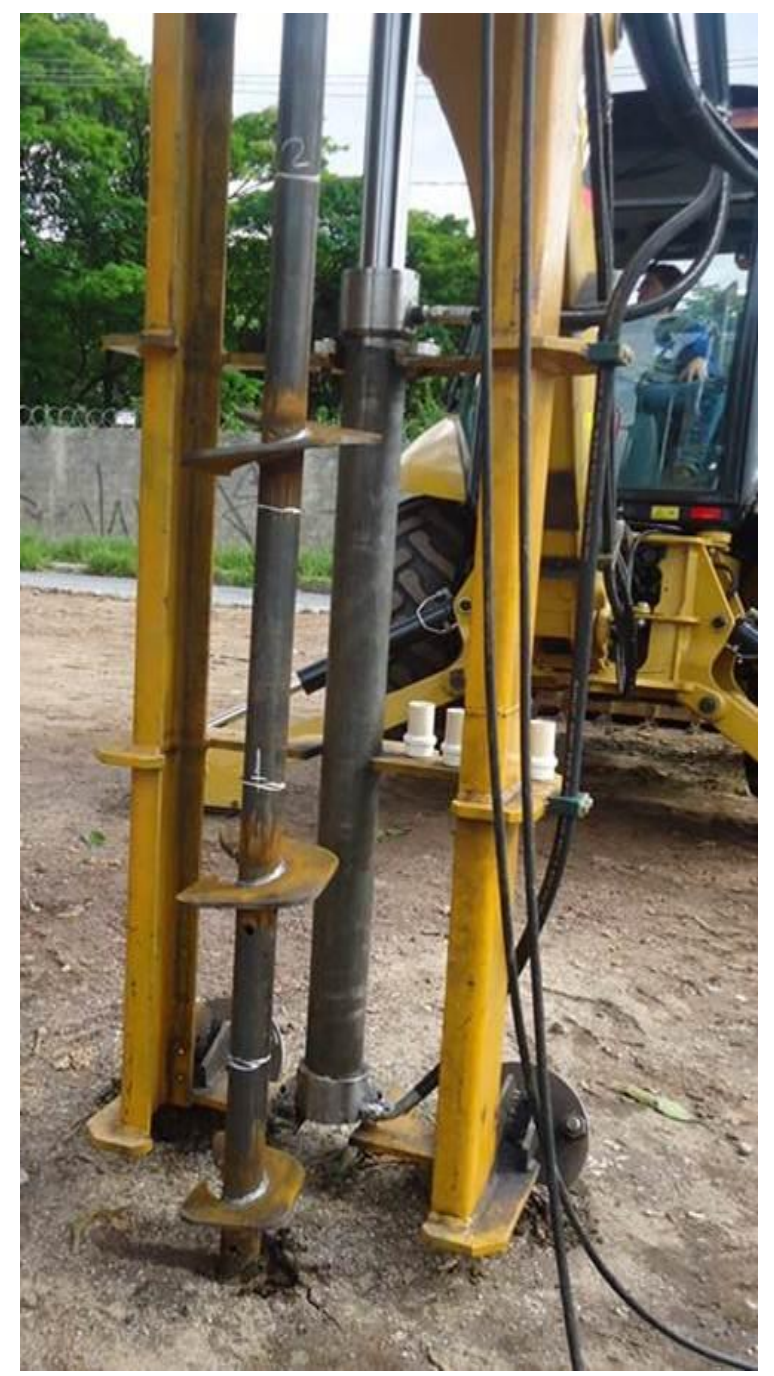

Figura 30 - Procedimento de instalação das estacas helicoidais.

O traço utilizado na realização da argamassa foi 1:2 (um de cimento tipo CP IV 32 e dois de areia). Foi acrescentando também $1 \%$ de expansor na argamassa. A argamassa foi colocada suficientemente líquida para que pudesse fluir no furo formado pelas chapas de aço. A resistência à compressão da argamassa foi obtida por meio de corpos-de-prova cilíndricos de 5x10cm (foi de 16,59 MPA após 28 dias, com velocidade de aplicação de carga igual a $0,50 \mathrm{kN} / \mathrm{s})$. 
A estaca A1 foi preenchida com argamassa ao redor da haste, formando-se um fuste de 2 metros de comprimento, o que equivale a 50\% do comprimento da estaca (Figura 32).

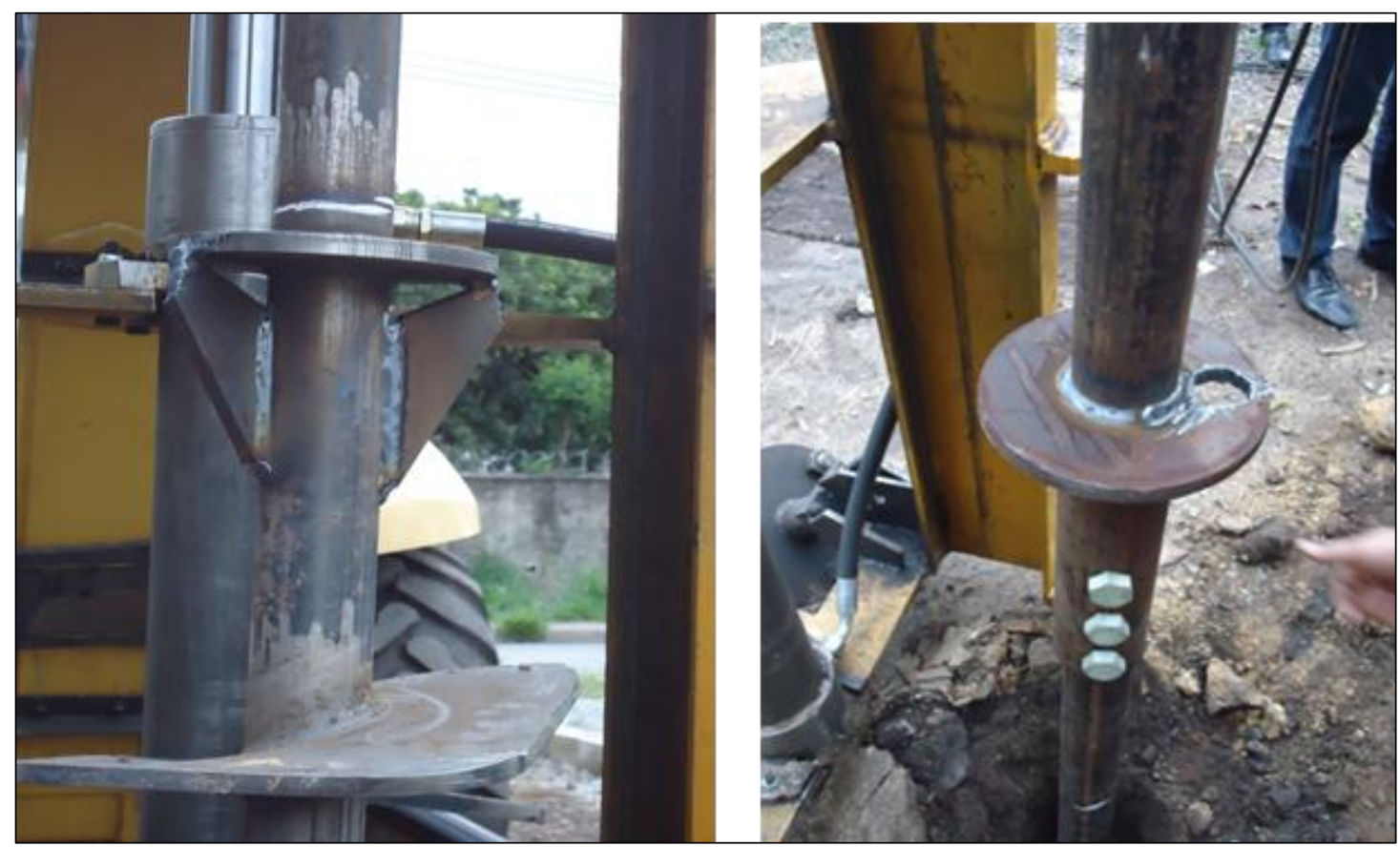

Figura 31- Chapas de aço soldadas na haste da estaca (a primeira contém as aletas e a segunda contém o

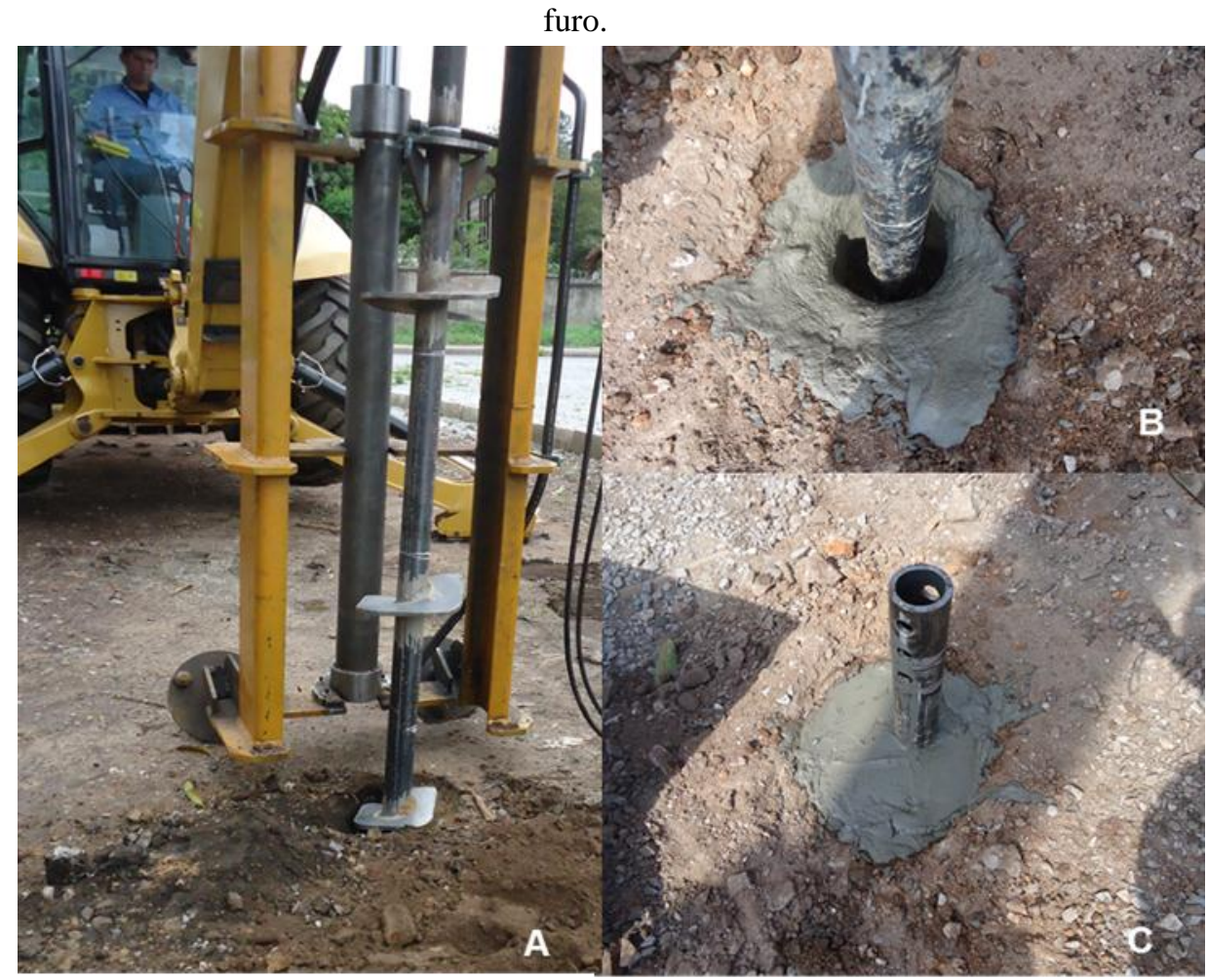

Figura 32 - Processo de instalação e preenchimento da argamassa no fuste da estaca helicoidal (A-1). 
As estacas injetadas C1 e C2 foram instaladas normalmente aplicando-se torque até se atingir a profundidade de 4 metros. A injeção foi realizada ao final da instalação, como mostram as Figuras 33 e 34.

A única variante ocorreu na injeção da estaca C2. Para esta estaca, após finalizar a injeção, foi aplicada uma rotação na estaca, sem aprofundar o comprimento, para verificar se esta rotação da hélice ajudaria na formação de um bulbo mais uniforme em torno da hélice. A ideia foi comparar, após a escavação, a superfície do bulbo da $\mathrm{C} 2$ com o bulbo da $\mathrm{C} 1$, na qual não foi aplicada esta rotação.

Para a realização da injeção, foi realizado e utilizado um acoplamento com rosca como mostra a Figura 33. Foi utilizado um misturador manual para dispersar bem os grãos de cimento e para suprir a bomba injetora com pressão de injeção de $8 \mathrm{~kg} / \mathrm{cm}^{2}$, a qual se manteve constante durante cada uma das injeções das estacas. Não foram utilizados aditivos na calda de cimento injetadas nas estacas.
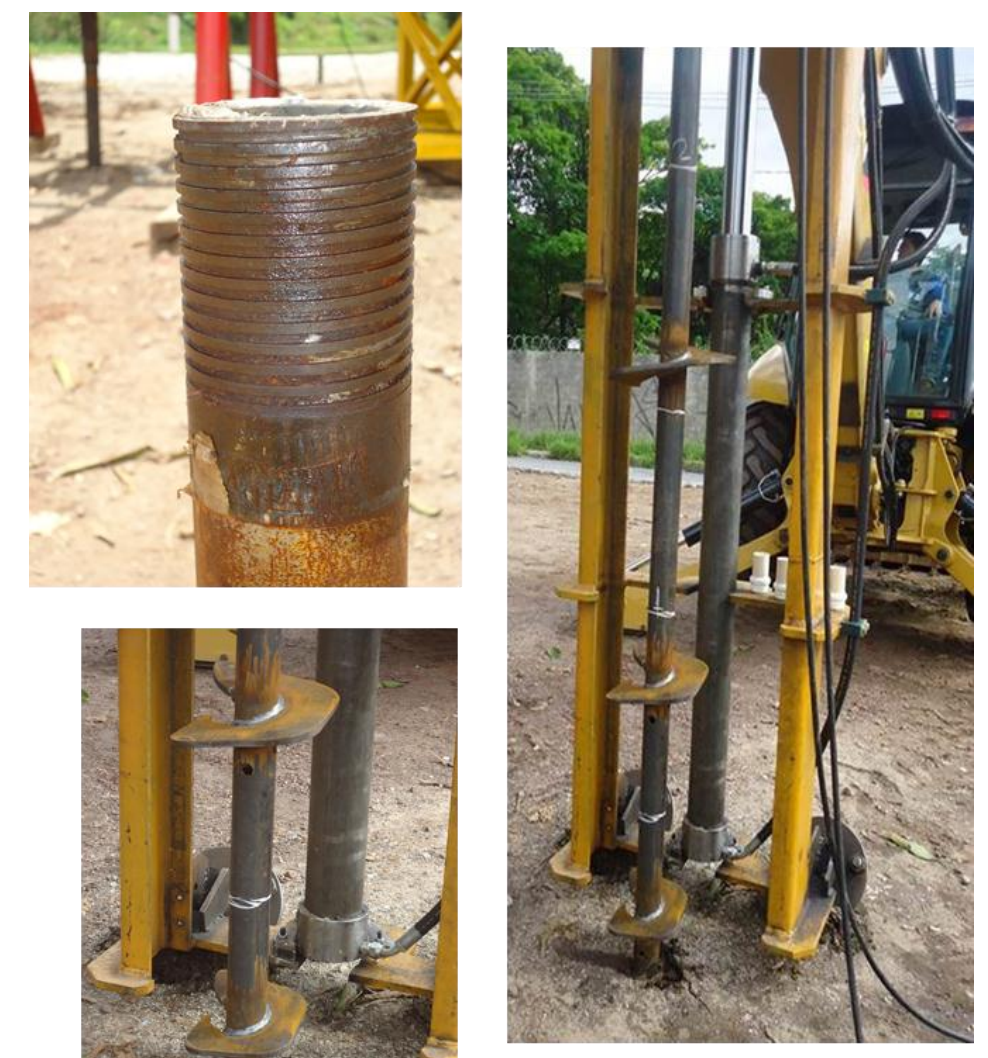

Figura 33 - Instalação da estaca com emenda tipo rosca e com furos na seção guia para aplicação de injeção no final da instalação. 


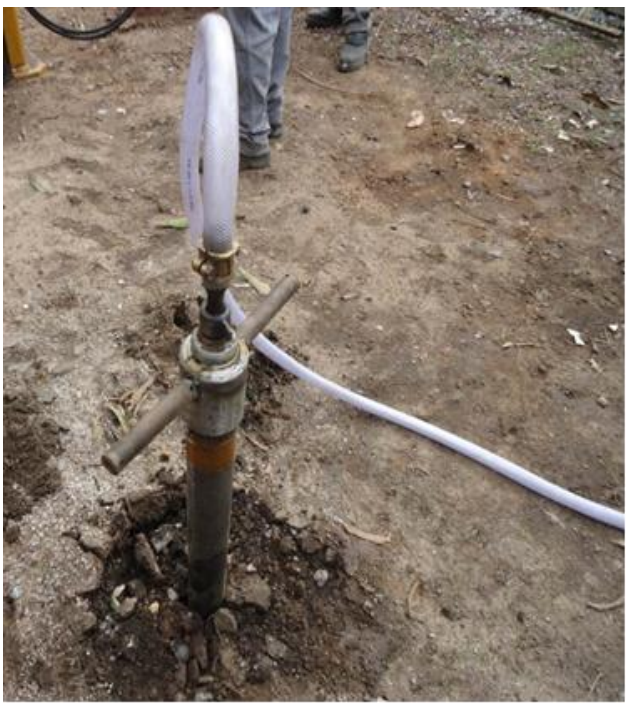

(a)

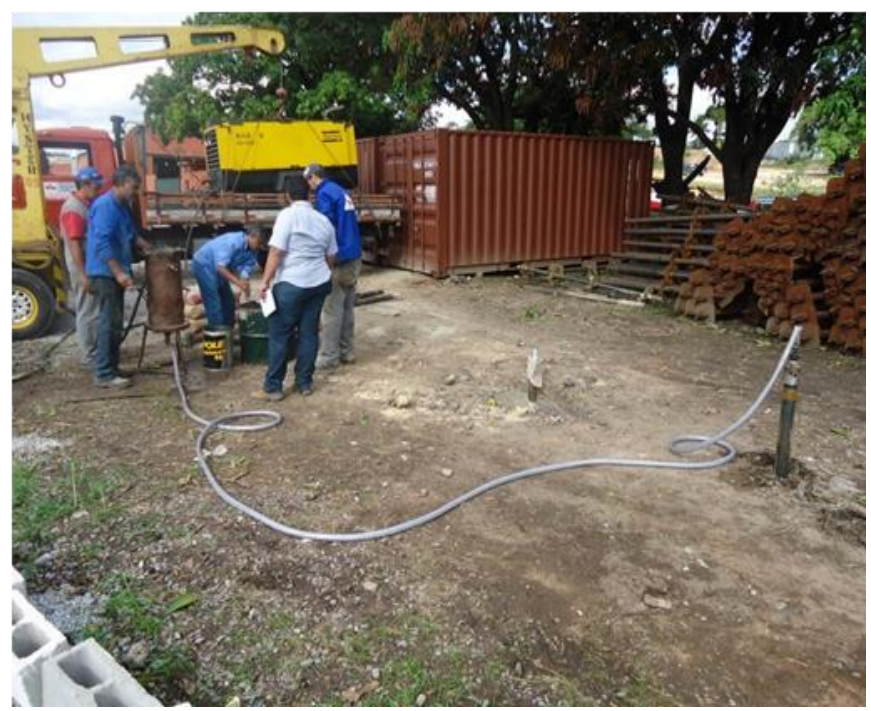

(b)

Figura 34 - (a) acoplamento com rosca para realização da injeção; (b) processo de injeção da estaca.
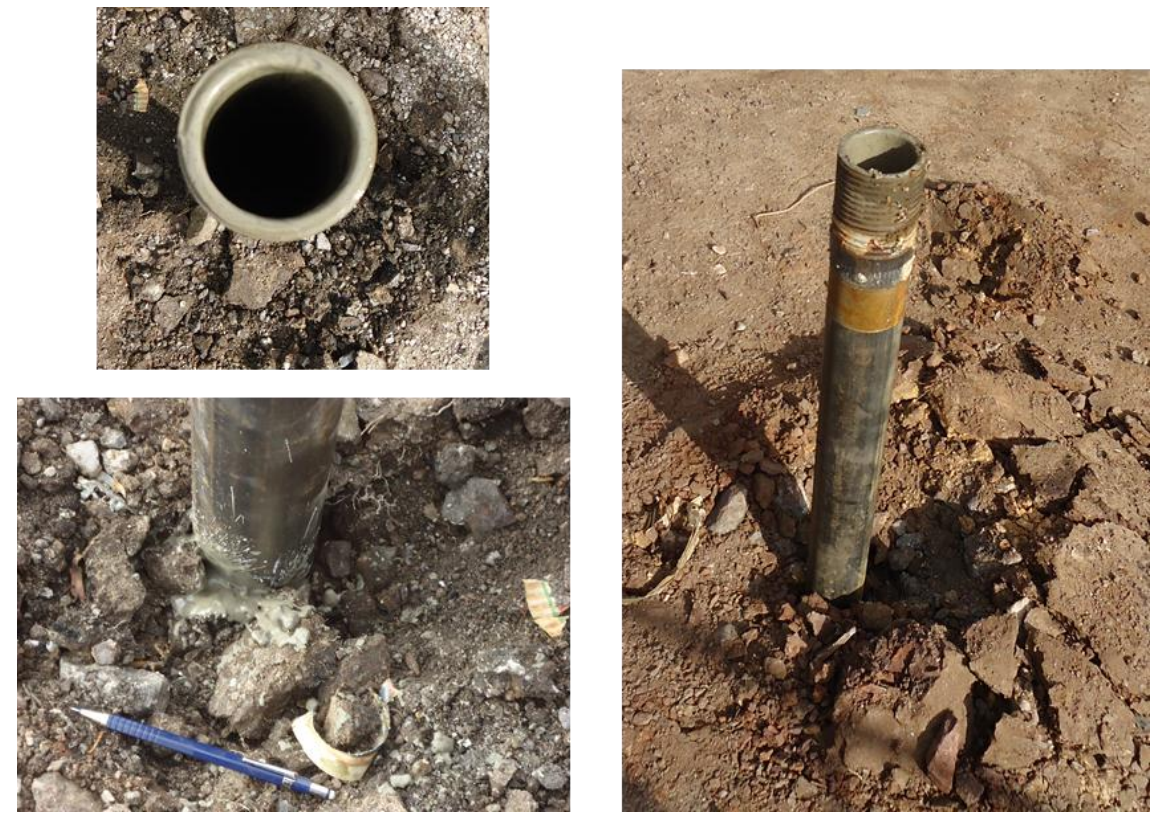

Figura 35 - Foto da cabeça da estaca C1 após término do processo de injeção.

Para a elaboração da calda cimento, foram utilizadas:

a. 30 litros de água da rede de abastecimento;

b. 1 saco de cimento CP IV 32 de $50 \mathrm{~kg}$.

Foi obtida uma relação A/C de (1,88/1) e uma resistência à compressão de 20,66 MPA 
em ensaios realizados em corpos-de-prova cilíndricos (Figura 36) de 5x10cm, após 28 dias (a velocidade de aplicação de carga nos ensaios foi de $0,50 \mathrm{kN} / \mathrm{s}$ ).
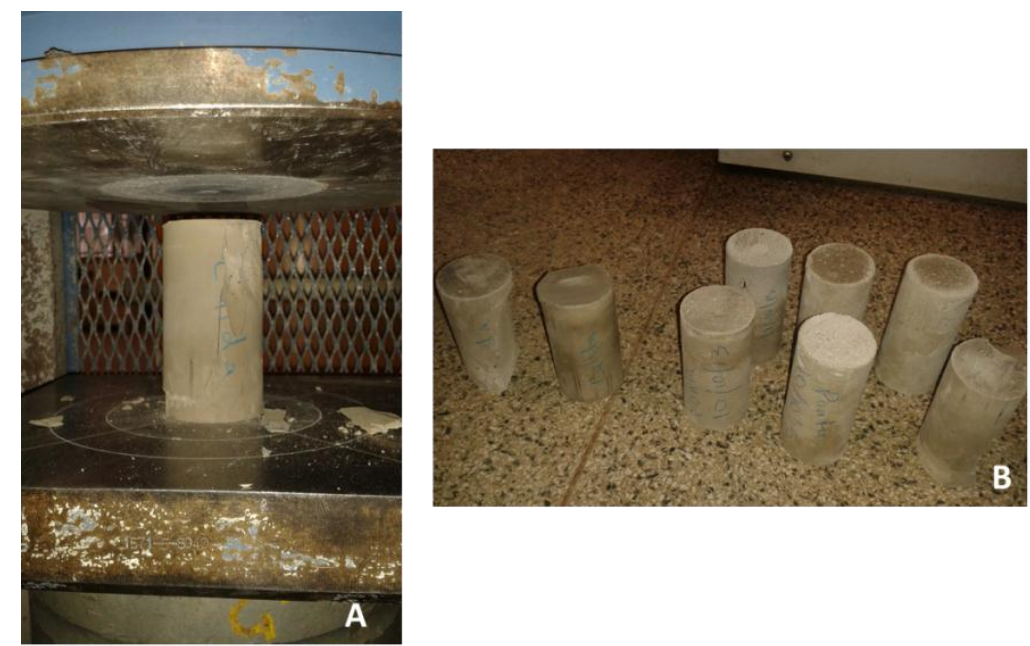

Figura 36 - a) ensaio de compressão em andamento; b) corpos-de-prova cilíndricos de $5 \times 10 \mathrm{~cm}$ cilíndricos ensaiados.

Os ensaios de compressão dos corpos-de-prova cilíndricos de $5 \times 10 \mathrm{~cm}$ foram realizados no Departamento de Estruturas da Escola de Engenharia de São Carlos (EESC)-USP.

\subsection{Provas de Carga}

As provas de carga foram realizadas de acordo com os procedimentos descritos pela ABNT NBR 12131/2006, para provas de carga estática em estacas, com carregamento rápido.

Adotou-se o ensaio com carregamento em estágios rápidos, já que as estacas são usualmente empregadas como fundação de torres de linhas de transmissão de energia, em que o carregamento principal é devido aos esforços do vento na torre.

Nestes ensaios, foram aplicados estágios de carregamento de aproximadamente 5\% de carga de ruptura, prevista para cada estaca ensaiada. Em cada estágio, os deslocamentos foram lidos imediatamente após a aplicação de carga correspondente, seguindo as leituras decorridos os 5 minutos contados a partir do início do ensaio (os deslocamentos foram 
medidos durante toda a prova de carga). Atingida a carga máxima do ensaio, o descarregamento foi feito em cinco estágios de $20 \%$ cada um.

Os equipamentos utilizados (e a quantidade entre parênteses) para as provas de carga foram os seguintes:

- Viga de reação de $5 \mathrm{~m}$ de comprimento (1);

- Cavaletes para serem utilizados como fogueiras nos laterais (2);

- Vigas de referência (2);

- Estacas helicoidais para reação com quatro hélices (diâmetros de 250, 300, 350, $350 \mathrm{~mm}$ ) utilizadas (2);

- Macaco hidráulico (1);

- Bomba hidráulica (1);

- Célula de carga (1);

- Sistema de aquisição de dados da célula de carga (1);

- Relógios comparadores ou medidores de deslocamentos (4);

- Peça de acoplamento (3);

- Barras dywidag (3);

- Hyster 110 para movimentação e instalação da viga de referência (1).

Os equipamentos detalhados acima foram usados nas nove provas de carga realizadas nesta pesquisa (cinco de tração e quatro de compressão).

O sistema de reação consistiu de uma viga composta por dois perfis tipo I (Figuras 37 e 38), apoiadas nos cavaletes para os ensaios à tração. No mesmo lugar, foram instaladas duas estacas helicoidais que serviriam como reação durante as provas e carga de compressão.

O carregamento foi realizado com o macaco hidráulico conectado a bomba manual e a célula de carga ligada ao sistema de aquisição de dados. A leitura dos deslocamentos foi tomada dos quatro relógios comparadores, com capacidade de $50 \mathrm{~mm}$, posicionados nas vigas de referência (pregadas ao chão em direção transversal ao sistema de reação).

Nas provas de carga à tração, o macaco e a célula de carga são instalados na parte superior da viga de referência para poder transmitir os esforços axiais à tração na estaca (ver Figura 37). Já no esquema das provas de carga à compressão, o macaco e a célula de carga foram instalados na cabeça da estaca, como são mostrados na Figura 38. 


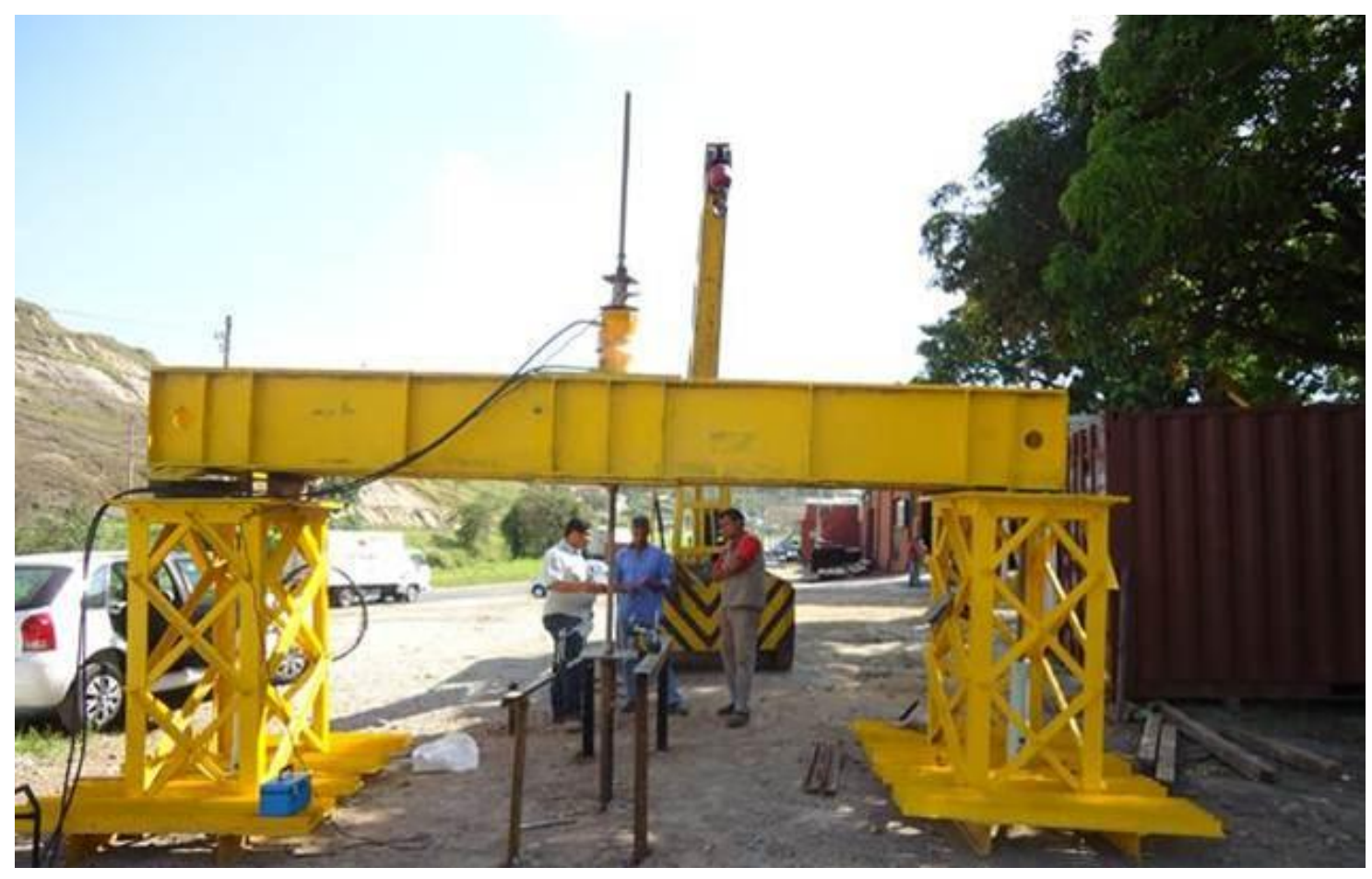

Figura 37 - Esquema típico das montagens das provas de carga à tração.

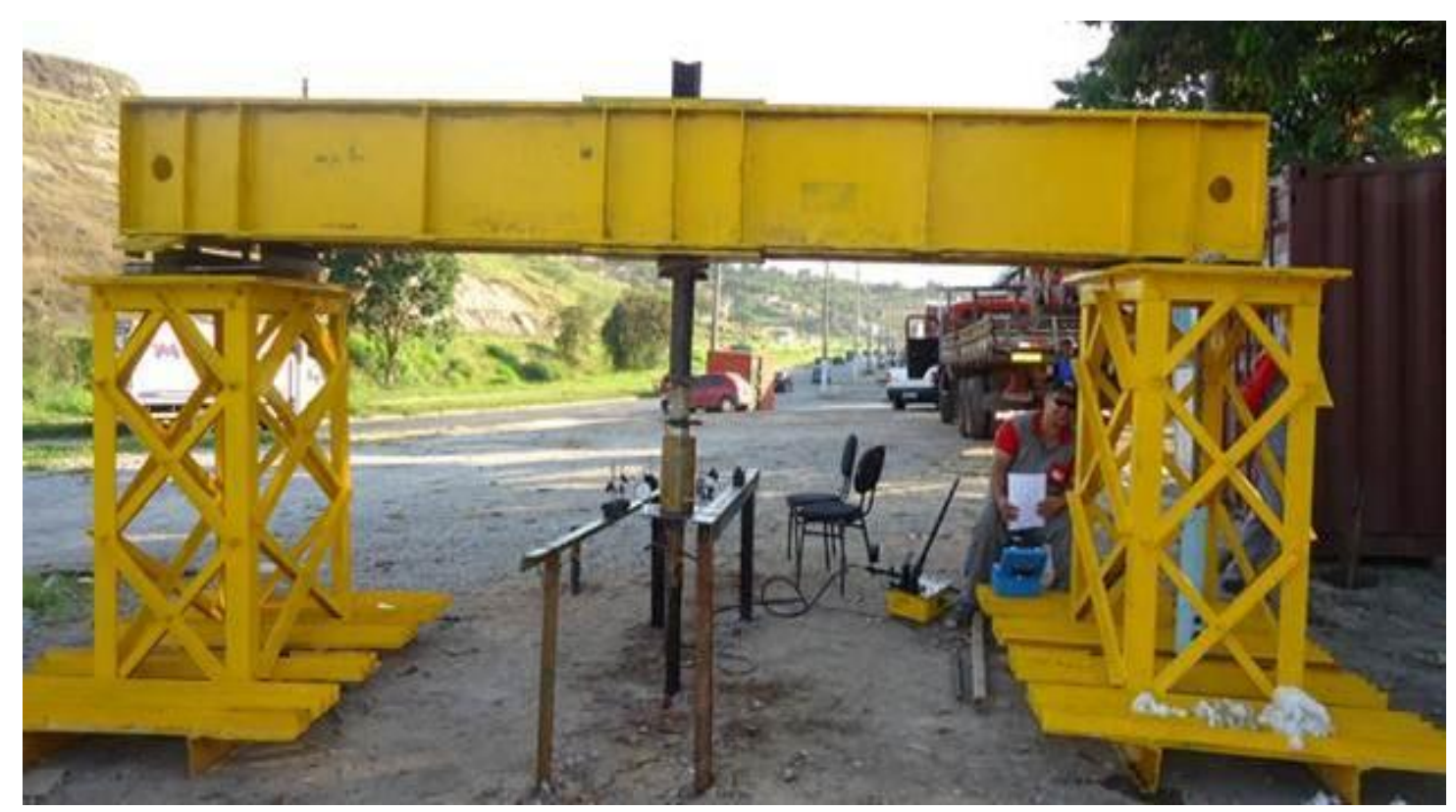

Figura 38 - Esquema típico das montagens das provas de carga à compressão. 
A sequência das nove provas de carga realizadas é detalhada na Tabela 10.

Tabela 10 - Sequência de provas de carga realizadas

\begin{tabular}{|c|c|c|c|}
\hline Estaca & Data de ensaio & Especificações & Prova de Carga \\
\hline E1 & $29 / 10 / 2013$ & Estaca com três hélices & Tração \\
\hline E1 & $30 / 10 / 2013$ & Estaca com três hélices & Compressão \\
\hline E2 & $5 / 11 / 2013$ & Estaca com três hélices & Tração \\
\hline A-1 & $1 / 11 / 2013$ & $\begin{array}{l}\text { Estaca com três hélices } \\
\text { e argamassa no fuste }\end{array}$ & Tração \\
\hline A-1 & $1 / 11 / 2013$ & $\begin{array}{l}\text { Estaca com três hélices } \\
\text { e argamassa no fuste }\end{array}$ & Compressão \\
\hline $\mathrm{C}-1$ & $2 / 11 / 2013$ & $\begin{array}{c}\text { Estaca com três hélices } \\
\text { injetada }\end{array}$ & Tração \\
\hline $\mathrm{C}-1$ & $4 / 11 / 2013$ & $\begin{array}{c}\text { Estaca com três hélices } \\
\text { injetada }\end{array}$ & Compressão \\
\hline $\mathrm{C}-2$ & $6 / 11 / 2013$ & $\begin{array}{c}\text { Estaca com três hélices } \\
\text { injetada com rotação } \\
\text { no final }\end{array}$ & Tração \\
\hline $\mathrm{C}-2$ & $12 / 11 / 2013$ & $\begin{array}{c}\text { Estaca com três hélices } \\
\text { injetada com rotação } \\
\text { no final }\end{array}$ & Compressão \\
\hline
\end{tabular}

\subsection{Escavações e Extrações das Estacas Metálicas Helicoidais}

Depois de realizadas as provas de carga, foram feitas escavações para se poder fazer as extrações das estacas injetadas e a preenchida com fuste de argamassa (Figuras 40 e 41). O objetivo da exumação das estacas foi observar o resultado das injeções e também para se medir:

a. Comprimentos e diâmetros dos bulbos de calda cimento-solo nos casos nas estacas injetadas $\mathrm{C} 1$ e $\mathrm{C} 2$;

b. Dimensões e diâmetro da argamassa ao redor do fuste, estaca A1. 
O equipamento necessário para realizar as extrações das estacas foram os seguintes:

- Retroescavadeira Case 580 para fazer escavações;

- Hyster 110 para realizar as extrações;

- Escada;

- Ferramentas manuais.

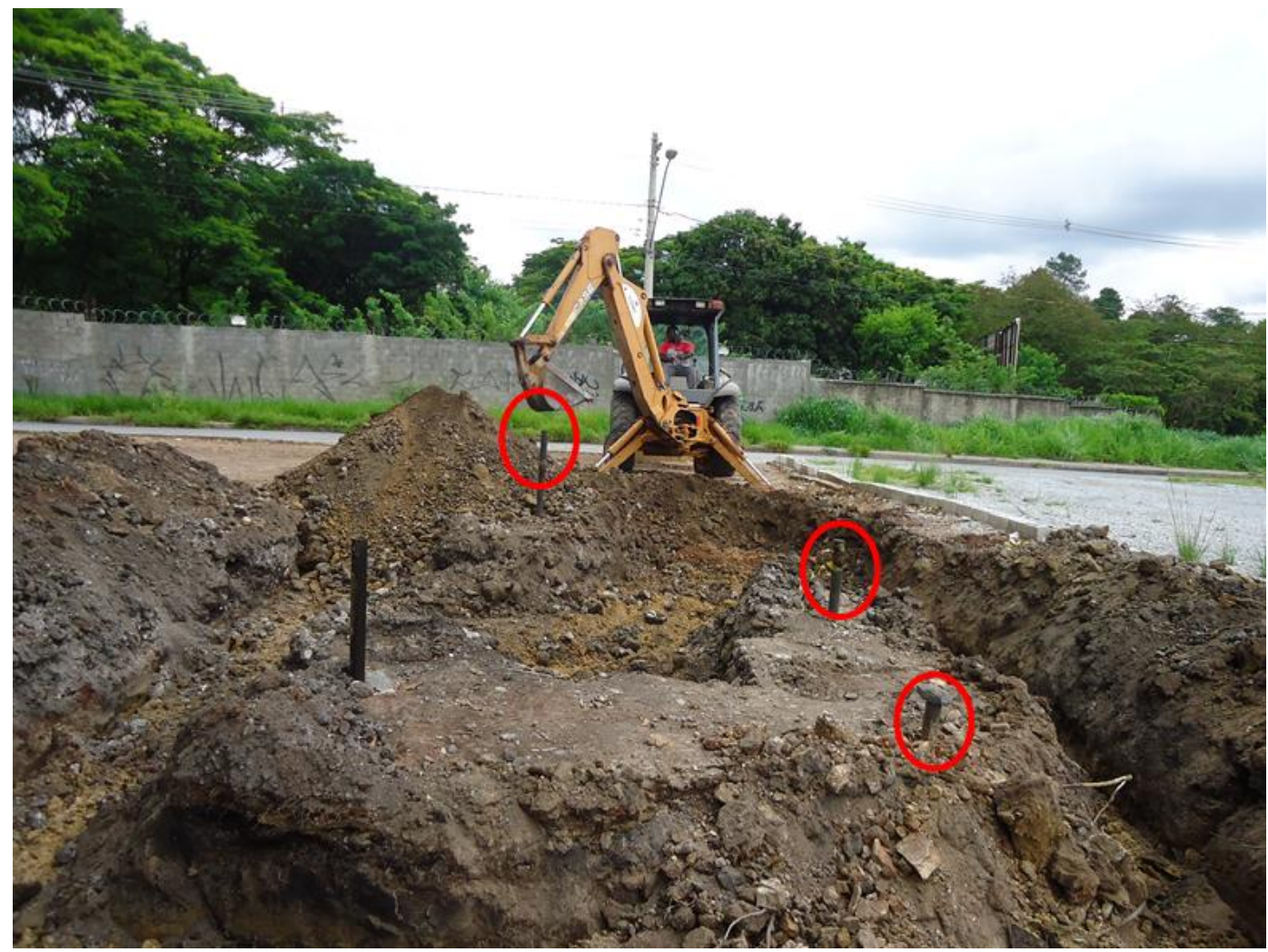

Figura 39 - Durante o processo de escavação (em vermelho estão indicadas as estacas a serem extraídas). 

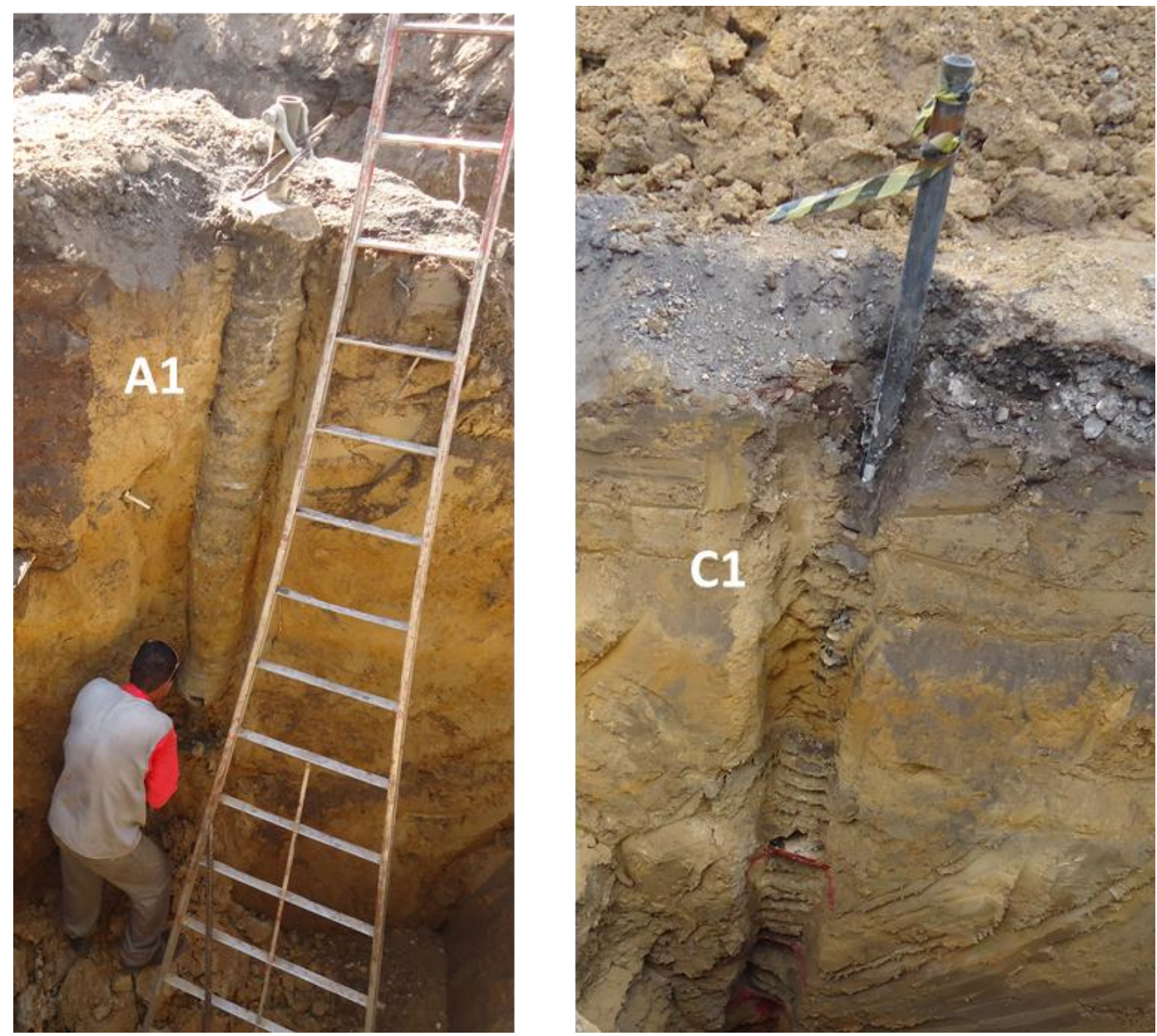

Figura 40 - Escavação mecânica e manual prévio para extração da estaca A1 e estaca C1.

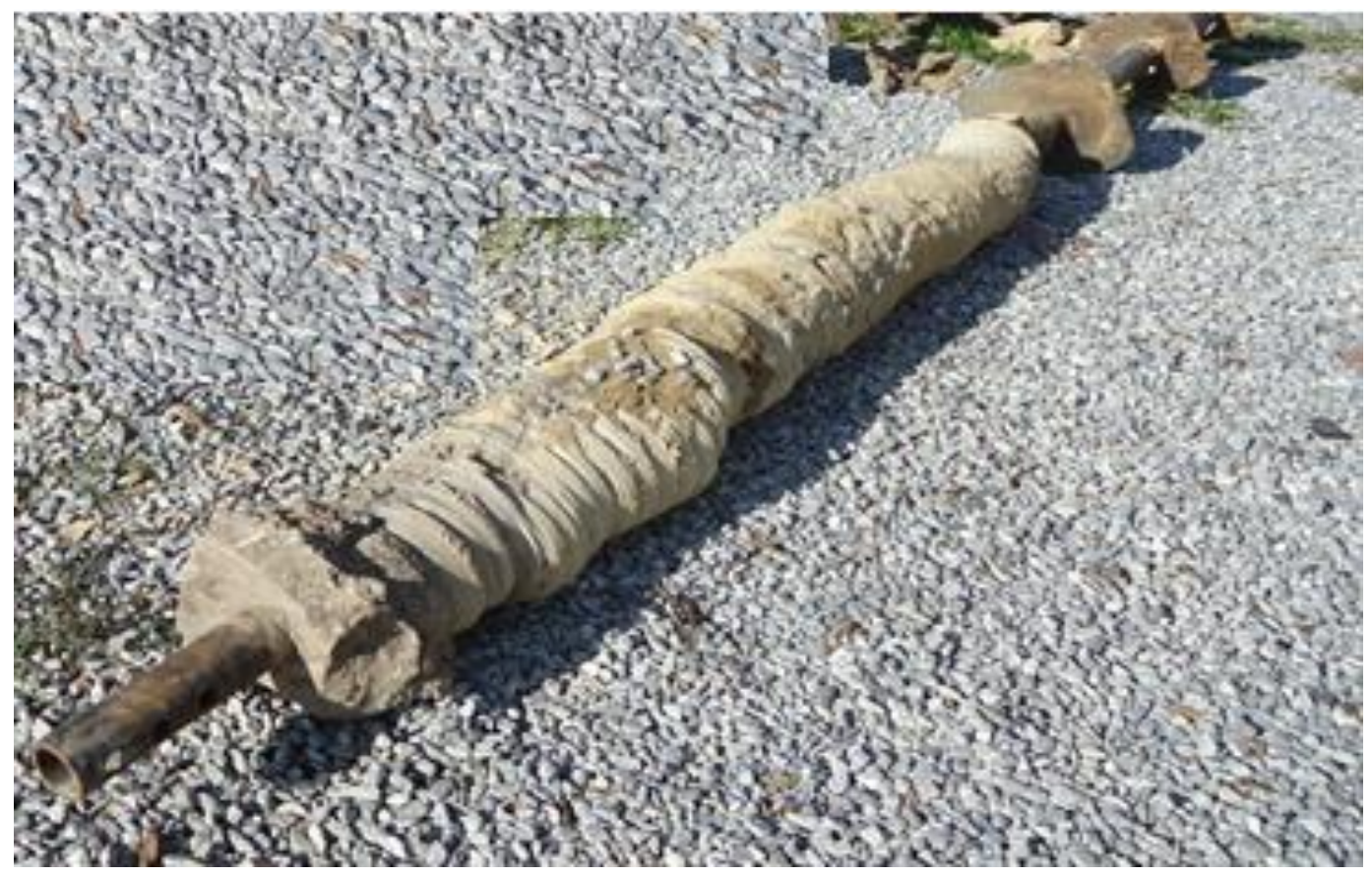

Figura 41 - Fuste de argamassa observado na estaca helicoidal A1, após a escavação. 


\section{RESULTADOS E ANÁLISE}

Neste capítulo, são apresentados os resultados e as análises realizadas a partir dos resultados dos experimentos executados na área experimental-Vercon Ind., Betim-MG.

\subsection{Instalação das Estacas}

As estacas foram instaladas conforme os procedimentos descritos no capítulo anterior. A profundidade final da ponta de todas as estacas foi de quatro metros.

Para a realização das provas de carga, foi necessário que o trecho final do topo das hastes das estacas fosse exposto, para o acoplamento com o sistema de aplicação de carregamentos de tração e de compressão. As medidas dos comprimentos de haste das estacas que ficaram acima do nível do terreno são apresentadas na Tabela 11.

Tabela 11 - Comprimentos da haste da estaca helicoidal acima do nível do terreno.

\begin{tabular}{lccccc}
\hline Estaca & E1 & E2 & A1 & C1 & C2 \\
\hline L medido (cm) & 40 & 40 & 40 & 60 & 60 \\
\hline
\end{tabular}

\subsubsection{Medidas de Torque de Instalação}

A Tabela 12 apresenta os valores de torque medidos a cada $0,50 \mathrm{~m}$ de penetração das estacas testadas no terreno, durante a instalação. 
Tabela 12 - Medidas de torque de instalação das estacas helicoidais registradas ao longo da profundidade

\begin{tabular}{|c|c|c|c|c|c|}
\hline \multirow[t]{2}{*}{$\begin{array}{c}\text { Prof } \\
\text { (m) }\end{array}$} & \multicolumn{5}{|c|}{$\begin{array}{c}\text { Torques de Instalação } \\
(\text { kN.m) }\end{array}$} \\
\hline & R-1 & R-2 & A-1 & $\mathrm{C}-1$ & C-2 \\
\hline $\mathbf{0}$ & 0 & 0 & 0 & 0 & 0 \\
\hline 0,50 & 1,90 & 0,54 & 0,75 & 2,58 & 2,30 \\
\hline 1,00 & 3,47 & 0,81 & 2,17 & 3,69 & 2,43 \\
\hline 1,50 & 3,90 & 1,49 & 2,17 & 3,12 & 3,66 \\
\hline 2,00 & 5,83 & 2,03 & 2,44 & 4,85 & 5,69 \\
\hline 2,50 & 3,12 & 2,17 & 3,57 & 3,66 & 5,83 \\
\hline 3,00 & 3,70 & 2,98 & 4,47 & 2,89 & 4,81 \\
\hline 3,50 & 3,32 & 3,12 & 3,74 & 2,45 & 4,62 \\
\hline 4,00 & 2,98 & 2,85 & 4,07 & 2,71 & 4,07 \\
\hline
\end{tabular}

No Gráfico 3, é mostrada a variação de torque de instalação ao longo da profundidade, resultante da instalação de todas as estacas. Estes resultados indicam uma grande variabilidade do solo no terreno na profundidade em torno de 2 metros. Na profundidade de 4 metros, os valores de torque final de instalação variam em torno de 4 a 6 kN.m. Estes resultados mostram que as estacas A1 e C2 ficaram com a ponta instalada em solo de maior capacidade, em relação às outras estacas.

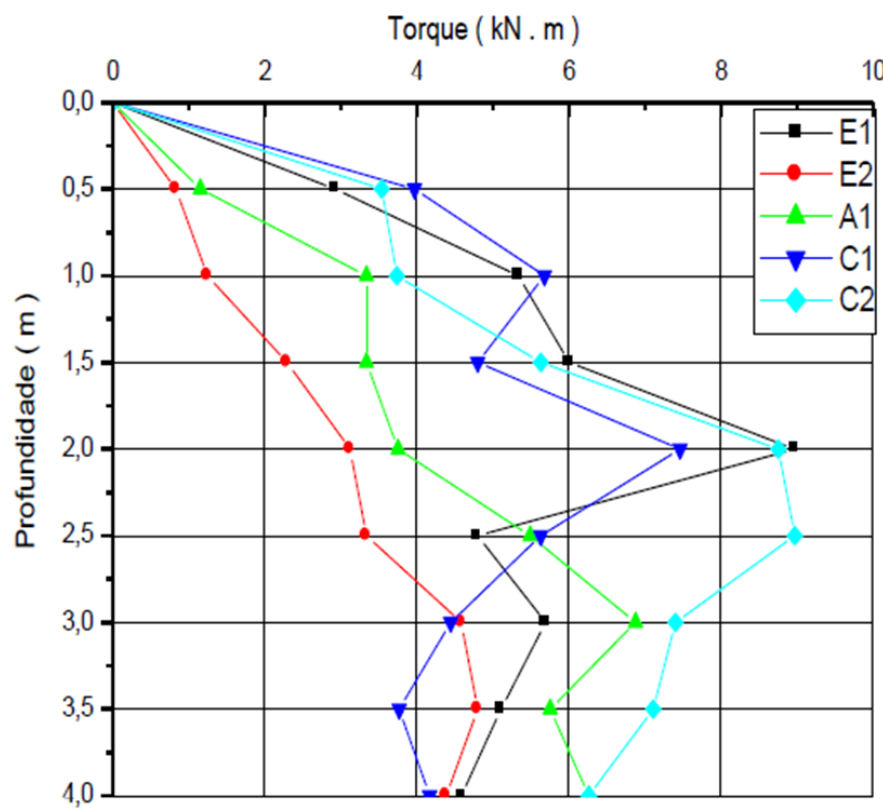

Gráfico 3 - Torques registrados em todas as estacas instaladas ao longo da profundidade de instalação. 
Pode-se observar que o torque obtido na profundidade de $2 \mathrm{~m}$ na instalação das estacas E1, C1 e C2 é maior em relação ao resto das estacas.

Para as estacas helicoidais convencionais E1 e E2, observa-se, no Gráfico 3, que foi necessário menor torque para se instalar a estaca E2 até 3,5 metros de profundidade, e, ao final da instalação, os valores de torque se aproximam. Portanto, esta variabilidade deve ser levada em conta no momento de analisar e comparar os resultados de provas de carga.

\subsubsection{Relações entre Torque de Instalação e o $N_{S P T}$}

O valor de torque de instalação de uma estaca helicoidal varia de acordo com o perfil do solo, quanto mais resistente for a camada de solo atravessada pelas hélices, maior será o torque aplicado para atravessá-la. Portanto, este valor de torque geralmente apresenta correlação com resultados de outros métodos de investigação de campo como, por exemplo, os ensaios SPT ou CPT.

Na Tabela 13, é apresentado o resultado da razão entre o valor de torque e o valor de $\mathrm{N}_{\mathrm{SPT}}$ obtido a cada metro de penetração. Nesta Tabela, foram usados os resultados da sondagem SPT SP-01. O Gráfico 4 apresenta os resultados desta razão $T / N_{S P T}$, ao longo da profundidade do terreno.

Tabela 13 - Resultados da razão entre torque de instalação e o $\mathrm{N}_{S P T}$ (SP-01)

\begin{tabular}{cccccc}
\hline \multicolumn{5}{c}{ Torques de Instalação (kN.m) / $\mathbf{N}_{\text {SPT }}$} \\
\hline Profund.(m) & E-1 & E-2 & A-1 & C-1 & C-2 \\
$\mathbf{1}$ & 0,87 & 0,20 & 0,54 & 0,61 & 0,71 \\
$\mathbf{2}$ & 0,83 & 0,29 & 0,35 & 0,52 & 0,59 \\
$\mathbf{3}$ & 0,55 & 0,50 & 0,75 & 0,80 & 0,47 \\
$\mathbf{4}$ & 0,50 & 0,47 & 0,68 & 0,68 & 0,76 \\
\hline
\end{tabular}




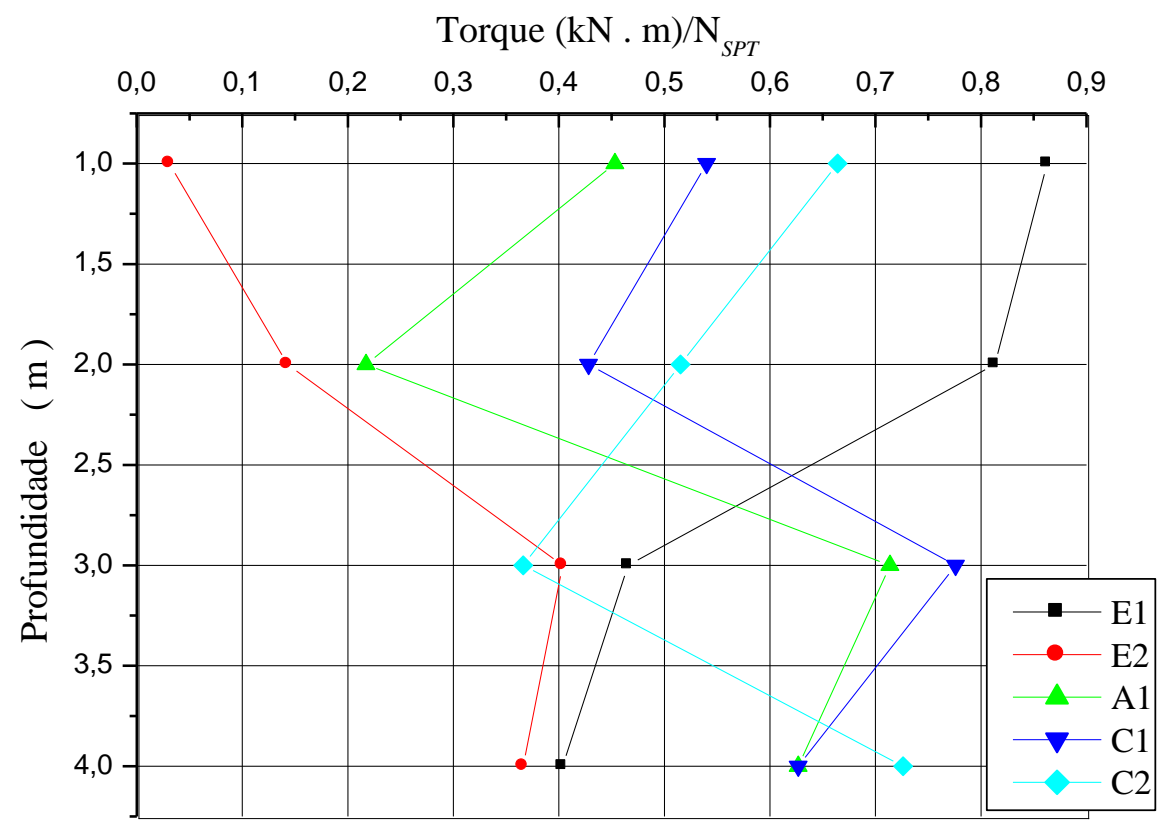

Gráfico 4 - Relação Torque/N $\mathrm{N}_{S P T}(\mathrm{SP}-01)$ e profundidade de instalação para as cinco estacas instaladas.

Nos resultados exibidos no Gráfico 4, nota-se que para os primeiros 3 metros não existe uma correlação entre o valor e o torque para instalar a estaca e o valor do $N_{S P T}$ do terreno. Isto ocorreu devido à variabilidade do solo até a profundidade de 3 metros, mostrada no Gráfico 3, pela variabilidade nos valores de torque de instalação. Porém, a partir de 3 metros, a razão entre o torque e $N_{S P T}$ tende a ser mais próxima para todas as estacas.

\subsection{Provas de Carga à Tração}

\subsubsection{Resultados}

Foram realizadas cinco provas de carga rápida de tração (conforme a Tabela 14), de acordo com a NBR 12131 (2006). O carregamento foi aplicado em estágios, sendo realizadas leituras dos deslocamentos a cada cinco minutos, independentemente da ocorrência da estabilização. 
Tabela 14 - Ensaios realizados à Tração

\begin{tabular}{cc}
\hline Estaca & Tipo de Estaca \\
\hline E1 & Convencional \\
E2 & Convencional \\
C1 & Injetada \\
C2 & Injetada (com rotação no final) \\
A1 & Fuste com argamassa \\
\hline
\end{tabular}

Na Tabela 15, é apresentado um resumo da carga máxima aplicada e o deslocamento máximo para cada estaca ensaiada.

Tabela 15 - Cargas e deslocamentos máximos das provas de carga à tração.

\begin{tabular}{ccc}
\hline Estaca & $\begin{array}{c}\text { Carga Máxima } \\
\text { Aplicada }(\mathbf{k N})\end{array}$ & $\begin{array}{c}\text { Deslocamento } \\
\text { Máximo (mm) }\end{array}$ \\
\hline E1 & 63 & 36,80 \\
E2 & 78 & 38,28 \\
A1 & 150 & 38,39 \\
C1 & 145 & 38,83 \\
C2 & 130 & 44,03 \\
\hline
\end{tabular}

Nos Gráficos 5 a 10, são apresentadas as curvas carga aplicada versus deslocamentos das cinco provas de carga à tração. 


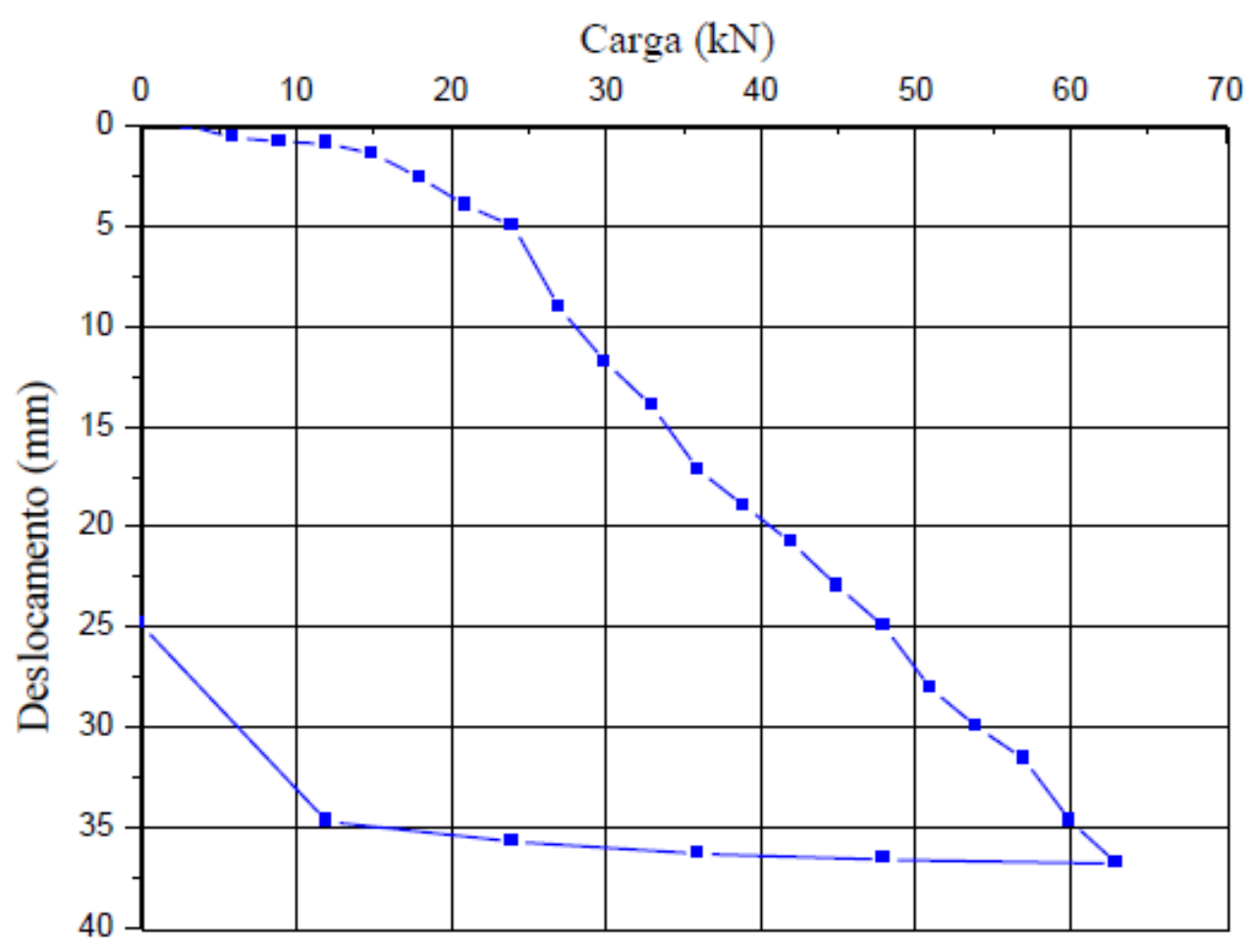

Gráfico 5 - Carga x deslocamento da prova de carga na estaca E1.

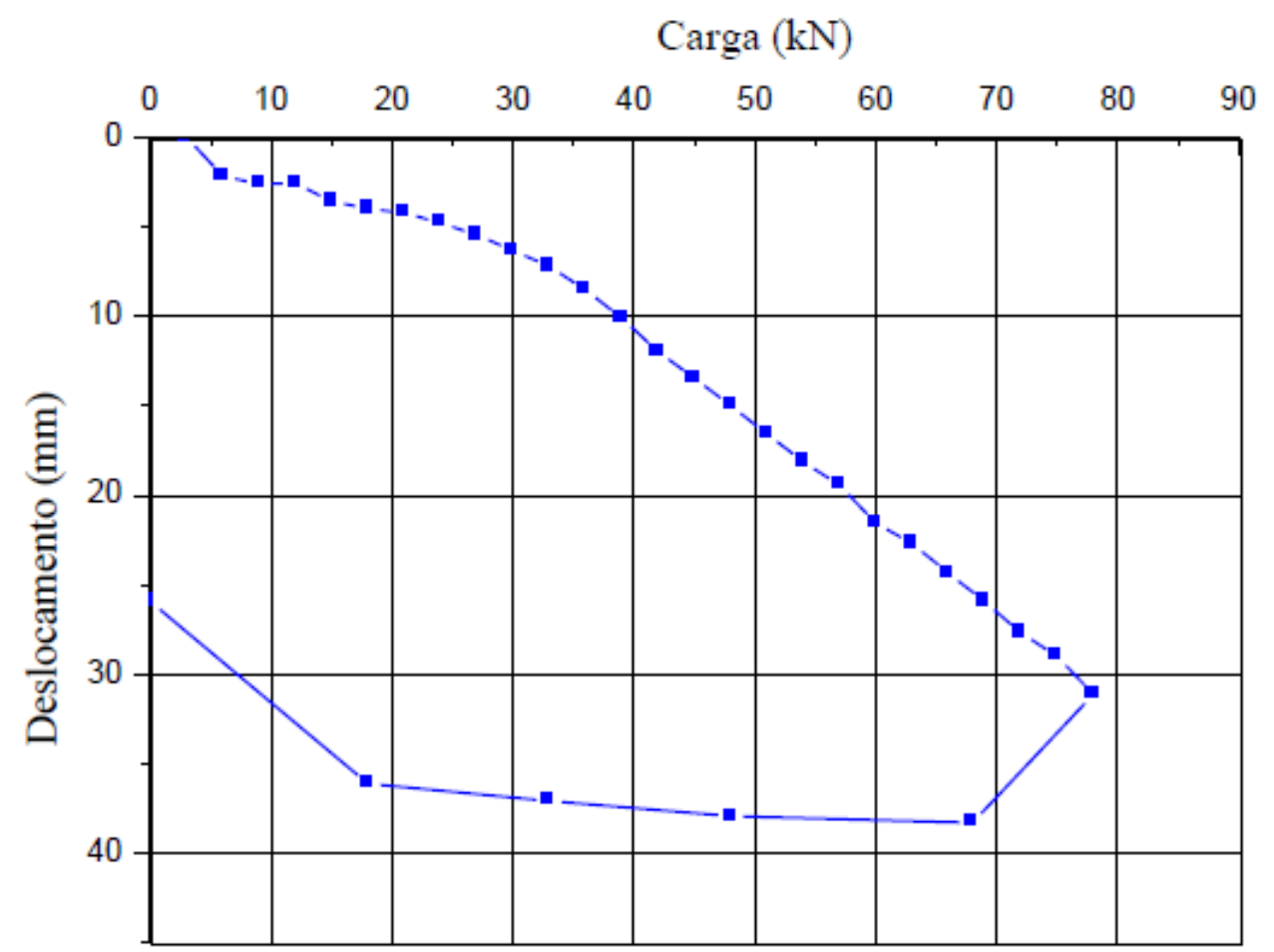

Gráfico 6 - Curva carga x deslocamento da prova de carga na estaca E2. 


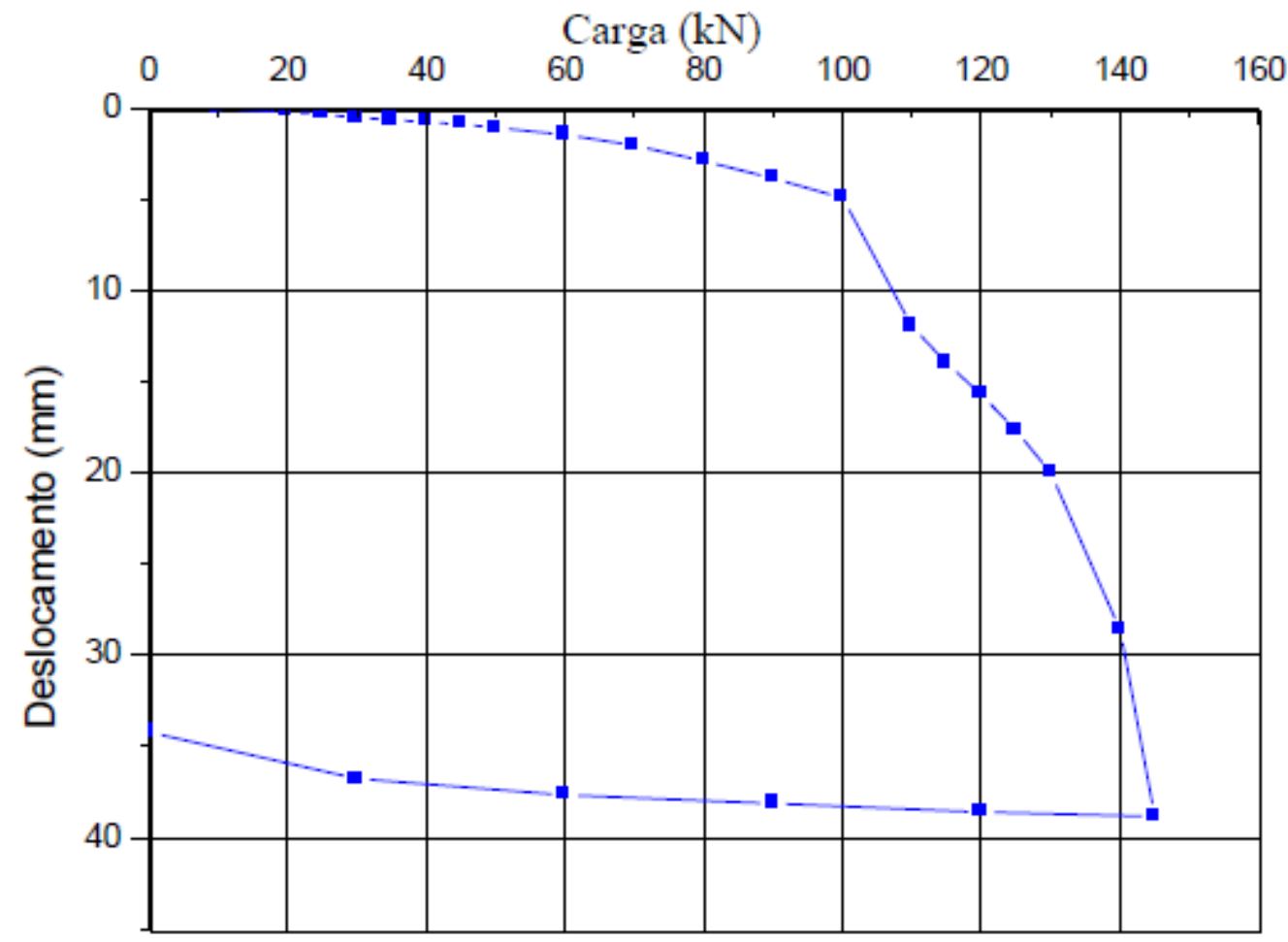

Gráfico 7 - Curva carga x deslocamento da prova de carga na estaca C1.

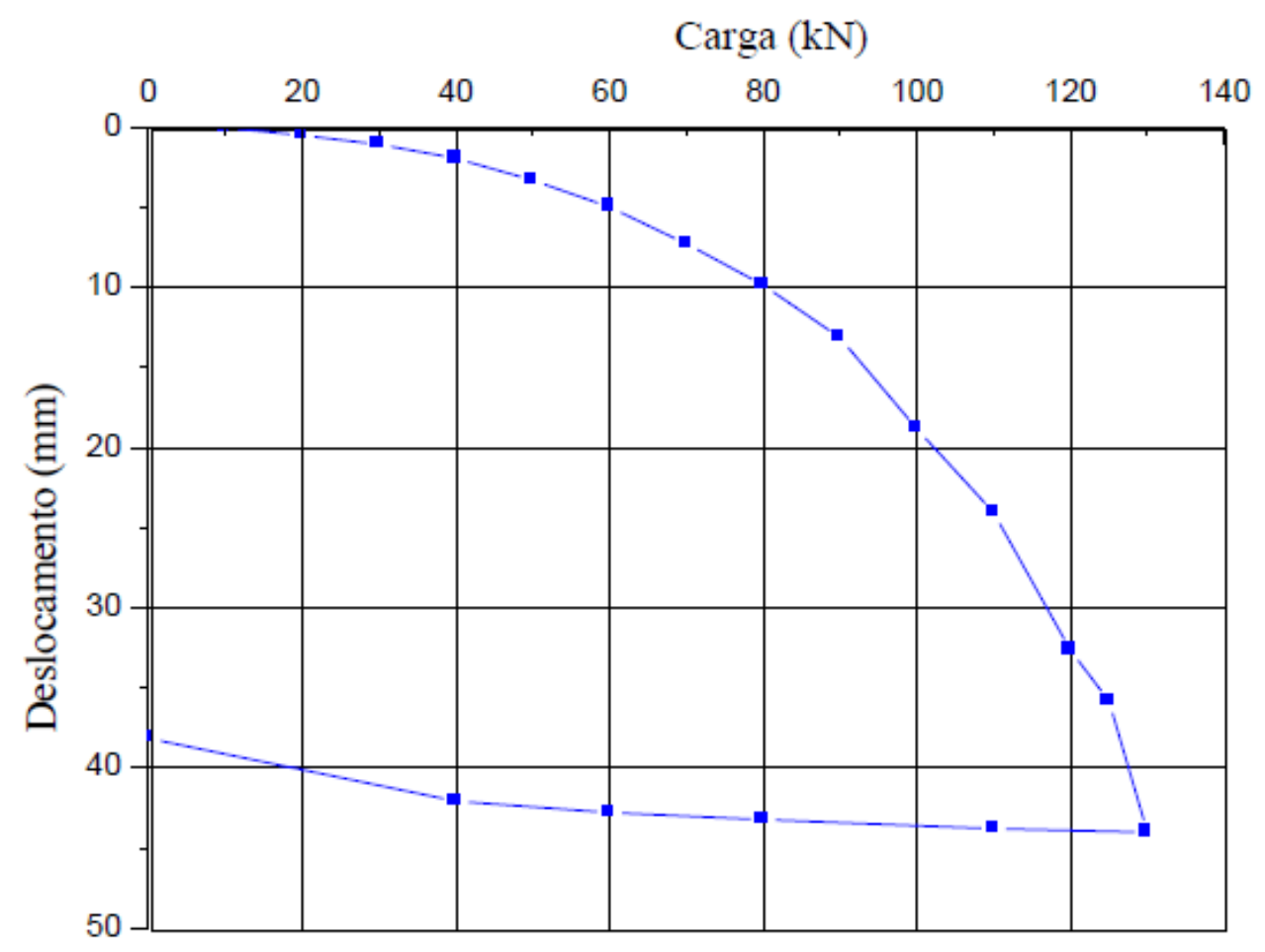

Gráfico 8 - Curva carga x deslocamento da prova de carga na estaca C2. 


\section{Carga $(\mathrm{kN})$}

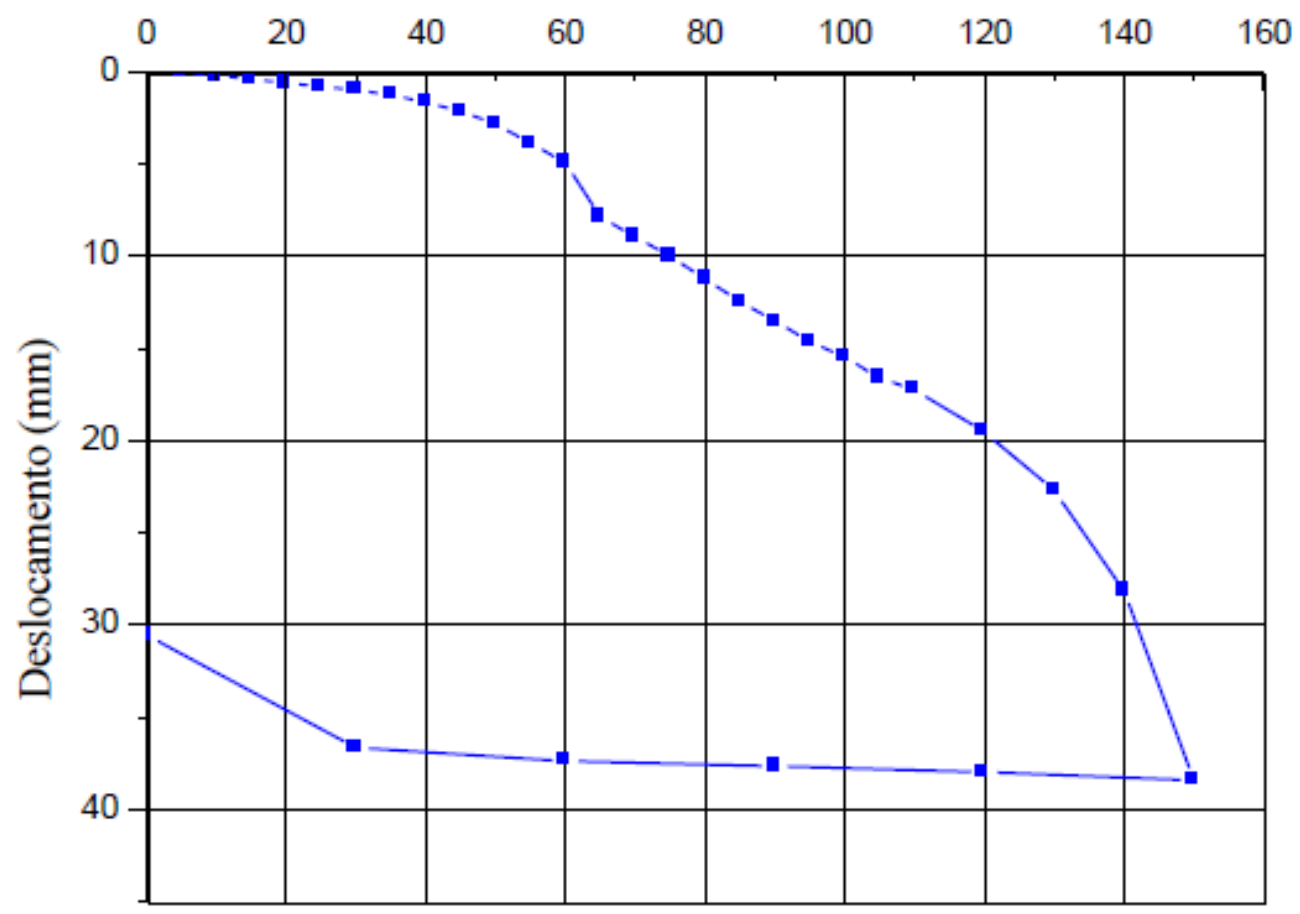

Gráfico 9 - Curva carga x deslocamento da prova de carga na estaca A1.

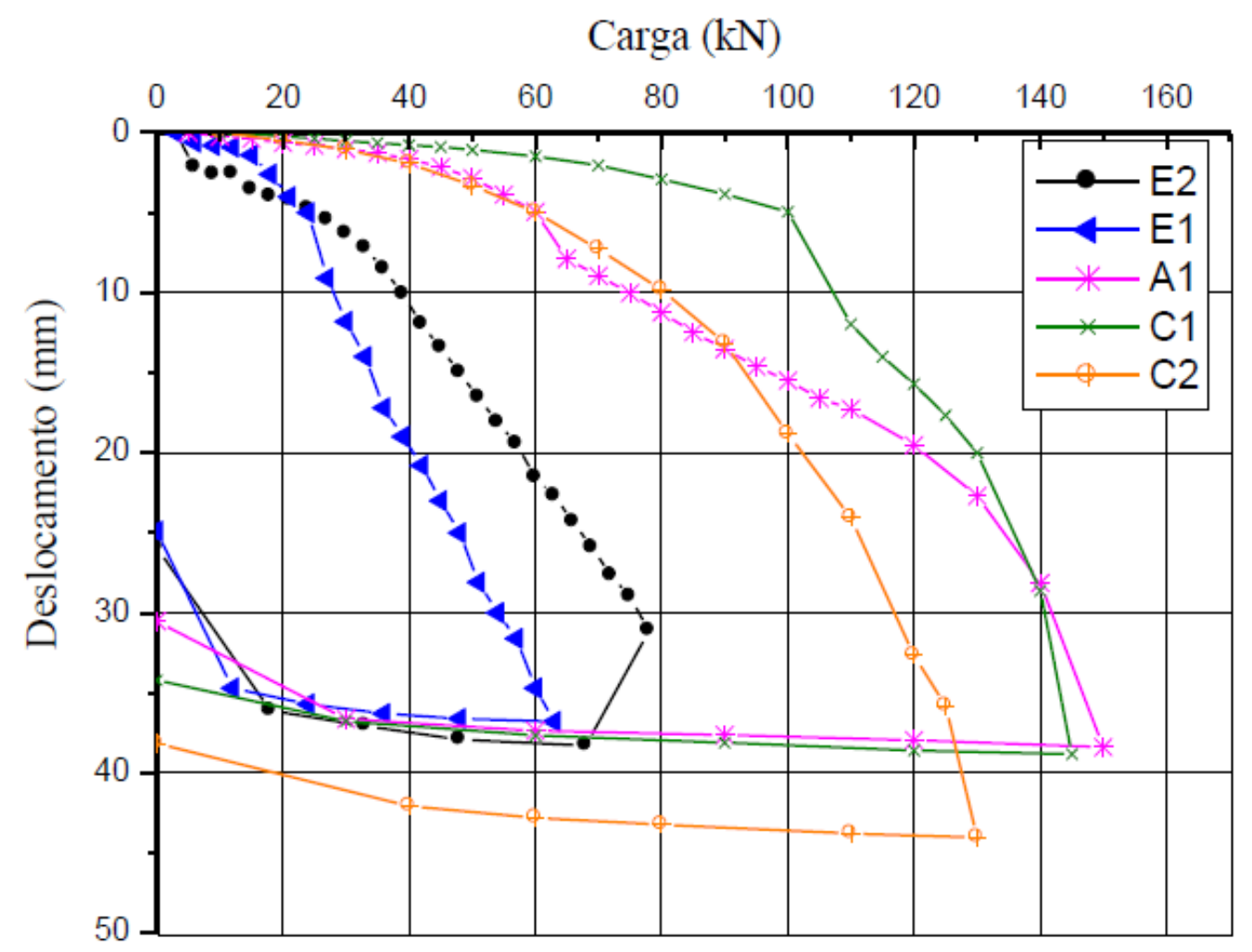

Gráfico 10 - Curva carga x deslocamento de todas as estacas ensaiadas à tração. 
Como mostra o Gráfico 10, das cinco provas de cargas realizadas, pode-se observar que a estaca $\mathrm{C} 1$ apresentou melhor comportamento, seguida pela estaca A1. No entanto, as três estacas melhoradas (A1, C1 e C2) apresentam capacidade de carga à tração superior às estacas helicoidais convencionais (E1 e E2).

\subsubsection{Interpretação das Provas de Carga}

Na presente interpretação de curvas de provas de carga à tração das estacas helicoidais, foi usado o critério de ruptura convencional adotado por Zhang (1999). Neste critério, os valores de capacidade de carga à tração das estacas correspondem ao deslocamento do topo da estaca igual a $10 \%$ do diâmetro médio das hélices (critério de Terzaghi, 1942). Neste trabalho também foi usado o critério de ruptura convencional da NBR 6122 (2010). A Tabela 16 apresenta os resultados obtidos por estes critérios.

Tabela 16 - Resultados das provas de carga à tração realizados

\begin{tabular}{cccc}
\hline No. & Estaca & NBR 6122 (kN) & $\begin{array}{c}\text { 10\% Dmédio das } \\
\text { hélices }(\mathbf{k N})\end{array}$ \\
\hline $\mathbf{1}$ & E1 & 22,5 & 49 \\
$\mathbf{2}$ & E2 & 29 & 72 \\
$\mathbf{3}$ & C1 & 90 & 137 \\
$\mathbf{4}$ & C2 & 60 & 111 \\
$\mathbf{5}$ & A1 & 60 & 135 \\
\hline
\end{tabular}

Observa-se, pelos resultados da Tabela 16, que tanto as estacas injetadas (C1 e C2) quanto a estaca com fuste preenchido de argamassa (A1) tiveram a capacidade de carga à tração aumentada consideravelmente, comparadas às estacas convencionais (E1 e E2).

Para avaliar esta melhoria, optou-se, neste trabalho, por utilizar os resultados de capacidade de carga interpretados pelo critério $\mathrm{D} / 10$, por ser o mais utilizado na literatura para estacas helicoidais à tração. Deste modo, para se comparar os resultados de capacidade de cargas das estacas helicoidais convencionais com as das estacas melhoradas, adotou-se, como 
valor de capacidade de carga à tração, o valor médio igual a $61 \mathrm{kN}$ para as estacas E1 e E2. A partir deste valor, a Tabela 17 apresenta o ganho percentual em capacidade de carga à tração das estacas melhoradas.

Tabela 17 - Ganho em capacidade de carga a tração $\left(Q_{u}\right)$

\begin{tabular}{ccc}
\hline Estaca & Tipo de estaca & Ganho em $\mathrm{Q}_{\mathrm{u}}(\%)$ \\
\hline C1 & Injetada & $137 / 61=225 \%$ \\
C2 & Injetada (com rotação no final) & $111 / 61=182 \%$ \\
A1 & Preenchida com argamassa & $135 / 61=221 \%$ \\
\hline
\end{tabular}

Como mostra a Tabela 17, o ganho na capacidade de carga da estaca A1 foi semelhante ao caso da estaca $\mathrm{C} 1$. No entanto, observando-se a rigidez inicial das curvas de provas de carga (Gráfico 10), a resposta da estaca injetada $\mathrm{C} 1$, para deslocamentos de até $5 \mathrm{~mm}$, foi bem superior ao da estaca A1.

Este resultado pode ser compreendido com o auxílio dos dados da exumação da estaca C1 (Figura 48). Na estaca C1, parte da calda da injeção subiu pelo vazio criado pela trajetória das hélices no terreno, preenchendo e melhorando o solo acima da hélice, e outra parte ficou abaixo da hélice da ponta. Deste modo, a injeção além de criar um tipo de fuste (solo+calda) na haste da estaca (preenchimento do caminho atravessado pela hélice), o solo acima de cada hélice foi melhorado, aumentando-se também a parcela de capacidade de carga das hélices, consequentemente aumentando a rigidez do sistema na parte inicial da curva carga $\mathrm{x}$ deslocamento. Na curva da estaca $\mathrm{C} 1$, nota-se que a estaca deslocou pouco até um carregamento em torno de $100 \mathrm{kN}$, após este estágio de carga, em torno de $140 \mathrm{kN}$, as curvas das estacas A1 e C1 se encontram. Já no caso da estaca A1, apesar do fuste criado ser maciço de argamassa, não foram feitas melhoras no solo acima das hélices para aumentar a parcela de capacidade de carga das hélices. Além disso, foi também criado um fuste de solo-calda na estaca C1.

$\mathrm{O}$ aumento na capacidade de carga foi maior na estaca $\mathrm{C} 1$ que na $\mathrm{C} 2$, devido à diferença no procedimento de injeção. Na estaca $\mathrm{C}$ 1, a calda subiu preenchendo e melhorando o solo acima das hélices. Já no caso da estaca C2, com a rotação na estaca, a calda de cimento misturou-se com o solo e não subiu pelo vazio causado pela trajetória das hélices durante a instalação. Neste caso, a capacidade de carga foi inferior comparada ao caso da C1, em que a nata preencheu os vazios de solo perturbado pela instalação da hélice. 


\subsubsection{Estimativas da Capacidade de Carga}

Para estimar a capacidade de carga à tração de estacas helicoidais pelos métodos apresentados no capítulo da revisão bibliográfica, além dos parâmetros de solo são necessárias as dimensões das estacas, que são apresentadas na Tabela 18.

Tabela 18 - Características das estacas ensaiadas

\begin{tabular}{|c|c|c|c|}
\hline Descrição & Símbolo & Unidade & Valores \\
\hline Passo das hélices & $\mathrm{P}$ & $\mathrm{m}$ & 0,075 \\
\hline Diâmetro do fuste & $\mathrm{d}$ & $\mathrm{m}$ & 0,073 \\
\hline Profundidade da primeira hélice & H1 & $\mathrm{m}$ & 2,48 \\
\hline Profundidade da segunda hélice & $\mathrm{H} 2$ & $\mathrm{~m}$ & 3,24 \\
\hline Profundidade da terceira hélice & H3 & $\mathrm{m}$ & 3,85 \\
\hline Diâmetro da primeira hélice & D1 & $\mathrm{m}$ & 0,305 \\
\hline Diâmetro da segunda hélice & D2 & $\mathrm{m}$ & 0,254 \\
\hline Diâmetro da terceira hélice & D3 & $\mathrm{m}$ & 0,203 \\
\hline Distância entre hélices H1-H2 & $\mathrm{H} 1-\mathrm{H} 2$ & $\mathrm{~m}$ & 0,76 \\
\hline Distância entre hélices H2-H3 & $\mathrm{H} 2-\mathrm{H} 3$ & $\mathrm{~m}$ & 0,61 \\
\hline Comprimento do fuste após as hélices & Ls & $\mathrm{m}$ & 0,15 \\
\hline Área da primeira hélice & A1 & $\mathrm{m}^{2}$ & 0,069 \\
\hline Área da segunda hélice & $\mathrm{A} 2$ & $\mathrm{~m}^{2}$ & 0,046 \\
\hline Área da terceira hélice & A3 & $\mathrm{m}^{2}$ & 0.028 \\
\hline Altura efetiva de adesão/atrito na haste & $\mathrm{H}_{\mathrm{ef}}$ & $\mathrm{m}$ & 2,48 \\
\hline Tensão efetiva $\mathrm{H} 1$ & $\mathrm{q} 1$ & $\mathrm{kN} / \mathrm{m}^{2}$ & 44,64 \\
\hline Tensão efetiva H2 & $\mathrm{q} 2$ & $\mathrm{kN} / \mathrm{m}^{2}$ & 58,32 \\
\hline Tensão efetiva H3 & q3 & $\mathrm{kN} / \mathrm{m}^{2}$ & 69,30 \\
\hline $\begin{array}{l}\text { Relação entre a profundidade e o diâmetro } \\
\text { da primeira hélice }\end{array}$ & H1/D1 & - & 8,13 \\
\hline Diâmetro médio das hélices & $\mathrm{D}_{\mathrm{a}}$ & $\mathrm{m}$ & 0,254 \\
\hline Área da hélice com diâmetro médio & $\mathrm{Aa}$ & $\mathrm{m}^{2}$ & 0,046 \\
\hline Área efetiva da haste $\left(\boldsymbol{\pi} \boldsymbol{d} \boldsymbol{H}_{\boldsymbol{e f}}\right)$ & $\mathrm{A}_{\mathrm{f}}$ & $\mathrm{m}^{2}$ & 0,569 \\
\hline $\begin{array}{l}\text { Área do cilindro formado entre hélices } \\
\boldsymbol{A}_{\boldsymbol{c i l}}=\boldsymbol{\pi} \boldsymbol{D}_{\boldsymbol{a}}\left(\boldsymbol{H}_{\mathbf{1}}-\boldsymbol{H}_{\mathbf{3}}\right)\end{array}$ & $\mathrm{A}_{\text {cil }}$ & $\mathrm{m}^{2}$ & 1,09 \\
\hline
\end{tabular}




\subsubsection{Estacas Helicoidais Convencionais}

As capacidades de carga à tração das estacas helicoidais convencionais (E1 e E2) ensaiadas nesta pesquisa foram estimadas usando os métodos das capacidades individuais, do cilindro de cisalhamento e de Silva (2014). Os resultados destas estimativas são apresentados na Tabela 19.

As estacas helicoidais ensaiadas foram fabricadas com um espaçamento entre as hélices igual a três vezes o diâmetro da menor hélice, o que favorece que a mobilização das cargas aplicadas ocorra individualmente acima de cada hélice. No entanto, o método do cilindro de cisalhamento também foi avaliado nesta pesquisa.

Tabela 19 - Valores estimados e medidos da capacidade de carga à tração das estacas E1 e E2.

\begin{tabular}{|c|c|c|c|c|c|c|c|}
\hline Estaca & $\begin{array}{c}\text { Método 1 } \\
\text { (Capacidades } \\
\text { individuais) } \\
(\mathbf{k N})\end{array}$ & $\begin{array}{l}\text { Método } 2 \\
\text { (Ruptura } \\
\text { cilindro) } \\
(\mathbf{k N})\end{array}$ & $\begin{array}{c}\text { Método } 3 \\
\text { (Silva, } \\
\text { 2014) }\end{array}$ & $\begin{array}{c}\text { Valor } \\
\text { medido } \\
Q_{\text {u medido }} \\
(\mathbf{k N})\end{array}$ & $\begin{array}{c}\mathbf{Q}_{\text {met1 }} / \\
\mathbf{Q}_{\text {medido }}\end{array}$ & $\begin{array}{l}\mathbf{Q}_{\text {met2 }} / \\
\mathbf{Q}_{\text {medido }}\end{array}$ & $\begin{array}{l}\mathbf{Q}_{\text {met3 }} / \\
\mathbf{Q}_{\text {medido }}\end{array}$ \\
\hline E1 & 101,4 & 79,5 & 62 & 49 & 2,1 & 1,6 & 1,3 \\
\hline E2 & 101,4 & 79,5 & 62 & 72 & 1,4 & 1,1 & 0,9 \\
\hline
\end{tabular}

Para estimativa da capacidade de carga na Tabela 19 pelos métodos 1 e 2, foram utilizados os parâmetros de solo estimados por meio de correlações com os valores do $\mathrm{N}_{\mathrm{SPT}}$ na profundidade das hélices. Foi considerada a hipótese de cálculo para solo arenoso. Nota-se que os resultados calculados foram bem superiores aos valores medidos, principalmente pelo método 1. Os valores calculados foram superestimados, já que as previsões foram feitas com parâmetros de solo intacto e não do solo perturbado após instalação.

Para o caso da estaca E1, os resultados calculados pelo método 2 foram superiores aos medidos, e para a estaca E2, os resultados calculados foram próximos aos medidos. Esta diferença nos valores medidos é devida à variabilidade do terreno, observada pelos valores de torque de instalação.

No entanto, resultado do método 3 mostrado na Tabela 19 (método semi-empírico que correlaciona a capacidade de carga das hélices diretamente com os valores de NSPT, proposto em Silva 2014), mostrou-se mais próximo dos valores medidos, sendo que o valor médio 
medido nos ensaios realizados nas duas estacas idênticas é igual a $61 \mathrm{kN}$, e o método de Silva (2014) resultou no valor de capacidade de carga de $62 \mathrm{kN}$.

\subsubsection{Estacas Helicoidais com Fuste de Argamassa}

O valor de capacidade de carga das hélices da estaca A1 adotado para se avaliar separadamente o cálculo de resistência por atrito lateral no fuste de argamassa é o valor médio medido nas provas de carga das estacas E1 e E2 $(61 \mathrm{kN})$. Este valor é praticamente o mesmo estimado por Silva (2014) para a capacidade de carga das hélices. Para a resistência por atrito lateral no fuste de argamassa foi utilizado o método de Gouvenot (Li, 2006) e o método de Decourt Quaresma (1996) para estaca escavada.

As dimensões do fuste de argamassa para o cálculo da resistência por atrito lateral foram obtidas em campo após a exumação da estaca (diâmetro médio de fuste de 0,23m e comprimento de $2,0 \mathrm{~m})$.

Tabela 20 - Valores estimados e medidos da capacidade de carga à tração da estaca A1

\begin{tabular}{|c|c|c|c|c|c|}
\hline Estaca & $\begin{array}{c}\text { Parcela das } \\
\text { hélices } \\
\text { medida nas } \\
\text { provas de } \\
\text { carga }(k N)\end{array}$ & $\begin{array}{c}\text { Parcela } \\
\text { calculada de } \\
\text { atrito no } \\
\text { fuste de } \\
\text { argamassa } \\
(\mathbf{k N})\end{array}$ & $\begin{array}{l}\text { Valor } \\
\text { total } \\
Q_{u \text { cal }} \\
(k N)\end{array}$ & $\begin{array}{c}\text { Valor total } \\
\text { Medido } \\
Q_{u \text { med }} \\
\text { (critério } \\
\text { D/10) }\end{array}$ & $\begin{array}{c}\mathbf{Q}_{\mathrm{u} \text { cal }} / \\
\mathbf{Q}_{\mathbf{u} \text { medido }}\end{array}$ \\
\hline $\begin{array}{c}\text { A1 } \\
\text { (atrito lateral por } \\
\text { Gouvenot) }\end{array}$ & 61 & 13 & 75 & 135 & 0,56 \\
\hline $\begin{array}{c}\quad \mathbf{A 1} \\
\text { (atrito lateral } \\
\text { por Decourt } \\
\text { Qauresma) }\end{array}$ & 61 & 27 & 89 & 135 & 0,66 \\
\hline
\end{tabular}

A Tabela 20 mostra duas hipóteses para estimar a capacidade de carga da estaca A1. Os valores calculados de capacidade de carga pelos dois métodos estão bem abaixo dos valores medidos. 
Como o valor medido total de capacidade de carga da estaca A1 é de $135 \mathrm{kN}$, supõe-se que a resistência por atrito no fuste de argamassa seja aproximadamente a diferença entre o valor medido na estaca com fuste de argamassa $(135 \mathrm{kN})$ e o medido nas estacas convencionais $(61 \mathrm{kN})$. Neste caso esta parcela de atrito lateral medida seria em torno de 74 $\mathrm{kN}$. Porém os métodos de previsão propocionaram valores de 13 e $27 \mathrm{kN}$, bem inferiores ao possível valor medido. Ou seja, o valor medido do ganho na resistência por atrito lateral usando-se o fuste de argamssa foi superior aos valores estimados.

\subsubsection{Estacas Helicoidais Injetadas}

Antes da realização e exumação das estacas injetadas pretendíasse calcular a parcela de contribuição do bulbo para a capacidade de carga de estacas helicoidais, usando-se o método apresentado na revisão bibliográfica desta dissertação, feito para bulbo com geometria definida (Figura 22).

No entanto, o resultado da injeção na estaca C1, ilustrado na Figura 42 após a exumação da estaca, mostra que não é coerente fazer uma estimativa de capacidade de carga para esta estaca.

Como ilustrado nas Figuras 42, a calda de cimento da estaca C1 preencheu o vazio deixado pelas hélices durante a instalação, e como consequência placas de cimento espaçadas um passo de hélice entre si foram deixadas acima das hélices. Este fato melhorou a capacidade individual de cada hélice à tração por ter melhorado a qualidade do solo penetrado acima das hélices. Porém, não é possível quantificar adequadamente esta melhoria em um método de previsão de capacidade de carga.

Já na estaca C2, foi verificado um bulbo excêntrico abaixo da base da estaca, composto de uma mistura de solo e cimento (Figura 43), portanto também não é possível estimar adequadamente a capacidade de carga da estaca $\mathrm{C} 2$. 

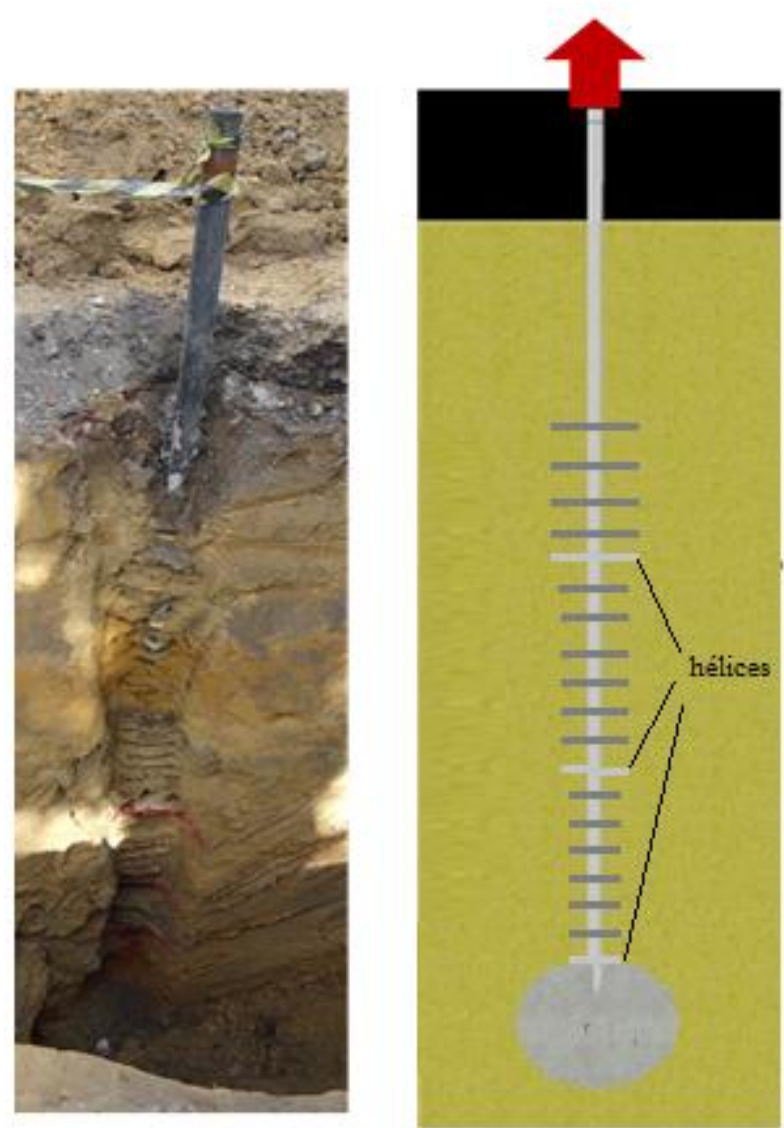

Figura 42- Preenchimento da injeção observado ao longo da estaca C1 após exumação.
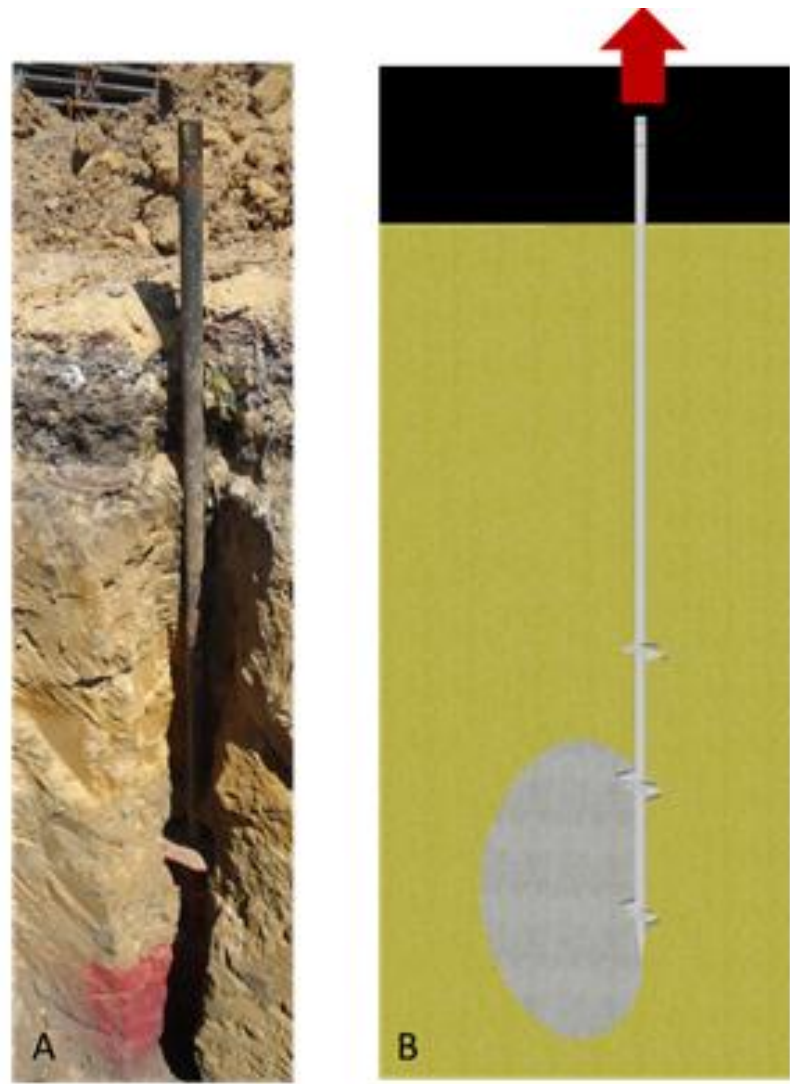

Figura 43- Preenchimento da injeção observado ao longo da estaca C2 após exumação. 


\subsubsection{Método do Torque de Instalação Para as Estacas Helicoidais Convencionais}

A relação entre o torque final de instalação e a capacidade de carga das estacas helicoidais, segundo Hoyt \& Clemence (1989), é baseada na seguinte equação:

$$
K_{t}=\frac{Q_{u}}{T}
$$

Para as estacas helicoidais convencionais (E1 e E2), os valores de $\mathrm{K}_{\mathrm{t}}$ encontrados são distintos e inferiores aos valores recomendados na literatura (Tabela 21). No entanto, deve-se considerar que os valores recomendados na literatura por Hoyt e Clemence (1989) são relativos à carga de ruptura física da estaca e não para uma carga equivalente a $10 \% \mathrm{D}$ como neste caso. Portanto, o valor de $\mathrm{K}_{\mathrm{t}}$ também varia de acordo com o critério de definição de capacidade de carga usado em sua estimativa.

As estacas ensaiadas na presente pesquisa tem o diâmetro da haste de $73 \mathrm{~mm} \mathrm{e}$, de acordo com as recomendações de Hoyt \& Clemence (1989), o valor de $\mathrm{K}_{\mathrm{t}}$ seria de $33 \mathrm{~m}^{-1}$, e, segundo Perko (2009), o valor de $\mathrm{K}_{\mathrm{t}}$ seria $28 \mathrm{~m}^{-1}$. Estes valores inferiores aos da literatura também foram observados em Silva (2014), em estacas helicoidais instaladas em solos residuais estruturados, onde também considerou-se como capacidade de carga o valor equivalente a um deslocamento de $10 \%$ do diâmetro médio das hélices.

Os valores de $\mathrm{K}_{\mathrm{t}}$ mostrados na Tabela 21 são bem distintos para duas estacas de geometria idêntica, instaladas na mesma profundidade e mesmo terreno. No entanto, as diferenças nos valores de torque de instalação destas estacas ao longo da profundidade (Gráfico 3) mostra grande variabilidade horizontal deste terreno até a profundidade de 3 metros. Como ambas as estacas são curtas (4 metros de embutimento no terreno), esta variabilidade é provavelmente responsável pelas diferenças nos valores de capacidade de carga. No entanto, como os valores de torque final de instalação das duas estacas, medidos na profundidade de 4 metros, são próximos, e os valores de capacidade de carga bem distintos, os valores de $\mathrm{K}_{\mathrm{t}}$ (capacidade de carga/ torque final de instalação) ficou 35\% maior para a estaca E2 
Tabela 21 - Valores de Kt das estacas helicoidais ensaiadas à tração no presente projeto

\begin{tabular}{ccccc}
\hline Estaca & $\begin{array}{c}\text { Diâmetro das } \\
\text { hélices }(\mathbf{c m})\end{array}$ & $\mathbf{Q}_{\mathbf{u}}(\mathbf{k N})$ & Torque $(\mathbf{k N . m})$ & $\mathbf{K t}\left(\mathbf{m}^{-1}\right)$ \\
\hline E1 & $20 / 25 / 30$ & 49 & 2,98 & \\
E2 & $20 / 25 / 30$ & 72 & 2,85 & 25,3 \\
\hline
\end{tabular}

\subsection{Comparações entre Capacidade de Carga à Tração e à Compressão}

Após a realização dos ensaios de tração nas estacas, foram realizados ensaios de compressão para verificar a melhoria no comportamento à compressão das estacas helicoidais com injeção e fuste de argamassa.

No entanto, como as estacas foram deslocadas para cima ao final dos ensaios de tração, nos ensaios de compressão ocorreu um grande deslocamento inicial com pouca carga aplicada. A Figura 48 ilustra o vazio acima das hélices deixado após o ensaio de compressão em uma das estacas. O mesmo vazio deve ter ocorrido embaixo das hélices após o ensaio de tração.

No caso da estaca helicoidal convencional E1 (Gráfico 11), a estaca "subiu” 25mm ao final do ensaio de tração, e após um primeiro ciclo de carregamento em compressão (deslocando $17 \mathrm{~mm}$ para baixo), a estaca E1 apresenta melhora em seu comportamento, já que a hélice inferior se apoia em solo natural (o solo solicitado na tração é o solo acima da hélice, perturbado pela instalação).

Neste caso, o segundo ciclo é mais representativo do comportamento à compressão da estaca E1. Na compressão, solicita-se o solo não perturbado abaixo da primeira hélice, por isso o comportamento é melhor do que em tração, como mostra a inclinação final. 


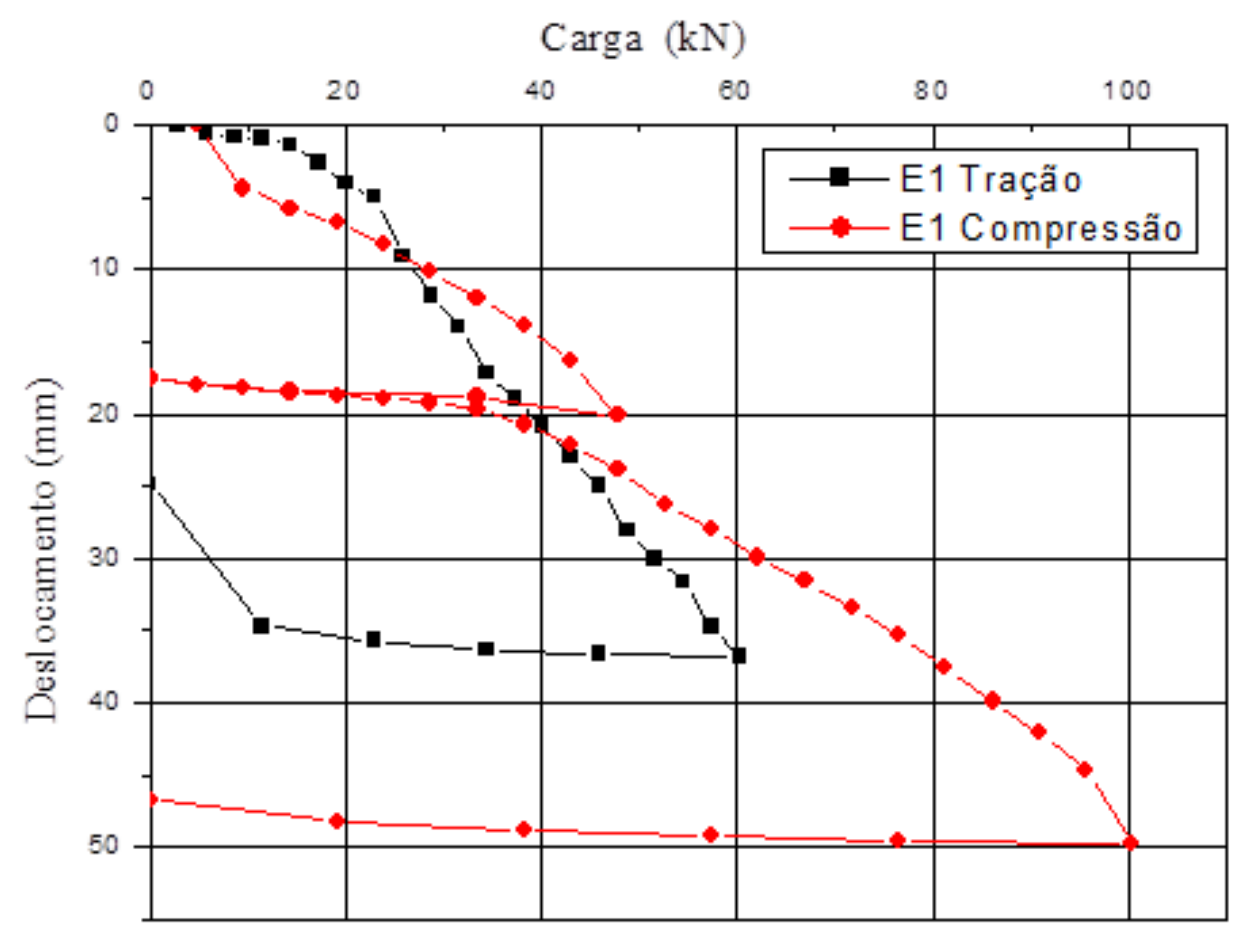

Gráfico 11 - Curva carga x deslocamento dos ensaios na estaca E1 (convencional).

O comportamento à compressão da estaca A1 (fuste de argamassa) do mesmo modo é melhor representado no segundo ciclo da curva do ensaio de compressão, nota-se que os valores da capacidade de carga (pelo critério D/10) à compressão são um pouco maiores que os valores da capacidade de carga à tração, como esperado.

No primeiro ciclo de compressão na estaca A1 nota-se que após a mobilização da resistência por atrito no fuste de graute (carregamento em torno de $25 \mathrm{kN}$ ), a curva apresenta um grande deslocamento que provavelmente representa os $25 \mathrm{~mm}$ que as hélices deslocaram para cima no ensaio de tração.

Pelos Gráficos 13 e 14, nota-se que, no primeiro ciclo de compressão, após serem tracionadas, as duas estacas com injeção, $\mathrm{C} 1$ e $\mathrm{C} 2$, tiveram um comportamento bem ruim. Após os ensaios de tração, provavelmente foram deixados espaços vazios abaixo dos bulbos e, além disso, pode ter ocorrido fratura da calda de cimento injetada. Portanto, o resultado de capacidade de carga à compressão no primeiro ciclo foi bem inferior à capacidade de carga à tração. 
No entanto, observa-se, no segundo ciclo de ensaio de compressão nas estacas injetadas, que a compactação ocorrida no primeiro ciclo proporcionou aumento da capacidade de carga. Este aumento foi bem mais significativo para estaca C1 (Gráfico 13).

Porém, tanto para a estaca $\mathrm{C} 1$ quanto para a C2, o pré-ensaio de tração modificou o sistema estaca-bulbo, portanto os ensaios de compressão desta pesquisa não são adequados para avaliar o comportamento à compressão da estaca helicoidal com injeção de cimento.

Portanto, não foi possível neste trabalho avaliar adequadamente a melhoria de estacas helicoidais injetadas e com fuste de argamassa em relação às estacas convencionais no caso de compressão. Por esta razão, os resultados dos ensaios à compressão estão separados no Apêndice A desta dissertação

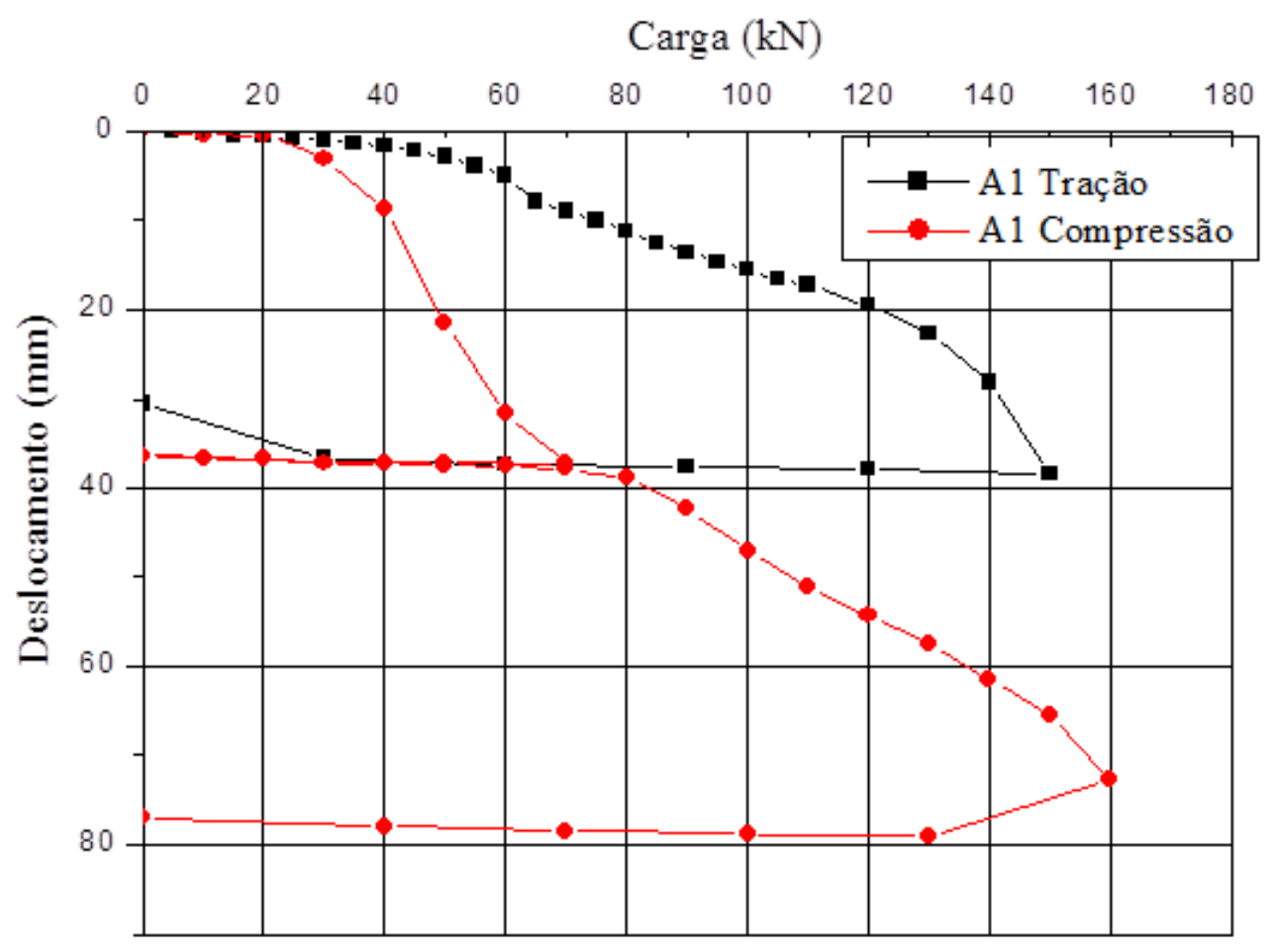

Gráfico 12 - Curva carga x deslocamento dos ensaios na estaca A1 (fuste de argamassa). 


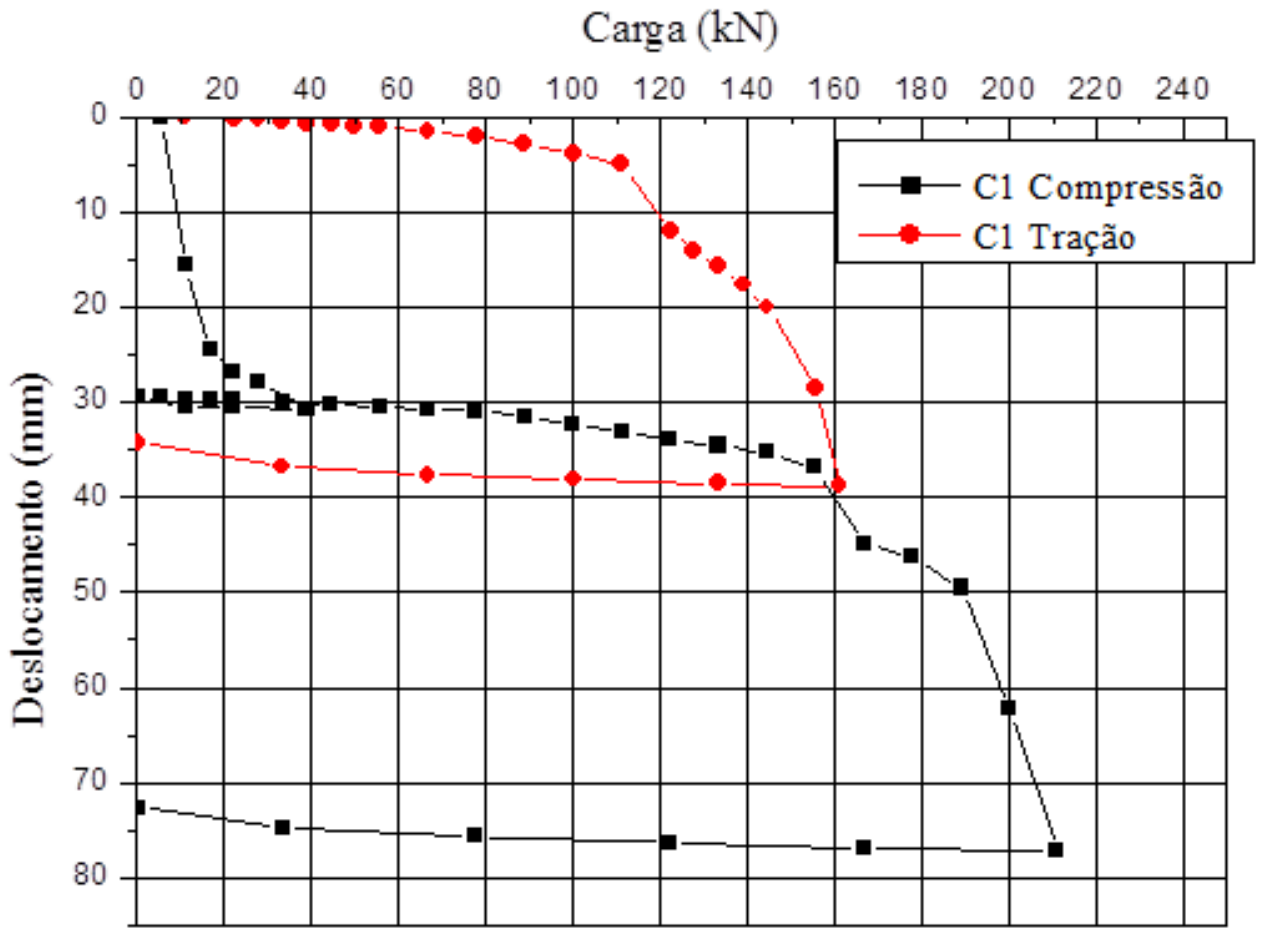

Gráfico 13 - Curva carga x deslocamento dos ensaios na estaca C1 (injeção sem rotação).

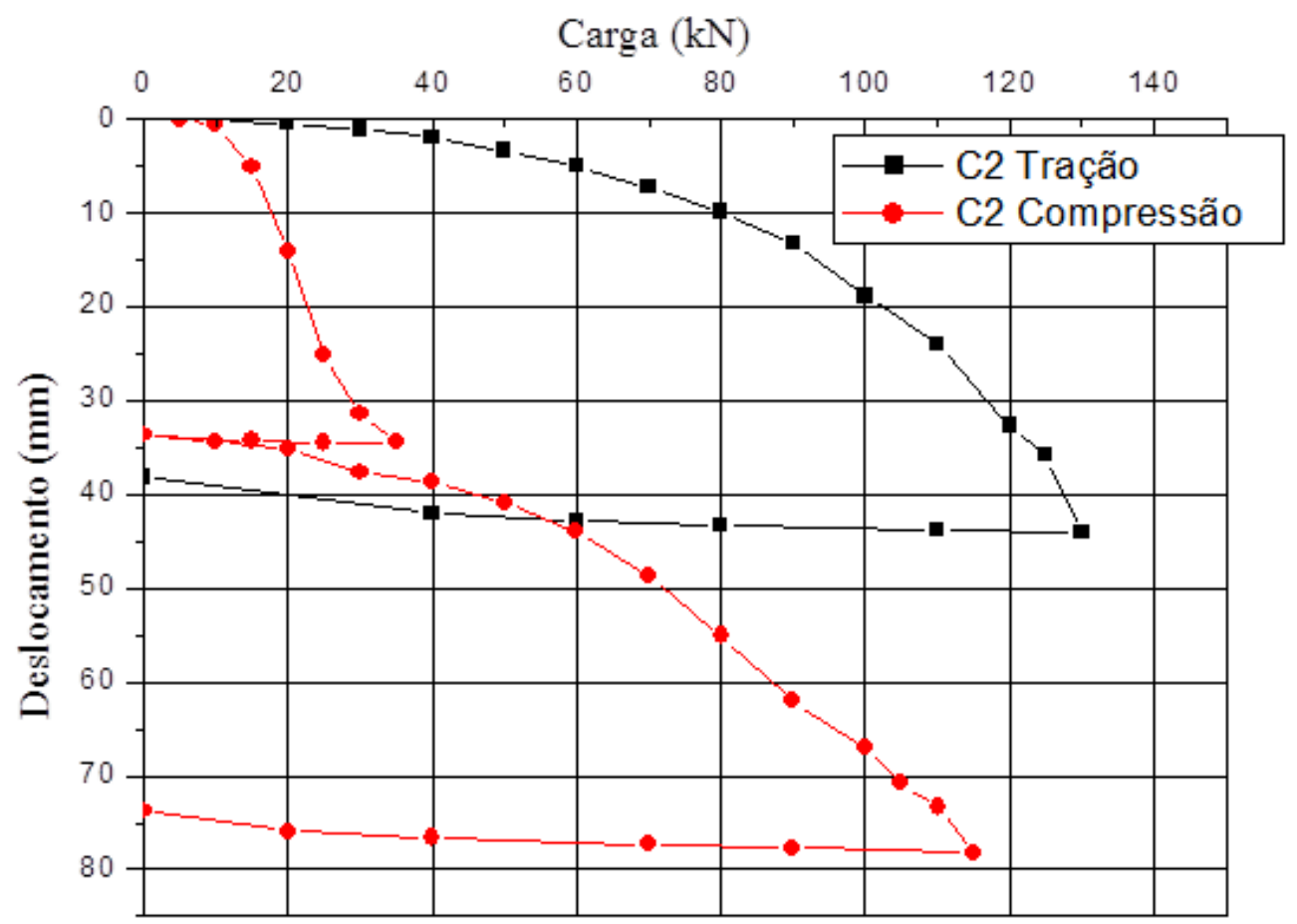

Gráfico 14 - Curva carga x deslocamento dos ensaios na estaca C2 (injeção com rotação). 
A Tabela 22 mostra uma comparação entre os resultados de capacidade de carga à tração e à compressão (obtida no $2^{\circ}$ ciclo) das estacas E1 e A1. Nesta tabela, nota-se que as estacas apresentam maior capacidade de carga à compressão do que à tração, como esperado. Na estaca A1 com fuste de argamassa a melhora na compressão é muito pequena.

Tabela 22 - Resultados das provas de carga à tração e à compressão $\left(2^{\circ}\right.$ ciclo $)$, segundo o critério $\mathrm{D} / 10$

\begin{tabular}{ccccc}
\hline Estaca & Tipo de Estaca & $\begin{array}{c}\text { Tração } \\
(\mathrm{kN})\end{array}$ & $\begin{array}{c}\text { Compressão } \\
2^{\circ} \text { ciclo } \\
(\mathrm{kN})\end{array}$ & $\begin{array}{c}\text { Qu Comp (2。 ciclo) } \\
\text { Qu Tração }\end{array}$ \\
\hline E1, E2 & $\begin{array}{c}\text { Convencional } \\
\text { A1 }\end{array}$ & 61 & 95 & 1,56 \\
& $\begin{array}{c}\text { Preenchida com } \\
\text { argamassa }\end{array}$ & 135 & 140 & 1,04 \\
\hline
\end{tabular}

\subsection{Escavação e Exumação}

Após a conclusão de todas as provas de carga, o processo de escavação das estacas A1, C1 e C2 foi cuidadosamente iniciado. O principal objetivo desta exumação de estacas foi verificar como as estacas se apresentaram com relação à argamassa ao redor do fuste e à injeção de calda de cimento.

Primeiramente, foi feita a escavação da estaca A1, a qual foi cuidadosamente escavada até uma profundidade de 3 metros, com o auxílio de uma retroescavadeira.

\subsubsection{Estaca A1}

Uma vez terminada a fase de escavação de 3 metros, a estaca foi fotografada e medida. As dimensões da estaca foram medidas com uma fita métrica. Considerando-se que o diâmetro da coluna de argamassa era irregular, foram tomadas quatro leituras do diâmetro da coluna de argamassa a cada $50 \mathrm{~cm}$, para se determinar um diâmetro médio (Dmédio $=0,23 \mathrm{~m}$, 
com medidas variando entre 0,19 e $0,25 \mathrm{~m}$ ). O comprimento verificado do cilindro preenchido de argamassa foi de 2 metros (Figura 44).
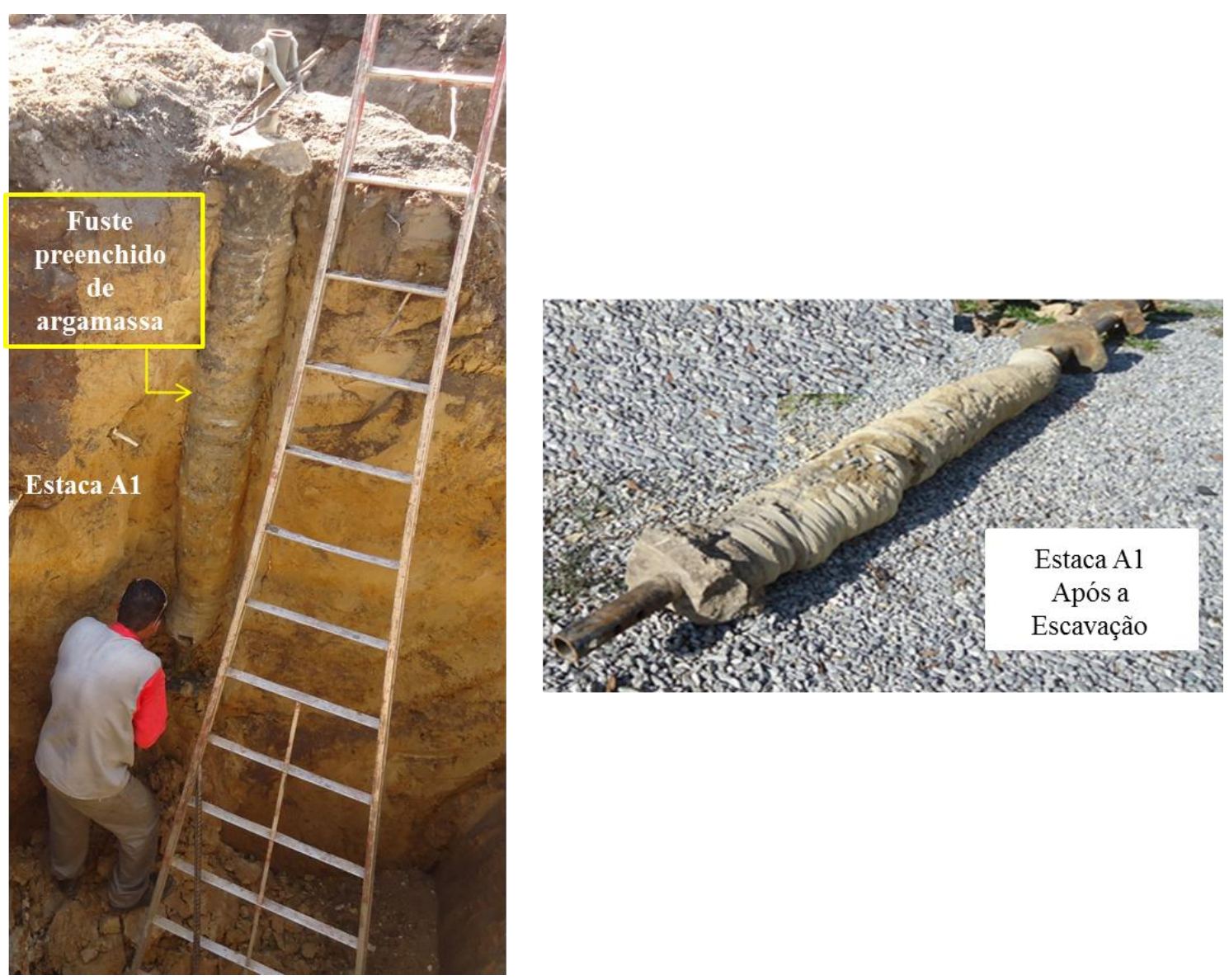

Figura 44- Exumação da estaca helicoidal A1

Após a exumação, constatou-se que a estaca foi corretamente concretada, não apresentando vazios na coluna de argamassa. Constatou-se, ainda, que a coluna de argamassa apresentava uma fissura em sua estrutura, provavelmente causada pelas provas de carga (Figura 45). 


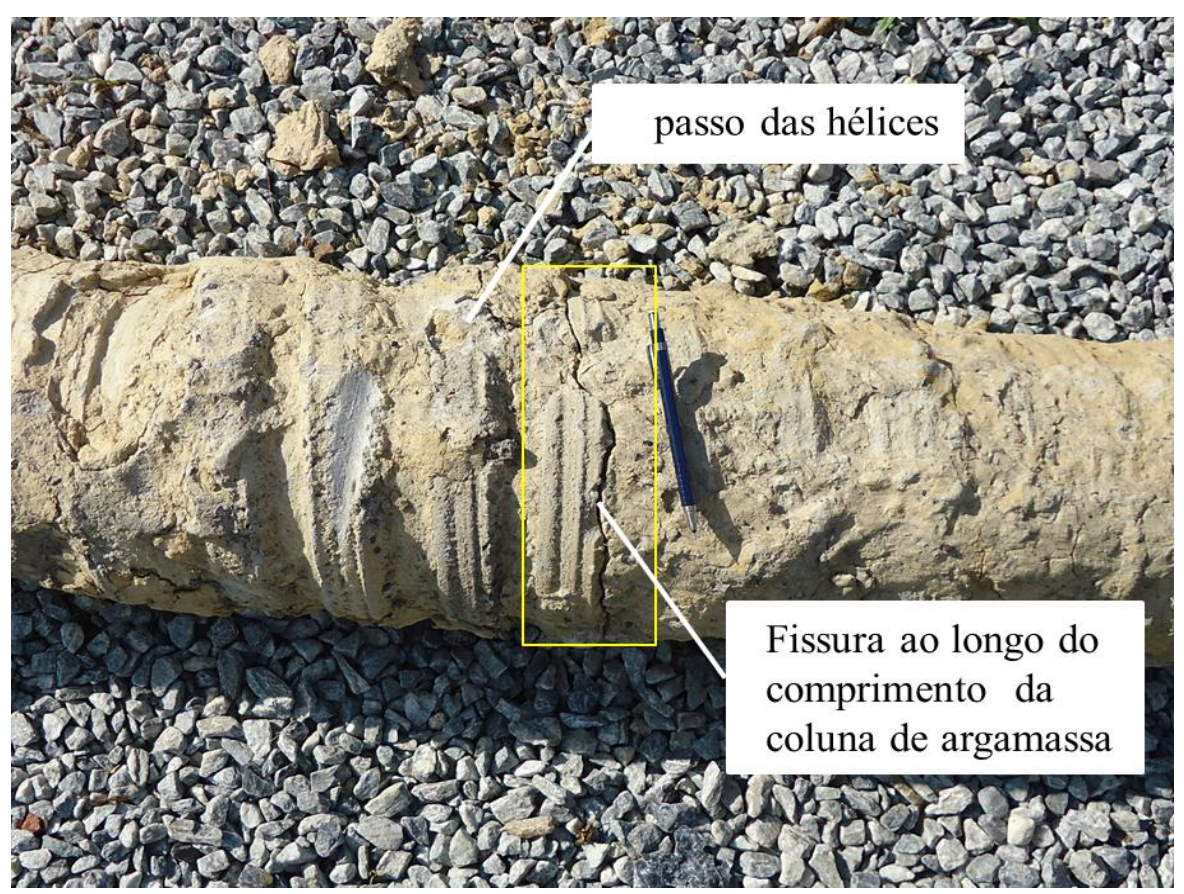

Figura 45- Coluna de argamassa da estaca A1.

A Figura 46 ilustra a estaca helicoidal com argamassa A1 após a instalação.

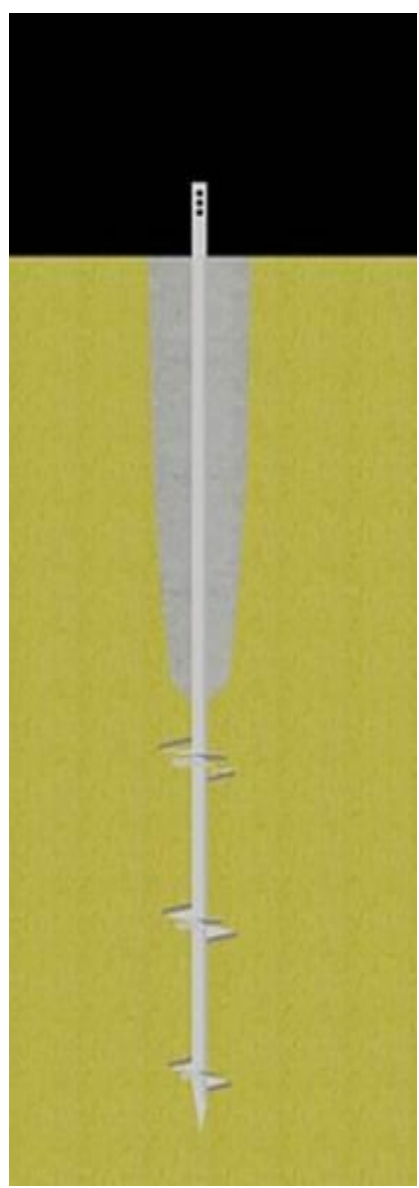

Figura 46- Forma da estaca A1 verificada após a escavação. 


\subsubsection{Estaca C1}

A estaca $\mathrm{C} 1$ pertence ao grupo das estacas injetadas. Para se realizar a exumação desta, foi necessário escavar até uma profundidade de 5 metros. A Figura 48 mostra as partes preenchidas com injeção de calda de cimento após terem sido realizadas as provas de carga de tração e de compressão.
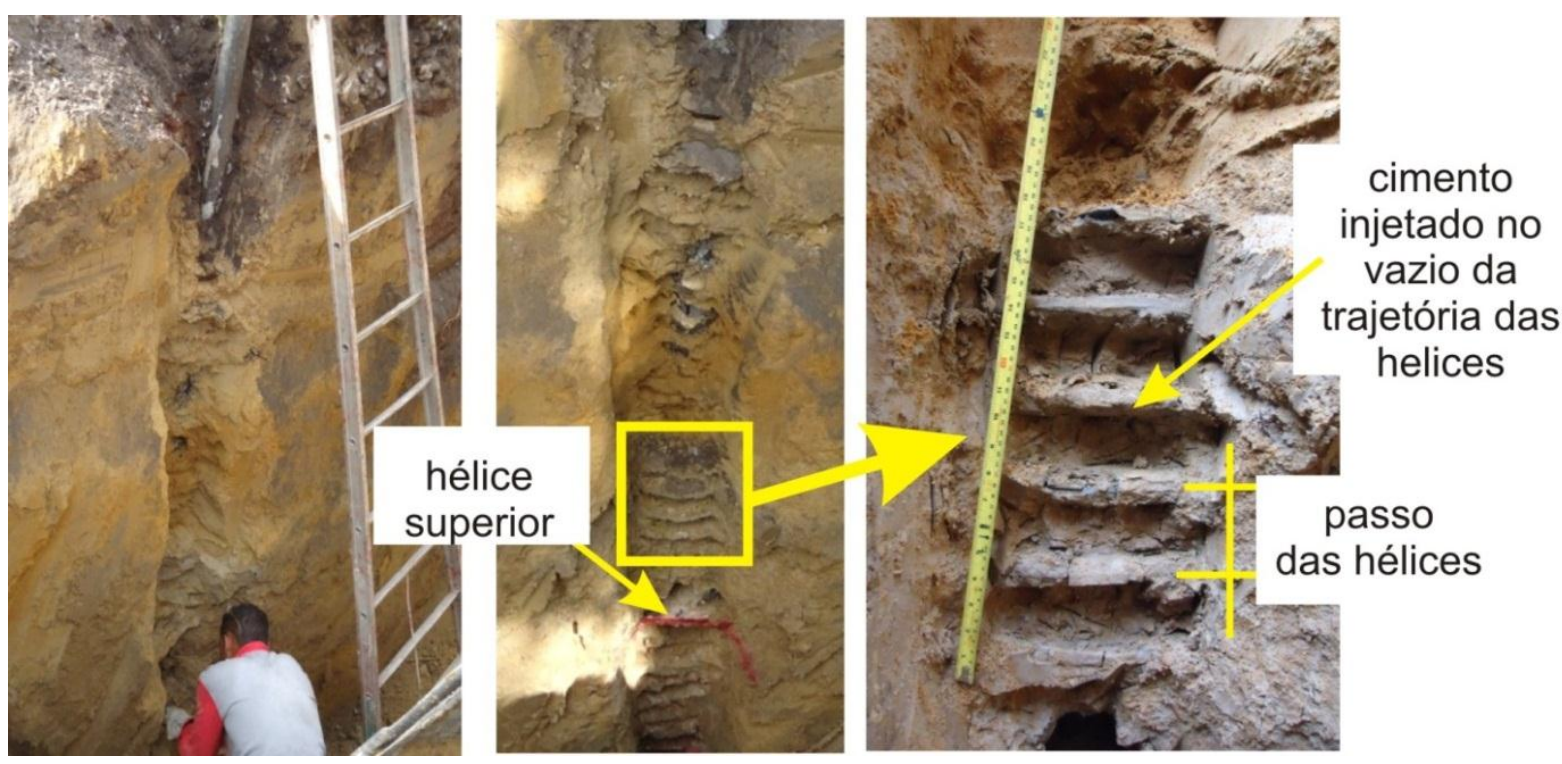

Figura 47- Exumação da estaca helicoidal C1.

$\mathrm{Na}$ Figura 47, notam-se hélices de "calda cimento" (espaçadas igualmente), que preencheram os vazios causados pela trajetória helicoidal das hélices, durante a instalação da estaca no terreno. O espaço do solo por onde passaram as hélices não se fechou, deixando esses vazios. Isto ocorreu por ser um solo coesivo e acima do N.A. Provavelmente, se o solo fosse de areia pura, a trajetória cortada após a passagem da hélice seria fechada, e o preenchimento da calda de cimento seria diferente.

Neste caso, o solo cortado durante a instalação da estaca abriu um caminho que não se fechou completamente, formando no solo atravessado um volume espiralado vazio, que foi preenchido pela calda cimento, melhorando consideravelmente a capacidade de carga à tração da estaca.

Na Figura 48, observa-se o vazio no solo acima e abaixo da hélice, deixado após a realização dos ensaios. Durante os ensaios de tração, a estaca subiu, mas a coluna de calda de 
cimento não subiu. Posteriormente, quando ensaiada à compressão, a estaca desceu e ficou um vazio acima das hélices.

Na ponta da estaca $\mathrm{C}$, formou-se um bulbo de calda cimento-solo, com diâmetro de $45 \mathrm{~cm}$ e comprimento de $40 \mathrm{~cm}$, o qual pode ser observado claramente na Figura 49.

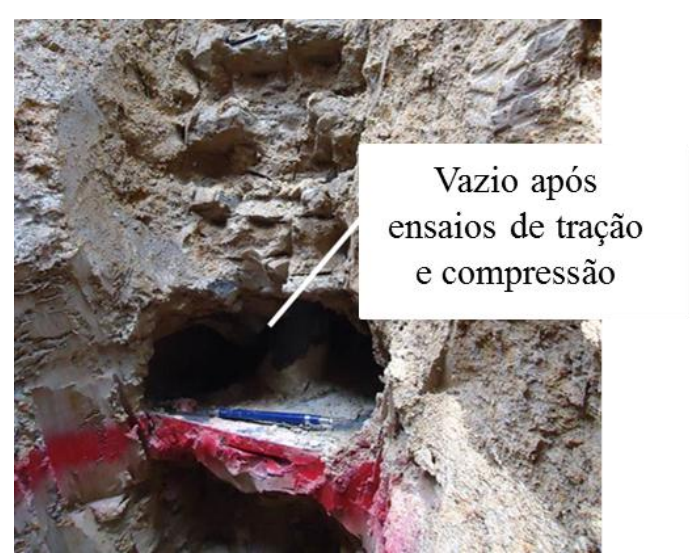

Figura 48- Vazio acima e abaixo das hélices, após os ensaios realizados de tração e de compressão na estaca $\mathrm{C} 1$.

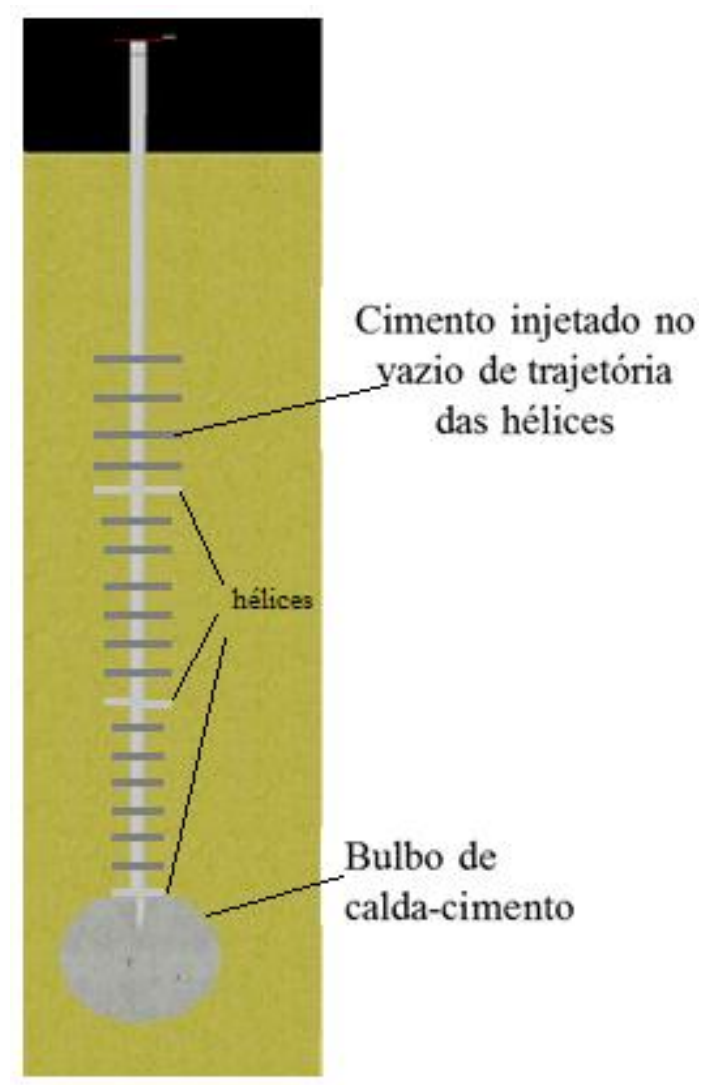

Figura 49- Estaca C1 após injeção calda de cimento.

A Figura 49 mostra a distribuição da injeção de calda de cimento em torno da estaca. 
Infelizmente, na escala real não foi possível tirar uma fotografia devido ao grande comprimento (5 metros) de onde foi realizada a escavação.

O volume total injetado na estaca foi de $0,133 \mathrm{~m}^{3}$, o qual misturou-se com o solo ao redor da estaca. No entanto, a porcentagem desse volume de solo-cimento não pôde ser estabelecida.

\subsubsection{Estaca C2}

$\mathrm{Na}$ estaca $\mathrm{C} 2$, após a injeção, foi realizada uma rotação na estaca e a calda de cimento misturou-se com o solo e não subiu pelo vazio causado pela trajetória da hélice, durante a injeção (como na C1). Neste caso, as capacidades de carga à tração foi inferior em relação ao caso da estaca $\mathrm{C} 1$.

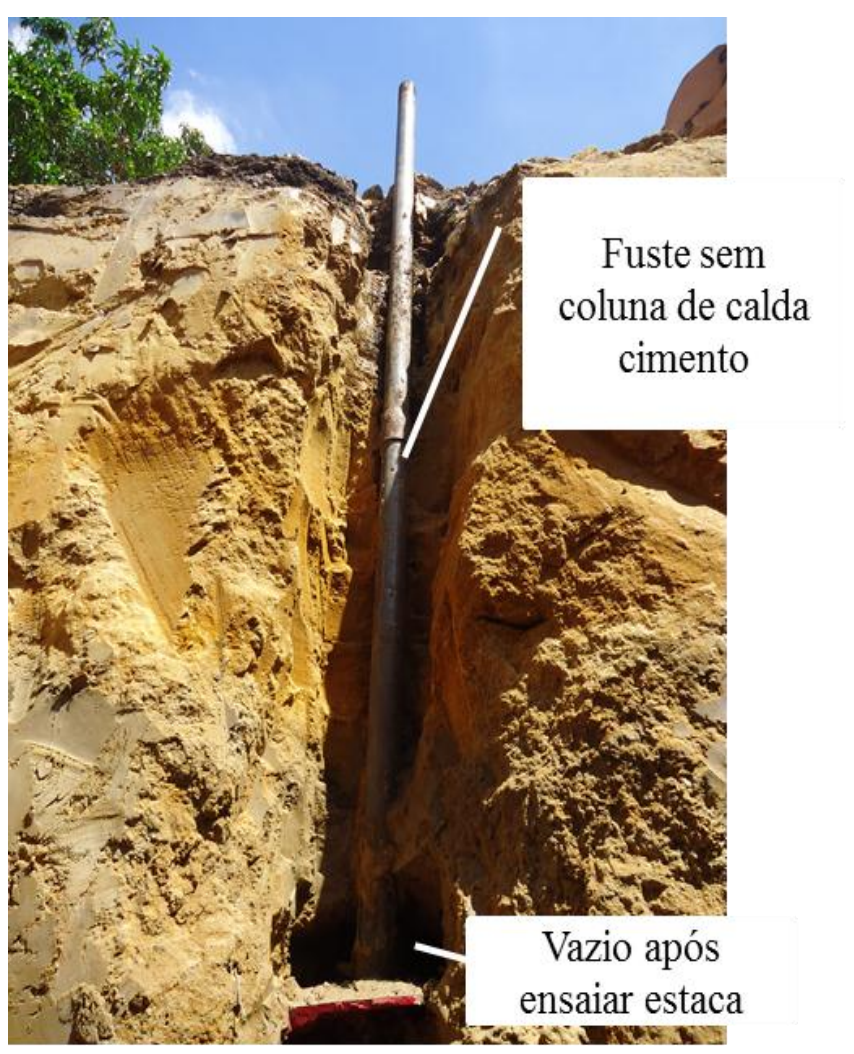

Figura 50- Exumação da estaca C2 - primeira parte 


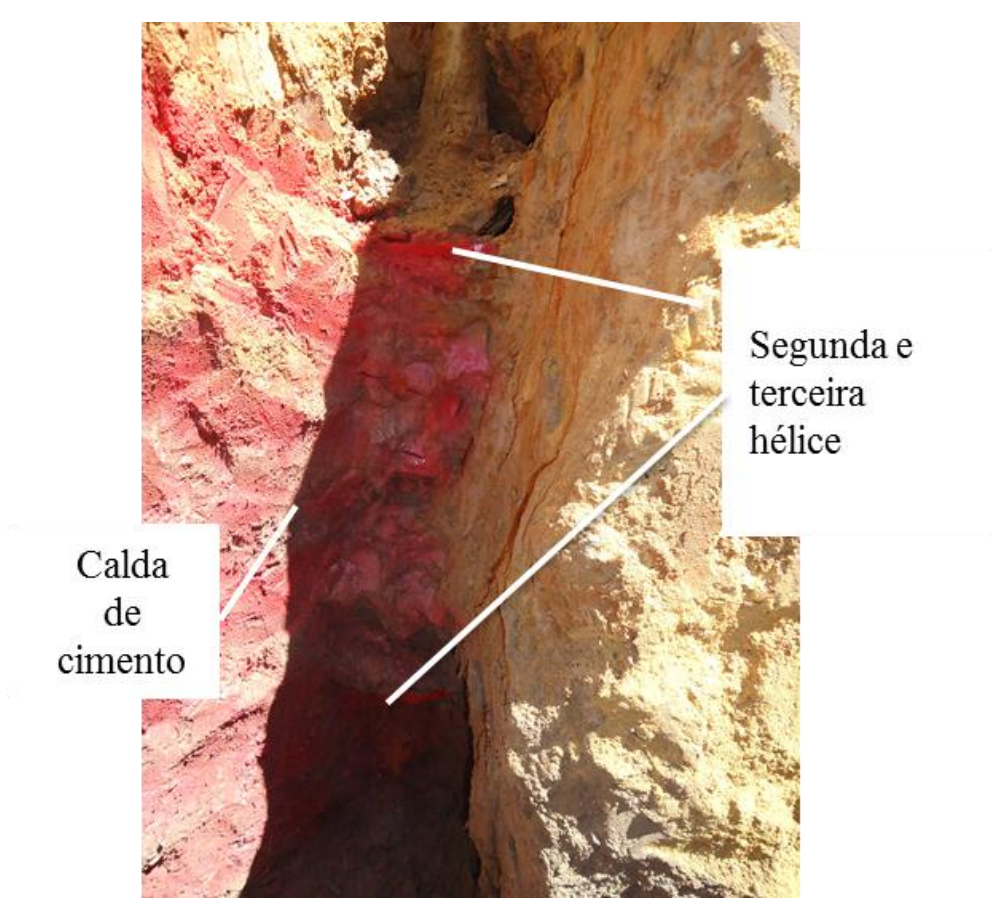

Figura 51- Exumação da estaca C2 - segunda parte (calda de cimento marcado com vermelho).

Nas figuras 50 e 51, pode-se observar que a calda de cimento cobriu a hélice do meio, a hélice inferior e a ponta. A calda não subiu devido à rotação aplicada na estaca após injeção, porém a calda de cimento foi direcionada para o lado esquerdo da estaca (Figura 52).

Com a rotação aplicada, era esperada a formação de um bulbo maior. De fato, o bulbo da $\mathrm{C} 2$ foi maior que o da estaca $\mathrm{C} 1$, mas ficou fora do eixo axial da estaca (Figura 52).

O volume total injetado na estaca foi de $0,133 \mathrm{~m}^{3}$, o qual se misturou com o solo ao redor da estaca. No entanto, não foi possível estabelecer qual a porcentagem desse volume é solo-calda de cimento. 

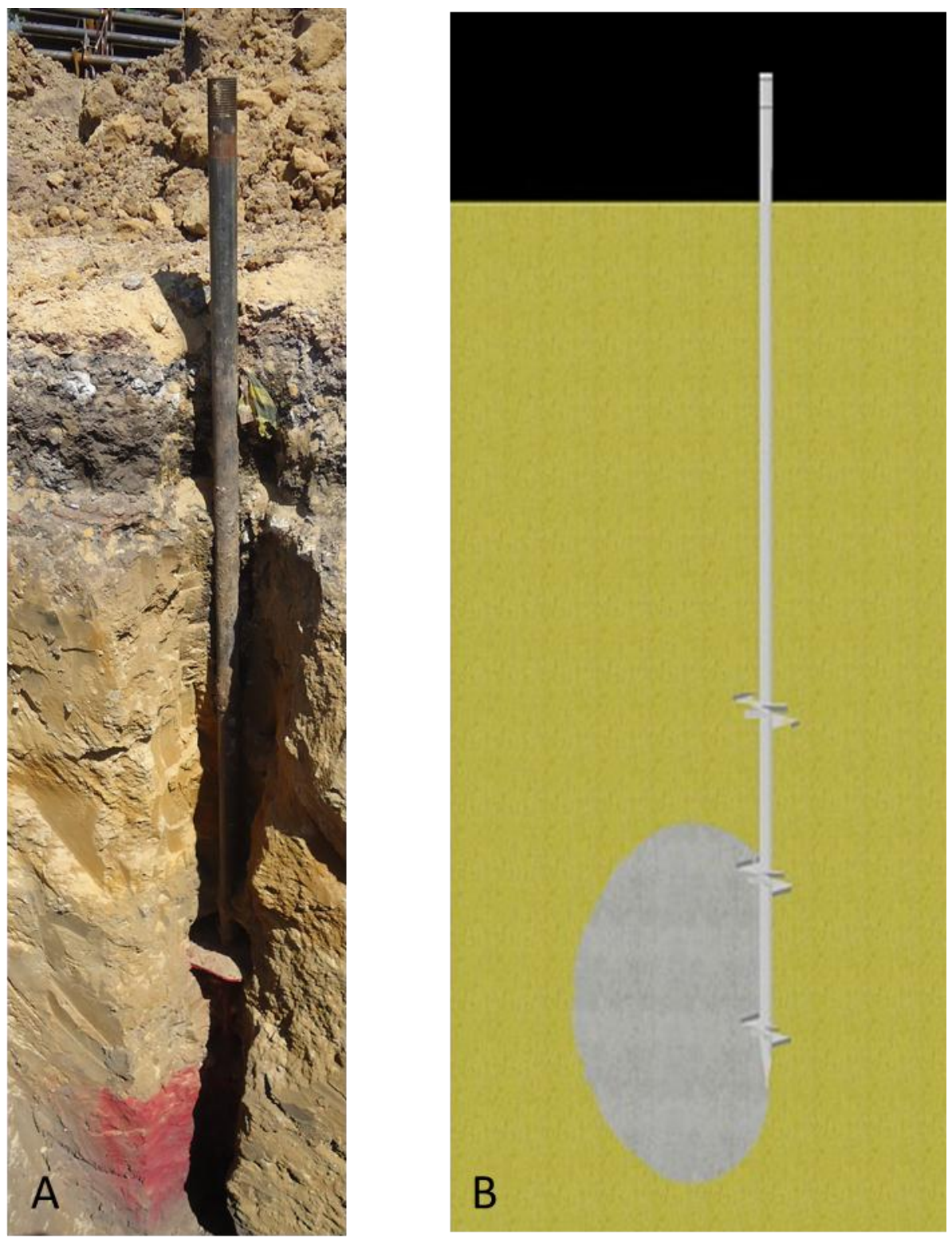

Figura 52- a) exumação da estaca $\mathrm{C} 2$; b) modelo do resultado da injeção na estaca. 


\section{CONCLUSÕES}

$\mathrm{Na}$ presente pesquisa, foi comparado o comportamento de estacas helicoidais convencionais e com melhorias, instaladas na mesma profundidade e próximas entre si, por meio de provas de carga à tração e à compressão.

O objetivo principal deste trabalho foi verificar duas soluções alternativas distintas de estacas helicodiais melhoradas para a aplicação em casos em que a estaca helicoidal deve ser instalada em condições de solo de apoio de capacidade insuficiente.

Para este fim, cinco estacas foram instaladas em solo silte arenoso não saturado, e de baixa capacidade $\left(\mathrm{N}_{\mathrm{SPT}}\right.$ em torno de 6 golpes $\left./ 30 \mathrm{~cm}\right)$. Nestes casos foi comparado o desempenho de duas estacas helicoidais convencionais com o de: uma estaca helicoidal com fuste de argamassa (solução 1) e duas estacas com calda de cimento injetada (solução 2). No caso das estacas injetadas, foram testados dois procedimentos distintos de injeção (um em cada estaca), para verificarmos qual seria o mais eficiente.

Posteriormente aos ensaios, as estacas com melhorias foram escavadas e exumadas para se observar as formas resultantes das injeções e do fuste de argamassa.

Como as estacas foram ensaiadas primeriamente à tração, e depois à compressão, não foi possível avaliar adequadamente o comportamento à compressão das estacas melhoradas. Após os ensaios de tração, os bulbos das estacas foram modificados. Supõe-se que o ensaio prévio de tração na estaca injetada tenha deixado vazios abaixo do bulbo, e também fraturado parte da calda de cimento, prejudicando os resultados do ensaio à compressão.

Os resultados mostraram que a capacidade de carga à tração das estacas helicoidais pode ser aumentada injetando-se calda de cimento na ponta da estaca, ou preenchendo-se o fuste de argamassa acima das hélices.

Levando-se em conta a variabilidade do terreno de instalação, verificada pelos valores de torque de instalação, as principais conclusões desta pesquisa foram as seguintes:

- A estaca helicoidal com fuste de argamassa apresentou uma grande melhora na capacidade de carga à tração comparada à estaca helicoidal convencional. Esta melhora é devido à maior área de contato entre solo e fuste da estaca, que aumenta a 
resistência por atrito lateral ao longo da parcela de estaca aima das hélices. A inclusão do fuste de argamassa aumentou a capacidade de carga à tração em $221 \%$. O valor de capacidade de carga à tração nesta pesquisa foi convencionado como sendo a carga da curva carga $\mathrm{x}$ descolamento das provas de carga equivalente ao deslocamento igual a $10 \%$ do diâmetro médio das hélices.

- Para avaliar o caso de estacas helicoidais com injeção de calda de cimento na ponta da estaca, dois procedimentos distintos foram testados. Para a estaca $\mathrm{C} 1$, a injeção foi realizada após o término da instalação da estaca, sem nenhum procedimento adicional. Para a estaca C2, após a injeção, foi aplicada uma rotação com o intuito de se formar um bulbo maior. No entanto, a estaca C1 (sem rotação no final), apesar de proporcionar um menor bulbo na ponta, apresentou melhor comportamento (em tração e em compressão) do que a estaca C2. Isto ocorreu porque na estaca C1 a calda de cimento subiu ao longo do fuste da estaca, seguindo o caminho atravessado (e aberto) pelas hélices durante a instalação, reforçando o solo ao longo da estaca com placas helicoidais de cimento. No caso da $\mathrm{C} 2$, a rotação fez com que a calda se concentrasse na ponta da estaca, somente, e ficasse excêntrica em relação ao eixo da estaca.

- Para este terreno avaliado, o procedimento de injeção realizado na estaca C1 proporcionou um grande ganho de capacidade de carga tanto à tração. Neste caso, o ganho em capacidade de carga comparado à estaca helicoidal convencional foi de $225 \%$.

- O procedimento de injeção realizado na estaca C2 também proporcionou um grande ganho de capacidade de carga à tração, apesar de ser inferior ao ganho proporcionado pela $\mathrm{C} 1$. Neste caso, o ganho em capacidade de carga, comparado à estaca helicoidal convencional, foi de $182 \%$.

- Comparando-se o trecho inicial das curvas carga x deslocamentos das estacas C1 (com injeção) e A1 (com fuste de argamassa), nota-se que apesar de ambas proporcionarem quase a mesma capacidade de carga convencionada em tração, o comportamento da estaca $\mathrm{C} 1$ até o deslocamento inicial de $5 \mathrm{~mm}$ foi bem superior ao da estaca A1. Para uma carga de serviço equivalente à metade da carga de ruptura (em torno de $68 \mathrm{kN}$ ), o 
deslocamento na estaca $\mathrm{C} 1$ seria em torno de $1 / 4$ do deslocamento da estaca A1.

- Após a exumação das estacas, foi verificado que a estaca A1 apresentou um fuste uniforme, com um diâmetro quase que praticamente constante (variando entre 19 e 25 $\mathrm{cm}$ ) próximo ao valor da chapa de $20 \mathrm{~cm}$ que empurrou o solo para baixo deixando o vazio para preenchimento do fuste. Portanto, conclui-se que a melhoria da estaca A1 pode ser estimada por um método de cálculo para estimar a resistência por atrito lateral no fuste de argamassa formado. Diferentemente, a geometria final das estacas injetadas devido ao modo que a injeção se espalhou no solo, não resultou em algo que pudesse ser calculado por um método de previsão de capacidade de carga.

Estes ensaios em estacas helicoidais com métodos de injeção e preenchimento de argamassa são os primeiros realizados no Brasil. Portanto, é necessário realizar mais ensaios em diferentes condições de subsolo para se poder avaliar a eficiência destes procedimentos. 


\section{SUGESTÕES PARA FUTURAS PESQUISAS}

Para futuras pesquisas sobre estacas helicoidais com melhorias, recomenda-se:

- Realização de injeções de calda de cimento em estacas helicoidais abaixo do N.A. e em solo mais arenoso;

- Investigar a resistência lateral de estacas helicoidais com argamassa no fuste, por meio de provas de carga horizontais;

- Desenvolver métodos de cálculo para estacas helicoidais injetadas a partir dos resultados de bulbos verificados em diferentes condições de subsolo. 


\section{REFERENCIAS BIBLIOGRÁFICAS}

A.B. CHANCE CO. Helical Pier Foundation Systems - Technical Manual.

A.B. CHANCE CO. (2004) Encyclopedia of Anchoring, Centralia, USA.

A.B.CHANCE CO. (2006) "Civil construction installing tools for screw anchors and piles", Centralia Bulletin 01-0203.

ABDELGHANY, Y; EL NAGGAR, M.H. (2010) Full Scale Experimental and Numerical Analysis of Instrumented Helical Screw Piles Under Axial and Lateral Monotonic and Cyclic Loadings. A Promising Solution for Seismic Retrofitting. In Proceeding of the $6^{\text {th }}$ International Engineering and Construction Conference, American Society of Civil Engineers, Cairo, Egypt.

ADAMS, J.I.; KLYM, T.W. (1972) "A study of anchors for transmission tower foundations", Canadian Geotechnical Journal, v9, n.1, pg 89-104.

ASSOCIAÇÃO BRASILEIRA DE NORMAS TÉCNICAS (2001). NBR 6484: SoloSondagem de Simples Reconhecimento com SPT-Método de Ensaio. Rio de Janeiro, 17 p

ASSOCIAÇÃO BRASILEIRA DE NORMAS TÉCNICAS (2006) NBR 12131: EstacasProva de Carga Estática- Método de Ensaio. Rio de Janeiro, 8p.

BENVENUTTI, M. (2009): Dissertação de Mestrado. Prova de Carga Rápida com Recalque Estabilizado. Escola de Engenharia de São Carlos, Universidades de São Paulo.

BIAN Y. et al. (2008), Experimental Investigation of Grouted Helical Piers for Use in Foundation Rehabilitation, Journal of Geotechnical and Geoenvironmental Engineering ASCE. 1280-1288p

BIAN, Y. (2006). .Development and Testing of Centrifuge Tools for Use in Grouted Helical Pier Based Foundation Rehabilitation Studies, Master Thesis -University of California, Irvine. $114 \mathrm{p}$ 
BRAJAS M.DAS (1990). Earth Anchors. Elsevier Science Publishing Company Inc, New York, $241 \mathrm{p}$

BRAJAS M.DAS (2006), Principios de Ingenieria de Cimentaciones 5E, Cengage Learning $743 \mathrm{p}$.

CARVALHO, I.P.G. (2007). Estudo Teórico-Experimental da Capacidade de Carga à Tração e Compressão de Estacas Metálicas Helicoidais. Dissertação de Mestrado, Departamento de Engenharia de Estruturas, Universidade Federal de Minas Gerais, Belo Horizonte, 205 p.

CINTRA, J.C.A. et al. (2013) Fundações Ensaios Estáticos e Dinâmicos, Oficina de Textos. $144 \mathrm{p}$.

CINTRA, J.C.A.; AOKI, N. (2010) Fundações por Estacas Projeto Geotécnico, Oficina de Textos. $96 \mathrm{p}$.

CINTRA, J.C.A.; AOKI, N.; ALBIERO, J.H. (2003) Tensão Admissível em Fundações Diretas. São Carlos.

CINTRA, J.C.A.; AOKI, N.(1999) Carga Admissível em Fundações Profundas, EESC-USP, São Carlos/SP. 61 p.

CLAYTON, D.J. (2013). Utility Industry Anchor Design and Maintenance Manual, Earth Contact, $88 \mathrm{p}$.

CLEMENCE, S.P (2014). Recent Advances in Design and Construction of Helical Foundations. Annual Kansas City Specialty Seminar 2014. Kansas City ASCE Geotechnical Seminar, January 10, 2014.

CLEMENCE, S.P. (1985). Uplift Behavior of Anchor Foundations in Soil. In Proceeding of a Session Sponsored by the Geotechnical Engineering Division of ASCE, Detroit. 
CLEMENCE, S.P.; PEPE F.D Jr. (1984). Measurement of Lateral Stress Around Multi-helix Anchors in Sand. Geotechnical Testing Journal, Vol. 7, n 3, p. 145-152.

DAS, B.M.; SEELEY, G.R. (1975) Breakout Resistance of Horizontal Anchors. Journal of Geotechnical Engineering Division. ASCE, Vol. 101, No.9, p 999-1003.

DAS, B.M (1980). A Procedure for Estimation of Ultimate Uplift Capacity of Foundations in Clay. Soils and Foundations. Vol. 20, No.1, p. 77-82,

DAS, B.M. (1990) Earth Anchors. Elsevier Science, First Edition, Amsterdam, 1990, p. 252.

DÉCOURT, L. Parâmetros do solo para projetos de Fundações, In: SEFE V, 5, 2004, São Paulo. Vol. "2, São Paulo: Seminário de Engenharia de execução de fundações”, Rio de Janeiro, ABNT, (04/1996).

DUARTE, V.M. (1990). Caracterização Hidro geotécnica e Injeção de Vedação: Tentativa de Padronização de Alguns Critérios e Procedimento. Inc: CONGRESO SURAMERICANO DE MECANICA DE ROCAS,3, Caracas, 1990. Memorias...Caracas: ISRM 253-262 p.

EL SHARNOUBY, M.M. and EL NAGGAR, M.H. (2012) Field Investigation of Axial Monotonic and Cyclic Performance of Reinforced Helical Pulldown Micropiles. Canadian Geotechnical Journal, 49 (5)m 560-573

FLORES, C.A.S.; MARCOLINO, F.G.L.; DUARTE, R.D.A.; GOMEZ, J.I. (2001). "Estacas Metálicas Helicoidais como Elemento de Fundação para Torres de Linhas de Transmissão". In: XVI Seminário Nacional de Produção e Transmissão de Energia Elétrica, Campinas.

GHALY, A.; HANNA, A. (1991) Experimental and Theoretical Studies on Installation Torque of Screw Anchors. Canadian Geotechnical Journal, v.28, n.3, p 353-364

GODOY, N.S. (1983). Estimativa da Capacidade de Carga de Estacas a Partir de Resultados de Penetrometrô Estático. Palestra proferida na Escola de Engenharia de São Carlos- USP. 
GOUVENOT, D., 1973. Essais En France et a L'Etranger sur le Frottement Lateral en Foundation: Amelioration par Jection. Travaux, 464, Nov, Paris, France.

HARGRAVE R.L.; THORSTEN R.E.,(1992) Helical Piers in Expansive soils of Dallas Texas, $7^{\text {th }}$ international Conference on Expansive Soils, Section 24 , pg. 1-6

HAWKINS KELLY; THORSTEN R. (2009), Load Test Results- Large Diameter Helical Pipe Piles, International Foundation Congress and Equipment Expo, Asce

HOYT, R.M.; CLEMENCE, S.P. (1989) Uplift Capacity of Helical Anchors in Soil. In: XII International Conference on Soil Mechanics and Foundation Engineering, Vo. 2, 1019-102 p.

IGOR PORTELlA GARCIA DE CARVALHO (2007), Dissertação de Mestrado "Estudo Teórico-Experimental da Capacidade de Carga a Tração e Compressão de Estacas Metálicas Helicoidais" Universidade Federal de Minas Gerais.179 p.

IYOMASA, W.S. (2000). Injeção de Solo-Cimento em Solo Residual de Granitoide, Tese de Doutorado, Escola de Engenharia de São Carlos, Universidade de São Paulo, São Carlos, 248 p.

KULHAWY, F.H. (1985). Uplift Behavior of Shallow Soil Anchors- An overview. Uplift Behavior of Anchor Foundation in Soil, ASCE, New York. 1-25p

LIVNETH B.; NAGGAR M.H. (1999), Axial Testing and Numerical Modeling of Square Shaft Helical Piles Under Compressive and Tensile Loading, Geotechnical Research Centre, Faculty of Engineering, University of Western Ontario, London Canada.

LI, Y (2006) Compressive Behavior of Grouted Helical Foundations. PHD Dissertation, Syracuse University, p. 238

LUTENEGGER A.J. (2010). Shaft Resistance of Grouted Helical Micropile in Clay. In proceeding of the $10^{\text {th }}$ International Workshop on Micropiles, IWN, Washington, D.C., USA p 22-25 
LUTENEGGER A.J. (2011). Historical Development of Iron Screw-Pile Foundations: 18361900, Eng. \& Tech., Vol 81 N1, 108-128 p.

LUTENEGGER, A.J. (2014). Screw-Piles, Helical Anchors and Soil Mechanics- Where are We?. Annual Kansas City Specialty Seminar 2014. Kansas City ASCE Geotechnical Seminar, January 10, 2014

MANKE, J.P. (2004). Assestment of Superposition as a Design Framework for the Combined Effects of Soil Improvement and Foundation Remediation. Master Thesis, North Carolina State University, $221 \mathrm{p}$.

MEYERHOF, G.G. (1951) The Ultimate Bearing Capacity of Foundations. Geotechnique, Vol2 (4), 301-331 p.

MEYERHOF, G.G. (1976) “Bearing Capacity and Settlement of Pile Foundations”. Journal of the Geotechnical Engineering Division, American Society of Civil Engineers, Vol 102.

MEYERHOF, G.G.; ADAMS, J.I. (1968) The Ultimate Uplift Capacity of Foundations. Canadian Geotechnical Journal, Vol. 5 (4), 225-244 p.

MITSCH, M.P.; CLEMENCE S.P. (1985). The Uplift Capacity of Helix Anchors in Sand. Proceedings of Uplift Behavior of Anchor Foundation in Soil, ASCE, Detroit, 26-47p.

MOONEY, J.S.; ADAMCZARK JR, S.; CLEMENCE, S.P. (1985). Uplift Capacity of Helical Anchors in Clay and Silt. In: Uplift Behavior of Anchor Foundations in Soil, 1985 Detroit. Detroit: Proceeding of a Session Sponsored by the Geotechnical Engineering Division of the American Society of Civil Engineers, 1985, 48-72 p.

MORAES, L.S. (2010) Tese de Doutorado. Estacas Escavadas com Base Injetada. EESC Universidade de São Paulo. 154p

MOSELEY, M.P. e KIRSCH, K (2004). "Ground Improvement ( $2^{\text {nd }}$ ed.)." Spon Press, new York, $432 \mathrm{p}$. 
NAGGAR, B. L.; A. M. H. E. (2008). "Axial Testing and Numerical Modeling of Square

Shaft Helical Piles Under Compressive and Tensile Loading." Canadian Geotechnical Journal: 13.

NARASHIMA RAO, S.; PRASAD, Y.V.S.N.; SHETTY, M.D. (1991) The Behavior os Screw Piles in Cohesive Soils. Soil \& Foundations, vol. 31 (2), 35-30 p

NASR M. 2009, Performance-Based design for Helical Pile, International Foundation Congress and Equipment Expo, ASCE pg. 496-502

NORVEILLER, E (1989). Grouting, Theory and Practice, Amsterdam, New York, Elsevier $250 \mathrm{p}$.

PERKO H.; BROWN D.(2009), Helical Piles a Practical Guide to Design and Installation, John Wiley \& Sons, New York.

PERKO H.A.; STAN, J.; RUPIPER, P.E. (2000). Helical Pier Engineering Handbook 2000. Ingal Precision Foundation, Inc. Worldwide Helix Pier Distributors.

PERKO, H.A. (2000). "Energy Method for Predicting the Installation Torque of Helical Foundations and Anchors." New Technological and Design Developments in Deep Foundation Technologies, ASCE, 342-352 p.

PERLOW M. (2011), Helical Pile Acceptance Criteria, Design Guideliness and Load Test Verification, GEO-Frontiers, ASCE.

RADHAKRISHNA, H.S., 1976. Helix Anchor Tests in Sand. Edited by T.S. Essa. Ontario Hydro Research Division, Research Report No. 76-130-K.

SAMPAIO, A.J.M. (1988). O Emprego de Injeção de Calda de Cimento no Tratamento de Fundações Basálticas de Barragens do Tipo de Concreto-Gravidade no Brasil Meridional: Aspetos Práticos. Dissertação de Mestrado, Escola de Engenharia de São Carlos, Universidade de São Paulo. 118p 
SANHUEZA, M.I.A., (2012). Evaluación del Diseño de Fundaciones con Micro pilotes Tipo Tornillo en Torres de Alta Tensión. Tesis para optar al título de Ingeniero Civil en Obras Civiles, Universidad Austral de Chile, Valdivia Chile. 163 p.

SANTOS et al. (1985). Experimental Grouting of Residual of the Balbina Earth Dam Foundation, Amazon, Brazil, In: INTERNATIONAL CONFERENCE ON

GEOMECHANICS IN TROPICAL LATERITIC AND SAPROLITIC SOILS, 1, Brasilia, 1985. Proceedings São Paulo: ABMS, v2 143-154 p.

SANTOS, T. D. C. (2013). Estudo da Capacidade de Carga a Tração de Estacas Metálicas Helicoidais em Solos Tropicais. Dissertação de Mestrado Escola de Engenharia de São Carlos, Universidade de São Paulo, São Carlos, 140p.

SARK M.(2009). Performance of Helical Piles in oil Sand, Canadian Geotechnical Journal, Vol 46 (9) 1046-1061 p

SARK M.; PARSON W. (2011.) Helical Piles-Effective Foundation System for Solar Plant, Geotechnical Conference 2011 Pan-Am CGS, Edmond-Albeta, Canada,

SARK, M. (2011). "Installation and Performance Characteristics of High Capacity Helical Piles in Cohesionless Soils." DFI Journal 5(1): 18.

SEIDER, G.L., (2002). Bearing and Uplift Capacity of Helical Screw Anchors and Foundations in Soil. A.B. Chance Helical Anchor and Foundation Seminar, Centralia, MO.

SEIDER, G.L.; CLEMENCE S.P; THORSTEN, R.E. (2003) Helical Piles with Grouted Shaft. A Practical Review. Proceeding of the $28^{\text {th }}$ Annual Conference on Deep Foundation, ASCE p 221-231.

SHARNOUBY M.M., Monotonic and Cyclic Axial Full Scale Testing of Reinforced Helical Pulldown Micropiles, Geotechnical Conference, 2011 Pan-Am CGS.

SHARNOUBY, M. M. E. (2012). Monotonic And Cyclic Behaviour of Steel FibreReinforced and FRP-Steel Fibre-Reinforced Helical Pulldown Micropiles.Ph Thesis. Graduate 
Program in Engineering Science Department of Civil and Environmental Engineering. London, Ontario, Canada, University of Western Ontario. 256p.

SCHIAVON, J.A. (2010). Aplicação da Técnica da Fotoeslasticidade na Analise de fundações por Estacas Helicoidais Dissertação de Mestrado Escola de Engenharia de São Carlos, Universidade de São Paulo, São Carlos, 133p

SILVA, B. C. (2014). Estimativa da Capacidade de Carga à Tração de Estacas Helicoidais com Base no Ensaio SPT. Dissertação de Mestrado. Escola de Engenharia de São Carlos, Universidade de São Paulo, São Carlos, 2014.

SKEMPTON, A.W. (1959). Cast-In-Situ Bored Piles in London Clay. Geotechnique, Vol. 9, No. 4 153-173 pp.

SPRINCE A.,PARKRASTINSH L.,2010, Helical Bahaviour and Load Transfer Mechanism in Different Soils, $10^{\text {th }}$ Internacional Conference, Vilnius Lithuania, pg. 1174-1180

STEPHENSON, R.W (1997). Helical Foundation and Tie Backs - State of the Art. University of Missouri-Rolla, 43 p.

STEPHENSON, R.W. (2003). Design and Installation of Torque Anchors for Tiebacks and Foundations. Missouri University of Science and Technology, Rolla. 45 p.

TERZAGHI, K. (1943). Theoretical Soil Mechanics. John Wiley \& Sons, New York.

TROFIRNENKOV, J. G., AND MARIUPOLSKII, L. G. (1965). "Screw Piles Used for Mast and Tower Foundations"; Proceedings of Sixth lnternational Conference on Soil Mechanics and Foundation Engineering, Montreal, Quebec, Vol.11, pp. 328-332.

TSUHA, C.H.C. ET. AL (2012) Evaluation of the Efficiencies of Helical Plates in Sand by Centrifuge Model Test. Canadian Geotechnical Journal, vol. 49. 1102-1114. 
TSUHA, C.H.C. (2007) Modelo Teórico para Controle da Capacidade de Carga a Tração de Estacas Metálicas Helicoidais em Solo Arenoso, Dissertação de Doutorado -EESC Universidade de São Paulo. 275p

TSUHA,C.H.C.; AOKI, N. (2010) Relationship Between Installation Torque and Uplift Capacity of Deep Helical Piles in Sand. Canadian Geotechnical Journal, vol 47, 635-647 p.

VARGAS, M.(1990). Prova de carga em Estacas - Uma apreciação histórica. Revista solo e Rocha. São Paulo Volume 13

VÉRTICE Eng. (2004). Produtos e serviços - Estacas Metálicas Helicoidais. Disponível em: http://www.verticebr.com.br/2004/index.html. Acesso em 17/09/2013.

VICKARS R.A., CLEMENCE S.P., (2000), Performance of Helical Piles with Grouted Shaft, New Technological and Design Developments in Deep Foundation, ASCE, 327-341p.

WARNER, P.E. J. (2004). Practical Handbook of Grouting - Soil, Rock and Strutures, New Jersey, John Wiley \& Sons, 700p.

WEAVER, K.D. (2000). A Critical Look at Use of "Rules of Thumb"for Selection of Grout Injection Pressures. In Krizek, R.J.; Sharp. K; ASCE (eds.), Advances in Grouting and Ground Modification: Proceeding of Sessions of Geo-Denver 2000, 5-8 August, Denver, CO, Geotechnical Special Publication No. 104, 173-180 pp.

WILDER, D.S. (1989). The Bearing Capacity of Grouted Helical Anchors in Sand. Master Thesis, Syracuse University.

ZHANG, D. J. Y. (1999). Predicting Capacity of Helical Screw Piles in Alberta Soils. Master Thesis, Departamento of Civil and Environmental Engineering. Edmont, Alberta, University of Alberta, 334p. 


\section{APENDICE A}

\section{Provas de Carga à Compressão}

\section{Resultados}

Foram realizadas quatro provas de carga rápida de compressão (conforme a Tabela 23), de acordo com a NBR 12131 (2006). O carregamento foi aplicado em estágios, sendo realizadas leituras dos deslocamentos a cada cinco minutos, independentemente da ocorrência da estabilização.

Tabela 23 - Provas de carga à compressão

\begin{tabular}{cc}
\hline Estaca & Tipo de Estaca \\
\hline E1 & Convencional \\
C1 & Injetada \\
C2 & Injetada (com rotação no final) \\
A1 & Preenchida com argamassa \\
\hline
\end{tabular}

Nos Gráficos 15 a 18, são mostradas as curvas carga aplicada de compressão versus deslocamento de cada estágio de carregamento das cinco provas de carga.

As provas de carga à compressão foram realizadas em dois ciclos após a realização da prova de carga à tração. Portanto, o deslocamento inicial importante observado na curva do ensaio na estaca convencional E1 (Gráfico 15) não representa a capacidade de carga à compressão da estaca, mais sim o fato de que a estaca "subiu" durante o ensaio de tração, e quando se iniciou o carregamento de compressão, havia um vazio abaixo da estaca.

Nota-se que, após o primeiro ciclo, o comportamento carga x deslocamento das estacas foi melhorado, devido à compactação do solo abaixo das hélices e dos bulbos formados.

Nos Gráficos 15 a 18, são mostradas as curvas carga aplicada de compressão versus 
deslocamento de cada estágio de carregamento das quatro provas de carga. As curvas carga $\mathrm{x}$ deslocamento de todas as estacas ensaiadas à compressão são apresentadas no Gráfico 19.

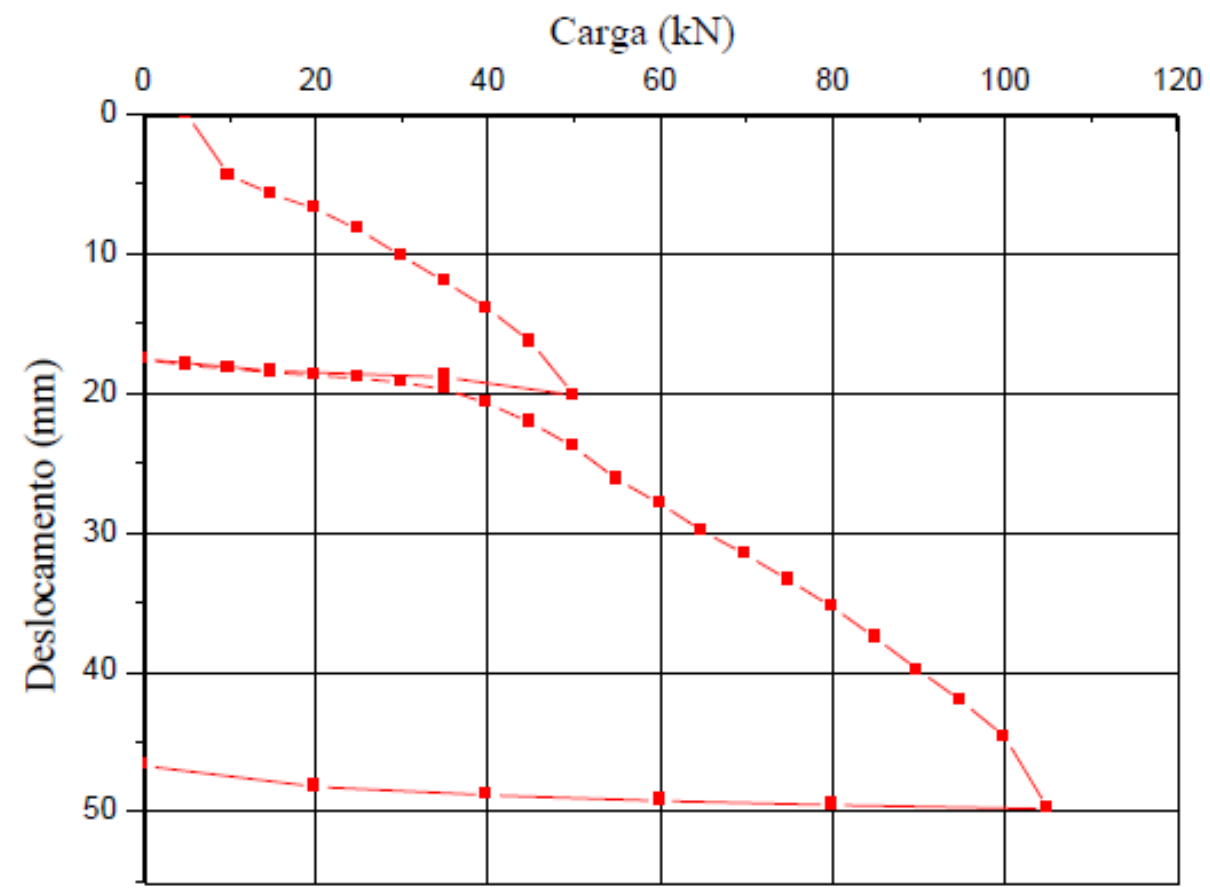

Gráfico 15 - Curva carga x deslocamento da prova de carga na estaca convencional E1.

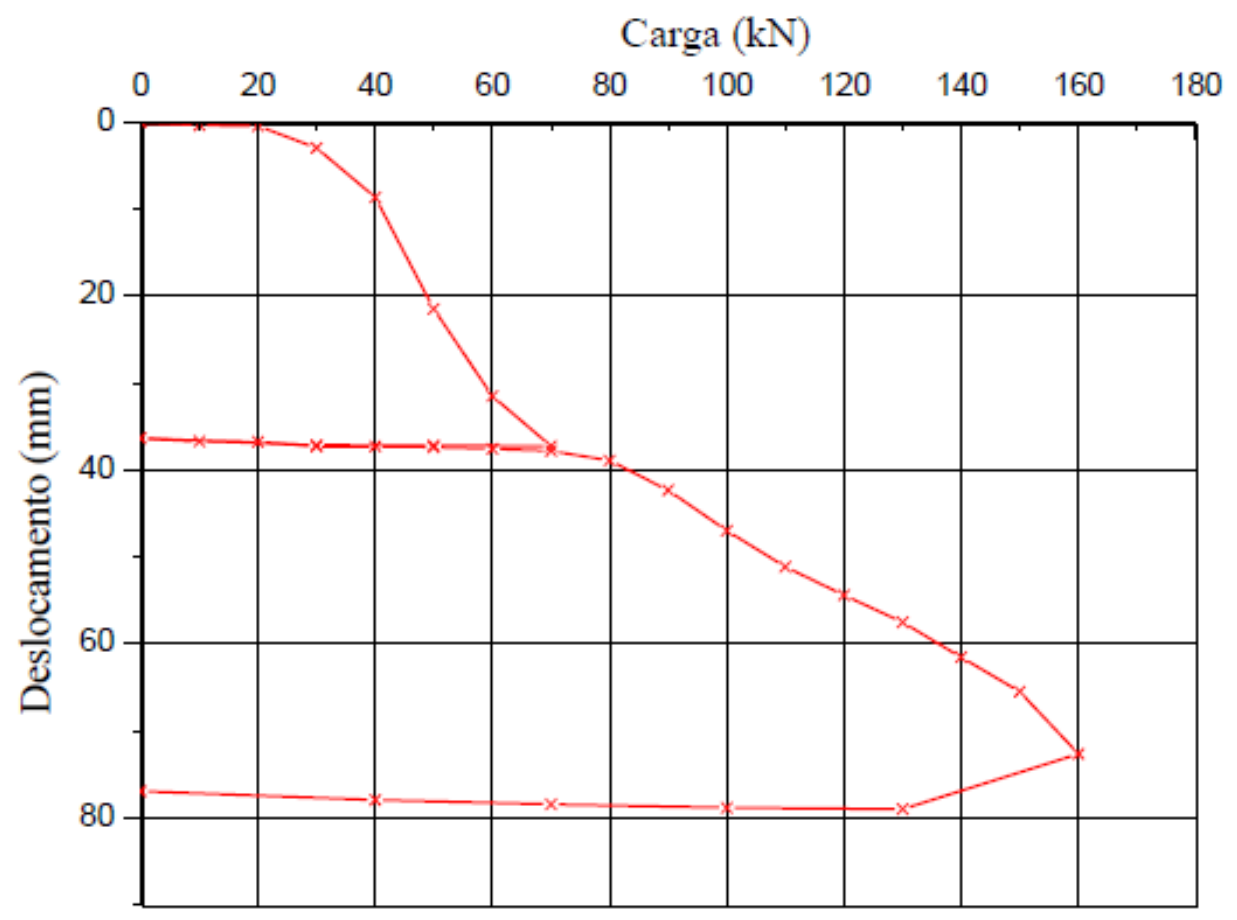

Gráfico 16 - Curva carga x deslocamento da prova de carga na estaca com argamassa A1. 


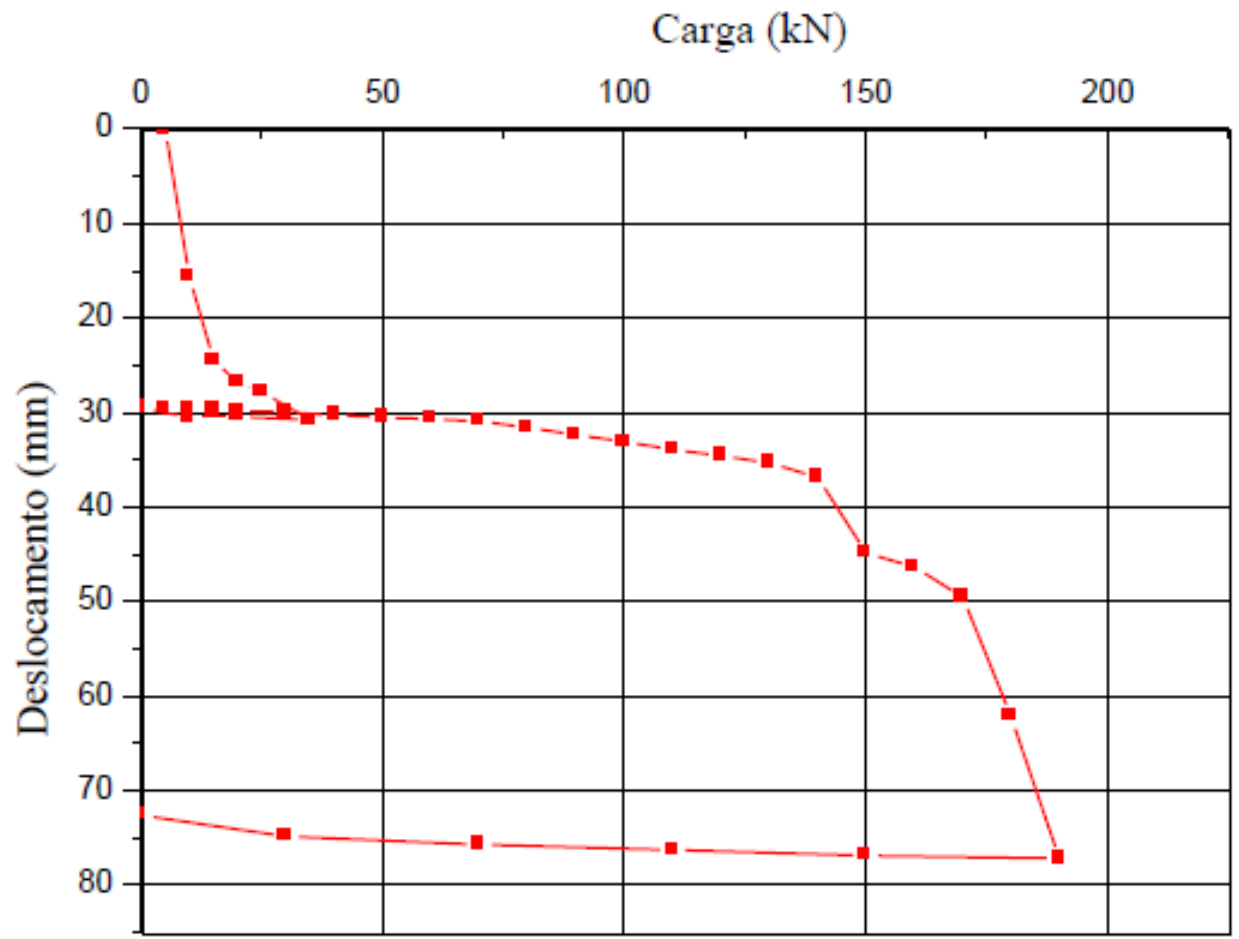

Gráfico 17 - Curva carga x deslocamento da prova de carga na estaca injetada C1.

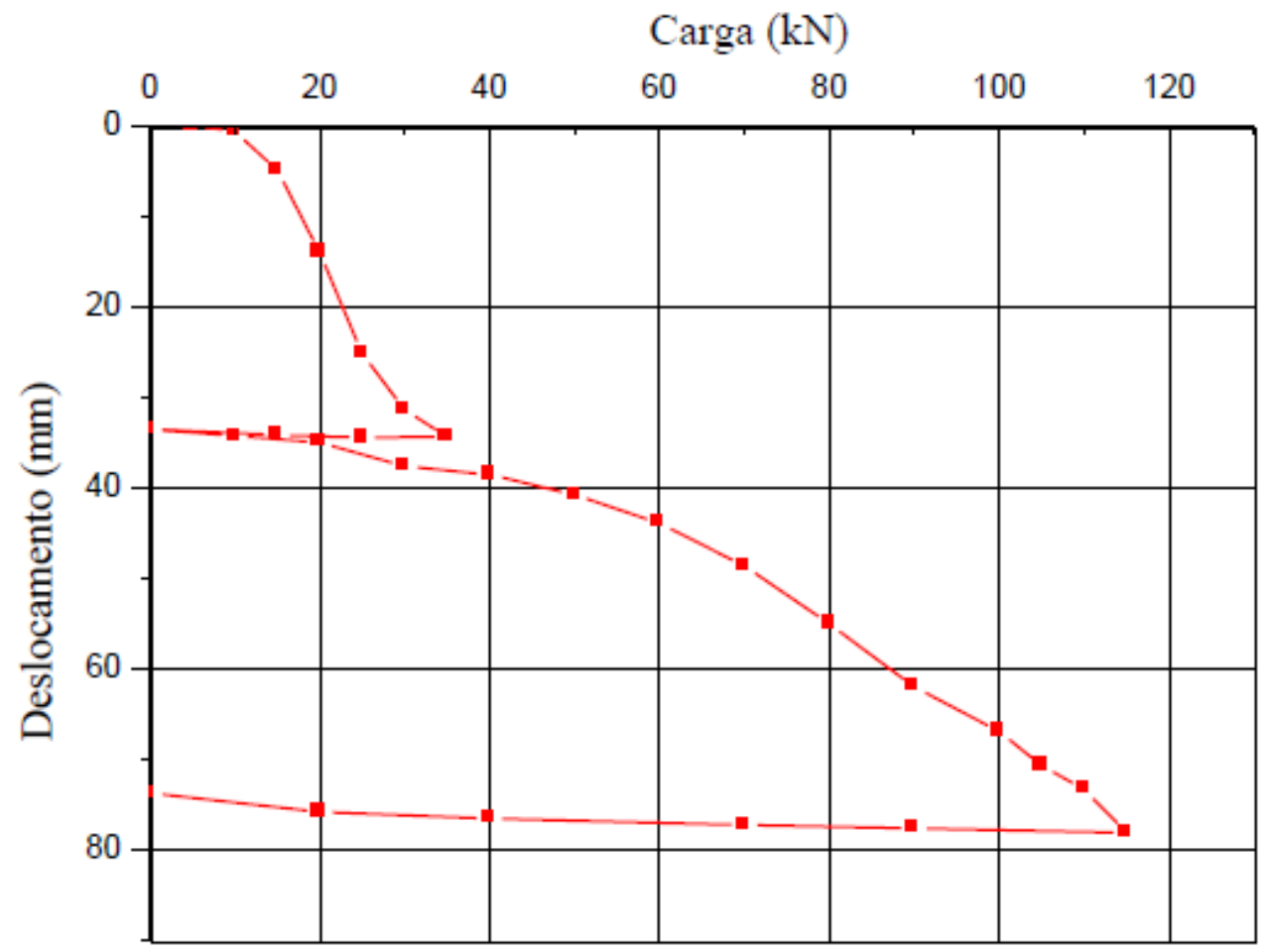

Gráfico 18 - Curva carga x deslocamento da prova de carga na estaca injetada C2. 


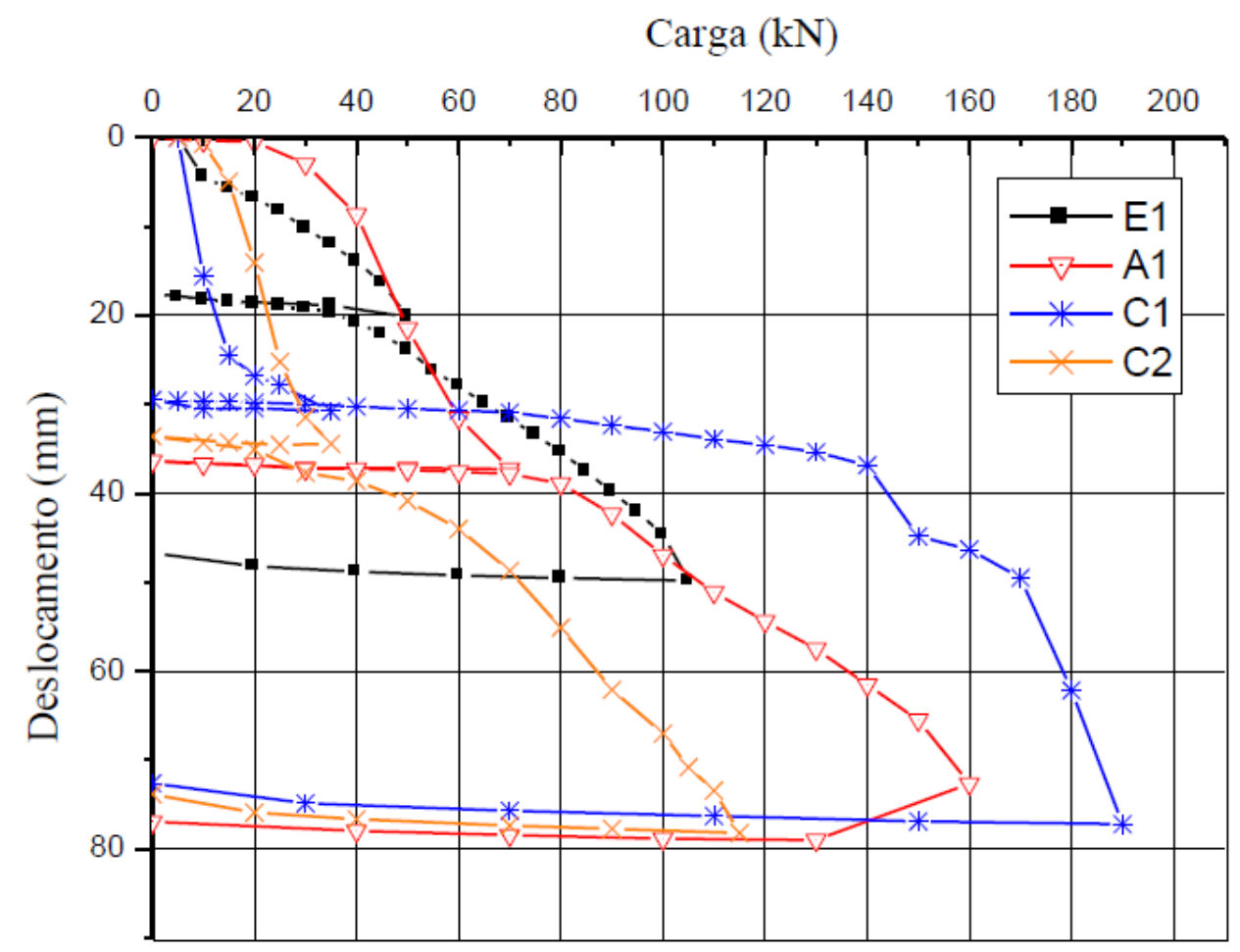

Gráfico 19 - Curva carga x deslocamento de todas as estacas ensaiadas à compressão. 


\section{APENDICE B}

A seguir, são apresentados os resultados da realização das cinco provas de carga à tração.

\section{Ensaios de Campo-Provas de Carga à Tração}

Prova de carga da estaca E1-Convencional

\begin{tabular}{|c|c|}
\hline Carga de Tração $\mathbf{( k N )}$ & Deslocamentos $\mathbf{( m m})$ \\
\hline 0 & -- \\
3 & 0,0 \\
6 & 0,6 \\
9 & 0,8 \\
12 & 0,9 \\
15 & 1,4 \\
18 & 2,6 \\
21 & 4,0 \\
24 & 5,0 \\
27 & 9,1 \\
30 & 11,8 \\
33 & 14,0 \\
36 & 17,2 \\
39 & 19,0 \\
42 & 20,8 \\
45 & 23,0 \\
48 & 25,0 \\
51 & 28,1 \\
54 & 30,0 \\
57 & 31,6 \\
60 & 34,7 \\
63 & 36,8 \\
48 & 36,6 \\
36 & 36,3 \\
24 & 35,7 \\
12 & 34,7 \\
0 & 24,9 \\
\hline & \\
\hline & \\
\hline & \\
\hline
\end{tabular}


Prova de carga da estaca E2-Convencional

\begin{tabular}{|c|c|}
\hline Carga de Tração (kN) & Deslocamentos (mm) \\
\hline 0 & -- \\
\hline 3 & 0,00 \\
\hline 6 & 2,19 \\
\hline 9 & 2,63 \\
\hline 12 & 2,59 \\
\hline 15 & 3,59 \\
\hline 18 & 4,00 \\
\hline 21 & 4,24 \\
\hline 24 & 4,79 \\
\hline 27 & 5,47 \\
\hline 30 & 6,33 \\
\hline 33 & 7,22 \\
\hline 36 & 8,54 \\
\hline 39 & 10,11 \\
\hline 42 & 11,99 \\
\hline 45 & 13,46 \\
\hline 48 & 15,00 \\
\hline 51 & 16,57 \\
\hline 54 & 18,12 \\
\hline 57 & 19,45 \\
\hline 60 & 21,55 \\
\hline 63 & 22,71 \\
\hline 66 & 24,34 \\
\hline 69 & 25,94 \\
\hline 72 & 27,68 \\
\hline 75 & 29,00 \\
\hline 78 & 31,12 \\
\hline 68 & 38,28 \\
\hline 48 & 37,92 \\
\hline 33 & 37,06 \\
\hline 18 & 36,10 \\
\hline 0 & 25,91 \\
\hline
\end{tabular}


Prova de carga da estaca A1-Argamassa no Fuste

\begin{tabular}{|c|c|}
\hline Carga de Tração (kN) & Deslocamentos (mm) \\
\hline 0 & -- \\
\hline 5 & 0,00 \\
\hline 10 & 0,23 \\
\hline 15 & 0,39 \\
\hline 20 & 0,64 \\
\hline 25 & 0,81 \\
\hline 30 & 1,02 \\
\hline 35 & 1,27 \\
\hline 40 & 1,67 \\
\hline 45 & 2,15 \\
\hline 50 & 2,85 \\
\hline 55 & 3,88 \\
\hline 60 & 4,95 \\
\hline 65 & 7,88 \\
\hline 70 & 8,95 \\
\hline 75 & 10,02 \\
\hline 80 & 11,23 \\
\hline 85 & 12,47 \\
\hline 90 & 13,52 \\
\hline 95 & 14,62 \\
\hline 100 & 15,48 \\
\hline 105 & 16,60 \\
\hline 110 & 17,25 \\
\hline 120 & 19,52 \\
\hline 130 & 22,70 \\
\hline 140 & 28,14 \\
\hline 150 & 38,39 \\
\hline 120 & 37,95 \\
\hline 90 & 37,63 \\
\hline 60 & 37,36 \\
\hline 30 & 36,63 \\
\hline 0 & 30,52 \\
\hline
\end{tabular}


Prova de carga da estaca C1- Injetada

\begin{tabular}{|c|c|}
\hline Carga de Tração $(\mathbf{k N})$ & Deslocamentos $\mathbf{( m m})$ \\
\hline 0 & -- \\
10 & 0,00 \\
20 & 0,23 \\
25 & 0,36 \\
30 & 0,53 \\
35 & 0,64 \\
40 & 0,78 \\
45 & 0,89 \\
50 & 1,08 \\
60 & 1,47 \\
70 & 2,05 \\
80 & 2,91 \\
90 & 3,85 \\
100 & 4,94 \\
110 & 11,96 \\
115 & 13,99 \\
120 & 15,71 \\
125 & 17,66 \\
130 & 20,01 \\
140 & 28,62 \\
145 & 38,83 \\
120 & 38,59 \\
90 & 38,11 \\
60 & 37,65 \\
30 & 36,76 \\
0 & 34,21 \\
\hline
\end{tabular}


Prova de carga da estaca C2- Injetada

\begin{tabular}{|c|c|}
\hline Carga de Tração (kN) & Deslocamentos (mm) \\
\hline 0 & -- \\
\hline 10 & 0,00 \\
\hline 20 & 0,50 \\
\hline 30 & 1,06 \\
\hline 40 & 1,93 \\
\hline 50 & 3,30 \\
\hline 60 & 4,97 \\
\hline 70 & 7,28 \\
\hline 80 & 9,82 \\
\hline 90 & 13,14 \\
\hline 100 & 18,82 \\
\hline 110 & 24,06 \\
\hline 120 & 32,65 \\
\hline 125 & 35,82 \\
\hline 130 & 44,03 \\
\hline 110 & 43,79 \\
\hline 80 & 43,23 \\
\hline 60 & 42,80 \\
\hline 40 & 42,08 \\
\hline 0 & 38,15 \\
\hline
\end{tabular}




\section{APENDICE C}

Abaixo, seguem os resultados da realização das quatro provas de carga à compressão.

\section{Ensaios de Campo-Provas de Carga à Compressão}

Prova de carga da estaca E1-Convencional

\begin{tabular}{|c|c|}
\hline Carga de Tração $(k N)$ & Deslocamentos (mm) \\
\hline 0 & -- \\
\hline 5 & 0,00 \\
\hline 10 & 4,43 \\
\hline 15 & 5,75 \\
\hline 20 & 6,81 \\
\hline 25 & 8,30 \\
\hline 30 & 10,18 \\
\hline 35 & 12,02 \\
\hline 40 & 13,94 \\
\hline 45 & 16,34 \\
\hline 50 & 20,16 \\
\hline 35 & 18,86 \\
\hline 15 & 18,41 \\
\hline 0 & 17,56 \\
\hline 0 & 17,56 \\
\hline 5 & 18,01 \\
\hline 10 & 18,25 \\
\hline 15 & 18,51 \\
\hline 20 & 18,74 \\
\hline 25 & 18,93 \\
\hline 30 & 19,25 \\
\hline 35 & 19,72 \\
\hline 40 & 20,75 \\
\hline 45 & 22,14 \\
\hline 50 & 23,86 \\
\hline 55 & 26,21 \\
\hline 60 & 27,92 \\
\hline 65 & 29,94 \\
\hline 70 & 31,59 \\
\hline 75 & 33,44 \\
\hline 80 & 35,35 \\
\hline 85 & 37,54 \\
\hline 90 & 39,88 \\
\hline 95 & 42,09 \\
\hline 100 & 44,65 \\
\hline 105 & 49,81 \\
\hline 80 & 49,51 \\
\hline 60 & 49,23 \\
\hline 40 & 48,81 \\
\hline 20 & 48,21 \\
\hline 0 & 46,70 \\
\hline
\end{tabular}


Prova de carga da estaca A1-Argamassa no Fuste

\begin{tabular}{|c|c|}
\hline Carga de Tração (kN) & Deslocamentos (mm) \\
\hline 0 & \\
\hline 10 & 0,00 \\
\hline 20 & 0,09 \\
\hline 30 & 2,59 \\
\hline 40 & 8,27 \\
\hline 50 & 21,11 \\
\hline 60 & 31,13 \\
\hline 70 & 36,87 \\
\hline 50 & 36,78 \\
\hline 30 & 36,77 \\
\hline 0 & 35,99 \\
\hline 0 & 35,99 \\
\hline 10 & 36,32 \\
\hline 20 & 36,39 \\
\hline 30 & 36,90 \\
\hline 40 & 36,90 \\
\hline 50 & 37,00 \\
\hline 60 & 37,19 \\
\hline 70 & 37,43 \\
\hline 80 & 38,54 \\
\hline 90 & 41,96 \\
\hline 100 & 46,58 \\
\hline 110 & 50,74 \\
\hline 120 & 54,01 \\
\hline 130 & 57,12 \\
\hline 140 & 61,14 \\
\hline 150 & 65,10 \\
\hline 160 & 72,26 \\
\hline 130 & 78,61 \\
\hline 100 & 78,44 \\
\hline 70 & 78,05 \\
\hline 40 & 77,56 \\
\hline 0 & 76,56 \\
\hline
\end{tabular}


Prova de carga da estaca C1- Injetada

\begin{tabular}{|c|c|}
\hline Carga de Tração (kN) & Deslocamentos (mm) \\
\hline 0 & \\
\hline 5 & 0,00 \\
\hline 10 & 15,58 \\
\hline 15 & 24,47 \\
\hline 20 & 26,81 \\
\hline 25 & 27,82 \\
\hline 35 & 30,76 \\
\hline 20 & 30,42 \\
\hline 10 & 30,49 \\
\hline 0 & 29,48 \\
\hline 5 & 29,57 \\
\hline 10 & 29,63 \\
\hline 15 & 29,72 \\
\hline 20 & 29,80 \\
\hline 30 & 29,95 \\
\hline 40 & 30,25 \\
\hline 50 & 30,50 \\
\hline 60 & 30,68 \\
\hline 70 & 30,90 \\
\hline 80 & 31,58 \\
\hline 90 & 32,35 \\
\hline 100 & 33,07 \\
\hline 110 & 33,90 \\
\hline 120 & 34,55 \\
\hline 130 & 35,34 \\
\hline 140 & 36,82 \\
\hline 150 & 44,84 \\
\hline 160 & 46,31 \\
\hline 170 & 49,50 \\
\hline 180 & 62,15 \\
\hline 190 & 77,17 \\
\hline 150 & 76,86 \\
\hline 110 & 76,26 \\
\hline 70 & 75,69 \\
\hline 30 & 74,83 \\
\hline 0 & 72,60 \\
\hline
\end{tabular}


Prova de carga da estaca C2- Injetada

\begin{tabular}{|c|c|}
\hline Carga de Tração (kN) & Deslocamentos (mm) \\
\hline 0 & -- \\
\hline 5 & 0,00 \\
\hline 10 & 0,68 \\
\hline 15 & 4,96 \\
\hline 20 & 14,05 \\
\hline 25 & 25,21 \\
\hline 30 & 31,43 \\
\hline 35 & 34,44 \\
\hline 25 & 34,54 \\
\hline 15 & 34,26 \\
\hline 0 & 33,58 \\
\hline 10 & 34,33 \\
\hline 20 & 35,06 \\
\hline 30 & 37,70 \\
\hline 40 & 38,62 \\
\hline 50 & 40,82 \\
\hline 60 & 43,99 \\
\hline 70 & 48,71 \\
\hline 80 & 55,09 \\
\hline 90 & 62,06 \\
\hline 100 & 67,00 \\
\hline 105 & 70,79 \\
\hline 110 & 73,38 \\
\hline 115 & 78,19 \\
\hline 90 & 77,72 \\
\hline 70 & 77,34 \\
\hline 40 & 76,64 \\
\hline 20 & 75,90 \\
\hline 0 & 73,81 \\
\hline
\end{tabular}

